\title{
GRADIENTES DE COR E O CENÁRIO DE EVOLUÇÃO SECULAR EM GALÁXIAS ESPIRAIS DE TIPO TARDIO
}

\section{DIMITRI ALEXEI GADOTTI}

Orientadora: Profa. Dra. Sandra dos Anjos

Dissertação apresentada ao Instituto Astronômico e Geofísico da Universidade de São Paulo para a obtenção do título de Mestre em Astronomia. 
Aos meus pais.

E à Inaê. 


\section{Agradecimentos}

Agradeço ao NExGal - ProNEx e ao CNPq pelo apoio financeiro durante a realização deste trabalho.

Agradeço à Secretaria do Departamento de Astronomia, com a qual sempre pude contar nas tarefas de cunho administrativo, e aos professores com quem travei um contato mais estreito e que sempre me foram uma fonte de dúvidas, inquietações, árduos trabalhos, esclarecimentos e deslumbramentos. Agradeço também ao pessoal do OPD/LNA - CNPq pela ajuda dedicada nas noites frias e escuras.

Em especial, agradeço a minha orientadora, Sandra dos Anjos, pelo papel fundamental que desempenhou no aspecto profissional de minha vida, pela infinidade de lições que me deu a oportunidade de aprender, e pela presença sempre prestativa, dedicada e companheira.

Agradeço a Ronaldo E. de Souza pelas prazerosas e intrigantes discussões, e pelas respostas claras que tanto contribuíram para o engrandecimento deste trabalho. Outros pesquisadores que contribuíram de forma fundamental a este trabalho foram Rob Kennicutt e Tim Beers, aos quais deixo aqui meus agradecimentos.

Agradeço a todos os meus amigos e companheiros do Clube Alpino Paulista, que têm de me ouvir sempre extasiado nas noites frias e estreladas das montanhas. Muitas razões tenho eu para estimar os colegas que ganhei no Departamento, e as amizades que aqui se solidificaram, em especial, Nélson, Ricardo Schiavon, Daniel, Júlio, Jocel, Eraldo, Jairo, Ednilson, Jan, Alex Ignácio, Armando, Ronaldo (Monstro!!!), Alexandre, Rodrigo, Iran, Jaqueline, Bruno, Jorge, Lucimara e Adriano, já que em todos eles pude buscar conforto ao notar que a luz no fim do túnel era a luz de um outro trem! Deixei para falar com distinção da Amélia, com quem tive o prazer de dividir um tranqüilo deslumbramento com a ciência em tardes de música nem tão tranqüila. Outra distinção quero fazer para o Grupo de Astronomia Extragaláctica do Departamento, com quem sempre aprendo muito a partir de discussões acaloradas e bem-humoradas.

Um inesperado e delicioso agradecimento eu deixo aqui para Aline, que de forma 
repentina e decisiva faz parte agora de minha vida, que mais do que eu próprio desejou o fechamento deste estudo, e por quem, por muitos, muitos motivos, eu tenho imenso orgulho e carinho.

Finalmente, quero expressar minha eterna gratidão a minhas irmãs, Tainá, Tábata e Inaê, que sempre compreenderam a minha ausência e que, ainda assim, tanto amor me dão; a minha mãe, por me fazer sentir tão orgulhoso de mim mesmo, e pelo apoio com o qual sempre posso contar; a meu pai, inextinguível fonte de incentivo e inspiração, com suas perguntas desconcertantes. 
"If the conquest of a great peak brings moments of exultation and bliss, which in the monotonous, materialistic existence of modern times nothing else can approach, it also presents great dangers. It is not the goal of grand alpinism to face peril, but it is one of the tests one must undergo to deserve the joy of rising for an instant above the state of crawling grubs. On this proud and beautiful mountain, we have lived hours of fraternal, warm and exalting nobility. Here, for a few days, we have ceased to be slaves and have really been men."

\section{Lionel Terray}

"I worked very hard into the night, sitting at a small table in the kitchen, next to a window. It was getting later and later - about 2:00 or 3:00 A.M. I'm working hard, getting all these calculations packed solid with things that fit, and I am thinking, and I am concentrating, and it's dark, and it's quiet ..."

Dick Feynman 
RESUMO ix

ABSTRACT $\quad$ x

1 Introdução $\quad 1$

1.1 Formação de bojos ....................... . 7

1.1.1 O cenário monolítico de formação . . . . . . . . . . . . 8

1.1.2 O cenário hierárquico de formação . . . . . . . . . . . . . . 10

1.1.3 O cenário de evolução secular . . . . . . . . . . . . . . . 11

1.2 Gradientes de cor e o cenário de evolução secular - Motivação do trabalho 16

2 Gradientes de Cor $\quad 18$

2.1 Magnitudes, cores e populações estelares . . . . . . . . . . . . . 19

2.2 Seleção da amostra . . . . . . . . . . . . . . . . . 24

2.3 Cálculo dos gradientes de cor . . . . . . . . . . . . . 25

2.3.1 Determinação dos índices de cor característicos dos bojos e discos $\quad 29$

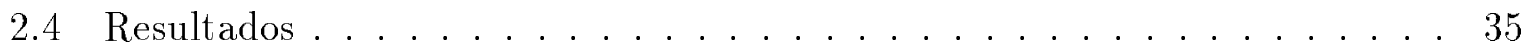

2.4.1 Distribuição dos gradientes . . . . . . . . . . . . 36

2.4.2 Três categorias para os gradientes: negativos, nulos e positivos . . . 43 
2.4.3 Comparação com os gradientes de Prugniel \& Héraudeau (1998) . 45

2.4.4 A morfologia quantitativa de barras de Martin (1995) . . . . . . . 46

2.4.5 Gradientes de abundância $\mathrm{O} / \mathrm{H} \ldots \ldots . \ldots . \ldots 51$

2.4.6 Índices de cor para bojos e discos ................ . . 53

2.5 Discussão e conclusões . . . . . . . . . . . . . . 56

2.5.1 Gradientes de cor . . . . . . . . . . . . . 57

2.5 .2 Índices de cor ..................... 61

2.5.3 Barras recorrentes e a importância do cenário de evolução secular 61

3 Fotometria Superficial $\quad 64$

3.1 Seleção da sub-amostra . . . . . . . . . . . . . . . . 65

3.2 As imagens do DSS . . . . . . . . . . . . . . . 66

3.3 Decomposição bojo/disco . . . . . . . . . . . . . . . . 68

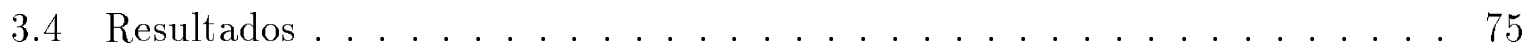

3.5 Observações no LNA . . . . . . . . . . . . . . . . . 78

3.5.1 Aquisição e tratamento das imagens . . . . . . . . . . . . 78

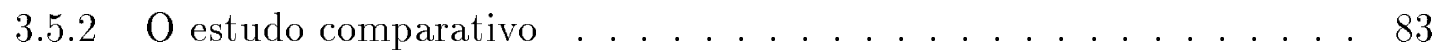

3.5.3 Discussão e conclusões acerca do estudo comparativo . . . . . . . 87

3.6 Discussão e conclusões . . . . . . . . . . . . . . . . . . 90

4 Conclusões e perspectivas $\quad 92$

4.1 Conclusões . . . . . . . . . . . . . . . . . . . 92

4.2 Perspectivas . . . . . . . . . . . . . . . . . . 95

$\begin{array}{ll}\text { REFERENNCIAS } & 96\end{array}$ 
A Nossa amostra

B Exemplos de gradientes de cor

C Exemplos de resultados da decomposição bojo/disco 


\section{Lista de Figuras}

1.1 O sistema de classificação morfológica de galáxias proposto por Hubble em 1936. Note que a classe das lenticulares ainda era de natureza um tanto hipotética (Extraído de Hubble 1936). . . . . . . . . . . . . . 2

2.1 Curvas de resposta para os filtros U, B e V de Johnson e Morgan. No eixo das abscissas está o comprimento de onda em nanometros, e no eixo das ordenadas a resposta normalizada. A curva tracejada indica uma distribuição espectral de energia típica de uma estrela de tipo A0. A posição da descontinuidade de Balmer também está destacada. (Extraído de Kitchin

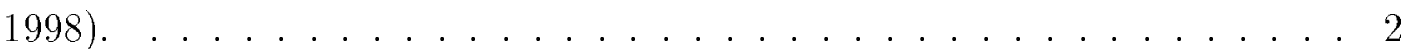

2.2 Relação entre o tipo espectral e o índice de cor (B-V) (Extraído de Kitchin 1998)

2.3 Um exemplo da robustez do método de regressão linear pela mínima mediana. Em (a), o resultado do ajuste ao conjunto de pontos é indiferente do método. Em (b), o método clássico (linha tracejada) é gravemente perturbado pela contaminação de um único ponto, enquanto que o método da mínima mediana (linha cheia) permanece atribuindo aos pontos o mesmo

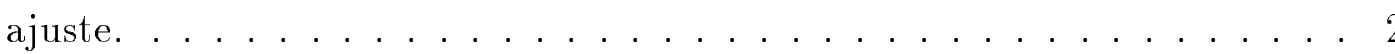


2.4 Exemplos de gradientes de cor para quatro galáxias em nossa amostra. O típico gradiente negativo de NGC 1425 e NGC 2613, o gradiente nulo de NGC 1672, e o raro gradiente positivo de UGC 3973 (confira os valores na Tabela A.1). Os índices de cor em magnitudes estão expressos em função do logaritmo da abertura do diafragma em unidades de 0.1 minutos de arco. Os quadrados indicam o índice $(\mathrm{B}-\mathrm{V})$, enquanto que os círculos indicam o (U-B). As linhas tracejadas correspondem ao ajuste através do método dos mínimos quadrados; linhas pontilhadas representam o ajuste pelo método da mínima mediana e a linha cheia corresponde ao ajuste determinado pelo algoritmo de PRoGress. ................... 28

2.5 Gradientes de cor $(\mathrm{B}-\mathrm{V})$ e (U-B) para as galáxias de nossa amostra em função do excesso de cor $\mathrm{E}(\mathrm{B}-\mathrm{V})$ provocado pela extinção Galáctica (painéis superiores), e em função da inclinação da galáxia, representada aqui pelo parâmetro $R_{25}$ do RC3 (painéis inferiores). A ausência de correlações indica que as extinções Galáctica e intrínseca não interferem na determinação dos gradientes de cor. . . . . . . . . . . . . . . 30

2.6 Distribuição dos gradientes de cor (U-B) e (B-V) para: (a) galáxias ordinárias vistas de face, (b) barradas vistas de face, (c) ordinárias vistas de perfil, e (d) barradas vistas de perfil. . . . . . . . . . . . . 37

2.7 Distribuição dos gradientes de cor $(\mathrm{U}-\mathrm{B})$ e (B-V) para: (a) todas as galáxias ordinárias, e (b), todas as barradas. Como se vê, galáxias barradas tendem a apresentar gradientes em (U-B) menos acentuados do que galáxias ordinárias. No entanto, esta característica desaparece em (B-V) . . . . . . 40

2.8 Comparação normalizada entre as distribuições dos gradientes de cor em galáxias ordinárias e barradas. Galáxias barradas apresentam uma maior fração de galáxias com gradientes próximos de zero, ou positivos, em ambas as cores. . . . . . . . . . . . . . . . . . .

2.9 Gradientes de cor (U-B) em função dos gradientes (B-V) para: (a) galáxias ordinárias, (b) barradas e (c) toda a nossa amostra. A linha cheia corresponde a um ajuste linear para os pontos. Claramente, os gradientes são correlacionados. . . . . . . . . . . . . . . . . . . 42 
2.10 Comparação com os gradientes obtidos por PH98. O diagrama superior mostra que a correlação entre os gradientes (U-B) e (B-V) em PH98 é ligeiramente menor do que a apresentada pelos valores obtidos por nós (ver Figura 2.9(c)). Os outros dois diagramas apresentam os nossos gradientes em função dos de PH98. A linha tracejada indica uma correlação perfeita. A linha cheia mostra o ajuste linear para os pontos do gráfico. . . . . . . . 47

2.11 A diferença entre os valores dos gradientes obtidos aqui e os de PH98 em função dos gradientes por nós determinados. A linha cheia indica o ajuste linear para os pontos. . . . . . . . . . . . . . . 48

2.12 O brilho superficial efetivo na banda B, obtido por PH98 para as galáxias em comum com a nossa amostra, em função dos gradientes de cor determinados por nós. Evidentemente, não há uma forte correlação entre esses parâmetros. Pode-se notar, entretanto, uma leve tendência de as galáxias com gradientes nulos ou positivos apresentarem uma maior concentração central de luz. . . . . . . . . . . . . . . . . .

2.13 Gradientes de cor em função dos parâmetros obtidos em M95 para as barras de 45 galáxias de nossa amostra. Nos diagramas superiores os gradientes estão em função da razão axial das barras. Os diagramas centrais apresentam os gradientes em função do comprimento normalizado das barras, e nos diagramas inferiores em função da elipticidade aparente das barras. É evidente que não existe correlação alguma. . . . . . . . . . . . . . 50

2.14 Correlação entre os gradientes de cor e os gradientes de abundância $\mathrm{O} / \mathrm{H}$, utilizando os valores obtidos por MR94 (diagrama superior) e ZKH94 (diagrama inferior). Os quadrados indicam os gradientes em (B-V), enquanto que o sinal + indica aqueles em (U-B). No canto inferior direito de cada gráfico, barras de erro típicas estão desenhadas. . . . . . . . . . . 52

2.15 Índices de cor do bojo em função dos índices do disco para as galáxias com gradientes negativos (painéis superiores) e positivos (painéis inferiores), estimados em primeira aproximação (ver seção 2.3.1). Percebe-se claramente haver uma correlação entre ambos os parâmetros. . . . . . . . . . . . . 54

2.16 Índices de cor do bojo em função dos índices do disco para as galáxias com gradientes negativos (painéis superiores) e positivos (painéis inferiores), determinados através das equações $(2.8)$ e (2.9) (ver seção 2.3.1) . . . . . . 55 
3.1 Resultados da decomposição bojo/disco para a galáxia Sb(r) NGC 488. No alto está especificada a dimensão das imagens em segundos de arco. Para legendas, ver texto. . . . . . . . . . . . . . 74

3.2 A correlação entre os raios efetivos de bojos e os raios característicos de discos. ........................... 76

3.3 Parâmetros característicos dos perfis dos bojos em função dos gradientes

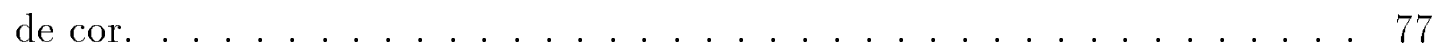

3.4 (a): comparação entre os gradientes obtidos dos dados do LdV83,85 e aqueles determinados através do imageamento em CCD. (b), (c) e (d): comparação entre os índices de Sérsic e as razões bojo/disco determinados nas imagens DSS e no imageamento CCD. A linha cheia representa perfeita equivalência. . . . . . . . . . . . . . . . . . 84

3.5 Comparações entre os parâmetros característicos dos perfis de bojos e discos obtidos através da decomposição em imagens DSS e no imageamento CCD. A linha cheia representa perfeita equivalência. . . . . . . . . . . 86

B.1 Mais exemplos de gradientes de cor para vinte galáxias em nossa amostra. Pode-se notar, mais uma vez, a existência das três categorias de gradientes (confira os valores na Tabela A.1). Os índices de cor em magnitudes estão expressos em função do logaritmo da abertura do diafragma em unidades de 0.1 minutos de arco. Os quadrados indicam o índice (B-V), enquanto que os círculos indicam o $(\mathrm{U}-\mathrm{B}) \ldots \ldots \ldots \ldots$. . . . . . . . . . . . . . . .

C.1 Mais exemplos dos resultados obtidos através da aplicação do algoritmo de decomposição bojo/disco em imagens do DSS. As figuras são análogas à Figura 3.1. . . . . . . . . . . . . . . 116

C.2 Exemplos de resultados obtidos através da aplicação do algoritmo de decomposição em imagens obtidas em CCD. Os resultados referentes às imagens DSS para essas mesmas galáxias foram exibidos na Figura C.1 e na Figura 3.1. As figuras são análogas à Figura 3.1. . . . . . . . . . . 123 


\section{Lista de Tabelas}

2.1 Valores médios (e respectivos erros) e desvios para as distribuições apresentadas nas Figuras 2.6 e 2.7. N é o número total de galáxias em cada distribuição. . . . . . . . . . . . . . . . . . 38

2.2 Distribuição das galáxias de nossa amostra em relação às várias categorias a serem avaliadas. . . . . . . . . . . . . . . . . . 44 44

2.3 Distribuição das galáxias de nossa amostra (vistas de face) em relação às várias categorias a serem avaliadas. . . . . . . . . . . . . 45

2.4 Valores medianos dos índices de cor característicos de bojos e discos para as galáxias em nossa amostra, separadas por categoria. Os índices determinados para galáxias vistas de face se encontram à direita. Os erros $(\sigma)$ estão apresentados entre parênteses. . . . . . . . . . . . 53

3.1 Resumo das observações. . . . . . . . . . . . . . . . . . . . . . . 79

3.2 Resumo das calibrações fotométricas. . . . . . . . . . . . . . . . 80

3.3 Gradientes de cor. . . . . . . . . . . . . . . . . . 85

A.1 A amostra. . . . . . . . . . . . . . . . . . . . . . . 104

A.2 A sub-amostra. . . . . . . . . . . . . . . . . . . 108 


\section{Resumo}

Nós realizamos um estudo estatístico do comportamento de perfis de cor em bandas largas (UBV) para 257 galáxias espirais do tipo Sbc, ordinárias e barradas, utilizando dados obtidos através de fotometria fotoelétrica de abertura, disponíveis na literatura (Longo \& de Vaucouleurs 1983,1985). Nós determinamos os gradientes de cor (B-V) e (UB) para as galáxias da amostra total, bem como os índices de cor (B-V) e (U-B) de bojos e discos separadamente, utilizando métodos estatísticos robustos. Utilizamos uma técnica de decomposição bi-dimensional para modelar os perfis de brilho de bojos e discos em imagens dos arquivos do "Digitised Sky Survey" (DSS), obtendo parâmetros estruturais característicos para 39 galáxias. A aquisição de imagens de 14 galáxias no Laboratório Nacional de Astrofísica permitiu-nos realizar um estudo fotométrico comparativo, e atestar a validade dos resultados obtidos neste estudo.

Entre os principais resultados obtidos, destacam-se: (i) - 65\% das galáxias possuem gradientes de cor negativos (mais vermelhos no centro), $25 \%$ possuem gradientes nulos, e $10 \%$ apresentam gradientes positivos; (ii) - galáxias que apresentam gradientes de cor nulos tendem a ser barradas; (iii) - os índices de cor ao longo das galáxias com gradientes nulos são similares aos índices de cor dos discos das galáxias com gradientes negativos; (iv) - confirmamos a correlação entre os índices de cor de bojos e discos, já obtida por outros autores; (v) - a ausência de correlação entre os gradientes de cor e de metalicidade sugere que o excesso de galáxias barradas com gradientes de cor nulos ou positivos reflete uma diferença no comportamento da idade média da população estelar ao longo de galáxias barradas e ordinárias; (vi) - galáxias com gradientes de cor nulos ou positivos têm uma leve tendência a apresentar bojos maiores e com maior concentração central de luz; e (vii) - confirmamos a correlação entre as escalas de comprimento de bojos e discos, já obtida por outros autores.

Estes resultados são compatíveis e favoráveis ao cenário de evolução secular, no qual barras produzem fluxos radiais de massa para as regiões centrais de galáxias, não somente homogeneizando as populações estelares ao longo de galáxias, produzindo discos e bojos com índices de cor semelhantes, mas também contribuindo para a formação e/ou construção de bojos. 


\section{Abstract}

We have done a statistical study of the behaviour of the broadband color profiles (UBV) for $257 \mathrm{Sbc}$ galaxies, barred and unbarred, collecting data obtained through photoeletric aperture photometry, available in the literature (Longo \& de Vaucouleurs 1983,1985). We have determined (B-V) and (U-B) color gradients for the total sample of galaxies, as well as (B-V) and (U-B) color indices of bulges and disks separately, using robust statistical methods. Applying a bi-dimensional decomposition technique to model the brightness profiles of bulges and disks in images from the Digitised Sky Survey (DSS), we obtained characteristic structural parameters for 39 galaxies. The acquisition of images for 14 galaxies in the Laboratório Nacional de Astrofísica (Astrophysics National Laboratory) allowed us to do a comparative photometric study, and verify the validity of the results obtained in this work.

Among the main results obtained, we point out: (i) $-65 \%$ of the galaxies have negative color gradients (reddish inward), $25 \%$ have zero gradients, and $10 \%$ show positive gradients; (ii) - galaxies that show zero color gradients tend to be barred; (iii) - the color indices along the galaxies with zero color gradients are similar to the color indices of the disks of the galaxies with negative color gradients; (iv) - we confirm the correlation between the color indices of bulges and disks, already found by other authors; $(\mathbf{v})$ - the absence of correlation between color and metallicity gradients suggests that the excess of barred galaxies with zero or positive color gradients reflects a difference in the behaviour of the mean age of the stellar population along barred and unbarred galaxies; (vi) - galaxies with zero or positive color gradients show a slight tendency of having larger bulges, with a greater central concentration of light; and (vii) - we confirm the correlation between the scale lenghts of bulges and disks, already found by other authors.

These results are compatible and favourable to the secular evolutionary scenario, in which stellar bars induce radial mass fluxes to the central regions of galaxies, not only turning homogeneous the stellar populations along the galaxies, producing disks and bulges with similar color indices, but also contributing to the formation and/or building of galactic bulges. 


\section{Capítulo 1}

\section{Introdução}

Uma das grandes realizações de Edwin Hubble no período de 1926 a 1936 foi organizar e sintetizar, em um diagrama, padrões de galáxias representativos das morfologias observadas dos objetos que se encontram próximos e brilhantes. Este diagrama, conhecido como Sistema de Classificação de Hubble (SCH), com modificações que foram sendo introduzidas durante algumas décadas, é o que vem sendo amplamente utilizado até hoje na classificação morfológica de galáxias. Nesses trabalhos pioneiros, Hubble verificou que as galáxias podem ser naturalmente divididas em duas classes distintas, de acordo com suas características morfológicas, com o padrão comum de apresentarem simetria rotacional em torno de um núcleo central: as elípticas (E) e as espirais (S). A classe das elípticas é caracterizada basicamente por apresentar uma única componente, com morfologia esferoidal ou elipsoidal, cujo grau de elipticidade permite definir o indicador

$$
n=10\left(1-\frac{b}{a}\right),
$$

onde $a$ e $b$ são, respectivamente, os semi-eixos maior e menor da galáxia. Dessa forma, $(1-b / a)$ denota a elipticidade do objeto, representando, portanto, diferentes estágios de elipticidade, desde as mais esféricas, até as mais achatadas, conforme as respectivas notações (E0, E1, En, ... E7). A classe das espirais foi definida basicamente como sendo aquela que possui pelo menos duas componentes, uma delas associada à região central, aproximadamente esférica, denominada bojo, e a outra relativa à distribuição de luz em um plano achatado, definida como disco fino. Hubble percebeu que as espirais podiam ser subdivididas em duas famílias distintas, definidas como ordinárias (S) e barradas (SB). As 


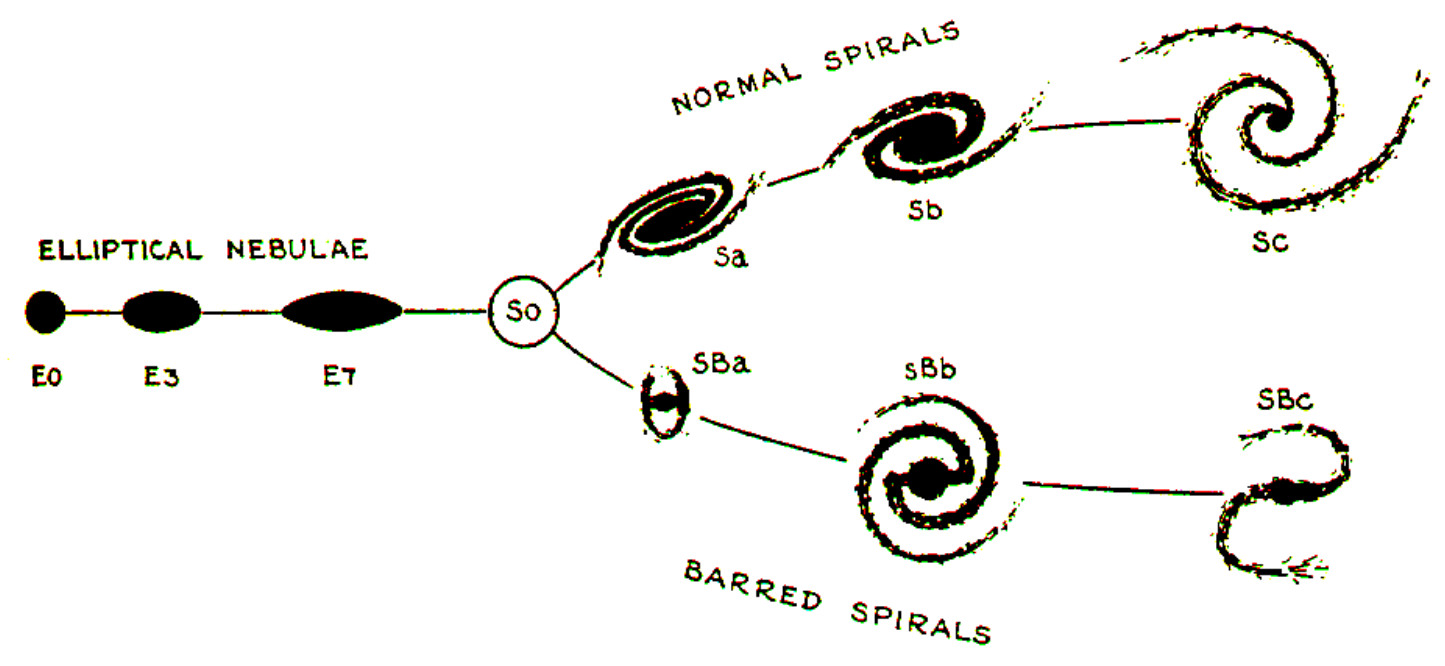

Figura 1.1: O sistema de classificação morfológica de galáxias proposto por Hubble em 1936. Note que a classe das lenticulares ainda era de natureza um tanto hipotética (Extraído de Hubble 1936).

galáxias espirais ordinárias cumprem os requisitos da definição básica da classe, e portanto se caracterizam por terem somente duas componentes, o bojo e o disco, enquanto que nas barradas observa-se uma componente adicional, denominada barra. As espirais também caracterizam-se por terem diferentes estágios, ou seja, as famílias podem ser divididas nos estágios a, b e c, conforme os critérios a seguir: (1) a abertura e definição dos braços espirais, (2) a razão entre as luminosidades de bojo e disco e (3) a resolução do disco e dos braços em estrelas e regiões HıI. Assim sendo, uma galáxia do tipo Sa (ou SBa), por exemplo, normalmente apresenta uma razão bojo/disco maior do que aquela apresentada por uma galáxia do tipo Sc (ou SBc), bem como braços menos definidos e com menor número de regiões HıI e estrelas resolvidas.

Observando que as galáxias ao fim da seqüência das elípticas (E7) têm características morfológicas relativamente similares àquelas no início da seqüência das espirais (Sa), Hubble sugeriu que as duas seqüências fossem contíguas, e que as espirais barradas formassem uma seqüência paralela à de espirais ordinárias, sintetizando, desta forma, o seu sistema de classificação de galáxias, como ilustrado em seu famoso diagrama, reproduzido na Figura 1.1. Mais ainda, definiu que as galáxias situadas à esquerda em seu diagrama são genericamente denominadas do tipo "early" (jovem) em relação àquelas situadas à direita, denominadas do tipo "late" (tardio). Atualmente, os termos "jovem" e "tardio" são utilizados somente para apontar a posição de uma galáxia no diagrama de classificação, sem qualquer conotação ao significado evolutivo. Portanto, neste sistema de classificação, uma galáxia Sc é mais tardia do que uma Sa, bem como uma Sa é mais jovem do que uma $\mathrm{Sb}$, por exemplo.

No entanto, ao perceber que as diferenças entre propriedades de elípticas e espi- 
rais são demasiado abruptas, Hubble introduziu uma nova classe de galáxias, a princípio hipotética, que é a classe das galáxias lenticulares, que teriam propriedades gerais intermediárias entre as elípticas e as espirais. As lenticulares seriam então mais tardias do que as E7, porém não chegariam a apresentar estrutura espiral. Posteriormente, verificou-se a existência real dessa classe de galáxias, tornando útil e natural sua introdução no sistema de classificação, apesar de haver ainda hoje grande controvérsia em relação à homogeneidade das propriedades gerais desta classe. As galáxias lenticulares também possuem duas grandes famílias, a das ordinárias ( $\mathrm{S} 0$ ) e a das barradas (SB0). Aquelas galáxias cuja morfologia não apresenta simetria rotacional, e portanto não têm lugar no diagrama de Hubble, são denominadas irregulares (Irr). Na época da elaboração do diagrama de Hubble, somente cerca de 3\% das galáxias eram classificadas como Irr (Hubble 1926,1936).

Ao longo dos anos, algumas etapas de refinamento foram aplicadas ao SCH, motivadas principalmente pelo aumento do número de catálogos que surgiram a partir da inspeção de galáxias em placas fotográficas de grande campo. Na revisão do sistema de Hubble, por G. de Vaucouleurs (1963), as alterações ${ }^{1}$ mais importantes introduzidas foram:

Refinamento das subclasses. São introduzidos estágios intermediários na classe das lenticulares e na classe das espirais, como Sab e Sbc, por exemplo. Além disso, essa seqüência foi estendida para as subclasses $\mathrm{cd}, \mathrm{d}$, $\mathrm{dm}$ e $\mathrm{m}$, onde $\mathrm{m}$ denota as espirais do tipo magelânicas. A classe das irregulares é substituída pelas subclasses Im e I, ordinárias ou barradas.

Refinamento da classificação de barras. São introduzidas as notações SA para galáxias ordinárias e SAB para os casos transitórios (ou incertos) entre SA e SB.

Introdução das variedades r e s. São adicionados na notação os símbolos (r), para aquelas galáxias em que os braços se iniciam tangentes a um anel, no qual a barra termina (no caso de a galáxia ser barrada), e (s), para as galáxias em que os braços partem das extremidades da barra (ou do bojo, no caso de a galáxia ser ordinária). Também há a notação (rs) para os casos transitórios. Embora essa notação seja mais própria para galáxias barradas, também pode ser utilizada para galáxias ordinárias.

Com o desenvolvimento de detectores, telescópios e técnicas observacionais, e o explosivo aumento do número de galáxias estudadas, novos catálogos foram publicados e pequenas alterações ao SCH foram sendo realizadas para representar com melhor precisão

\footnotetext{
${ }^{1}$ Parte destas alterações já havia sido vislumbrada em Hubble (1936).
} 
diferentes sutilezas morfológicas, de tal forma que a classificação morfológica de galáxias revisada, e amplamente utilizada, foi sintetizada como pode ser visto no "Third Reference Catalog of Bright Galaxies" (de Vaucouleurs et al. 1991 - doravante RC3). Uma dessas modificações consistiu na introdução do parâmetro T (índice do estágio de Hubble), que é definido por uma escala numérica, na qual galáxias do tipo Sa têm $\mathrm{T}=1$, galáxias Sab têm $\mathrm{T}=2, \mathrm{Sb}$ têm $\mathrm{T}=3$, e assim por diante. Por outro lado, galáxias $\mathrm{S} 0 /$ a têm $\mathrm{T}=0$, e as de tipos mais jovens possuem T's negativos. Para uma revisão sobre classificação de galáxias veja Sandage (1975); ou também van den Bergh (1997).

Outros sistemas de classificação de galáxias foram propostos com critérios e parâmetros novos e distintos. Entretanto, os sistemas de classificação posteriores ao de Hubble se baseiam, ainda que parcialmente, no $\mathrm{SCH}$, e podem ser considerados complementares. Morgan (1958), por exemplo, utiliza a concentração central de luz como critério de classificação e encontra correlação entre este parâmetro, o tipo espectral dominante na galáxia e o tipo de Hubble. Essa correlação é esperada, já que a razão bojo/disco diminui ao longo da seqüência de Hubble, quando se parte dos tipos jovens para os tipos tardios, e o tipo espectral dominante nestas componentes é notavelmente distinto. Este sistema de classificação, pouco utilizado nas décadas passadas, tem recentemente sido resgatado, devido à dificuldade em se utilizar o $\mathrm{SCH}$ em galáxias a grandes profundidades. Abraham et al. (1996), por exemplo, utilizam, para a classificação de galáxias a altos "redshifts" no "Hubble Deep Field", os parâmetros de concentração central de luz e de assimetria, além do tipo de Hubble, o que permite uma classificação mais quantitativa e objetiva. A concentração central de luz tem sido usada também em algoritmos de classificação automática (Abraham et al. 1994). Aplicações recentes deste sistema de classificação, utilizando a concentração central de luz em galáxias no aglomerado de Virgo, podem ser vistas em Koopmann \& Kenney (1998). van den Bergh (1960a,b) adiciona ao sistema de Hubble cinco classes de luminosidade, referentes à luminosidade absoluta das galáxias, e encontra correlação entre estas classes e a morfologia dos braços espirais, no sentido de que as galáxias mais luminosas apresentam braços bem definidos e desenvolvidos. Mais recentemente, Elmegreen \& Elmegreen (1982a,b) desenvolveram um sistema de classificação morfológica dos braços espirais, que parte do tipo 1 (floculento) em que os braços têm uma aparência não uniforme, caótica e pouco definida, até o tipo 12 ("grand design") no qual os braços são simétricos, bem definidos e desenvolvidos. Nesse trabalho, os autores concluem que existe uma forte tendência de as galáxias barradas, ou com companheiras próximas, apresentarem braços com o padrão "grand design".

Um sistema de classificação que se diferencia substancialmente dos acima citados é aquele proposto por Humason (1936) e Morgan \& Mayall (1957; ver também Sodré \& Cuevas 1994), e consiste na classificação espectral de galáxias. Neste sistema, uma galáxia é classificada segundo seu espectro integrado, o que também permite uma classificação 
quantitativa e objetiva. É importante ressaltar que existe uma forte correlação entre os tipos espectrais de galáxias e os tipos de Hubble (e.g., Sodré \& Cuevas 1997).

Apesar de o sistema de classificação de Hubble ser demasiado simples e subjetivo, seu sucesso reside exatamente em ignorar a miríade de detalhes na estrutura das galáxias, que, se considerados, forçariam a introdução de um sem-número de classes e tornariam a classificação extremamente penosa e complexa. Ao contrário, este sistema se concentra em características e padrões globais.

Por outro lado, van den Bergh (1997) argumenta que o sistema de classificação de Hubble incorpora somente galáxias luminosas, próximas e em ambientes pouco densos, como no campo ou em aglomerados pobres. Desta forma, torna-se difícil utilizar o sistema de Hubble para classificar, por exemplo, galáxias a altos "redshifts", galáxias anãs e galáxias de baixo brilho superficial. Além disso, van den Bergh enfatiza que o SCH não incorpora a classe das lenticulares de maneira satisfatória, já que esta classe parece ser tipicamente menos luminosa do que as elípticas e também menos luminosa do que as espirais do tipo Sa. van den Bergh continua, salientando que o SCH tão pouco incorpora adequadamente as galáxias cD's, tipicamente presentes nas regiões centrais de aglomerados, que parecem resultar de fusões entre galáxias. O mesmo parece ocorrer com as elípticas, que no SCH são posicionadas em função da elipticidade projetada, mas que recentemente têm sido apontadas como tendo também 2 famílias: a das "boxy" e a das "disky". Uma tentativa de incorporar as diferentes famílias de elípticas, bem como as irregulares ordinárias e barradas, foi proposta por Kormendy \& Bender (1996). Uma tentativa de incorporar ao SCH todas as classes que não estão devidamente representadas na sequência de Hubble, utilizando um diagrama tri-dimensional, foi feita por van den Bergh (1997).

Evidentemente, o valor de um sistema de classificação depende de sua utilidade, ou de sua capacidade em exibir correlações entre suas classes e vários parâmetros físicos relevantes, conectando, por exemplo, as propriedades morfológicas aparentes nos sistemas e as suas propriedades físicas. Assim, um sistema de classificação útil deve levar à formulação de hipóteses e previsões que possam contribuir para o desenvolvimento de modelos a respeito da formação, estrutura e evolução de galáxias. Nesse aspecto, é notória a utilidade da classificação de Hubble. O índice de cor integrado de galáxias, por exemplo, é uma propriedade física que se correlaciona com os tipos morfológicos de Hubble, no sentido de que galáxias de tipo jovem são mais vermelhas que as de tipo tardio, indicando a população estelar que domina a emissão de luz em cada classe morfológica.

Na seqüência das espirais, algumas tendências podem ser identificadas quando se parte dos tipos jovens para os tardios: (1) o aumento da fração da massa total na forma 
de gás e poeira no meio interestelar, (2) o aumento da luminosidade absoluta das estrelas e regiões Hı mais brilhantes resolvidas nos braços espirais e (3) o aumento no tamanho e no número de regiões HıI resolvidas nos braços. A maior fração de gás nos tipos tardios indica que estes sistemas converteram gás em estrelas com menor rapidez do que os tipos mais jovens (Larson 1990). Portanto, as espirais de tipo jovem consumiram praticamente todo o seu gás e hoje observamos uma maior fração de gás nas espirais tardias. Conseqüentemente, a taxa de formação estelar nas espirais tardias resulta ser também mais elevada atualmente. Luminosidade absoluta, massa total e a abundância de certos elementos químicos como o Oxigênio e o Ferro são outros exemplos de parâmetros físicos fundamentais que se correlacionam com os tipos de Hubble (veja Roberts \& Haynes 1994 para uma revisão).

Apesar de ser um dos critérios de classificação no sistema de Hubble, principalmente para as galáxias vistas de perfil, a correlação entre a razão bojo/disco e os tipos morfológicos apresenta considerável dispersão, i.e., a tendência desta razão de diminuir em direção aos tipos tardios reflete somente um comportamento médio. Assim, podemos encontrar sistemas de mesma subclasse, mesma luminosidade total, mas com razões entre as luminosidades de bojo e disco bastante diversas. Como exemplo, entre muitos outros, pode-se citar o caso de NGC 4800 e NGC 1068, que podem ser examinadas em "The Hubble Atlas of Galaxies" (Sandage 1961). Ambos os sistemas são classificados como $\mathrm{Sb}$, mas NGC 4800 possui um bojo muito mais proeminente que NGC 1068. Isto ocorre porque o critério fundamental utilizado na classificação é o grau de abertura e definição dos braços, e não a razão bojo/disco.

Evidentemente, toda essa variedade nas propriedades e na estrutura de galáxias deve estar relacionada aos processos de formação e evolução de galáxias. Por exemplo, galáxias de mesmo tipo morfológico, porém com diferentes razões bojo/disco, podem apresentar essa diferença devido ao fato de terem sofrido diferentes processos durante suas evoluções. Os processos que envolvem a formação e a evolução das componentes bojo e disco devem ter ocorrido de maneira distinta entre essas galáxias. Uma informação importante que pode nos trazer pistas a respeito dos diferentes processos evolutivos que ocorrem em galáxias é a análise de índices de cor. Estes índices proporcionam informações a respeito da população estelar e da história de formação estelar em galáxias.

O estudo de cores em galáxias, em particular, da cor integrada em bandas largas, tem sido realizado para obter informações a respeito da população estelar (e.g., Searle, Sargent \& Bagnuolo 1973; Tinsley 1980; Frogel 1985; Peletier 1989; Silva \& Elston 1994), bem como da extinção causada pela poeira interestelar (e.g., Evans 1994; Peletier et al. 1994). $\mathrm{O}$ uso de técnicas de fotometria superficial de cores em bandas largas, principalmente nos estudos que envolvem um enfoque estatístico, praticamente não foi realizado. Uma 
exceção é a tese de doutoramento de R.S. de Jong, no "Kapteyn Astronomical Institute" (de Jong \& van der Kruit 1994; de Jong 1996a,b,c).

Uma possibilidade de avaliar o comportamento da cor em galáxias, e portanto da distribuição da população estelar, que tem sido pouco explorada na literatura, é utilizar a distribuição radial de cor, ou seja, o perfil de cor. Esta informação pode oferecer também indicações sobre cenários de formação de bojos.

Nessa Dissertação, estudamos os índices de cor (B-V) e (U-B) ao longo das componentes bojo e disco de galáxias espirais do tipo Sbc, ordinárias e barradas. Neste estudo, damos especial ênfase às previsões dos cenários de formação de bojos nesta classe de galáxias. Assim, no restante deste Capítulo discorreremos brevemente acerca de alguns dos principais cenários de formação e evolução, e suas previsões. Finalizaremos o Capítulo 1 introduzindo com maior profundidade os objetivos deste trabalho.

\subsection{Formação de bojos}

Evidentemente, a formação da componente esferoidal em galáxias espirais está intimamente vinculada à formação de galáxias como um todo, de modo que um cenário de formação de galáxias deve poder explicar as propriedades observadas nas componentes bojo, disco e halo, simultaneamente. Existem, atualmente, três principais cenários sugeridos para a formação dos bojos em galáxias espirais, que buscam se adequar, principalmente, às relações observadas entre as propriedades de bojos e discos, já que ainda não existe um consenso a respeito do bojo ser somente a parte mais central do halo (Silk \& Bouwens 1999; Renzini 1999), ou de bojo e halo serem duas entidades estruturais distintas (Wyse, Gilmore \& Franx 1997). Além disso, as propriedades dos halos de galáxias são intrinsecamente mais difíceis de serem observadas. Como veremos, as diferenças entre os 3 cenários podem ser essencialmente resumidas na época de formação do bojo em relação à formação do disco. Bojos podem ter sido formados em uma época anterior à formação do disco, ou podem ter sido formados posteriormente. Uma terceira hipótese é a de que bojos e discos se formem concomitantemente. Antes de passar a uma breve descrição destes cenários, vejamos algumas das propriedades observadas; muitas delas tornaram-se conhecidas através de estudos do bojo e do disco da Galáxia.

Idades. Em princípio, a determinação das idades de bojos e discos seria um teste definitivo na escolha de um cenário de formação. No entanto, como foi deixado bem claro por Combes (1999), o bojo não tem necessariamente a mesma idade das estrelas que contém, já que pode ter sido formado recentemente, constituído por estrelas velhas. De qualquer 
forma, tem sido observado que os discos têm, em média, cores mais azuis que as dos bojos, o que pode indicar que as estrelas dos bojos são mais velhas. Entretanto, os gradientes de cor apresentados por galáxias espirais mostram que as regiões mais externas dos discos são mais jovens do que suas regiões mais internas (de Jong 1996c). De fato, Peletier \& Balcells (1996) mostram que as cores de bojos e das regiões internas dos discos são bastante similares, concluindo que a diferença nas idades médias das estrelas nestas componentes é menor do que $30 \%$, apesar de existir uma incerteza devido à degenerescência idade-metalicidade.

Metalicidades. Na Galáxia, a metalicidade (i.e., a abundância Fe/H) média das regiões externas do bojo é similar à do disco na vizinhança solar. Porém, a distribuição de metalicidades das estrelas do bojo é muito mais alargada. A distribuição de metalicidades das estrelas do halo, na vizinhança solar, é também muito alargada, mas o valor da metalicidade média é substancialmente inferior (Wyse, Gilmore \& Franx 1997).

Dinâmica. Apesar de um certo suporte rotacional, os bojos são mantidos, em geral, pela dispersão anisotrópica de velocidades das estrelas que contêm, enquanto que os discos são mantidos quase integralmente pelo movimento rotacional das estrelas. No entanto, as estrelas nos bojos de baixa luminosidade têm maior momento angular, o que os torna mais similares aos discos, enquanto que os bojos de alta luminosidade são dinamicamente mais semelhantes às galáxias elípticas (Silk \& Bouwens 1999). Além disso, os bojos seguem o mesmo Plano Fundamental das galáxias elípticas, e a mesma relação luminosidademetalicidade (Combes 1999 e referências aí contidas). Isso sugere que a formação dos bojos de alta luminosidade seja semelhante à formação das elípticas, enquanto que a origem dos bojos de baixa luminosidade esteja ligada à origem dos discos.

Vejamos agora com mais detalhes cada um dos principais cenários propostos na literatura para a formacao de bojos, e as previsões com relação às propriedades acima citadas, além de outras descobertas e propriedades mais específicas.

\subsubsection{O cenário monolítico de formação}

Um estudo clássico sobre a cinemática de 221 estrelas anãs, cujas órbitas cruzam a vizinhança solar, foi publicado em um famoso artigo de Eggen, Lynden-Bell \& Sandage (1962). Esse estudo indicou que estrelas de baixa metalicidade movem-se invariavelmente em órbitas bastante excêntricas, enquanto que as estrelas de alta metalicidade possuem órbitas quase circulares. Também foi encontrada uma correlação entre a metalicidade 
estelar e o momento angular da estrela: estrelas de baixa metalicidade possuem pouco momento angular. Também foi mostrado que as estrelas de alta metalicidade se concentram no plano do disco da Galáxia, enquanto que aquelas de baixa metalicidade podem ser encontradas não somente no disco, mas como também em várias alturas distintas em relação ao plano Galáctico.

A interpretação destas correlações levou os autores a formular um cenário para a formação da Galáxia que, posteriormente, foi estendido para as outras galáxias, e denominado por monolítico. Neste cenário, o bojo seria formado através do colapso radial do gás protogaláctico de abundância química primordial. Este colapso termina rapidamente, em escalas de tempo da ordem de $10^{8}$ anos, quando o aumento do momento angular na região central interrompe a queda radial do gás. Entretanto, o colapso do gás na direção paralela ao momento angular continua, dando origem ao disco.

Como a densidade do gás nas regiões centrais cresce rapidamente, também cresce assim a taxa de formação estelar. Portanto, a primeira geração de estrelas é formada durante o colapso, com órbitas de alta excentricidade, metalicidade baixa, e vai constituir o bojo. Enquanto a primeira geração estelar evolui, o gás remanescente que está dando origem ao disco se enriquece com os elementos químicos resultantes da nucleossíntese estelar. Assim, as estrelas que constituem o disco possuem órbitas quase circulares, alta metalicidade, e são mais jovens que as estrelas do bojo. É evidente que, neste cenário, a formação do bojo ocorre em uma época anterior à do disco.

Apesar da advertência apontada acima por Combes (1999), as evidências de uma população estelar mais velha no bojo da Galáxia, e no de outras galáxias, têm levado pesquisadores a dar suporte ao cenário monolítico (Silk \& Bouwens 1999).

No entanto, é difícil conciliar as previsões das metalicidades estelares neste cenário com a largura da distribuição das metalicidades das estrelas no bojo Galáctico e, em especial, com a descoberta de estrelas super-ricas em metais nesta componente (McWilliam \& Rich 1994). Tentativas de conciliação levaram ao modelo de ciclo fechado (Ibata \& Gilmore 1995 e referências aí contidas; veja também François, Vangioni-Flam \& Audouze 1990; Larson 1990), onde o gás é processado localmente, resultando na população estelar em cada ponto do sistema.

Além disso, a análise de imagens obtidas pelo Telescópio Espacial Hubble por Carollo et al. (1997) mostra que os bojos em galáxias espirais exibem freqüentemente pontos brilhantes, que são, muito provavelmente, regiões de formação estelar. Evidências de que o mesmo fenômeno pode estar ocorrendo no bojo da Galáxia são apresentadas em Rich \& Terndrup (1997). Pfenniger (1993) aponta que a simples existência de galáxias espirais sem bojos ( $\mathrm{Sd}, \mathrm{Sm}$ ), ou com bojos muito pequenos (Sc) já é um indício de que o cenário 
monolítico não é a única possibilidade para a formação de galáxias. Outros fortes vínculos que devem ser obedecidos pelos modelos de formação que seguem o cenário monolítico podem ser encontrados em Avila-Reese \& Firmani (1998).

\subsubsection{O cenário hierárquico de formação}

Toomre \& Toomre (1972) mostraram, através de simulações numéricas, que encontros entre galáxias podem produzir forças de maré suficientemente fortes para dar origem a várias características morfológicas observadas em galáxias, tais como pontes e caudas. Entre os exemplos que podem endossar as previsões das simulações, pode-se destacar NGC 4038 + NGC 4039 ("as Antenas") e M 51 + NGC 5195 (a galáxia "Redemoinho"). Estas simulações monstraram que o encontro entre galáxias certamente tem um importante papel na evolução destes objetos, e que características morfológicas observadas poderiam ser produzidas por tais encontros. Estudos posteriores (ver Alladin \& Narasimhan 1982 para uma revisão) indicaram que colisões mais fortes, resultando na posterior fusão, entre galáxias espirais, poderiam dar origem a uma galáxia elíptica. Schweizer (1982), por exemplo, mostra que NGC 7252 (também conhecida como galáxia "Átomos pela Paz") apresenta várias características que sugerem ser um resultado de uma recente fusão entre duas galáxias espirais de massas similares. No entanto, esta galáxia possui um único núcleo, que tem uma distribuição de luminosidade seguindo a lei $r^{1 / 4}$, típica do perfil de luminosidade de galáxias elípticas.

De maneira similar, a acrescência de uma galáxia companheira anã por uma galáxia espiral poderia contribuir para a formação da componente esferoidal de galáxias espirais. Este processo poderia se repetir várias vezes, já que o encontro entre galáxias certamente não é um raro fenômeno, contribuindo para a construção de um bojo cada vez mais proeminente, constituindo, assim, o cenário hierárquico de formação. Enquanto galáxias elípticas podem ser o resultado de uma fusão entre duas galáxias espirais de tamanhos similares, os bojos seriam formados pela acrescência de galáxias satélites anãs.

A existência de vários exemplos de galáxias espirais gigantes com numerosas companheiras anãs favorece este cenário, que possui duas versões principais. Na primeira delas, a fusão das galáxias destrói o disco já existente, que volta a se formar através da queda do gás remanescente. Nesta versão, o disco é continuamente destruído e reconstruído, enquanto o bojo torna-se cada vez mais importante. Assim, bojos serão mais velhos que discos. Seguindo este raciocínio, Baugh, Cole \& Frenk (1996) elaboraram um modelo simples, que explica de maneira natural diversas propriedades observadas em galáxias, tais como a relação densidade-morfologia (segregação morfológica) e o efeito Butcher-Oemler. No entanto, uma das previsões deste modelo é a de que os bojos em 
galáxias espirais de tipo tardio, que possuem uma baixa razão bojo/disco, devem ser mais velhos do que aqueles em espirais de tipo jovem, já que para ter um disco maior a galáxia deve ter permanecido sem ser perturbada por companheiras e adquirindo gás por um longo tempo. Essa previsão não parece ser compatível com a observação de que galáxias com alta razão bojo/disco não mostram evolução na função de luminosidade até "redshifts" da ordem de 1 (Wyse, Gilmore \& Franx 1997 e referências aí contidas). Por outro lado, pode-se construir modelos (Bouwens, Cayón \& Silk 1998) em que a acrescência de uma galáxia companheira anã contribui tanto para a formação do bojo quanto para a formação do disco, sem destruir um eventual disco já existente (ver também Kauffmann \& White 1993). Nesta versão do cenário hierárquico, bojos e discos têm idades similares.

O cenário hierárquico pode se adequar muito bem às idades observadas de bojos e discos. Entretanto, se os bojos são formados via acrescência, então as metalicidades observadas em bojos, e em particular no bojo da Galáxia, impõem fortes vínculos na metalicidade dos objetos acrescidos. Estes devem possuir metalicidades relativamente elevadas, o que traz limites na fração do bojo que pode ter sido acrescida recentemente (Combes 1999 e referências aí contidas). Além disso, dada a correlação entre metalicidade e luminosidade, então os bojos devem ter sido formados por galáxias anãs de luminosidades semelhantes às dos bojos (Wyse, Gilmore \& Franx 1997 e referências aí contidas).

No caso da Galáxia, as diferenças entre as propriedades cinemáticas e químicas das estrelas no bojo, nas Nuvens de Magalhães e na (recentemente descoberta) galáxia anã esferoidal Sagittarius, indicam que, se a acrescência de companheiras teve um papel importante na formação do bojo Galáctico, então, certamente, estas companheiras eram bastante distintas das que nós temos atualmente. No entanto, a existência de um grande número de estrelas no halo Galáctico com órbitas retrógradas (Larson 1990) é um indício de que a acrescão de pequenos satélites pode ser importante na origem dos halos galácticos. Por outro lado, esse processo pode não ter um papel fundamental na origem de discos e bojos em geral, já que a observação de órbitas retrógradas nestas componentes é rara (Wyse, Gilmore \& Franx 1997).

\subsubsection{O cenário de evolução secular}

Muitos estudos numéricos têm demonstrado que instabilidades dinâmicas em dis$\cos$, tais como braços espirais ${ }^{2}$, mas, principalmente barras, podem ser responsáveis pela formação de bojos em escalas de tempo maiores que a escala de tempo dinâmica de galáxias (i.e., $>10^{8}$ anos).

\footnotetext{
${ }^{2}$ Ver, por exemplo, Zhang $(1996,1998)$.
} 
Evidências observacionais mostram que mais da metade das galáxias brilhantes no universo local possuem barras. Muito trabalho a respeito desta estrutura galáctica foi realizado para que o nosso conhecimento sobre barras possa ser considerado hoje pouco mais do que qualitativo (veja Friedli 1999 para uma revisão).

Sabemos que, devido a instabilidades dinâmicas, é muito provável o surgimento espontâneo de uma barra em discos galácticos, e que estas estruturas também podem ser induzidas por galáxias companheiras interactuantes. Uma vez presentes, as barras produzem uma série de fenômenos evolutivos na galáxia hospedeira. Estudos teóricos (e.g., Friedli \& Benz 1993, 1995 e referências aí contidas) mostram que, através de choques e torques gravitacionais, uma barra estelar é capaz de coletar gás das regiões externas do disco para as regiões internas. Assim, deve ocorrer uma mistura em grande escala do gás ao longo da galáxia, que, em princípio, deveria afetar o comportamento dos perfis de abundância de alguns elementos químicos. Em acordo com essa previsão, Martin \& Roy (1994) e Zaritsky, Kennicutt \& Huchra (1994) concluem, a partir de um estudo de abundância química em galáxias espirais, que as barradas tendem a apresentar gradientes da abundância $\mathrm{O} / \mathrm{H}$ menos acentuados do que galáxias não-barradas. Além disso, Sakamoto et al. (1999) mostram que galáxias barradas apresentam uma maior concentração central de gás molecular $(\mathrm{CO})$ do que galáxias ordinárias. Estes autores argumentam que estes resultados indicam que o transporte de gás ao longo da barra para as regiões centrais das galáxias deve ter ocorrido.

Por outro lado, simulações N-Corpos (e.g., Combes \& Sanders 1981) mostram que uma barra que se desenvolve em um disco plano não permanece fina, i.e., não permanece no plano do disco, já que ressonâncias orbitais (e/ou as instabilidades "bar-buckling" ou "fire-hose") provocam o aquecimento vertical da barra, que se manifesta na formação de uma estrutura perpendicular ao plano do disco, ou seja, no espessamento da barra, em uma escala de tempo de cerca de 1 Giga-ano após a formação desta. Este espessamento é mais importante na região central da barra, que acaba desenvolvendo um bojo com morfologia retangular ou em forma de amendoim (Sellwood 1993). Em uma série de trabalhos recentes (Kuijken \& Merrifield 1995; Merrifield \& Kuijken 1999; Bureau \& Athanassoula 1999; Athanassoula \& Bureau 1999; Bureau \& Freeman 1999; Bureau, Freeman \& Athanassoula 1999) a natureza destes bojos foi estudada, considerando evidências observacionais em favor de mecanismos de acrescência ou de instabilidades em barras. Os resultados indicam que, apesar dos mecanismos de acrescência serem possíveis e prováveis, eles não são os mecanismos primários, e que instabilidades "bar-buckling" devem ser responsáveis pela ocorrência da maioria dos bojos com estas morfologias. Estes resultados reforçam, portanto, a hipótese de que bojos retangulares ou em forma de amendoim são, de fato, galáxias barradas vistas de perfil, conforme sugerido por de Souza \& dos Anjos (1987), e que o cenário de evolução secular em galáxias barradas deve gerar as morfologias 
observadas nestes tipos de bojos.

Além disso, o aumento da concentração de massa nas regiões centrais da galáxia, provocado pelo transporte de gás ao longo da barra, dá origem a órbitas estelares irregulares que transportam estrelas do disco para o bojo (e.g., Berentzen et al. 1998). Assim, temos, por um lado, o transporte de gás para as regiões centrais das galáxias que pode produzir surtos de formação estelar e o enriquecimento químico destas regiões. E, por outro lado, o transporte de estrelas do disco para o bojo via aquecimento vertical da barra e a indução de órbitas estelares irregulares. Dessa forma, os processos evolutivos relacionados a barras estelares podem ser responsáveis pela construção de bojos galácticos.

Norman, Sellwood \& Hasan (1996), entre outros trabalhos teóricos, mostram que a concentração central de massa, induzida pela barra, faz com que as órbitas que a sustentam (entre essas as órbitas do tipo $x_{1}$, que são órbitas estáveis, de alta excentricidade, ao longo do eixo maior da barra) desapareçam. Portanto, a barra pode ser destruída devido aos processos que ela própria induz. Estes autores vão mais além, sugerindo que a formação da barra, sua dissolução e conseqüente construção do bojo, possa ser um processo recorrente.

O transporte de gás para as regiões centrais de galáxias, induzido pela barra, tem sido estudado também como uma possível alternativa para a alimentação de núcleos ativos de galáxias. Através de processos dinâmicos (desacoplamento), uma barra secundária pode surgir interna à barra primária e conduzir o gás até pequenas escalas de distância, próximas ao núcleo ativo (Shlosman, Frank \& Begelman 1989; Shlosman, Begelman \& Frank 1990). Erwin \& Sparke (1998) apresentam galáxias onde a barra secundária pode ser identificada. Em NGC 2681, Erwin \& Sparke (1999) encontram uma hierarquia de três barras. Embora ainda não haja um consenso a respeito da relação das barras com os núcleos ativos (Ho, Filippenko \& Sargent 1997; Knapen 1998), a formação e dissolução de barras hierárquicas favorece ainda mais o cenário no qual a construção de bojos está intimamente ligada aos processos dinâmicos nos discos galácticos (Friedli \& Martinet 1993). Neste último trabalho, é sugerido que a contínua construção do bojo pode transformar a morfologia de uma galáxia. Assim sendo, uma galáxia do tipo Sc pode, através destes processos de evolução secular, tornar-se uma galáxia do tipo Sb, fazendo com que pelo menos a seqüência tardia de Hubble ganhe um significado evolutivo entre tipos contíguos.

Muitos outros estudos observacionais dão suporte ao cenário de formação de bojos via evolução secular. A similaridade das cores em bandas largas de bojos e das regiões internas de discos, encontrada por Peletier \& Balcells (1996) para uma amostra de espirais de tipo jovem, é um exemplo, já que indica que as idades e as metalicidades das estrelas nessas regiões são semelhantes, embora a degenerescência idade-metalicidade nas cores de populações estelares possa trazer incertezas. Courteau, de Jong \& Broeils (1996 - 
veja também de Jong 1996b) mostram que existe uma correlação entre as escalas de comprimento de bojos e discos para uma amostra de espirais de tipos jovem e tardio. Estes resultados podem estar indicando que as formações de bojo e disco não podem ser fenômenos tão distintamente separados como no cenário monolítico, mas que deve existir uma conexão evolutiva entre essas duas componentes. Além disso, os surtos de formação estelar observados por Carollo et al. (1997) em bojos extragalácticos são naturalmente explicados no cenário de evolução secular.

Outras evidências que dão apoio a este cenário são encontradas em observações a respeito da dinâmica e cinemática de bojos. Kormendy (1982) mostra que bojos triaxiais, que são dinamicamente semelhantes a barras, têm uma velocidade máxima de rotação maior do que os bojos de galáxias ordinárias e, portanto, são mais semelhantes a discos. Neste artigo, Kormendy conclui que "uma fração significativa do bojo em muitas galáxias barradas deve consistir de gás do disco que foi transportado para o centro pela barra. Na medida em que este gás se acumula, forma estrelas e dá origem a uma distribuição estelar muito centralmente concentrada, a qual é fotometricamente semelhante a um bojo, mas dinamicamente semelhante a um disco.". Kormendy \& Illingworth (1983) mostram que bojos de galáxias barradas têm, em geral, uma dispersão central de velocidade menor do que os bojos de galáxias ordinárias de mesma luminosidade. Como os discos têm uma dispersão central de velocidade menor do que bojos, este resultado é consistente com a hipótese de que os bojos em galáxias barradas foram acrescidos com material do disco, transportado pela barra. A semelhança entre a distribuição de elipticidades de bojos e discos também foi utilizada como um argumento de que as formações destas duas componentes são eventos conexos (Kormendy 1993). Outra evidência de que os processos evolutivos em barras contribuem para a formação de bojos vem do fato de que estrelas ricas em metais no bojo Galáctico possuem características cinemáticas de barras, enquanto que as estrelas pobres em metais nesta região não possuem esta propriedade (Rich \& Terndrup 1997).

Entretanto, Wyse, Gilmore \& Franx (1997) apontam para um problema potencial para a aplicabilidade geral deste cenário de formação de bojos. Este problema vem do fato de que as barras em galáxias espirais de tipo jovem possuem um perfil de luminosidade constante, enquanto que aquelas em espirais de tipo tardio têm perfis exponenciais, ou ainda mais abruptos. Por outro lado, a decomposição de perfis de luminosidade de galáxias espirais mostra que os discos e os bojos em espirais tardias são melhor ajustados por um perfil exponencial, enquanto que os bojos em espirais de tipo jovem têm um perfil mais próximo à lei $r^{1 / 4}$ (e.g., Courteau, de Jong \& Broeils 1996). Estes resultados podem indicar que o cenário de evolução secular somente tem um importante papel na formação de bojos em espirais tardias. 
Por outro lado, analisando a densidade no espaço de fase das estrelas no bojo e no disco da Galáxia (que têm valores típicos para outras galáxias também), Wyse (1998) mostra que bojos de galáxias não podem se formar através da instabilidade dinâmica de discos estelares puros; uma componente dissipativa (gás) precisa ser invocada para o processo, o que impõe vínculos nos modelos que se baseiam no cenário de evolução secular.

Apesar de Courteau, de Jong \& Broeils (1996) afirmarem que a correlação entre os comprimentos de escala de bojos e discos é melhor compreendida em um modelo no qual o disco se forma primeiro e dá origem ao bojo, cada vez mais torna-se claro que os 3 cenários que acabamos de descrever devem ocorrer, e que a formação de bojos pode ser uma combinação destes 3 cenários. No caso da Galáxia, por exemplo, a pequena diferença nas idades de aglomerados globulares de mesma metalicidade, e a também pequena variação nas idades destes em relação à distância Galactocêntrica, favorece o cenário monolítico, já que, neste cenário, os aglomerados globulares se formariam rapidamente durante o colapso da protogaláxia. No entanto, a existência de alguns aglomerados globulares Galácticos que têm um comportamento anômalo indica que houve, em algum momento, a captura de companheiras anãs pela Galáxia (Stetson, VandenBergh \& Bolte 1996). Além disso, todas as evidências observacionais e os resultados dos estudos numéricos descritos acima tornam pouco provável que os processos de evolução secular não tenham ocorrido, ou não ocorram, na Galáxia, principalmente porque muitas evidências apontam para a existência de uma barra em nosso sistema estelar (e.g., referências em Binney \& Tremaine 1987).

A questão que permanece para ser respondida por estudos futuros é a de determinar a importância relativa de cada um destes cenários, e como o papel de cada um deles varia em diferentes condições físicas, como, por exemplo, em ambientes de diferentes densidades galácticas. Certamente, o estudo de galáxias em altos "redshifts", ou seja, a observação de galáxias no processo de formação, trará progressos na tentativa de obter estas respostas. Por exemplo, Abraham et al. (1994,1996) e van den Bergh et al. (1996) fazem um estudo das propriedades morfológicas de galáxias no "Hubble Deep Field", utilizando um sistema de classificação baseado na concentração central de luz e na assimetria dos objetos. Estes autores concluem que: (i) galáxias barradas são raras no "Hubble Deep Field"; (ii) a fração de espirais de tipo jovem (i.e., com alta razão bojo/disco) é similar à mesma fração no Universo local, e (iii) a fração de objetos peculiares, ou em interação ou fusão é significativamente maior do que entre as galáxias próximas. Este resultado pode favorecer o cenário hierárquico. No entanto, Marleau \& Simard (1998) obtêm parâmetros estruturais para as galáxias no "Hubble Deep Field", através da decomposição do perfil de brilho superficial destas galáxias em um perfil exponencial para o disco e um perfil de Sérsic para o bojo. Os resultados obtidos por Marleau e Simard contradizem os descritos acima, já que estes autores encontram que somente $8 \%$ dos objetos têm bojos dominantes. Este resultado claramente favorece um cenário no qual a formação do bojo ocorre posterior 


\subsection{Gradientes de cor e o cenário de evolução secular - Motivação do trabalho}

O objetivo deste estudo é o de verificar a existência de correlações que possam indicar a ocorrência dos efeitos de evolução secular em galáxias barradas, apresentados na seção 1.1.3. Para tanto, realizamos duas principais abordagens distintas, porém complementares. A primeira delas consiste, essencialmente, na determinação e análise dos gradientes de cor de uma amostra de galáxias barradas e ordinárias. A segunda abordagem consiste na determinação e na análise dos parâmetros característicos dos perfis de luminosidade de bojos e discos de parte de nossa amostra principal de galáxias. Na primeira abordagem, para determinar os gradientes de cor, utilizamos dados obtidos na literatura, enquanto que, na segunda abordagem, a decomposição bojo/disco foi realizada através de imagens digitalizadas do DSS ("Digitized Sky Survey"), adquiridas em placas fotográficas. Finalmente, realizamos um estudo comparativo, com dados adquiridos por nós, em CCD ("Charge-Coupled Device"), em missões observacionais realizadas no Observatório do Pico dos Dias (Laboratório Nacional de Astrofísica - OPD/LNA).

Gradientes de cor (Capítulo 2). Uma importante ferramenta que pode trazer pistas a respeito dos diferentes processos evolutivos que ocorrem em galáxias é a análise de índices de cor. Veremos na seção 2.1 como estes índices nos proporcionam informações a respeito da população estelar e da história de formação estelar em galáxias. Uma conseqüência natural do cenário de evolução secular é a homogeneização das populações estelares ao longo de bojo e disco, que deve se manifestar, de maneira análoga, na homogeneização dos índices de cor ao longo da galáxia. Para verificar este efeito, determinamos os gradientes de cor (B-V) e (U-B) para uma amostra de 257 galáxias de tipos morfológicos Sb, Sbc e $\mathrm{Sc}$, barradas e ordinárias. Os gradientes foram calculados através de métodos estatísticos robustos, utilizando dados da literatura, obtidos através de fotometria fotoelétrica de abertura.

Fotometria superficial (Capítulo 3). Neste capítulo, o objetivo é verificar, através de técnicas de fotometria superficial, correlações que possam contribuir para corroborar, ou não, o cenário de evolução secular em galáxias barradas. Este cenário provê mecanismos para a formação e/ou construção de bojos em galáxias espirais ${ }^{3}$. Uma conseqüência

\footnotetext{
${ }^{3}$ Deixemos clara a distinção entre os termos "formação" e "construção" de bojos. A formação do bojo pressupõe a anterior inexistência desta componente. Por sua vez, a construção do bojo se refere ao seu
} 
natural que seria esperada para as galáxias que sofreram estes efeitos de evolução secular é a de que a componente bojo cresceria. Além disto, como conseqüência destes processos, deveríamos esperar fortes correlações entre as dimensões de bojo e disco, já que estas duas componentes teriam seus processos de evolução compartilhados. Portanto, uma correlação compatível com o cenário de evolução secular seria a de que aquelas galáxias cujas populações estelares de bojo e disco são similares seriam também aquelas que apresentam bojos mais proeminentes. Para verificar esta correlação, realizamos decomposições bojo/disco para 39 galáxias, que constituem uma sub-amostra representativa de nossa amostra inicial. O algoritmo de decomposição ajusta perfis de brilho distintos para as componentes bojo e disco ao perfil de brilho total da galáxia, fornecendo-nos parâmetros característicos, tais como o raio efetivo do bojo, o brilho superficial efetivo do bojo e a razão entre as luminosidades de bojo e disco. É importante enfatizar que o algoritmo de decomposição utiliza a imagem das galáxias e, portanto, realiza um ajuste bi-dimensional, raramente apresentado na literatura. As imagens utilizadas nessa abordagem são do DSS. Como os gradientes de cor foram determinados com dados obtidos através de fotometria fotoelétrica de abertura, e a decomposição bojo/disco foi realizada em imagens digitalizadas, adquiridas em placas fotográficas, é relevante verificar se os resultados assim obtidos são compatíveis com aqueles obtidos através do imageamento em CCD, já que essa é uma técnica mais moderna e refinada. Portanto, realizamos o imageamento em CCD para 14 galáxias de nossa amostra no OPD/LNA. Com essas imagens, os gradientes de cor foram determinados, e a decomposição bojo/disco foi realizada, da mesma maneira como foi efetuado para o restante de nossa amostra. Esses dados nos permitiram realizar um estudo comparativo, apresentado na seção 3.5 .

Finalizando esta Dissertação, o Capítulo 4 apresenta nossas conclusões finais e nossas perspectivas futuras para este trabalho.

crescimento e, portanto, necessita que esta componente já exista, independentemente de qual tenha sido o seu processo de formação. 


\section{Capítulo 2}

\section{Gradientes de Cor}

Neste capítulo, apresentamos um estudo estatístico do comportamento dos índices de cor ao longo da direção radial de galáxias espirais tardias (Sb's, Sbc's e Sc's). O objetivo principal é o de verificar, através da informação da distribuição de cor, e portanto, em princípio, da população estelar, como os gradientes de cor se comportam nas galáxias da amostra. Em particular, estamos interessados em verificar a presença de gradientes de cor nulos, ou seja, índices de cor semelhantes em bojos e discos, que indicariam, portanto, a homogeneização das populações estelares, como previsto por processos de evolução secular em galáxias barradas (ver seção 1.1.3). Para este fim, selecionamos uma amostra de 257 galáxias dos tipos Sb, Sbc e Sc, ordinárias e barradas, com medidas dos índices de cor (B-V) e (U-B) ao longo de cada uma delas, publicadas em "A General Catalogue of Photoeletric Magnitudes and Colors of Galaxies in the U, B, V System" (Longo \& A. de Vaucouleurs 1983,1985 - doravante LdV83,85).

No decorrer deste capítulo, vamos mostrar que, na maioria das galáxias, os índices de cor variam suavemente da região central para a região periférica, caracterizando, assim, um gradiente de cor. Veremos também que a maior parte das galáxias em nossa amostra apresenta um acentuado gradiente de cor negativo, i.e., têm índices mais vermelhos nas regiões centrais (bojo), e índices mais azuis nas regiões periféricas (disco).

A diferença entre os índices de cor dos bojos e discos indica que a população estelar dominante varia ao longo das galáxias. Este fato está em acordo com a previsão do cenário monolítico de formação de galáxias espirais (ver seção 1.1.1), que identifica essa diferença nas populações estelares de bojos e discos como conseqüência de que a formação destas componentes se dá de forma distinta e separada. 
Por outro lado, uma das conseqüências naturais do cenário de evolução secular em galáxias barradas (ver seção 1.1.3) é a homogeneização das populações estelares ao longo do bojo e disco, já que os processos de evolução promovem uma conexão entre essas duas componentes. Desde que haja uma quantidade suficiente de gás no disco e desde que a barra esteja presente durante um intervalo de tempo suficiente para que esse gás seja transportado para as regiões centrais da galáxia, dando origem aí a surtos de formação estelar, as populações do bojo e disco deverão ser mais semelhantes entre si do que aquelas em uma galáxia que não sofreu tais processos. Essa homogeneização é ainda mais acentuada na medida em que a barra induz o transporte de estrelas do disco para o bojo através do esquentamento vertical do disco. Evidentemente, a homogeneização das populações estelares deve se refletir de modo análogo no comportamento dos índices de cor ao longo da galáxia. Assim sendo, uma galáxia que sofreu tais processos deve apresentar índices de cor semelhantes no bojo e no disco, ou seja, deve apresentar um gradiente de cor aproximadamente nulo ou menos acentuado. De fato, cerca de $25 \%$ das galáxias em nossa amostra apresentam este comportamento. Veremos que há, entre essas galáxias, um excesso estatisticamente significativo de galáxias barradas. Também veremos que os índices de cor destas galáxias são similares aos índices dos discos das galáxias com o típico gradiente negativo. Estes resultados podem estar indicando que, pelo menos em algumas galáxias, a barra atua unificando as populações estelares de bojos e discos, em acordo com o cenário de evolução secular.

Na próxima seção, introduzimos os conceitos básicos que fundamentam este estudo. As seções 2.2 e 2.3 descrevem, respectivamente, a seleção da amostra estudada e a determinação dos gradientes de cor, bem como dos índices de cor característicos do bojo e do disco de cada galáxia. Os resultados são apresentados em 2.4, e analisados e discutidos na seção 2.5, que também traz um resumo de nossas conclusões.

\subsection{Magnitudes, cores e populações estelares}

As 1022 estrelas catalogadas no "Almagesto" de C. Ptolomeu estão divididas em 6 grupos distintos, ou magnitudes, de acordo com o brilho aparente desses objetos, de modo que as estrelas mais brilhantes são de magnitude 1 e as estrelas mais tênues que podem ser vistas pelo olho desarmado são de magnitude 6. Esta obra foi elaborada na primeira metade do século II A.D. e é uma compilação de todo o conhecimento de Astronomia adquirido até então na Grécia Antiga. A essência dessa classificação do brilho das estrelas perdurou e é utilizada até hoje. Acreditava-se, na época, que essa divisão em magnitudes correspondia a diferenças equivalentes em luminosidade, mas como a resposta do olho humano à radiação é logarítmica, i.e., nossos olhos reconhecem razões iguais 
de luminosidade, mas não incrementos iguais na luminosidade ${ }^{1}$, a escala de magnitudes resulta ser uma escala logarítmica. Estudos posteriores por N. Pogson em 1856 mostraram que, de fato, uma estrela de sexta magnitude é cerca de 100 vezes menos brilhante que uma de magnitude 1 , mas somente 2.5 vezes menos brilhante que uma estrela de magnitude 5 . Levando estes fatos em consideração, podemos escrever:

$$
m_{1}-m_{2}=-2.5 \log _{10}\left(\frac{f_{1}}{f_{2}}\right)
$$

ou

$$
\frac{f_{1}}{f_{2}}=10^{-0.4\left(m_{1}-m_{2}\right)}
$$

onde $m_{1}$ e $m_{2}$ são as magnitudes de duas estrelas distintas com fluxos de energia irradiada iguais a $f_{1}$ e $f_{2}$, respectivamente. Pode-se verificar imediatamente através da equação (2.1) que a escala de magnitudes é uma escala relativa, e portanto, deve ser fixa, arbitrando-se a magnitude de estrelas definidas como padrões.

No entanto, a atmosfera terrestre absorve parte dos fótons emitidos pela estrela, e outros fótons são absorvidos pelo sistema detector utilizado na observação. Assim, sendo $f_{\nu}$ o fluxo aparente de uma estrela em um intervalo de freqüências, podemos expressar o fluxo integrado aparente $f$ em função do fluxo intrínseco em um intervalo de freqüências $f_{\nu}^{0}$ por:

$$
f=\int_{0}^{\infty} f_{\nu} d \nu=\int_{0}^{\infty} f_{\nu}^{0} T_{\nu} F_{\nu} R_{\nu} d \nu
$$

onde $T_{\nu}$ é a fração de fótons transmitida pela atmosfera, $F_{\nu}$ é a transmissão do sistema de filtros utilizado, $R_{\nu}$ é a eficiência na detecção de fótons pelo sistema de detecção do telescópio e $\nu$ é a freqüência da radiação emitida.

Evidentemente, a fração de fótons absorvida pela atmosfera é menor quando a estrela encontra-se no zênite e aumenta em direção ao horizonte. De fato, a atenuação da luz emitida por uma estrela ao atravessar a atmosfera segue a seguinte relação:

$$
m_{z}-m_{0}=k_{\nu} \sec z
$$

\footnotetext{
${ }^{1}$ Esta relação é conhecida como a lei de Fechner dos estímulos.
} 
onde $m_{0}$ é a magnitude da estrela no zênite e $m_{z}$ é a sua magnitude na distância zenital $z$. A constante $k_{\nu}$ é determinada ao se observar a magnitude de uma estrela em várias distâncias zenitais. Conhecendo esta constante, podemos extrapolar a equação (2.4) para obter o valor da magnitude da estrela no caso em que a observação fosse realizada acima da atmosfera ("sec $z=0$ "). Como a extinção atmosférica varia de uma noite para outra, o valor de $k_{\nu}$ deve ser determinado em cada noite de observação. Além disso, como $k_{\nu}$ varia com o comprimento de onda da luz observada, deve ser determinado para cada filtro utilizado. De fato, o efeito da atmosfera terrestre não é somente atenuar a luz das estrelas, mas também torná-la mais avermelhada, já que espalha com maior eficiência luz com comprimentos de onda mais curtos. Após determinar $k_{\nu}$, podemos corrigir os efeitos da extinção atmosférica para todos os outros objetos observados durante a noite, desde que conheçamos também as distâncias zenitais em que estes foram observados.

A correção para os outros termos da equação $(2.3), F_{\nu}$ e $R_{\nu}$, é realizada ao mesmo tempo em que se transforma as magnitudes obtidas para a escala padrão, i.e., quando se calibra os dados obtidos utilizando-se estrelas-padrão observadas durante a noite, de modo que as magnitudes instrumentais obtidas para essas estrelas possam ser comparadas às que estão publicadas na literatura. Por exemplo, Graham (1982) apresenta estrelaspadrão para observações no hemisfério sul.

O fato de o meio interestelar ser preenchido por gás e poeira em baixas densidades, faz com que tenhamos que corrigir as magnitudes estelares por ainda mais um fator, que é a extinção interestelar. Os grãos de poeira presentes entre as estrelas absorvem mais fortemente a luz de comprimentos de onda mais curtos (como a luz ultravioleta, por exemplo), transformando os fótons absorvidos em luz de comprimentos de onda mais longos (infravermelho). Por outro lado, a luz de comprimentos de onda mais longos atravessa as camadas de poeira sem sofrer muita absorção. Portanto, o efeito da extinção interestelar é o de avermelhar a luz emitida pelas estrelas.

Como este trabalho versa sobre galáxias, precisamos conhecer o efeito da distribuição da poeira interestelar na Galáxia sobre a luz emitida por estes objetos. Este efeito pode ser parametrizado pelo o que se conhece como excesso de cor. Este parâmetro corrige os valores observados dos efeitos da extinção (ou avermelhamento) Galáctica e pode ser descrito como uma função das coordenadas galácticas $(1, b)$ do objeto. Além disso, como as galáxias que estudamos aqui também possuem grãos de poeira no seu próprio meio interestelar, também precisamos fazer uma correção pelos efeitos desta extinção (ou avermelhamento) intrínseca, i.e., pelos efeitos da absorção de luz pela poeira presente em cada uma das galáxias. Trataremos do avermelhamento Galáctico e do avermelhamento intrínseco mais adiante, na determinação dos gradientes de cor (seção 2.3) e dos índices de cor caraterísticos de bojos e discos (seção 2.3.1). 


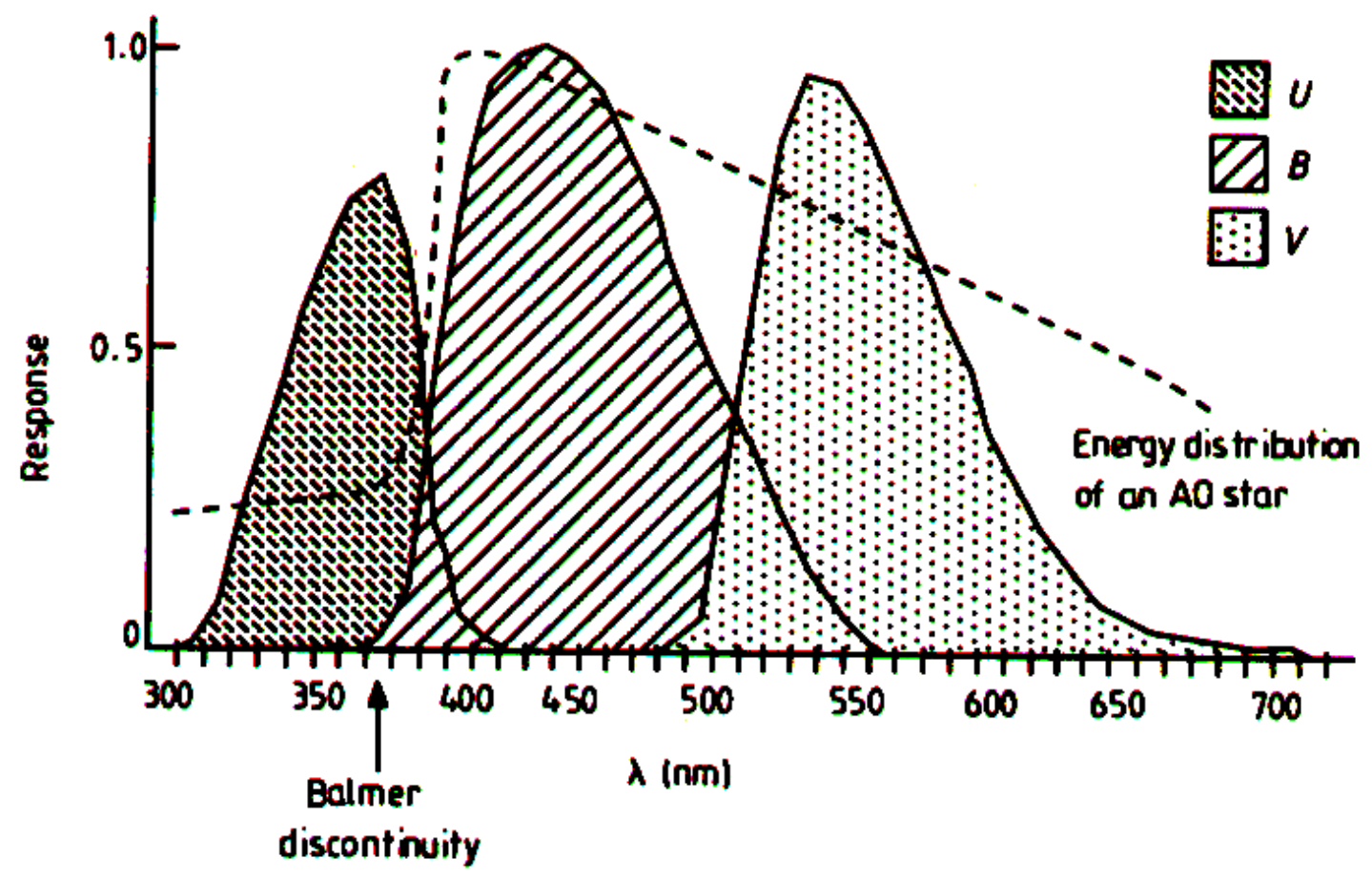

Figura 2.1: Curvas de resposta para os filtros U, B e V de Johnson e Morgan. No eixo das abscissas está o comprimento de onda em nanometros, e no eixo das ordenadas a resposta normalizada. A curva tracejada indica uma distribuição espectral de energia típica de uma estrela de tipo A0. A posição da descontinuidade de Balmer também está destacada. (Extraído de Kitchin 1998).

O sistema fotométrico utilizado neste trabalho é o sistema UBV desenvolvido por Johnson e Morgan em 1953. Consiste em 3 filtros que restringem a detecção da radiação emitida pela estrela a uma determinada faixa de freqüências, e cujas curvas de resposta podem ser vistas na Figura 2.1. O comprimento de onda efetivo e a largura FWHM ("full width at half maximum" - entre parênteses) dos filtros U, B e V são, respectivamente, 365 (66), 445 (94) e 551 (88), em nanometros.

Uma estrela vermelha é mais brilhante (possui magnitude menor) no filtro $\mathrm{V}$ do que no filtro B. Como, inversamente, uma estrela azul possui magnitude menor no filtro B do que no filtro $\mathrm{V}$, a diferença entre essas duas magnitudes, denominada índice de cor (B-V), é uma medida da cor da estrela, pois a estrela vermelha terá um índice (B-V) maior do que a azul. De fato, o índice (B-V) de uma estrela azul, com tipo espectral mais jovem do que A0, será negativo, enquanto que o da vermelha será positivo. Assim, o índice de cor $(\mathrm{B}-\mathrm{V})$ é definido como

$$
(B-V) \equiv m_{B}-m_{V}=c-2.5 \log _{10} \frac{\int_{0}^{\infty} f_{\nu} T_{\nu}(B) F_{\nu}(B) R_{\nu}(B) d \nu}{\int_{0}^{\infty} f_{\nu} T_{\nu}(V) F_{\nu}(V) R_{\nu}(V) d \nu}
$$

De maneira análoga se define o índice de cor (U-B). A constante $c$ é definida de 


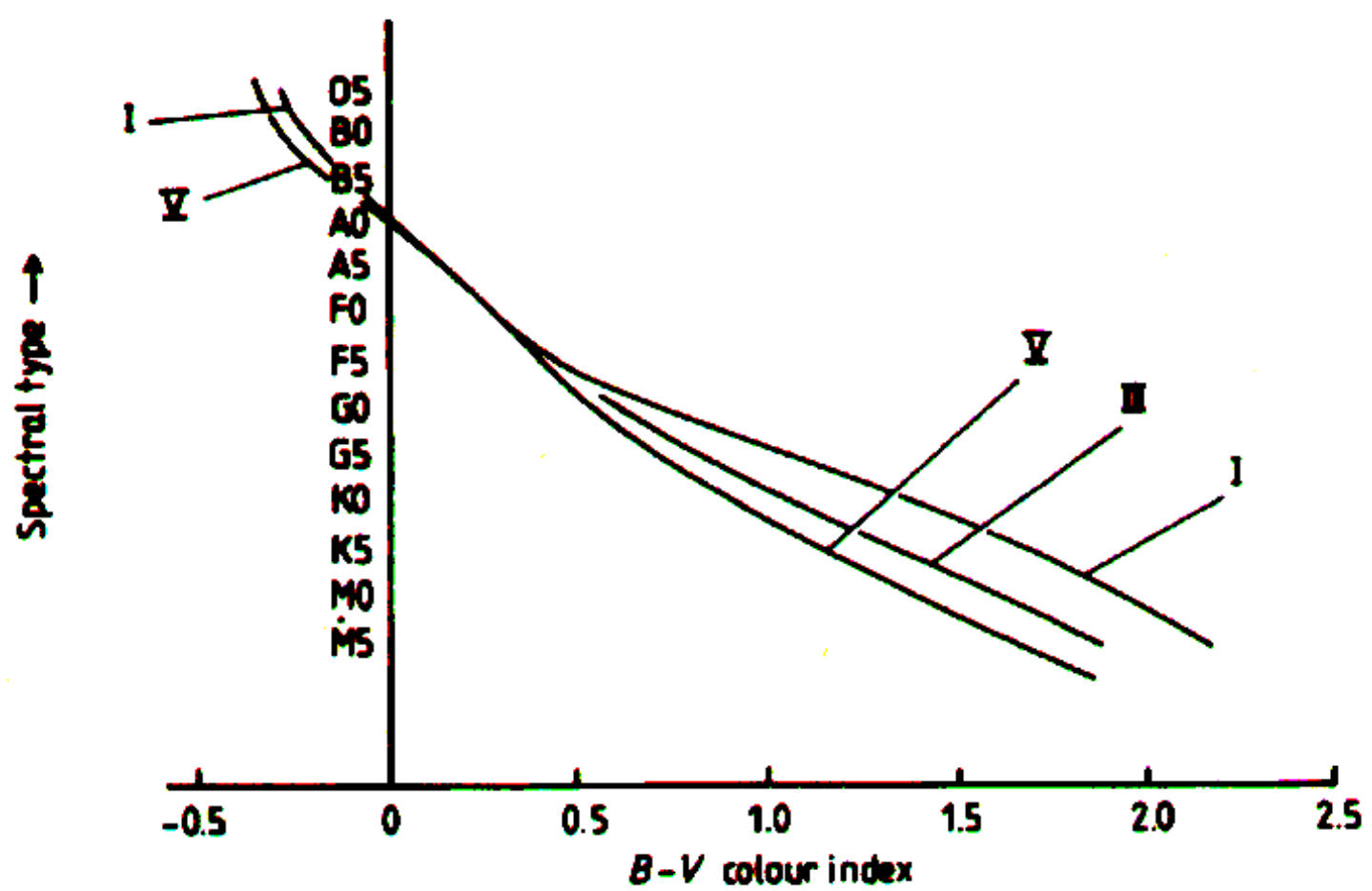

Figura 2.2: Relação entre o tipo espectral e o índice de cor (B-V) (Extraído de Kitchin 1998).

modo a se adequar à escala padrão de magnitudes, seguindo a convenção de que uma estrela de tipo espectral A0, como $\alpha$ Lyr (Vega), tenha a mesma magnitude em todos os comprimentos de onda, e portanto, $(U-B)=(B-V) \equiv 0$ para estrelas do tipo A0.

Assim sendo, o índice de cor é uma medida da razão de fluxos em duas bandas fotométricas distintas e é, portanto, independente da distância do objeto. Além disso, como depende da forma do espectro estelar, é uma medida aproximada da distribuição espectral da energia emitida pela estrela. Como pode ser visto na Figura 2.2, o índice de cor guarda realmente estreita relação com o tipo espectral.

A distribuição espectral de energia emitida por uma estrela depende de alguns parâmetros físicos, tais como temperatura, gravidade superficial e composição química. Como estrelas frias são vermelhas e estrelas quentes são azuis, o índice (B-V) é uma medida da temperatura da estrela. Além disso, como muitas linhas espectrais de absorção, relativas a elementos pesados, estão presentes na banda U, enquanto que a banda B é relativamente livre de linhas, o índice (U-B) reflete, ainda que grosseiramente, a composição química da estrela. Estes mesmos índices também são afetados pela idade de uma estrela. Estrelas jovens tendem a ser mais azuladas, e se tornam mais vermelhas conforme evoluem no Diagrama HR. Outra característica do espectro estelar que interefere no valor observado do índice (U-B) é a descontinuidade de Balmer. Essa descontinuidade consiste em uma queda abrupta na distribuição espectral de energia de uma estrela para 
comprimentos de onda menores do que 364 nanometros. Essa queda é provocada pela absorção do contínuo por átomos de Hidrogênio no nível $n=2$. A descontinuidade de Balmer atinge um máximo para estrelas de tipo A0, na seqüência principal, e para estrelas de tipo F0 para supergigantes. Por outro lado, pode ser desprezada para estrelas mais quentes (tipos O e B) e mais frias (tipos G0 e os ainda mais frios). Na Figura 2.1 pode se observar a descontinuidade de Balmer em uma distribuição espectral de energia típica de uma estrela A0.

A partir destas considerações podemos concluir que o índice de cor na região central de uma galáxia, por exemplo, reflete o tipo espectral médio das estrelas que dominam a emissão de luz nessa região. Mais ainda, se existe uma variação no índice de cor ao longo de uma galáxia, então existe também uma variação na população estelar dominante ao longo desta galáxia, seja devido à idade média da população, à sua metalicidade, ou a ambos os efeitos. Portanto, a maioria das galáxias, que apresenta gradientes de cor negativos, com os índices de cor diminuindo sistematicamente do centro para a periferia, possui populações estelares bastante distintas entre as regiões centrais, dominadas pelo bojo, e as regiões periféricas, dominadas pelo disco. Por outro lado, a homogeneização das populações estelares ao longo de bojo e disco, promovida pelos processos de evolução secular, pode provocar a homogeneização dos índices de cor ao longo dessas duas componentes, de forma a atenuar os gradientes de cor negativos, tornando-os menos acentuados ou até mesmo nulos. Portanto, a observação de que uma galáxia possui um gradiente de cor nulo pode ser um forte indício de que esta galáxia sofreu os processos de evolução secular descritos na seção 1.1.3.

\subsection{Seleção da amostra}

Os dados que utilizamos para determinar os gradientes de cor foram extraídos do LdV83,85. Na primeira etapa de seleção da amostra, somente utilizamos o LdV83, que se encontra disponível eletronicamente no CDS ("Centre de Données Astronomiques de Strasbourg”). Este catálogo é uma compilação de 16.680 observações (fotometria fotoelétrica de abertura) de 3578 galáxias, coletadas em 150 fontes distintas, desde 1936 até 1982. São apresentados, para cada galáxia e para diafragmas de diferentes aberturas, os índices de cor (B-V) e (U-B), a magnitude $\mathrm{V}$ aparente, o diâmetro e o tipo morfológico da galáxia, bem como a fonte de observação.

Selecionamos todas as galáxias no LdV83 com índice do estágio de Hubble $\mathrm{T}=3,4$ e 5, i.e., tipos morfológicos Sb, Sbc e Sc, ordinárias e barradas, com magnitudes menores 
do que 14 na banda $B^{2}$, segundo o RC3. Esta seleção resultou em 531 objetos com 2458 medidas através de aberturas distintas. Posteriormente, incluímos os dados contidos no LdV85, seguindo os mesmos critérios. Também foram feitas as correções apontadas neste suplemento, que dizem respeito a erros cometidos durante a confecção do LdV83.

Em seguida, retiramos da amostra aquelas galáxias para as quais o índice (B-V) foi medido em menos do que 5 aberturas distintas. Assim, somente trabalhamos com aquelas galáxias para as quais um estudo cuidadoso e completo do comportamento dos índices de cor ao longo das componentes bojo e disco pôde ser realizado. Além disso, realizamos uma inspeção visual de toda a amostra, utilizando imagens do DSS, eliminando objetos peculiares, que apresentam perturbações, tais como faixas de poeira conspícuas e companheiras em forte interação, que poderiam prejudicar a análise. Após este último passo, a amostra final consiste em 257 galáxias com 2906 medidas dos índices de cor através de aberturas distintas.

A escolha deste intervalo de classe morfológica está vinculada ao fato de que estes sistemas são os mais luminosos na banda B ao longo da seqüência de Hubble (Roberts \& Haynes 1994; van den Bergh 1997), o que pode indicar, portanto, que são os objetos que apresentam as maiores taxas de formação estelar na seqüência das espirais. Além disto, alguns estudos indicam que os objetos destas classes podem ser os que possuem maior instabilidade dinâmica, e portanto são mais vulneráveis à formação de barras. Mais ainda, outros estudos sugerem que os efeitos de evolução secular somente são importantes para galáxias de tipo tardio. Vale notar que várias galáxias foram distintamente classificadas no LdV83,85 e no RC3. Como a incerteza no índice do estágio de Hubble é da ordem de 2 (Lahav et al. 1995), podemos considerar as galáxias da presente amostra como pertencentes a uma única sub-classe morfológica $(\mathrm{T}=4 \pm 1)$.

\subsection{Cálculo dos gradientes de cor}

Os gradientes de cor (U-B) e (B-V) das galáxias da amostra foram determinados através dos índices de cor (U-B) e (B-V) apresentados no LdV83,85 para várias aberturas distintas ao longo de cada galáxia.

Como o LdV83,85 é uma compilação de dados adquiridos por vários observadores, utilizando diferentes instrumentos e telescópios, e em diferentes condições atmosféricas, é natural que algumas medidas pareçam inconsistentes entre si, já que alguns dados podem

\footnotetext{
${ }^{2}$ Este critério nos ajuda a garantir que a classificação morfológica da galáxia é confiável, já que sistemas mais tênues são, em geral, mais difíceis de serem classificados. De qualquer forma, a inclusão de objetos com maiores magnitudes não aumentaria substancialmente nossa amostra.
} 
estar mais perturbados por erros internos. Por exemplo, autores diferentes podem fornecer valores bastante distintos do índice (U-B) para a mesma galáxia e no diafragma de mesma abertura. De fato, este é o caso de NGC 2377 no diafragma de abertura de 2.6 minutos de arco, em que 3 fontes distintas atribuem ao índice (U-B) os valores $0.11,0.20$ e 0.38 ! Tentar ajustar uma reta ao gradiente de cor em magnitudes, assumindo que os índices de cor variam linearmente com o logaritmo da abertura, usando estes valores, através da mais comumente utilizada e clássica regressão linear pelo método dos Mínimos Quadrados (MQ), resultará em valores bastante incertos.

Assim sendo, torna-se muito importante o uso de técnicas estatísticas robustas para minimizar estas incertezas. Escolhemos aplicar o método da Mínima Mediana dos Quadrados (MMQ), que foi apresentado pela primeira vez por Rousseeuw (1984). Este método minimiza a mediana dos quadrados dos resíduos, no lugar da soma dos quadrados dos resíduos, como faz a clássica regressão linear pelo método dos mínimos quadrados. Os resultados obtidos podem resistir a até quase $50 \%$ de contaminação nos dados. A Figura 2.3 ilustra a robustez do método da mínima mediana (MMQ).
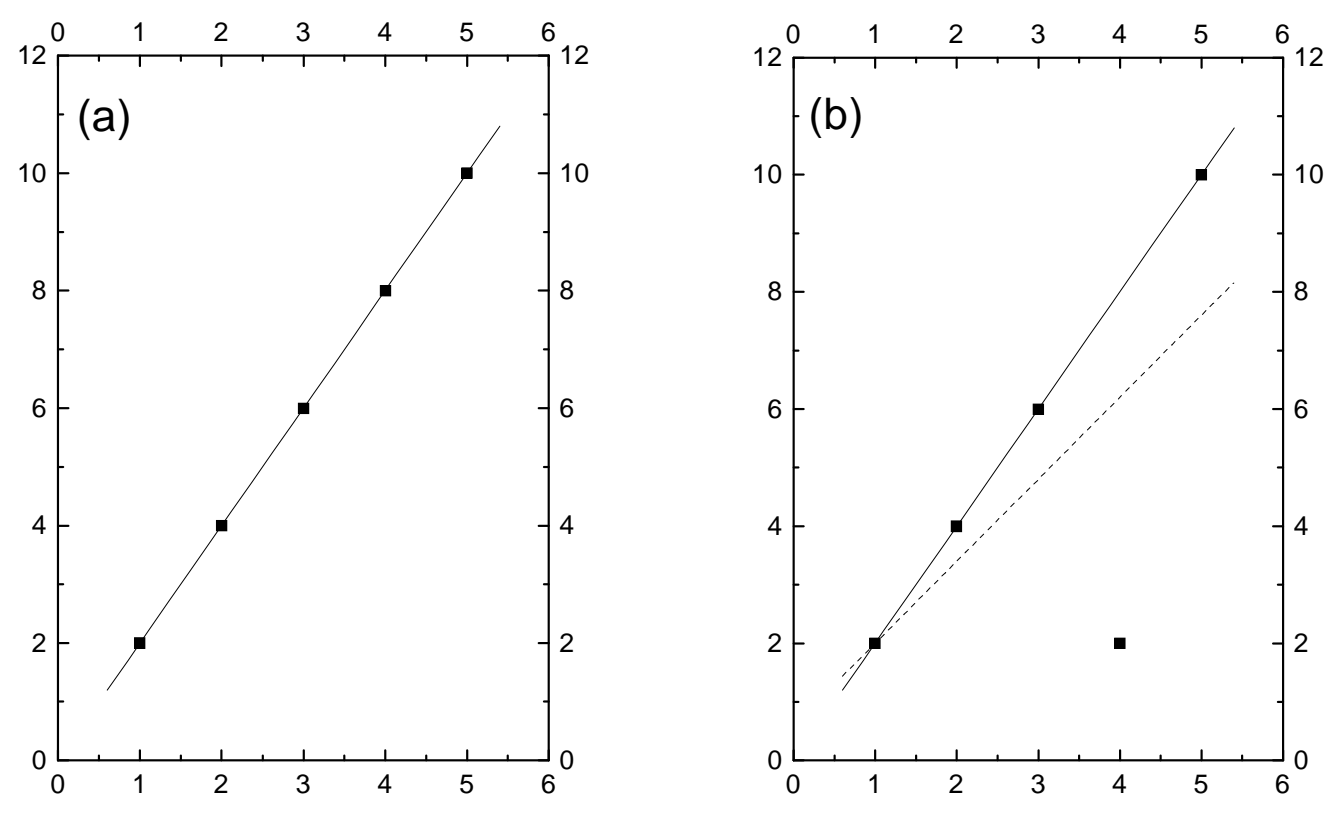

Figura 2.3: Um exemplo da robustez do método de regressão linear pela mínima mediana. Em (a), o resultado do ajuste ao conjunto de pontos é indiferente do método. Em (b), o método clássico (linha tracejada) é gravemente perturbado pela contaminação de um único ponto, enquanto que o método da mínima mediana (linha cheia) permanece atribuindo aos pontos o mesmo ajuste. 
Para calcular os gradientes de cor das galáxias em nossa amostra, aplicamos o programa PROGREss, desenvolvido por Rousseeuw \& Leroy (1987). Este programa executa uma análise robusta da regressão linear, e além de usar o método MMQ, fornece parâmetros de regressão confiáveis, e permite identificar pontos que pareçam inconsistentes com o restante dos dados ("outliers"). PROGRESs primeiro determina os parâmetros da regressão através do método dos mínimos quadrados, e depois através do método da mínima mediana dos quadrados. Com esses resultados, o algoritmo é capaz de separar pontos que estejam contaminando os dados e, atribuindo-lhes peso zero, recalcula o gradiente através do método dos mínimos quadrados. Com este algoritmo, os gradientes obtidos têm, na maioria das vezes, os mesmos valores que aqueles obtidos quando se aplica somente o método da mínima mediana dos quadrados. No entanto, o método MQ trabalha melhor que o método MMQ nos casos em que o número de pontos não é grande, característica importante no caso de nossa amostra. Assim, o algoritmo adotado em PROGRESs fornece resultados mais confiáveis.

O cálculo de cada gradiente foi acompanhado cuidadosamente, pois, em alguns casos, o resultado da regressão pelo método clássico é mais representativo do gradiente da galáxia do que aquele obtido através do algoritmo de PROGREss. Isto pode acontecer porque, ao tentar minimizar as incertezas, o método da mínima mediana pode caracterizar o gradiente global da galáxia utilizando somente alguns poucos pontos que se ajustam muito bem a uma linha reta. Nos casos em que este ajuste é muito bom, o algoritmo de PROGRESS não é capaz de recuperar o gradiente global da galáxia e descartar somente aqueles pontos que realmente são "outliers". Ao contrário, descarta todos os pontos que não satisfazem aquele excelente ajuste caracterizado por somente alguns poucos pontos. Portanto, em alguns casos, definimos o gradiente da galáxia como sendo aquele obtido pelo método clássico.

Das 257 galáxias de nossa amostra, obtivemos 239 gradientes de cor (B-V) e 202 (U-B). O restante dos gradientes foi desconsiderado, já que: (1) o número de medidas disponíveis é insuficiente para uma boa determinação do gradiente, e/ou (2) as medidas são demasiadamente inconsistentes, resultando em valores muito incertos para os gradientes. Os gradientes que determinamos para as galáxias de nossa amostra, bem como os respectivos erros, encontram-se na tabela A.1.

A Figura 2.4 exibe quatro exemplos do comportamento dos gradientes de cor para galáxias da presente amostra. Nesta figura pode-se avaliar os ajustes dos gradientes através dos diferentes métodos. As linhas tracejadas correspondem ao ajuste através do método dos mínimos quadrados; linhas pontilhadas representam o ajuste pelo método da mínima mediana e a linha cheia corresponde ao ajuste determinado pelo algoritmo de PRogress. Em cada gráfico está indicado o valor da diferença entre o gradiente 

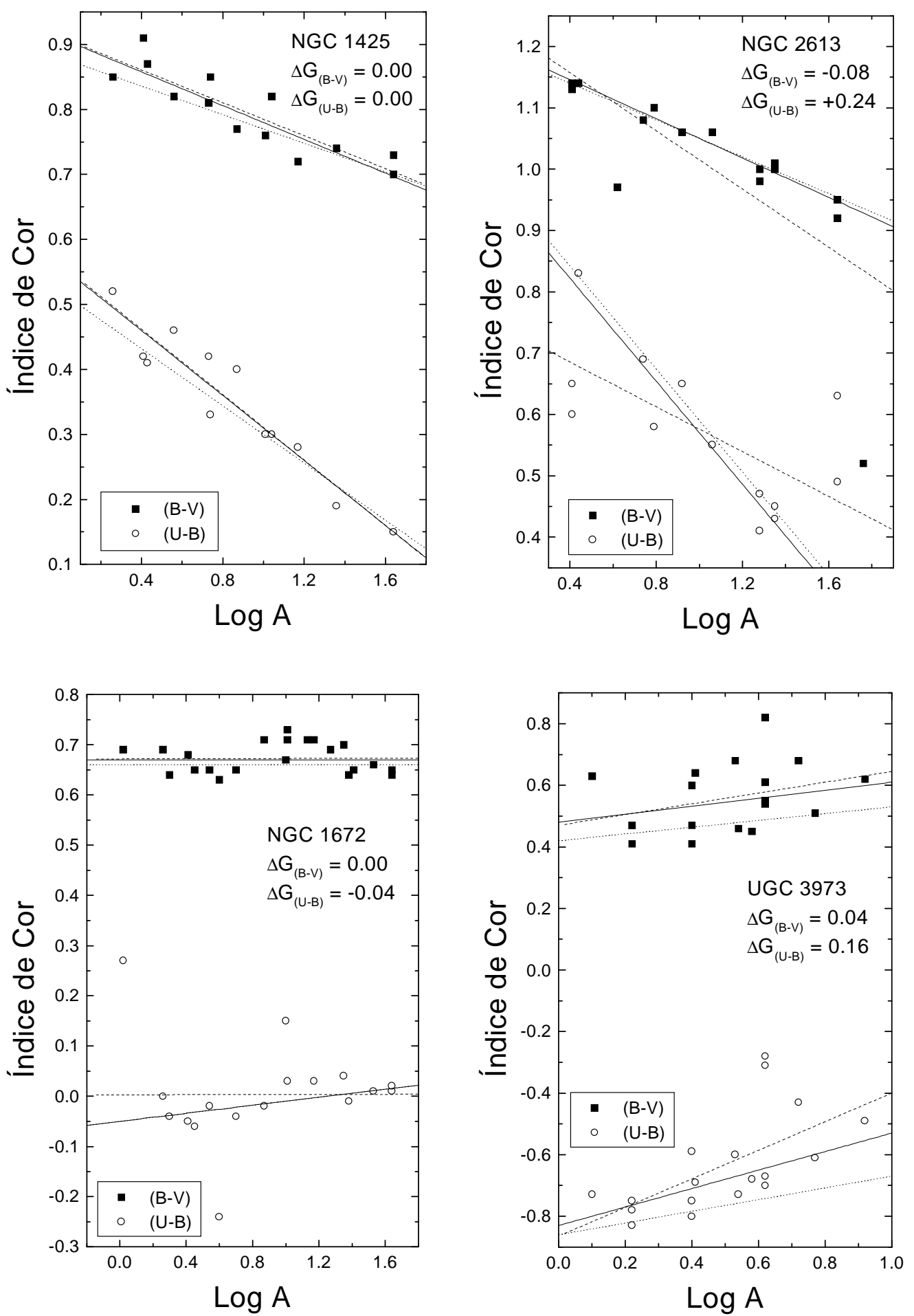

Figura 2.4: Exemplos de gradientes de cor para quatro galáxias em nossa amostra. O típico gradiente negativo de NGC 1425 e NGC 2613, o gradiente nulo de NGC 1672, e o raro gradiente positivo de UGC 3973 (confira os valores na Tabela A.1). Os índices de cor em magnitudes estão expressos em função do logaritmo da abertura do diafragma em unidades de 0.1 minutos de arco. Os quadrados indicam o índice (B-V), enquanto que os círculos indicam o (U-B). As linhas tracejadas correspondem ao ajuste através do método dos mínimos quadrados; linhas pontilhadas representam o ajuste pelo método da mínima mediana e a linha cheia corresponde ao ajuste determinado pelo algoritmo de PRoGREss. 
determinado pelo método dos mínimos quadrados e o determinado pelo algoritmo de Progress $(\Delta G \equiv G(\mathrm{MQ})-G(\mathrm{PRO}))$. Nota-se que, para NGC 2613, o método clássico é perturbado pela última medida de (B-V). Para esta galáxia, e para UGC 3973, os diferentes métodos atribuem valores substancialmente diferentes para os gradientes.

Os dados em LdV83,85 não estão corrigidos de fatores externos, tais como avermelhamento Galáctico e avermelhamento intrínseco, mas somente de fatores observacionais e da extinção atmosférica. Na determinação dos gradientes de cor, a correção por avermelhamento Galáctico não é necessária, já que somente provocaria um deslocamento vertical do gradiente, não afetando sua inclinação, pois a mesma correção é aplicada para toda a galáxia. Isto porque o excesso de cor produzido pela extinção Galáctica pode ser expresso como função somente das coordenadas galácticas do objeto ${ }^{3}$. A correção pelo avermelhamento intrínseco é difícil de prever corretamente, devido aos problemas de inclinação das galáxias e da questão da espessura óptica de galáxias espirais (e.g., Giovanelli et al. 1994,1995; de Jong 1996c). De qualquer maneira, tal correção acarretaria modificações sem importância nos gradientes de cor, tendo em vista as incertezas envolvidas. De fato, a Figura 2.5 mostra que os avermelhamentos Galáctico e intrínseco não interferem na determinação dos gradientes de cor. Os painéis superiores desta figura mostram que não há qualquer correlação entre os gradientes que determinamos e o avermelhamento Galáctico, representado pelo excesso de cor $E(B-V)$. Por outro lado, como a extinção intrínseca varia com a inclinação do disco da galáxia em relação à nossa linha de visada, elaboramos os painéis inferiores da figura, que exibem os gradientes em função do parâmetro $R_{25}$ do RC3, que representa a inclinação da galáxia. Nestes painéis, as galáxias cujos discos encontram-se mais inclinados em relação à nossa linha de visada, portanto vistos de perfil, são as que possuem valores maiores de $R_{25}$. A ausência de correlações indica que o avermelhamento intrínseco não interfere na determinação dos gradientes. No entanto, essas extinções produzem efeitos bastante consideráveis nos índices de cor. Voltaremos a tratar deste assunto na próxima seção.

\subsubsection{Determinação dos índices de cor característicos dos bojos e discos}

Com a determinação dos gradientes de cor podemos avaliar o comportamento global dos índices de cor ao longo das galáxias, e comparar os valores dos gradientes com outras propriedades desses objetos, tais como, a presença de barras, o brilho superficial, gradi-

\footnotetext{
${ }^{3} \mathrm{Na}$ verdade, se a cor varia ao longo da galáxia, o fato da extinção pela poeira interestelar variar com o comprimento de onda da luz faz com que a correção pelo avermelhamento seja distinta ao longo da galáxia. No entanto, estamos desprezando este efeito, considerando que este somente produz perturbações muito pequenas em comparação com os erros fotométricos e na determinação dos gradientes.
} 

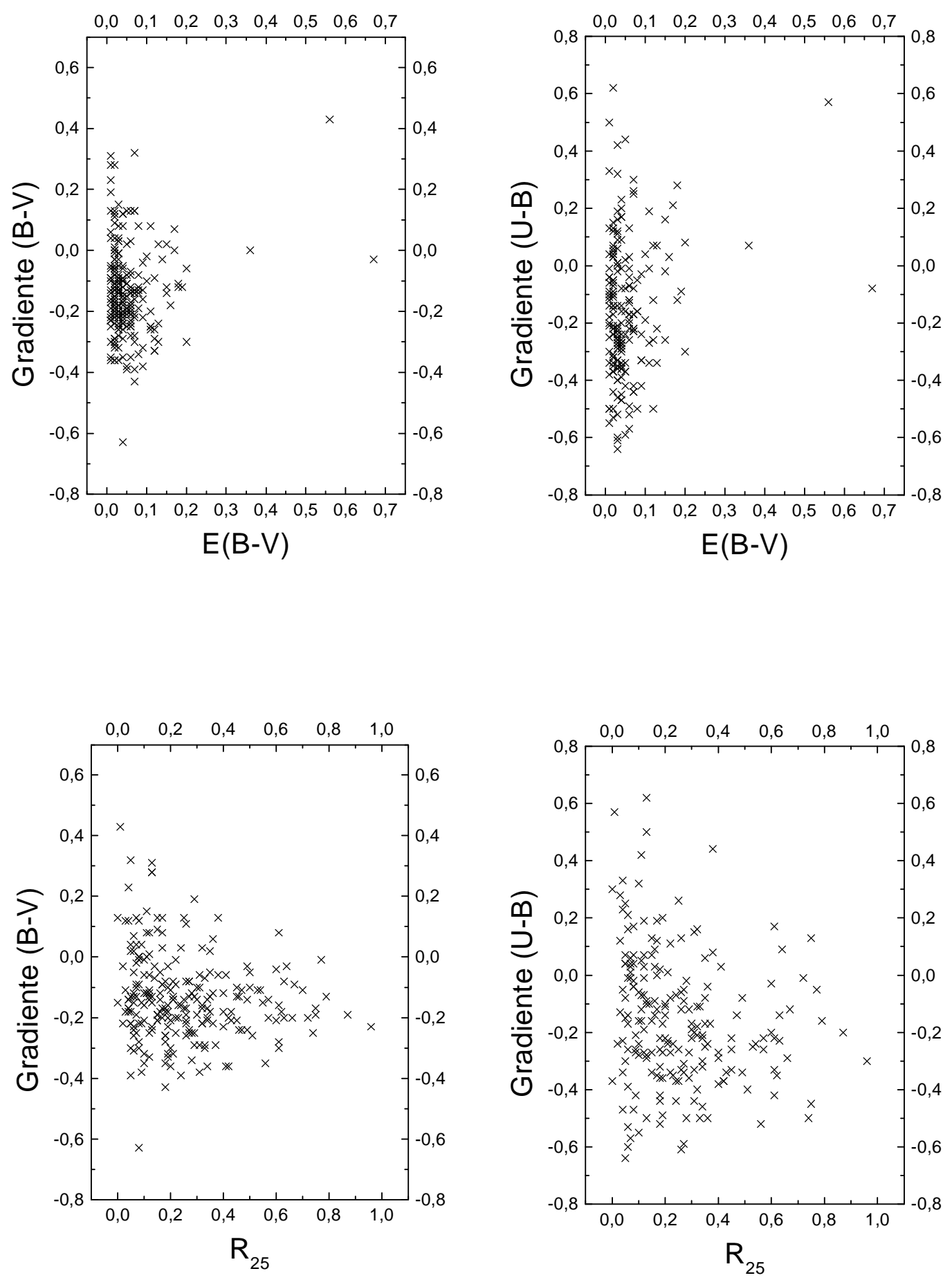

Figura 2.5: Gradientes de cor (B-V) e (U-B) para as galáxias de nossa amostra em função do excesso de cor E(B-V) provocado pela extinção Galáctica (painéis superiores), e em função da inclinação da galáxia, representada aqui pelo parâmetro $R_{25}$ do RC3 (painéis inferiores). A ausência de correlações indica que as extinções Galáctica e intrínseca não interferem na determinação dos gradientes de cor. 
entes de abundância química etc. Entretanto, uma das propostas deste estudo é avaliar e comparar os índices de cor das componentes disco e bojo separadamente, ou seja, é fazer um estudo que permita encontrar diferenças entre as populações estelares das componentes bojo e disco. Dessa forma, poderemos avaliar as diferenças entre as populações estelares nos bojos e discos em cada uma das galáxias da nossa amostra.

Aplicaremos, inicialmente, uma primeira aproximação na determinação dos índices de cor característicos de bojos e discos, para poder verificar se existe uma correlação entre as cores destas componentes, conforme apresentado anteriormente por Peletier \& Balcells (1996). Estes autores encontram correlação entre as cores de bojo (tomada como sendo aquela à metade do raio efetivo) e do disco (tomada como sendo aquela a dois comprimentos de escala) para os índices (U-R), (B-R), (R-K) e (J-K), para uma amostra de 30 galáxias espirais de tipo jovem.

Em nossa primeira metodologia, os índices foram estimados, em primeira aproximação, através da inspeção dos gradientes. O índice do bojo foi tomado como sendo aquele medido através do diafragma de menor abertura disponível. O índice do disco foi tomado como sendo aquele medido na abertura disponível que mais se aproxima daquela equivalente à isofota de brilho superficial em B igual a $25 \mathrm{mag} \operatorname{arcsec}^{-2}$, sendo este valor aquele apresentado no RC3. Em alguns casos, quando os dados disponíveis não alcançam as dimensões requisitadas, foi feita uma extrapolação linear do gradiente determinado. Por outro lado, naqueles casos que apresentam medidas com valores distintos para a mesma abertura, o valor médio foi considerado. Nenhuma correção foi aplicada aos valores obtidos nessa metodologia. Os resultados da nossa estimativa serão apresentados na seção 2.4.6. No entanto, podemos adiantar que, de fato, existe uma correlação entre os índices de cor de bojos e discos para as galáxias em nossa amostra.

No entanto, esta estimativa inicial apresenta o inconveniente de que, em muitos casos, os valores obtidos não são representativos da mesma região em galáxias diferentes. O fato das galáxias apresentarem tamanhos angulares distintos e de terem sido observadas com conjuntos de diafragmas de aberturas distintas, faz com que, em muitos casos, os índices característicos sejam tomados em distâncias galactocêntricas distintas de galáxia para galáxia.

Para comparar índices de cor característicos de bojos e discos em regiões semelhantes nas diferentes galáxias, adotamos a seguinte metodologia. Definimos o índice de cor característico do bojo como sendo aquele a uma distância galactocêntrica de $1 / 5$ do raio efetivo da galáxia. O índice característico do disco foi definido como sendo aquele a uma distância de 2 raios efetivos. Desta forma, definimos o gradiente de cor, $G$, como sendo, 


$$
G \equiv \frac{\Delta(X-Y)}{\Delta \log A},
$$

onde $(X-Y)$ representa o índice de cor e $A$ é a abertura do diafragma em unidades de 0.1 arcmin. Indicando os valores inicial e final da sequência de aberturas medidas em cada galáxia com os subescritos $i$ e $f$, temos:

$$
G=\frac{(X-Y)_{f}-(X-Y)_{i}}{\log A_{f}-\log A_{i}}
$$

Para determinar o índice do bojo, façamos as seguintes substituições: $(X-Y)_{f}=$ $(X-Y)_{e f},(X-Y)_{i}=(X-Y)_{b}, A_{f}=A_{e f}$ e $A_{i}=A_{e f} / 5$, onde $(X-Y)_{e f}$ é o índice de cor efetivo (dado pelo RC3), $(X-Y)_{b}$ é o índice característico do bojo e $A_{e f}$ é a abertura efetiva, também segundo o RC3. Desse modo, obtemos o índice característico do bojo como sendo:

$$
(X-Y)_{b}=(X-Y)_{e f}-0.7 G
$$

Analogamente, podemos obter o índice de cor do disco (a 2 raios efetivos) como sendo:

$$
(X-Y)_{d}=(X-Y)_{e f}+0.3 G
$$

As equações (2.8) e (2.9) foram utilizadas no programa PROGREss para determinar os índices de cor característicos de bojo e disco para cada galáxia. Note que, como estamos obtendo estes índices em distâncias galactocêntricas normalizadas pelo raio efetivo das galáxias, garantimos que as galáxias estão sendo igualmente amostradas. Ou seja, garantimos que estes índices representam as mesmas regiões em cada galáxia, mesmo quando observamos galáxias a distintas distâncias.

Porém, antes de avaliar os resultados obtidos, é preciso corrigir estes valores pelos efeitos da extinção Galáctica e da extinção intrínseca. Ao contrário dos gradientes, é óbvio que os efeitos da extinção sobre os índices de cor não podem ser desprezados.

A natureza dessas extinções é a mesma, qual seja, o fato da poeira presente no meio interestelar, principalmente no plano do disco de uma galáxia espiral, absorver e espalhar a luz. A diferença reside em que a extinção Galáctica se refere ao efeito da poeira na Galáxia sobre a luz emitida por objetos extragalácticos, enquanto que a extinção intrínseca 
se refere ao efeito da poeira presente nas galáxias sobre a luz emitida pela estrelas que estas contêm. No entanto, como a extinção varia com o comprimento de onda da luz, esta não só é atenuada, como também torna-se mais avermelhada. Assim, para podermos corrigir os índices de cor, precisamos conhecer o excesso de cor produzido pelas extinções. Este excesso de cor é definido como:

$$
E(X-Y)=(X-Y)-(X-Y)_{0}
$$

onde o subescrito 0 indica o valor intrínseco, i.e., corrigido, exatamente como a equação (3.59) de Binney \& Merrifield (1998). Os valores de $E(B-V)$ para a extinção Galáctica variam de acordo com as coordenadas galácticas das galáxias observadas, e foram determinados através dos mapas recentemente obtidos por Schlegel, Finkbeiner \& Davis (1998). Para determinar $E(U-B)$, utilizamos a relação

$$
\frac{E(U-B)}{E(B-V)}=0.72 \pm 0.03
$$

que é a equação (3.1.37) de Kitchin (1998).

O excesso de cor provocado pela extinção intrínseca é muito mais complicado de se determinar, já que o nosso conhecimento sobre a distribuição de poeira no meio interestelar das galáxias é ainda bastante primário (ver, e.g., Tully et al. 1998). Existem vários estudos (e.g., van Houten 1961; Bruzual, Magris \& Calvet 1988) que investigam os efeitos de extinção sobre as cores integradas de galáxias, e que assumem aproximações para a distribuição de poeira, considerando simetria esférica ou plano-paralela. Entretanto, os efeitos radiais da extinção sobre a cor raramente são determinados. Perfis de cores produzidos por modelos de poeira foram construídos por de Jong (1996c) para avaliar até que ponto a existência de gradientes de cor pode ser atribuída ao avermelhamento pela extinção por poeira. Os resultados indicam que o avermelhamento provocado por poeira não tem um papel muito importante nos perfis de cor.

Por outro lado, sabemos que a extinção intrínseca é proporcional à inclinação do disco da galáxia em relação à nossa linha de visada, já que, no caso de uma galáxia com alta inclinação, a luz emitida pelas estrelas nas regiões mais afastadas desta galáxia terá de atravessar uma quantidade maior de poeira, e será proporcionalmente mais atenuada. Estes efeitos provocados pela inclinação podem ser corrigidos. Desta forma, aplicamos uma correção que simula a situação em que todas as galáxias estão sendo observadas de face, quando os efeitos da extinção intrínseca são minimizados.

Obtivemos o $E(B-V)$ provocado pela extinção intrínseca, em função da inclinação 
da galáxia, através do seguinte raciocínio. Giovanelli et al. (1994), utilizando imagens de galáxias do tipo Sc na banda I, determinaram uma relação para o coeficiente de extinção intrínseca em função da inclinação da galáxia, que é:

$$
A_{I}=1.12( \pm 0.05) \log \frac{a}{b}
$$

onde $a$ e $b$ são, respectivamente, os eixos maior e menor da galáxia. Por outro lado, Elmegreen (1998) mostra que os coeficientes de extinção nas bandas U, B e V são, respectivamente, $3.81,3.17$ e 2.38 vezes maior que o coeficiente de extinção na banda I, segundo observações na Galáxia. Como a Galáxia é do tipo Sbc, podemos utilizar estes valores como sendo característicos das galáxias em nossa amostra, o que implica em admitir que a poeira nas galáxias tem propriedades semelhantes na Galáxia. Assim, temos que:

$$
\begin{aligned}
& A_{U}=4.27 \log \frac{a}{b}, \\
& A_{B}=3.55 \log \frac{a}{b}, \\
& A_{V}=2.67 \log \frac{a}{b} .
\end{aligned}
$$

Como

$$
E(X-Y)=A_{X}-A_{Y}
$$

segundo a equação (3.59) de Binney \& Merrifield (1998), então

$$
\begin{aligned}
& E(U-B)=0.68 \log \frac{a}{b}, \\
& E(B-V)=0.87 \log \frac{a}{b} .
\end{aligned}
$$

Para determinar as correções a serem aplicadas através das equações (2.17) e (2.18), substituímos $\log a / b$ pelo parâmetro $R_{25}$ do RC3, que pode ser considerado como equivalente. É interessante comparar as correções que aplicamos com as que são aplicadas no RC3. Este catálogo utiliza as seguintes relações para galáxias do tipo Sbc: 


$$
\begin{aligned}
& E(U-B)=0.38 R_{25}, \\
& E(B-V)=0.33 R_{25} .
\end{aligned}
$$

Portanto, a correção que estamos aplicando é $\sim 2-3$ vezes maior do que a aplicada no RC3. De fato, quando da confecção deste catálogo, acreditava-se que os discos de galáxias espirais fossem quase transparentes. Trabalhos recentes (Giovanelli et al. 1994,1995 e referências aí contidas; Tully et al. 1998) mostram que a espessura óptica dos discos é bem maior do que se acreditava. Assim, nossas correções consideram que os discos possuem alta espessura óptica.

Embora nossa amostra se componha de galáxias próximas, aplicamos também a correção K para compensar os efeitos do desvio para o vermelho provocados pela velocidade de recessão das galáxias sobre os índices de cor. Utilizamos as seguintes relações, seguindo os critérios do RC3:

$$
\begin{aligned}
& (B-V)_{0}=(B-V)-6.5 \times 10^{-6} c z, \\
& (U-B)_{0}=(U-B)-4.5 \times 10^{-6} c z,
\end{aligned}
$$

onde $c z$ é a velocidade da galáxia ao longo da linha de visada. Para as galáxias em nossa amostra, este parâmetro cobre o seguinte intervalo de valores: $-295 \mathrm{Km} / \mathrm{s}$ (NGC 224) $\leq c z \leq 8720 \mathrm{Km} / \mathrm{s}$ (UGC 4013). Porém, o valor típico é $c z \sim 2000 \mathrm{Km} / \mathrm{s}$, resultando em correções da ordem de milésimos de magnitude.

\subsection{Resultados}

A seguir apresentamos os principais resultados obtidos, quais sejam, gradientes de cor (U-B) e (B-V) para cada galáxia em nossa amostra, bem como os índices de cor (U-B) e (B-V) característicos para o bojo e o disco de cada uma dessas galáxias. Como o objetivo principal consiste em verificar a existência de indícios que possam corroborar, ou não, o cenário de evolução secular em galáxias barradas (seção 1.1.3), procuramos identificar diferenças entre as propriedades de galáxias barradas e ordinárias. É importante ressaltar que incluímos na classe de barradas as famílias fortemente (SB) e fracamente (SAB) barradas, conforme classificadas no RC3. 
Inicialmente, apresentamos os resultados relativos aos gradientes de cor das galáxias em nossa amostra, tais como aqueles relativos à distribuição dos gradientes, bem como comparações com resultados obtidos por outros autores. Só então os resultados concernentes aos índices de cor serão exibidos.

\subsubsection{Distribuição dos gradientes}

A avaliação da distribuição dos gradientes nas galáxias desta amostra requer um cuidado especial, já que esta se compõe de galáxias vistas em vários ângulos de inclinação. Desta forma, vamos avaliar a distribuição de gradientes de cor, separando a amostra inicial em 2 sub-amostras, uma contendo galáxias vistas de face, e a outra com galáxias vistas de perfil. O critério utilizado para a separação destas sub-amostras consiste em definir um limite para o ângulo de inclinação adequado para a separação destas duas sub-amostras. Levando em conta que temos como objetivo comparar os nossos resultados com os de outros autores, utilizamos o mesmo valor de inclinação definido por de Jong \& van der Kruit (1994), ou seja, as galáxias com $R_{25} \leq 0.20$, que corresponde a $b / a \geq 0.625$, são consideradas de face. Aquelas que não são incluídas neste critério fazem parte então da sub-classe das galáxias vistas de perfil.

A Figura 2.6 exibe a distribuição dos gradientes para: (a) galáxias ordinárias vistas de face, (b) barradas vistas de face, (c) ordinárias vistas de perfil, e (d) barradas vistas de perfil. A Tabela 2.1 apresenta, para cada um desses diagramas, o número total de galáxias, a média da distribuição (e seu respectivo erro padrão) e o desvio padrão na distribuição, calculados através do ajuste de uma Gaussiana. Nestes histogramas, cada barra corresponde a um intervalo de 0.05 magnitudes. Como a mediana dos erros nos gradientes é igual a 0.03 mag para (B-V) e 0.04 mag para (U-B), este intervalo é significativo.

Algumas informações básicas podemos obter avaliando os resultados obtidos com as distribuições na Figura 2.6, bem como com os valores dos gradientes médios listados na Tabela 2.1. A primeira é a de que as distribuições dos gradientes em (U-B) são sistematicamente mais alargadas do que em $(\mathrm{B}-\mathrm{V})$, tanto para as galáxias de face como para as de perfil. Este alargamento se reflete nas estimativas dos desvios, que são maiores para esta cor. Existem várias causas prováveis para esta diferença. Em primeiro lugar, os erros fotométricos na banda $U$ são mais expressivos e, em segundo lugar, o número de medidas em (U-B) para a determinação do gradiente é, em geral, menor do que em $(\mathrm{B}-\mathrm{V})$, o que certamente pode diminuir a precisão na estimativa do gradiente. Há ainda a questão da descontinuidade de Balmer (ver seção 2.1) e, evidentemente, esta propriedade pode também ser intrínseca das galáxias em nossa amostra. A segunda informação diz respeito às galáxias vistas de perfil. Nestas galáxias, existe uma tendência dos gradientes 

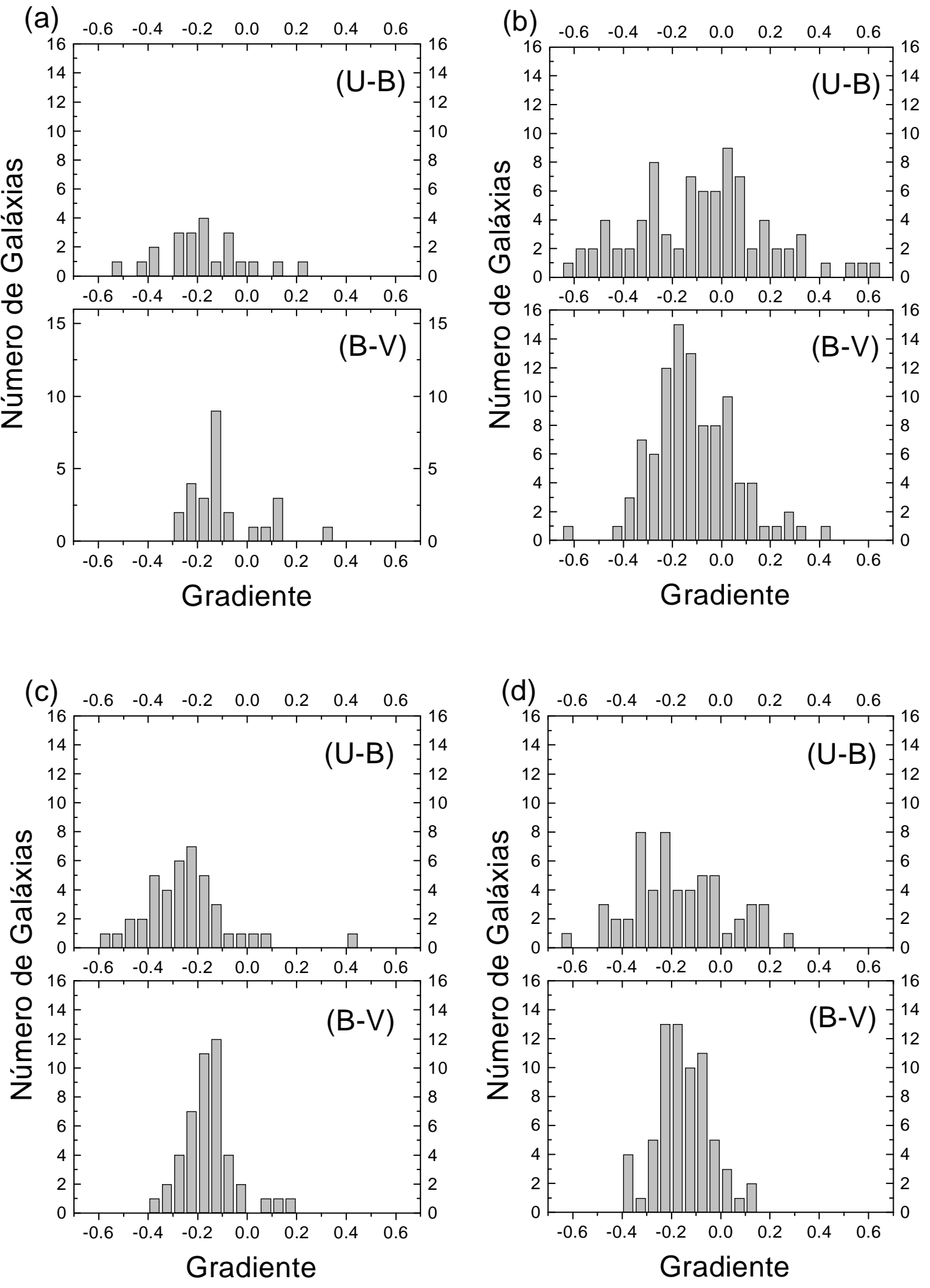

Figura 2.6: Distribuição dos gradientes de cor (U-B) e (B-V) para: (a) galáxias ordinárias vistas de face, (b) barradas vistas de face, (c) ordinárias vistas de perfil, e (d) barradas vistas de perfil. 
Tabela 2.1: Valores médios (e respectivos erros) e desvios para as distribuições apresentadas nas Figuras 2.6 e 2.7. N é o número total de galáxias em cada distribuição.

\begin{tabular}{||c|cccc|cccc||}
\hline \hline $\begin{array}{c}\text { Diagrama } \\
\text { (Figura 2.6) }\end{array}$ & $\mathrm{N}$ & média & $\begin{array}{c}\text { erro } \\
(\mathrm{B}-\mathrm{V})\end{array}$ & desvio & $\mathrm{N}$ & média & $\begin{array}{c}\text { erro } \\
(\mathrm{U}-\mathrm{B})\end{array}$ & desvio \\
\hline (a) & 26 & -0.14 & 0.01 & 0.06 & 22 & -0.19 & 0.03 & 0.14 \\
$(\mathrm{~b})$ & 98 & -0.14 & 0.02 & 0.15 & 82 & -0.08 & 0.03 & 0.27 \\
$(\mathrm{c})$ & 46 & -0.16 & 0.01 & 0.07 & 41 & -0.26 & 0.02 & 0.12 \\
$(\mathrm{~d})$ & 68 & -0.16 & 0.01 & 0.10 & 56 & -0.19 & 0.03 & 0.20 \\
\hline Diagrama & & & & & & & & \\
(Figura 2.7) & & & & & & & & \\
(a) & 72 & -0.16 & 0.01 & 0.07 & 63 & -0.24 & 0.02 & 0.13 \\
(b) & 166 & -0.15 & 0.01 & 0.13 & 138 & -0.13 & 0.02 & 0.25 \\
\hline \hline
\end{tabular}

Diagramas - Figura 2.6: (a): ordinárias vistas de face; (b): barradas vistas de face; (c): ordinárias vistas de perfil; (d): barradas vistas de perfil. Figura 2.7: (a): todas as galáxias ordinárias; (b): todas as barradas.

serem mais negativos (mais acentuados) quando comparados com as galáxias vistas de face, em particular em (U-B). Este comportamento pode estar ligado ao fato de a extinção intrínseca diferencial ser mais pronunciada nestas galáxias, cujos discos apresentam maior inclinação com relação à nossa linha de visada. Também pode-se notar que, em (U-B), a maior parte das galáxias barradas (ver painéis (b) e (d)), se concentra em valores de gradientes que são menos acentuados do que as galáxias ordinárias (ver painéis (a) e (c)), conforme pode-se verificar através dos valores médios, que se encontram na Tabela 2.1. Esta característica desaparece em (B-V). A quarta informação diz respeito ao alargamento das distribuições. Nota-se que a largura das distribuições é maior para as barradas, tanto para as galáxias de face como para as de perfil. Isto significa que uma proporção maior de galáxias barradas apresenta gradientes nulos ou positivos. Em (U-B), por exemplo, $55 \% \pm 8 \%$ das galáxias barradas vistas de face têm gradientes nulos ou positivos. Por outro lado, nas ordinárias vistas de face esta fração é de $32 \% \pm 12 \%$. Já em (B-V), cerca de $41 \% \pm 6 \%$ das barradas vistas de face têm gradientes nulos ou positivos, enquanto que $31 \% \pm 11 \%$ das ordinárias vistas de face apresentam este efeito.

Com a Figura 2.6 foi feita uma avaliação das diferenças nas distribuições dos gradientes para galáxias vistas de face e de perfil, separadamente. Na Figura 2.7, colocamos todas as galáxias da amostra, sem separar portanto as de face e as de perfil, para avaliar a distribuição dos gradientes de cor nas ordinárias (a) e nas barradas (b). Verificamos, mais uma vez, que as distribuições são similares em (B-V), mas, em (U-B), galáxias barradas tendem a apresentar gradientes menos acentuados do que aqueles apresentados por galáxias ordinárias (veja os valores da Tabela 2.1). Mais uma vez também, se observa que as distribuições são mais alargadas para as galáxias barradas. Estas propriedades podem 
estar relacionadas com os efeitos provocados pelas barras nas galáxias que as contêm, em particular, aos processos de evolução secular.

A Figura 2.8 exibe as mesmas distribuições apresentadas na Figura 2.7. No entanto, nesta figura fazemos uma comparação direta entre a distribuição dos gradientes para barradas e ordinárias, considerando cada cor separadamente, normalizando o número de galáxias barradas, em cada intervalo de gradiente, pelo número total de galáxias barradas, e fazendo o mesmo com as ordinárias. Verifica-se que, em ambas as cores, a fração de galáxias barradas que apresentam gradientes nulos, ou positivos, é maior do que esta mesma fração de galáxias ordinárias. É interessante observar que a proporção de barradas $\operatorname{com} G_{B-V} \geq 0$ é $37 \% \pm 5 \%$, enquanto que nas ordinárias temos $24 \% \pm 6 \%$. Portanto, dentro das incertezas, estes dois números são semelhantes, apesar de que existe uma proporção ligeiramente maior de barradas com $G_{B-V} \geq 0$. Já no caso de (U-B), existem $47 \% \pm 6 \%$ de barradas com $G_{U-B} \geq 0$, enquanto que apenas $19 \% \pm 5 \%$ das ordinárias têm $G_{U-B} \geq 0$. Como o índice (U-B) é mais sensível à metalicidade, bem como à idade da população estelar, isto significa que uma proporção maior de barradas deveria apresentar gradientes nulos ou positivos, o que, de fato, ocorre. Esta diferença no comportamento de $G_{B-V}$ e $G_{U-B}$ não pode ser atribuída aos erros de avaliação dos gradientes. De fato, os erros são maiores no $G_{U-B}$, mas os mesmos erros devem afetar barradas e ordinárias.

A Figura 2.9 mostra os gradientes de cor (U-B) em função dos gradientes (B-V) para: (a) galáxias ordinárias, (b) barradas e (c) toda a nossa amostra. Como se pode ver, os gradientes são correlacionados. Além disso, a correlação está presente de forma equivalente para barradas e para ordinárias. De fato, os coeficientes de correlação de Pearson R são: (a) 0.71, (b) 0.80 e (c) 0.78. O valor ligeiramente inferior de R para as ordinárias está provavelmente ligado ao fato de haver um número menor de galáxias neste grupo. A mesma correlação foi verificada separando-se as galáxias vistas de face, sem diferenças significativas. Estas correlações, na verdade, são esperadas, porque o gradiente representa, em última análise, uma variação na população estelar entre a região interna e externa. Ocorre que estas variações afetam tanto a cor (B-V), como a (U-B). Os modelos de Larson e Tinsley (1978), por exemplo, mostram que para uma população formada em um único "burst" (com duração de $2 \times 10^{7}$ anos), em uma galáxia espiral, o índice de cor $(\mathrm{B}-\mathrm{V})$ varia de $\Delta(B-V) \sim 1.1$, enquanto que o índice de cor $(\mathrm{U}-\mathrm{B})$ varia de $\Delta(U-B) \sim 1.5$, entre duas populações com cerca de 10 Giga-anos de diferença de idade. Portanto, devemos esperar que $\Delta(U-B) / \Delta(B-V) \sim 1$.4. Por outro lado, como $G_{B-V}=\Delta(B-V) / \Delta \log A$ e $G_{U-B}=\Delta(U-B) / \Delta \log A$, e esperamos que os gradientes de cor sejam causados por variações na população estelar, usando estes modelos podemos prever que $G_{U-B} / G_{B-V} \sim 1.4$. A correlação que observamos na Figura 2.9 tem uma inclinação $G_{U-B} / G_{B-V} \sim 1.2$, bastante próxima do previsto por estes modelos. 

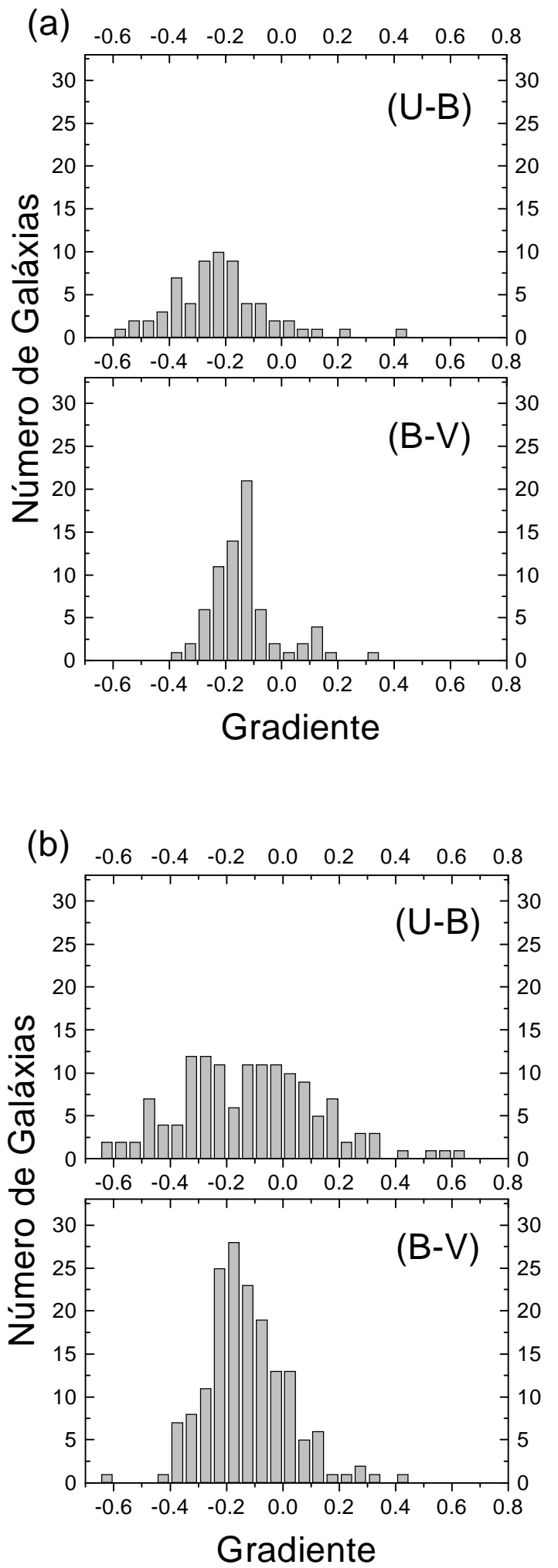

Figura 2.7: Distribuição dos gradientes de cor (U-B) e (B-V) para: (a) todas as galáxias ordinárias, e (b), todas as barradas. Como se vê, galáxias barradas tendem a apresentar gradientes em (U-B) menos acentuados do que galáxias ordinárias. No entanto, esta característica desaparece em (B-V). 

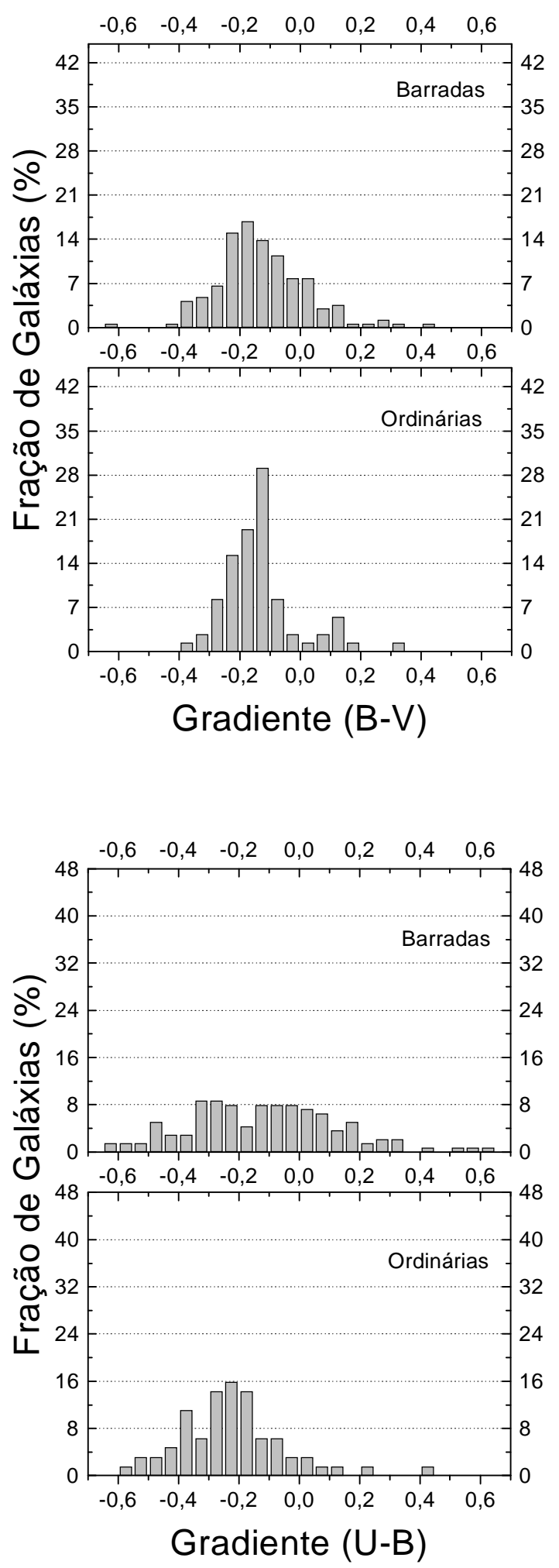

Figura 2.8: Comparação normalizada entre as distribuições dos gradientes de cor em galáxias ordinárias e barradas. Galáxias barradas apresentam uma maior fração de galáxias com gradientes próximos de zero, ou positivos, em ambas as cores. 

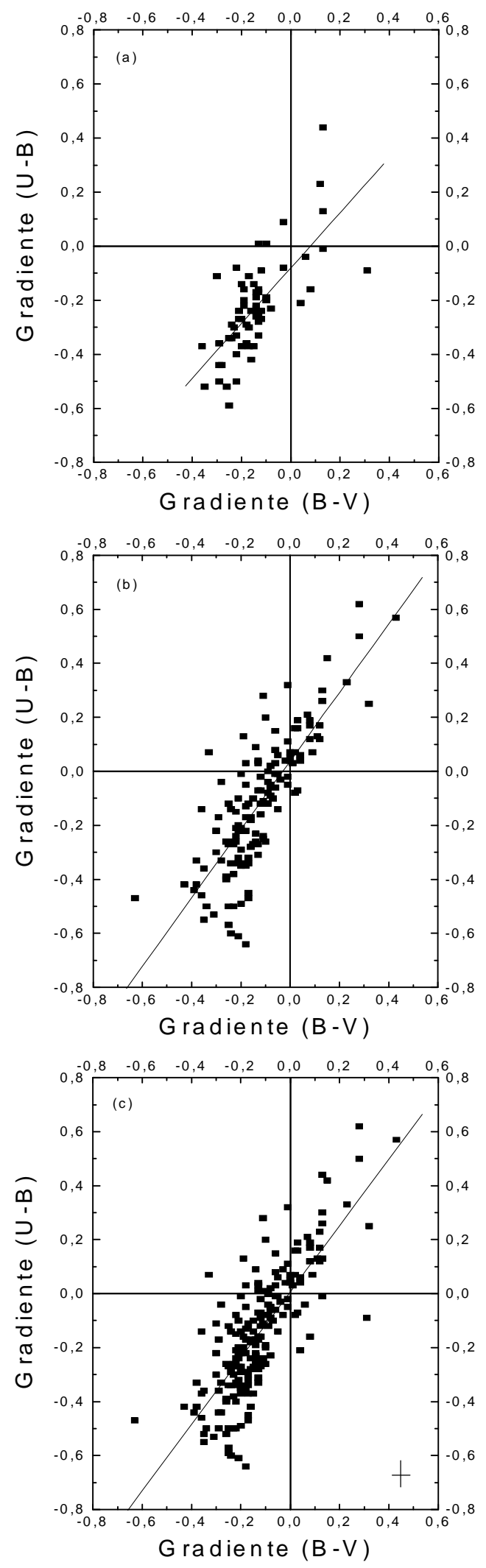

Figura 2.9: Gradientes de cor (U-B) em função dos gradientes (B-V) para: (a) galáxias ordinárias, (b) barradas e (c) toda a nossa amostra. A linha cheia corresponde a um ajuste linear para os pontos. Claramente, os gradientes são correlacionados. 


\subsubsection{Três categorias para os gradientes: negativos, nulos e positivos}

O cenário monolítico de formação, que na década de 60 parecia explicar definitivamente a questão da formação de galáxias, é consistente com uma distribuição radial de populações estelares, onde as populações mais velhas, ou mais avermelhadas, se concentram na região central da galáxia, e as estrelas jovens e mais azuis nas regiões externas. Este comportamento da distribuição radial de populações estelares se traduz em um gradiente de cor negativo, i.e., cores mais vermelhas nas regiões centrais e mais azuis nas regiões periféricas. As figuras 2.6 e 2.9 indicam que a grande maioria das galáxias analisadas neste estudo, têm, de fato, gradientes negativos. Entretanto, com a descoberta de populações estelares ricas em metais no bojo da Galáxia, a possibilidade de outros cenários de formação de galáxias tem sido explorada, conforme discutido na seção 1.1. Notamos em nossa amostra, que, além das galáxias com gradientes negativos, existem galáxias com gradientes nulos, e galáxias com gradientes positivos. De fato, podemos separar as galáxias em nossa amostra em três categorias distintas em relação ao comportamento do gradiente de cor. Definimos as galáxias com gradientes negativos como sendo aquelas que apresentam um gradiente $\leq-0.10$. As galáxias com gradientes nulos são aquelas em que o gradiente se encontra na faixa de valores $-0.10<G<0.10$. Por fim, as galáxias com gradientes positivos são aquelas em que $G \geq 0.10$. A Tabela 2.2 exibe a distribuição das galáxias em nossa amostra, segundo estas 3 categorias, para ambas as cores, e para uma quarta categoria, na qual a definição de galáxias com gradientes nulos é mais restrita, seguindo o critério $-0.05<G<0.05$. A coluna (1) desta tabela apresenta o número total de galáxias em cada categoria, enquanto que a coluna (2) dá a fração da amostra total que representa a categoria. Assim, temos aproximadamente $65 \%$ de galáxias com o típico gradiente negativo, $25 \%$ de galáxias com gradientes nulos e aproximadamente $10 \%$ com gradientes positivos, com pequenas variações em cada cor. Por sua vez, as colunas (3), (4) e (5) indicam, respectivamente, a fração de galáxias ordinárias, levemente barradas e barradas em cada categoria. A coluna (6) indica a fração total de barradas (SAB+SB) e, finalmente, a coluna (7) apresenta o número de galáxias com AGN ("Active Galactic Nuclei”), bem como a fração da categoria que estas galáxias representam. As galáxias com AGN foram identificadas através do catálogo de Véron-Cetty \& Véron (1998). A importância de se fazer uma análise da fração de galáxias com AGN em cada categoria decorre da sugestão apresentada por alguns autores (e.g., Shlosman, Frank \& Begelman 1989; Shlosman, Begelman \& Frank 1990) de que as barras podem gerar mecanismos para abastecer núcleos ativos, através de processos semelhantes àqueles que podem levar à evolução secular.

A fração de galáxias barradas $(\mathrm{SAB}+\mathrm{SB})$ em toda a amostra é de aproximadamente 
Tabela 2.2: Distribuição das galáxias de nossa amostra em relação às várias categorias a serem avaliadas.

\begin{tabular}{|c|c|c|c|c|c|c|c|c|}
\hline & Cor & $\begin{array}{c}\text { Total } \\
(1)\end{array}$ & $\begin{array}{c}\text { Amostra } \\
(2)\end{array}$ & $\begin{array}{l}\text { SA } \\
(3)\end{array}$ & $\begin{array}{l}\text { SAB } \\
(4)\end{array}$ & $\begin{array}{l}\text { SB } \\
(5)\end{array}$ & $\begin{array}{c}\mathrm{SAB}+\mathrm{SB} \\
(6)\end{array}$ & $\begin{array}{c}\text { AGN } \\
(7)\end{array}$ \\
\hline $\mathrm{G} \geq 0.1$ & $(\mathrm{~B}-\mathrm{V})$ & 18 & $8 \%$ & $33 \%$ & $22 \%$ & $45 \%$ & $67 \%$ & $6(33 \%)$ \\
\hline$-0.1<G<0.1$ & & 55 & $23 \%$ & $13 \%$ & $45 \%$ & $42 \%$ & $87 \%$ & $11(20 \%)$ \\
\hline$-0.05<\mathrm{G}<0.05$ & & 25 & $10 \%$ & $12 \%$ & $40 \%$ & $48 \%$ & $88 \%$ & $6(24 \%)$ \\
\hline $\mathrm{G} \leq-0.1$ & & 166 & $69 \%$ & $36 \%$ & $40 \%$ & $24 \%$ & $64 \%$ & $18(11 \%)$ \\
\hline $\mathrm{G} \geq 0.1$ & $(\mathrm{U}-\mathrm{B})$ & 27 & $13 \%$ & $11 \%$ & $41 \%$ & $48 \%$ & $89 \%$ & $9(33 \%)$ \\
\hline$-0.1<\mathrm{G}<0.1$ & & 47 & $24 \%$ & $19 \%$ & $38 \%$ & $43 \%$ & $81 \%$ & $10(21 \%)$ \\
\hline$-0.05<\mathrm{G}<0.05$ & & 22 & $11 \%$ & $18 \%$ & $32 \%$ & $50 \%$ & $82 \%$ & $6(27 \%)$ \\
\hline $\mathrm{G} \leq-0.1$ & & 128 & $63 \%$ & $41 \%$ & $35 \%$ & $24 \%$ & $59 \%$ & $13(10 \%)$ \\
\hline
\end{tabular}

(1): número de galáxias na categoria; (2): fração da amostra total na categoria; (3): fração de galáxias ordinárias; (4): fração de galáxias levemente barradas; (5): fração de galáxias barradas; (6): fração total de barradas; (7): galáxias com AGN.

70\%. Podemos ver na Tabela 2.2 que existe um excesso de galáxias barradas entre aquelas galáxias que apresentam gradientes nulos ou positivos. Para o índice de cor (B-V), a fração de galáxias barradas com o gradiente negativo é de $64 \%$, enquanto que esse valor sobe para $87 \%$ entre as galáxias com o gradiente nulo. Em (U-B), apenas $59 \%$ das galáxias com o gradiente negativo são barradas, enquanto que $81 \%$ das galáxias com o gradiente nulo são barradas. Se considerarmos o critério mais restrito para a definição de galáxias com gradientes nulos $(-0.05<G<0.05)$, esta diferença é ligeiramente mais acentuada. Portanto, isto indica que as galáxias barradas estão sendo super-representadas na categoria de objetos com gradiente nulo ou positivo, indicando que a barra age definitivamente como um mecanismo de homogeneização do índice de cor das galáxias.

Outra característica interessante é que, em (U-B), a fração de galáxias barradas com o gradiente positivo é ainda maior. Isto se deve ao fato de que esta cor é mais sensível à população e à metalicidade. No entanto, este comportamento não aparece em (B-V). Além disso, a fração de galáxias com AGN aumenta progressivamente das galáxias com gradientes negativos para as com gradientes nulos e, por fim, para as com gradientes positivos. Isto pode indicar que, pelo menos em parte, o fenômeno AGN está correlacionado com a presença de barras.

Para, mais uma vez, fazer uma avaliação destas propriedades de maneira a minimizar os efeitos da extinção intrínseca, recalculamos todos os valores apresentados na Tabela 2.2 somente para galáxias vistas de face. Estas perfazem um número de 124 em (B-V) e 104 em (U-B). A Tabela 2.3 é equivalente à Tabela 2.2, mas apresenta os valores calculados para as galáxias vistas de face, separadamente.

A fração de galáxias barradas na sub-amostra de galáxias vistas de face é de $79 \%$. 
Tabela 2.3: Distribuição das galáxias de nossa amostra (vistas de face) em relação às várias categorias a serem avaliadas.

\begin{tabular}{|c|c|c|c|c|c|c|c|c|}
\hline & Cor & $\begin{array}{c}\text { Total } \\
(1)\end{array}$ & $\begin{array}{c}\text { Amostra } \\
(2)\end{array}$ & $\begin{array}{l}\text { SA } \\
(3)\end{array}$ & $\begin{array}{c}\text { SAB } \\
(4)\end{array}$ & $\begin{array}{l}\text { SB } \\
(5)\end{array}$ & $\begin{array}{c}\mathrm{SAB}+\mathrm{SB} \\
(6)\end{array}$ & $\begin{array}{c}\text { AGN } \\
(7)\end{array}$ \\
\hline$G \geq 0.1$ & $(B-V)$ & 14 & $11 \%$ & $28 \%$ & $29 \%$ & $43 \%$ & $72 \%$ & $5(36 \%)$ \\
\hline$-0.1<\mathrm{G}<0.1$ & & 32 & $26 \%$ & $9 \%$ & $53 \%$ & $38 \%$ & $91 \%$ & $4(12 \%)$ \\
\hline$-0.05<\mathrm{G}<0.05$ & & 17 & $14 \%$ & $6 \%$ & $47 \%$ & $47 \%$ & $94 \%$ & $4(24 \%)$ \\
\hline $\mathrm{G} \leq-0.1$ & & 78 & $63 \%$ & $25 \%$ & $47 \%$ & $28 \%$ & $75 \%$ & $8(10 \%)$ \\
\hline $\mathrm{G} \geq 0.1$ & $(\mathrm{U}-\mathrm{B})$ & 19 & $18 \%$ & $10 \%$ & $37 \%$ & $53 \%$ & $90 \%$ & $7(37 \%)$ \\
\hline$-0.1<\mathrm{G}<0.1$ & & 30 & $29 \%$ & $17 \%$ & $53 \%$ & $30 \%$ & $83 \%$ & $2(7 \%)$ \\
\hline$-0.05<\mathrm{G}<0.05$ & & 16 & $15 \%$ & $12 \%$ & $38 \%$ & $50 \%$ & $88 \%$ & $5(31 \%)$ \\
\hline $\mathrm{G} \leq-0.1$ & & 55 & $53 \%$ & $27 \%$ & $42 \%$ & $31 \%$ & $73 \%$ & $4(7 \%)$ \\
\hline
\end{tabular}

(1): número de galáxias na categoria; (2): fração da amostra total na categoria; (3): fração de galáxias ordinárias; (4): fração de galáxias levemente barradas; (5): fração de galáxias barradas; (6): fração total de barradas; (7): galáxias com AGN.

Este aumento pode estar vinculado ao fato de que é mais fácil identificar a barra em uma galáxia quando esta é vista de face do que quando vista de perfil. Através da Tabela 2.3 , verifica-se que as propriedades da amostra total, apresentadas na Tabela 2.2 e nos parágrafos acima, permanecem aproximadamente iguais na sub-amostra de galáxias vistas de face. A única diferença é a de que, nessa sub-amostra, o excesso de galáxias barradas entre as galáxias com gradientes nulos é ligeiramente menos significativo, o que ocorre em ambas as cores.

\subsubsection{Comparação com os gradientes de Prugniel \& Héraudeau (1998)}

Prugniel \& Héraudeau (1998 - doravante PH98) apresentam, em um catálogo, estimativas de gradientes de cor $(\mathrm{U}-\mathrm{B})$ e $(\mathrm{B}-\mathrm{V})$ para a maior parte das galáxias em nossa amostra, calculados através de dados mais recentes que os apresentados em LdV83,85, incluindo fotometria com observações em CCD. Para evitar os efeitos da contaminação dos dados com observações imperfeitas, estes autores optaram por atribuir pesos estatísticos distintos para cada fonte de observação.

Evidentemente, é interessante comparar os valores dos gradientes obtidos por nós com os obtidos por Prugniel \& Héraudeau para as galáxias em comum nos dois trabalhos. Na Figura 2.10, o painel superior exibe a correlação entre os gradientes apresentados em PH98. Este diagrama é análogo à Figura 2.9(c), que apresenta a correlação para os nossos gradientes. Nota-se que a correlação para os gradientes de PH98 é ligeiramente menor. De fato, o valor do coeficiente de correlação de Pearson R é igual 0.68 para PH98, e igual 
a 0.78 para os nossos valores. Os outros dois painéis da Figura 2.10 apresentam os nossos gradientes em função dos de PH98. A linha tracejada indica o caso em que a correlação seria perfeita. A linha cheia mostra o ajuste linear para os pontos do gráfico. Como era de se esperar, a correlação é bastante boa, com $R=0.85$ para $(B-V)$ e $R=0.81$ para (U-B).

A Figura 2.11 apresenta a diferença entre os valores obtidos aqui e os de PH98 em função dos nossos gradientes. Verifica-se que os gradientes que são os mais acentuados, tanto negativa quanto positivamente, são os que apresentam as maiores diferenças, o que é natural de se esperar. É importante notar que não há nenhuma diferença sistemática entre os dois trabalhos. A linha cheia indica o ajuste linear para os pontos. O valor médio das diferenças é de $0.004 \mathrm{em}(\mathrm{B}-\mathrm{V})$ e de $0.011 \mathrm{em}$ (U-B).

PH98 também apresentam o brilho superficial efetivo (i.e., o brilho superficial interno ao raio efetivo da galáxia) na banda $\mathrm{B}$ para grande parte das galáxias em nossa amostra. Este parâmetro indica a concentração central de luz da galáxia. Para verificar se existe alguma correlação entre o brilho superficial efetivo e o gradiente de cor em uma galáxia, elaboramos os gráficos apresentados na Figura 2.12. Esta figura exibe os dados apresentados por PH98 em função dos gradientes de cor (U-B) e (B-V) por nós determinados. Como se vê, não há correlação forte. O que se pode notar, entretanto, é uma leve tendência de as galáxias com gradientes nulos ou positivos apresentarem uma maior concentração central de luz. Isto também indica que os gradientes estimados no presente trabalho não estão afetados por efeitos sistemáticos devido aos objetos de maior brilho superficial.

\subsubsection{A morfologia quantitativa de barras de Martin (1995)}

Martin (1995 - doravante M95) realiza visualmente medidas da razão axial, comprimento do eixo maior (normalizado pela isofota de $25 \mathrm{mag} \operatorname{arcsec}^{-2}$ ), e elipticidade aparente de barras em galáxias espirais. Os dois primeiros parâmetros são corrigidos por efeitos de inclinação. Neste trabalho, encontra-se uma relação entre o comprimento da barra e o diâmetro do bojo, no sentido de que galáxias com bojos menores possuem barras menores. Além disso, encontra-se aparentemente uma correlação entre a presença de formação estelar nuclear intensa e a razão axial da barra, no sentido de que barras fortes (i.e., com razão axial < 0.6) estão presentes em galáxias com surtos de formação estelar nuclear.

Felizmente, 45 galáxias de nossa amostra foram estudadas em M95, o que nos permite avaliar a existência de correlações entre os gradientes de cor e os parâmetros obtidos 

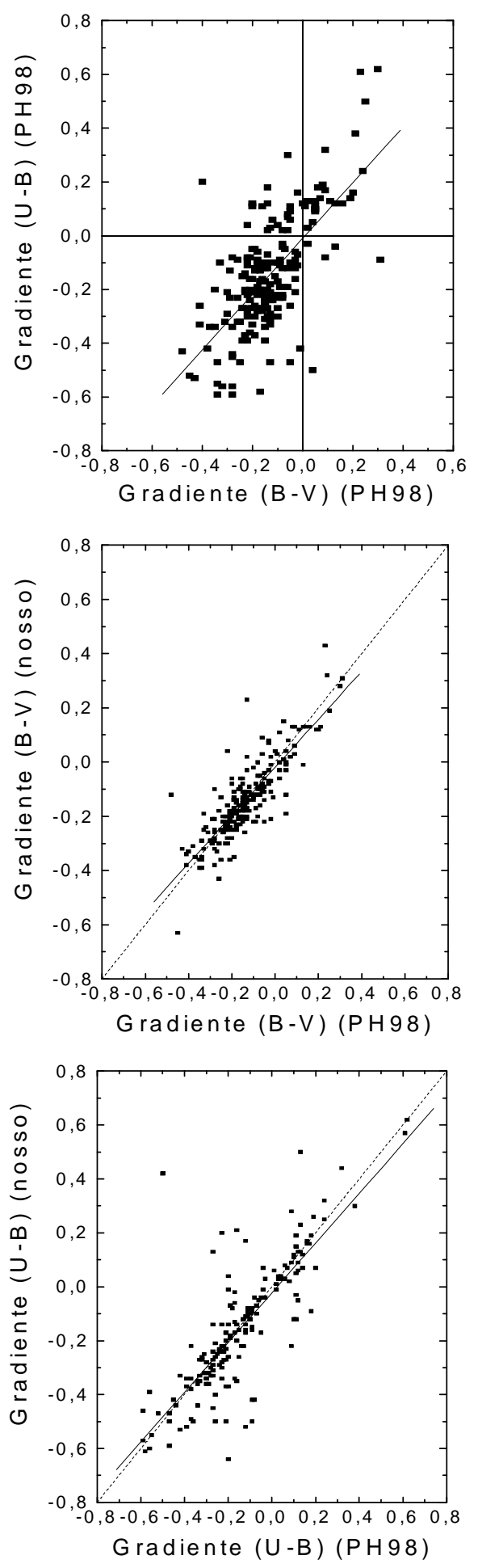

Figura 2.10: Comparação com os gradientes obtidos por PH98. O diagrama superior mostra que a correlação entre os gradientes (U-B) e (B-V) em PH98 é ligeiramente menor do que a apresentada pelos valores obtidos por nós (ver Figura 2.9(c)). Os outros dois diagramas apresentam os nossos gradientes em função dos de PH98. A linha tracejada indica uma correlação perfeita. A linha cheia mostra o ajuste linear para os pontos do gráfico. 

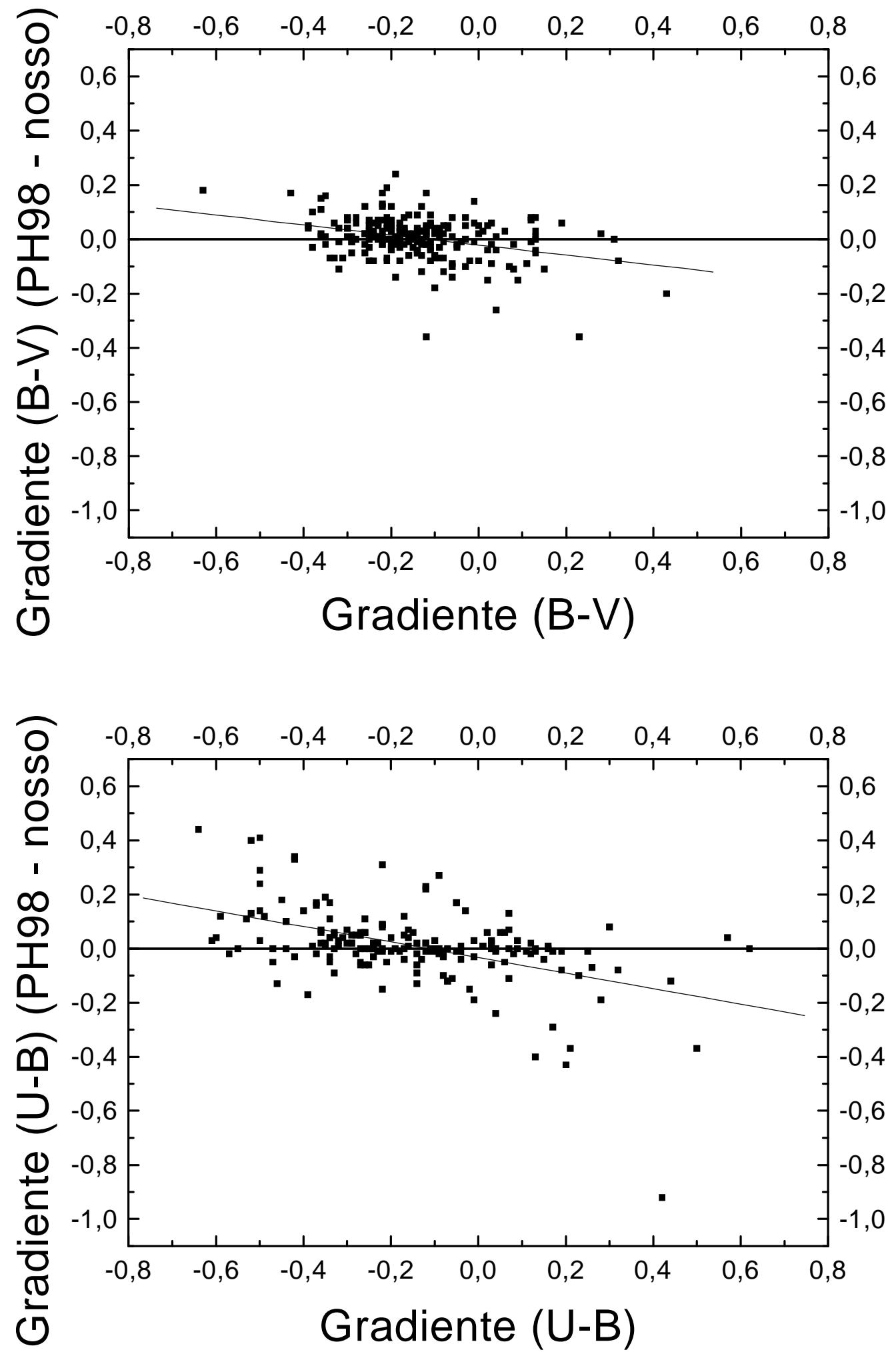

Figura 2.11: A diferença entre os valores dos gradientes obtidos aqui e os de PH98 em função dos gradientes por nós determinados. A linha cheia indica o ajuste linear para os pontos. 

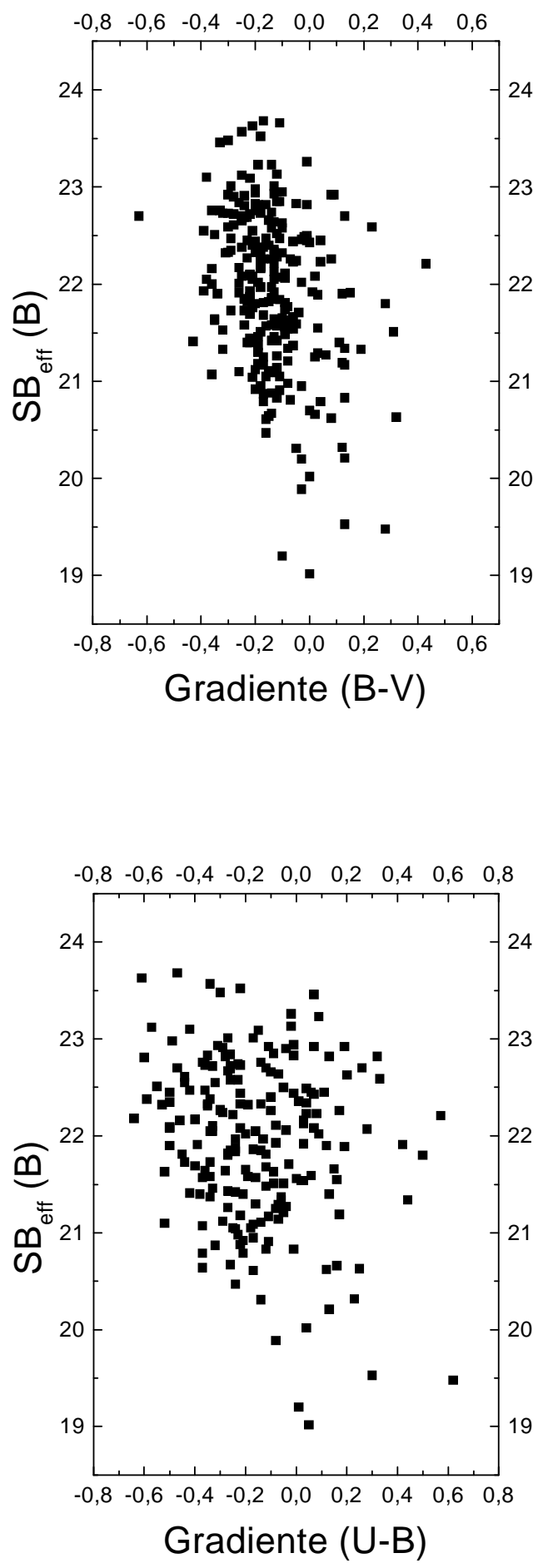

Figura 2.12: O brilho superficial efetivo na banda B, obtido por PH98 para as galáxias em comum com a nossa amostra, em função dos gradientes de cor determinados por nós. Evidentemente, não há uma forte correlação entre esses parâmetros. Pode-se notar, entretanto, uma leve tendência de as galáxias com gradientes nulos ou positivos apresentarem uma maior concentração central de luz. 

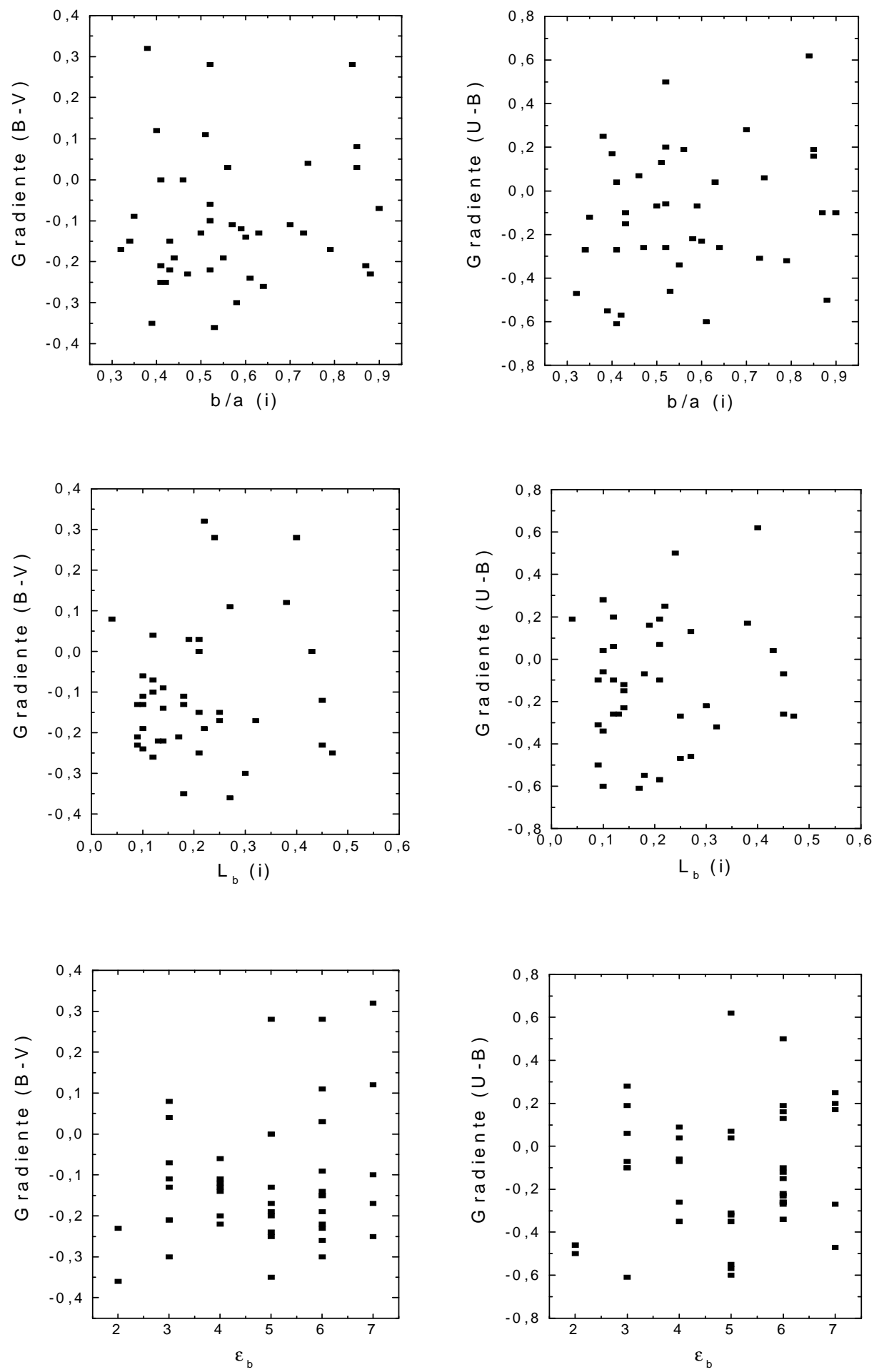

Figura 2.13: Gradientes de cor em função dos parâmetros obtidos em M95 para as barras de 45 galáxias de nossa amostra. Nos diagramas superiores os gradientes estão em função da razão axial das barras. Os diagramas centrais apresentam os gradientes em função do comprimento normalizado das barras, e nos diagramas inferiores em função da elipticidade aparente das barras. É evidente que não existe correlação alguma. 
por Martin. A Figura 2.13 exibe os diagramas que apresentam os gradientes de cor em função dos parâmetros obtidos em M95 para as barras destas galáxias. Como se vê, não há correlações. Isto significa que, apesar da correlação entre a presença de barra e a existência de gradiente (de cor ou metalicidade) nulo ou positivo, o valor do gradiente de cor não depende da morfologia das próprias barras. Tanto barras de maior ou menor extensão, como de maior ou menor razão axial, residem em galáxias que apresentam o mesmo comportamento do gradiente de cor.

\subsubsection{Gradientes de abundância $\mathrm{O} / \mathrm{H}$}

Martin \& Roy (1994 - doravante MR94) e Zaritsky, Kennicutt \& Huchra (1994 doravante ZKH94) apresentam o gradiente da abundância $\mathrm{O} / \mathrm{H}$ para galáxias espirais, determinado através de observações de regiões HıI. Martin \& Roy concluem que galáxias barradas tendem a apresentar gradientes menos acentuados do que galáxias ordinárias. Também concluem que os gradientes tornam-se menos acentuados à medida que o comprimento normalizado ou a elipticidade aparente das barras aumenta (ver seção 2.4.4). Zaritsky, Kennicutt \& Huchra encontram evidências de que a presença de uma barra induz a atenuação do gradiente.

Em nossa amostra, temos 12 galáxias em comum com MR94 e 18 com ZKH94. Na Figura 2.14, exibimos nossos gradientes de cor em função dos gradientes de abundância de MR94 (diagrama superior) e de ZKH94 (diagrama inferior). Os quadrados indicam (B$\mathrm{V})$, enquanto que o sinal + indica $(\mathrm{U}-\mathrm{B})$. O primeiro fato a notar nesta figura é a ausência de uma clara correlação entre os gradientes fotométricos, tanto $G_{B-V}$ como $G_{U-B}$, e o gradiente da abundância $\mathrm{O} / \mathrm{H}$. É difícil acreditar que esta ausência de correlação seja devido a erros na estimativa dos gradientes fotométricos. Estes estão na faixa de 0.02 a 0.05, tipicamente, e se encontram indicados na Figura 2.14. Os erros nas estimativas do gradiente de abundância são mais problemáticos de serem avaliados, conforme se pode constatar pelo gradiente O/H de NGC 2997, bem distinto entre MR94 ( $\left.-0.093 \mathrm{dex} \mathrm{kpc}^{-1}\right)$ e ZKH94 $\left(-0.020\right.$ dex $\left.\mathrm{kpc}^{-1}\right)$. Entretanto, raramente os erros no gradiente $\mathrm{O} / \mathrm{H}$ são superiores a $0.02 \mathrm{dex} \mathrm{kpc}^{-1}$ (ZKH94). Portanto, a alternativa que resta é a de que esta ausência de correlação é real. Entretanto, esta alternativa é muito interessante, porque, sendo o índice de cor sensível potencialmente a dois parâmetros, quais sejam, a idade e a metalicidade, esta ausência de correlação na Figura 2.14 indica que o gradiente fotométrico não está correlacionado com o gradiente de metalicidade. Portanto, a única alternativa que restaria para interpretar tal comportamento seria a de que o excesso de galáxias barradas com gradiente de cor nulo ou positivo, presente nas Figuras 2.6, 2.7 e 2.8, e Tabelas 2.1 e 2.2, reflete uma diferença no comportamento da idade média da população estelar ao longo de galáxias barradas e ordinárias. 

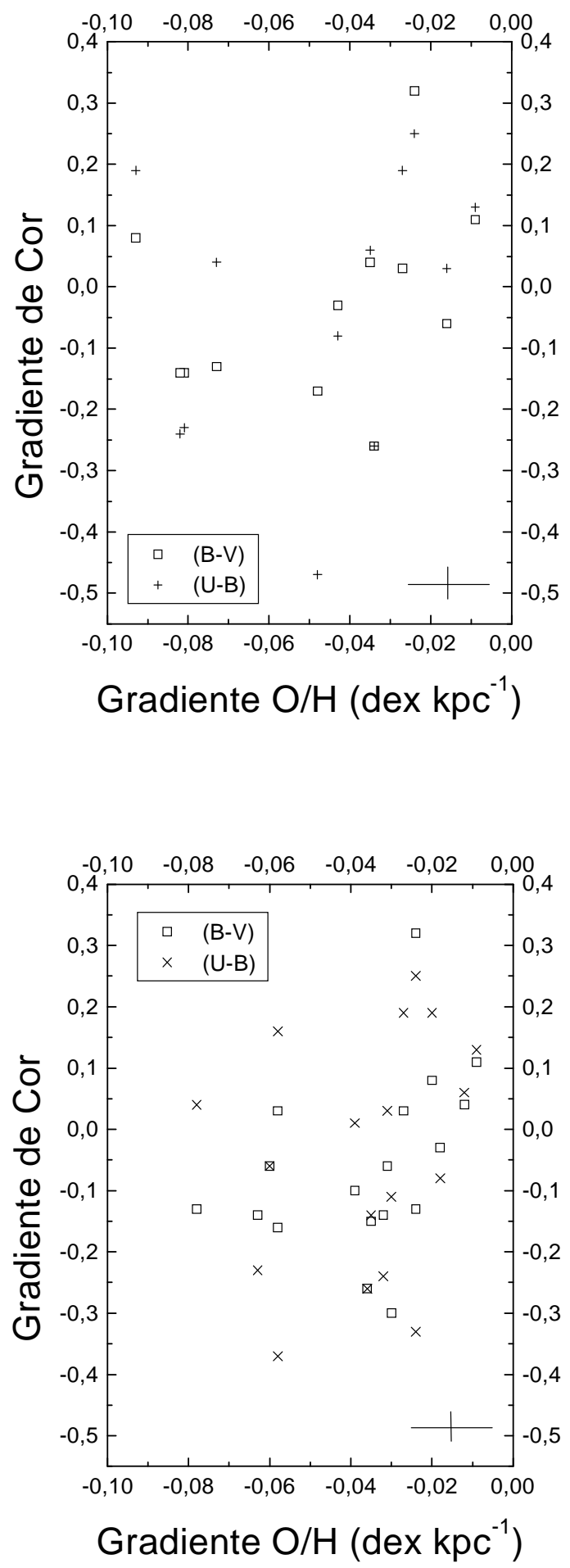

Figura 2.14: Correlação entre os gradientes de cor e os gradientes de abundância $\mathrm{O} / \mathrm{H}$, utilizando os valores obtidos por MR94 (diagrama superior) e ZKH94 (diagrama inferior). Os quadrados indicam os gradientes em (B-V), enquanto que o sinal + indica aqueles em (U-B). No canto inferior direito de cada gráfico, barras de erro típicas estão desenhadas. 
Tabela 2.4: Valores medianos dos índices de cor característicos de bojos e discos para as galáxias em nossa amostra, separadas por categoria. Os índices determinados para galáxias vistas de face se encontram à direita. Os erros $(\sigma)$ estão apresentados entre parênteses.

\begin{tabular}{|c|c|c|c|c|c|c|}
\hline & Cor & $\begin{array}{l}\text { Bojo } \\
\text { Total }\end{array}$ & Disco & Cor & $\begin{array}{l}\text { Bojo } \\
\text { Face }\end{array}$ & Disco \\
\hline $\mathrm{G} \geq 0.1$ & $(\mathrm{~B}-\mathrm{V})$ & $0.34(0.03)$ & $0.53(0.04)$ & $(\mathrm{B}-\mathrm{V})$ & $0.36(0.03)$ & $0.55(0.05)$ \\
\hline$-0.1<\mathrm{G}<0.1$ & & $0.52(0.03)$ & $0.52(0.03)$ & & $0.57(0.02)$ & $0.57(0.02)$ \\
\hline$-0.05<\mathrm{G}<0.05$ & & $0.51(0.04)$ & $0.51(0.04)$ & & $0.52(0.03)$ & $0.52(0.03)$ \\
\hline $\mathrm{G} \leq-0.1$ & & $0.64(0.01)$ & $0.43(0.01)$ & & $0.74(0.01)$ & $0.53(0.01)$ \\
\hline $\mathrm{G} \geq 0.1$ & $(\mathrm{U}-\mathrm{B})$ & $-0.35(0.06)$ & $-0.08(0.05)$ & $(\mathrm{U}-\mathrm{B})$ & $-0.31(0.07)$ & $0.05(0.07)$ \\
\hline$-0.1<\mathrm{G}<0.1$ & & $-0.06(0.03)$ & $-0.06(0.03)$ & & $-0.05(0.03)$ & $-0.05(0.03)$ \\
\hline$-0.05<\mathrm{G}<0.05$ & & $-0.05(0.04)$ & $-0.05(0.04)$ & & $-0.01(0.03)$ & $-0.01(0.03)$ \\
\hline $\mathrm{G} \leq-0.1$ & & $0.19(0.02)$ & $-0.14(0.01)$ & & $0.24(0.03)$ & $-0.05(0.02)$ \\
\hline
\end{tabular}

\subsection{6 Índices de cor para bojos e discos}

A Tabela A.1 exibe os valores dos índices de cor característicos de bojos e discos das galáxias em nossa amostra, estimados através das equações (2.8) e (2.9), e corrigidos apropriadamente (ver seção 2.3.1). Na Tabela 2.4, apresentamos os valores medianos destes índices. As galáxias estão divididas em categorias, da mesma forma como foram nas Tabelas 2.2 e 2.3. Logicamente, para as galáxias que apresentam gradientes nulos, não apresentamos os índices de bojos e discos separadamente, já que são, de fato, aproximadamente iguais, mas um único valor que se aplica ao longo de toda a galáxia. Este valor foi tomado como sendo o índice de cor efetivo da galáxia, como apresentado no RC3. Além disso, fizemos uma avaliação separada para aquelas galáxias vistas de face. Os dados referentes a estas galáxias se encontram à direita na tabela. Os erros $(\sigma)$ em cada índice de cor estão expressos entre parênteses, e foram calculados segundo a definição de erro padrão para uma amostra de objetos com erros independentes, i.e.,

$$
\sigma=\frac{\delta}{\sqrt{n}}
$$

onde $\delta$ é o desvio padrão das medidas e $n$ é o número de medidas.

Considerando somente as galáxias vistas de face (setor à direita na Tabela 2.4), percebe-se que o índice de cor das galáxias que apresentam gradientes nulos é aproximadamente igual ao índice de cor do disco das galáxias com o típico gradiente negativo. Mais ainda, o índice do disco permanece aproximadamente constante ao longo das três classes de gradientes, enquanto o bojo apresenta índices cada vez menores. Estes resultados se aplicam tanto a $(\mathrm{B}-\mathrm{V})$ quanto a (U-B). Isto significa que os discos das galáxias 

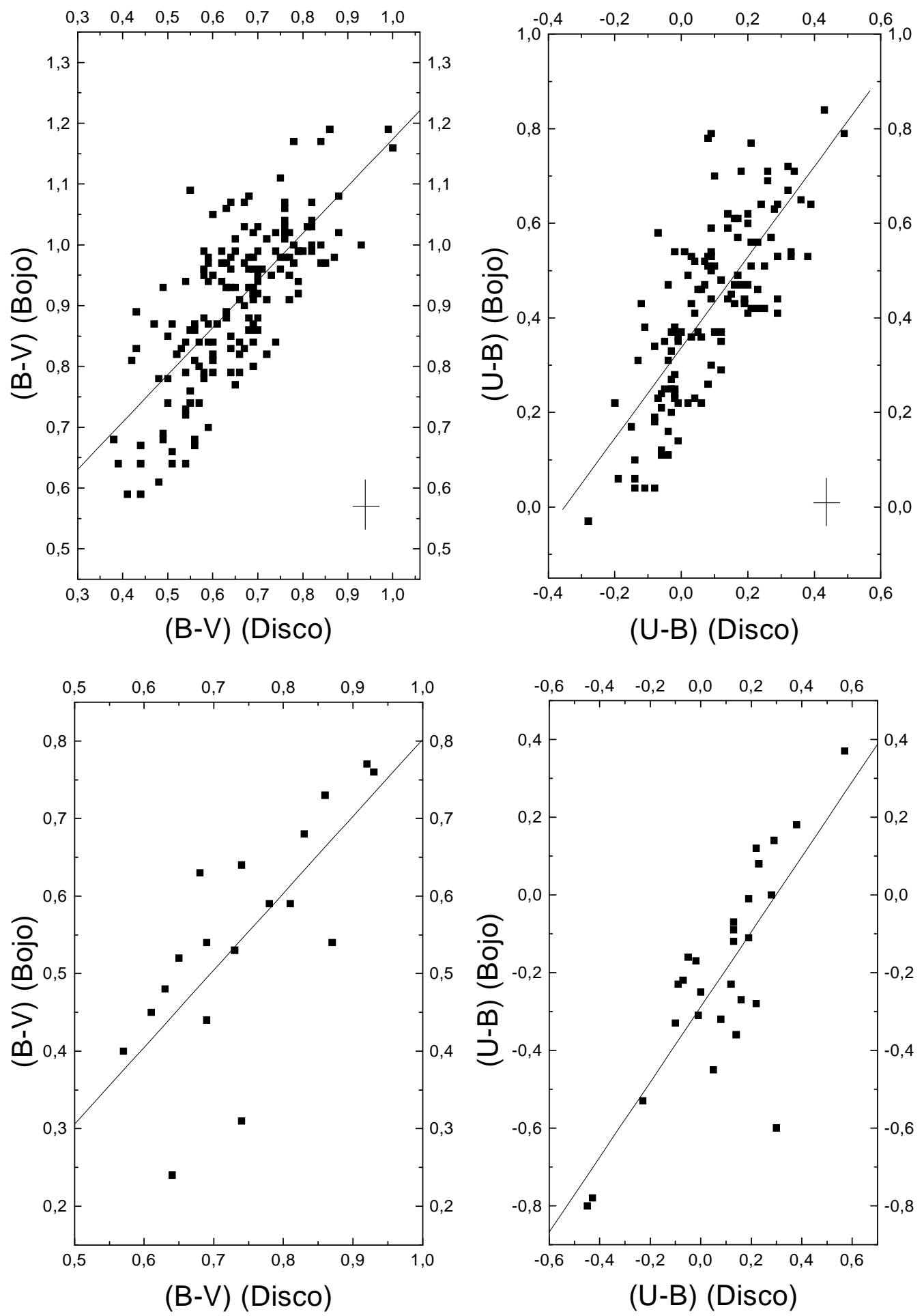

Figura 2.15: Índices de cor do bojo em função dos índices do disco para as galáxias com gradientes negativos (painéis superiores) e positivos (painéis inferiores), estimados em primeira aproximação (ver seção 2.3.1). Percebe-se claramente haver uma correlação entre ambos os parâmetros. 

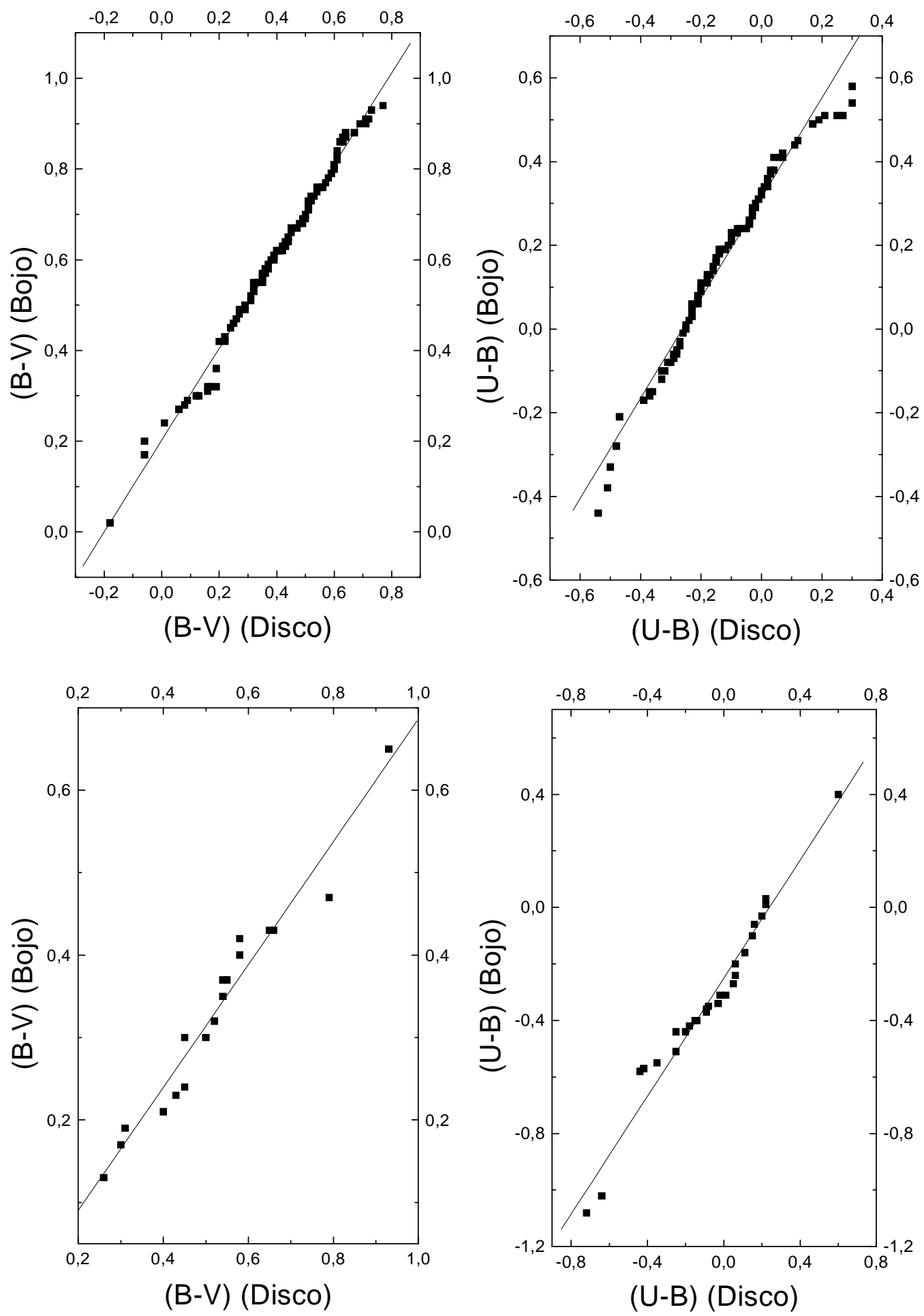

Figura 2.16: Índices de cor do bojo em função dos índices do disco para as galáxias com gradientes negativos (painéis superiores) e positivos (painéis inferiores), determinados através das equações (2.8) e (2.9) (ver seção 2.3.1). 
que apresentam diferentes comportamentos no gradiente, têm o mesmo índice de cor em comum.

Passando a analisar o comportamento dos índices de cor para toda a amostra (setor à esquerda na Tabela 2.4), vemos que o índice de cor das galáxias que apresentam gradientes nulos continua sendo aproximadamente igual ao índice de cor dos discos de galáxias com o raro gradiente positivo, tanto em (B-V) quanto em (U-B). Entretanto, o índice das galáxias com gradientes nulos assume valores mais intermediários entre os valores de bojo e disco das galáxias com o típico gradiente negativo, embora mais próximos dos índices dos discos. Mais uma vez, isto ocorre em ambas as cores. Como esta amostra pode estar mais afetada pela extinção intrínseca, devido à maior inclinação dos discos, não se pode descartar que seja esta a causa de tal comportamento.

A Figura 2.15 exibe os índices de cor característicos dos bojos em função dos índices dos discos para as galáxias com gradientes negativos (painéis superiores) e positivos (painéis inferiores). Nesta figura, os índices são aqueles determinados através da estimativa aproximada descrita na seção 2.3.1. Percebe-se claramente haver uma correlação entre ambos os parâmetros.

A Figura 2.16 é análoga à anterior. Neste caso, porém, os índices são aqueles determinados através das equações (2.8) e (2.9). Evidentemente, neste caso, a correlação entre os índices de bojos e discos surge naturalmente, uma vez que, subtraindo a equação (2.8) da (2.9), obtemos:

$$
(X-Y)_{d}=(X-Y)_{b}+G
$$

Assim, a estreita correlação apresentada nesta última figura indica, tão somente, que as galáxias apresentam gradientes semelhantes, dentro de cada categoria de gradiente. Deste ponto de vista, é interessante observar que, se bojo e disco estivessem passando por processos de evolução não correlacionados, então deveríamos observar uma maior variação no valor do gradiente. Portanto, o fato do gradiente ser aproximadamente o mesmo indica uma clara correlação evolutiva entre estas duas componentes.

\subsection{Discussão e conclusões}

Nesta seção, iremos discutir os resultados apresentados na seção anterior, separando os resultados relativos aos gradientes de cor em galáxias daqueles que se referem aos índices de cor de bojos e discos. 


\subsubsection{Gradientes de cor}

Um dos primeiros resultados apresentados na seção 2.4 foi o de que galáxias vistas de perfil tendem a ter gradientes de cor mais negativos (ver Tabela 2.1 e Figura 2.6), mas este comportamento só é observado com clareza no índice (U-B). Certamente que este efeito está relacionado ao fato de que, para galáxias vistas de perfil, o avermelhamento diferencial provocado pela extinção interestelar é maior, e também mais difícil de ser corrigido. Para que os gradientes em (U-B) sejam mais acentuados para galáxias vistas de perfil, devido ao avermelhamento interestelar, é preciso que as regiões centrais das galáxias sofram com maior intensidade os efeitos do avermelhamento do que as regiões periféricas. Assim, este resultado indica que a extinção interestelar é maior no bojo do que no disco das galáxias espirais, i.e., o bojo contém mais poeira do que o disco. Isso está de acordo com os resultados apresentados por de Jong (1996c). Neste trabalho, de Jong também concluiu que os gradientes de cor observados em galáxias não podem ser explicados somente pelo excesso de avermelhamento nas regiões centrais, mas que, de fato, o avermelhamento tem um papel insignificante. Este autor conclui que os gradientes podem ser explicados como um efeito conjunto da variação da idade e da metalicidade estelar ao longo de galáxias espirais.

Outros comportamentos que podem ser observados nas distribuições dos gradientes (Figura 2.7 e Tabela 2.1) são: (i) - galáxias barradas têm gradientes menos negativos, mas, novamente, este comportamento somente ocorre quando se considera o índice (U-B), e, (ii) - galáxias barradas têm distribuições mais alargadas, tanto em (U-B) quanto em (B-V). Estes dois comportamentos podem ser vistos como compatíveis com o cenário de evolução secular. A atenuação dos gradientes de cor em galáxias barradas pode decorrer dos efeitos de evolução secular relacionados a barras, já que estes promovem uma homogeneização das populações estelares ao longo da galáxia, conforme vimos nas seções 1.1.3 e 2.1. Ademais, este efeito deve mesmo ser mais visível na cor (U-B), já que quando ocorre um surto de formação estelar, as variações nesta cor são maiores do que em (B-V), conforme se pode concluir dos modelos de evolução fotométrica de Larson \& Tinsley (1978). O fato das galáxias barradas possuírem distribuições mais alargadas pode ser interpretado de algumas maneiras distintas, porém ainda dentro do cenário de evolução secular. Por um lado, a presença de uma barra pode não ser uma condição suficiente para que haja a homogeneização das populações estelares. A quantidade de gás disponível no disco da galáxia pode ter aí um papel fundamental. Uma barra em um disco pobre em gás pode não coletar a quantidade de gás necessária para induzir uma formação estelar central suficientemente poderosa a ponto de tornar similares as populações estelares do bojo e disco. Por outro lado, sendo as condições favoráveis, a presença da barra homogeneiza as populações estelares ao longo da galáxia, atenuando os gradientes de cor, ou até mesmo 
tornando-os positivos, no caso em que a formação estelar central, induzida pela barra, é ainda recente (o que torna as cores centrais mais azuladas). De fato, outro resultado que apresentamos, ainda relativo à distribuição dos gradientes de cor, é o de que a fração de galáxias com gradientes nulos ou positivos é maior entre as galáxias barradas (Figura 2.8). Todas essas observações não somente podem decorrer do cenário de evolução secular como também o favorecem.

Os resultados que apresentamos em relação às três categorias de gradientes (negativos, nulos e positivos), na seção 2.4.2, podem ser discutidos em duas etapas distintas. Primeiro, consideraremos toda a amostra, para, em seguida, analisar os resultados que se referem somente às galáxias vistas de face.

Considerando toda a amostra deste estudo, vemos que $70 \%$ das galáxias são barradas $(\mathrm{SAB}+\mathrm{SB})$. Através da Tabela 2.2, vimos que, no entanto, essa fração é menor entre as galáxias com o típico gradiente negativo, sendo igual a $64 \%$ em (B-V) e $59 \%$ em (UB). Além disso, essa fração aumenta entre as galáxias com gradientes nulos, indo para $87 \%$ em (B-V) e $81 \%$ em (U-B). Portanto, há uma diferença bastante significativa entre a fração de galáxias barradas que têm gradientes nulos, e essa mesma fração entre as galáxias com gradientes negativos. Essa diferença é ligeiramente mais acentuada quando utilizamos o critério mais restritivo para definir o gradiente nulo. Em outras palavras, as galáxias barradas estão super-representadas na amostra de objetos com gradientes nulos ou positivos. Esse resultado favorece o cenário de evolução secular, uma vez que mostra que as galáxias barradas tendem a ter gradientes de cor nulos, conforme previsto. A importância desse resultado é ainda maior na medida em que ocorre de maneira semelhante quer consideremos o índice (U-B) ou o índice $(\mathrm{B}-\mathrm{V})$. Se voltarmos os olhos apenas para as galáxias vistas de face, $79 \%$ das galáxias são barradas. Esse aumento é provavelmente devido ao fato de ser mais fácil identificar uma galáxia barrada quando esta é vista de face do que quando é vista de perfil. A diferença entre a fração de galáxias barradas que têm gradientes nulos, e essa mesma fração entre as galáxias com gradientes negativos é, nesse caso, menos acentuada, mas ainda está presente (ver Tabela 2.3). A fração de galáxias barradas que têm gradientes negativos é de $75 \%$ em (B-V) e de $73 \%$ em (U-B), subindo para $91 \%$ em (B-V) e $83 \%$ em (U-B), entre as galáxias com gradientes nulos. No entanto, a diferença é ainda significativa e, mais uma vez, o comportamento é semelhante nos dois índices de cor estudados. Além disso, se considerarmos o critério mais restritivo para definir o gradiente nulo, a diferença torna-se substancialmente mais acentuada. Enfim, o resultado permanece favorável ao cenário de evolução secular, mesmo quando se considera somente as galáxias vistas de face.

Ainda em relação às três categorias de gradientes, vimos que a maior fração de galáxias barradas ocorre entre as galáxias com gradientes positivos, tanto ao considerar- 
mos toda a amostra, quanto ao avaliarmos somente as galáxias vistas de face. Entretanto, esse comportamento só é observado em (U-B), já que, como mencionado antes, esta cor é mais sensível aos surtos de formação estelar recente. Por outro lado, a fração de galáxias com AGN's aumenta progressivamente das galáxias com gradientes negativos para aquelas com gradientes nulos e, por fim, para as galáxias com o raro gradiente positivo. Esse resultado ocorre nos dois índices de cor, e é válido para galáxias vistas de face ou não. Apesar de uma maior fração de AGN's entre as galáxias com gradientes positivos ser um resultado esperado, o fato de haver um excesso de galáxias barradas com gradientes positivos, pode estar indicando uma conexão entre a presença de barras e de AGN's. Essa conexão pode favorecer o cenário proposto por Shlosman, Frank \& Begelman (1989) e Shlosman, Begelman \& Frank (1990), no qual a barra é responsável pela manutenção de AGN's, coletando gás até as regiões centrais das galáxias. Por outro lado, o fato de haver galáxias barradas com gradientes positivos, mas que não têm AGN's pode indicar que a coleta de gás nem sempre chega às pequenas escalas de distância ao centro, exigidas para alimentar o AGN, ou ainda que a simples coleta de gás para as regiões centrais não é uma condição suficiente para originar um AGN. Ho, Filippenko \& Sargent (1997) mostram que, enquanto parece estar bem estabelecido que as barras de fato aumentam a formação estelar nuclear em galáxias, a conexão entre barras e AGN's é muito menos clara, sendo, portanto, uma questão que ainda precisa de uma investigação mais detalhada.

Vamos nos atentar agora à comparação dos gradientes obtidos por nós com aqueles determinados em PH98 (seção 2.4.3). Vimos, como era de se esperar, que existe uma boa correlação entre os gradientes determinados em cada trabalho (Figura 2.10 - painéis inferiores). Além disso, vimos que não existe nenhuma diferença sistemática entre os gradientes calculados em cada trabalho (Figura 2.11) e que as diferenças médias são bastante pequenas. Vimos também que os gradientes em (U-B) e em (B-V) se correlacionam entre si (Figura 2.10 - painel superior para PH98 e Figura 2.9(c) para este trabalho). No entanto, a correlação entre os gradientes (U-B) e (B-V) é mais significativa no nosso trabalho. $\mathrm{O}$ fato de haver tal correlação indica que os mesmos fenômenos físicos são responsáveis pela origem dos gradientes em ambas as cores. Um resultado semelhante foi apresentado por Balcells \& Peletier (1994) para os gradientes (U-R) e (B-R), utilizando, entretanto, apenas 18 galáxias. A melhor correlação apresentada por nós está provavelmente vinculada ao fato de que utilizamos métodos estatísticos mais robustos do que PH98 para determinar os gradientes. Assim, de certa forma, nossos gradientes são ligeiramente mais acurados.

Ainda utilizando os resultados em PH98, mostramos que existe uma leve tendência de as galáxias com gradientes nulos ou positivos apresentarem uma maior concentração central de luz, ou seja, um menor brilho superficial efetivo. No entanto, a dispersão é muito grande. Este resultado pode ser interpretado favoravelmente ao cenário de evolução 
secular, já que o transporte de gás das regiões periféricas para as regiões centrais, induzido pela barra, dando origem a surtos de formação estelar central, deve tornar a distribuição de massa (e, portanto, luminosidade) mais centralmente concentrada. Veremos, no Capítulo 3, que obtivemos um resultado análogo, que se refere, porém, ao brilho superficial efetivo da componente bojo, separadamente.

Vamos agora explorar os dados apresentados em M95, que se referem a uma morfologia quantitativa de barras. Nesse trabalho, Martin determina certos parâmetros morfológicos em barras de uma amostra de galáxias. Alguns deste parâmetros, como a razão axial, comprimento do eixo maior (normalizado pela isofota de $25 \mathrm{mag} \mathrm{arcsec}^{-2}$ ), e a elipticidade aparente das barras, podem ser considerados como uma medida da força da barra, ou seja, de sua capacidade em coletar gás para as regiões centrais. É interessante notar que MR94 encontram que os gradientes de abundância $\mathrm{O} / \mathrm{H}$ em galáxias barradas tornamse menos acentuados à medida que a elipticidade ou o comprimento da barra aumentam. Portanto, isto indica que galáxias com barras fortes têm gradientes de abundância $\mathrm{O} / \mathrm{H}$ menos acentuados, em completo acordo com o cenário de evolução secular. Surpreendentemente, entretanto, não existe nenhuma correlação entre os parâmetros de força das barras em 45 galáxias de nossa amostra, que foram estudadas em M95, com os gradientes de cor que nós determinamos (Figura 2.13). Seria mais natural esperarmos um resultado análogo ao encontrado em MR94, i.e., que as galáxias com barras mais fortes exibissem gradientes menos acentuados. Este resultado mostra que não podemos supor que os gradientes de cor (U-B) e (B-V) são completamente equivalentes aos gradientes de abundância $\mathrm{O} / \mathrm{H}$, e, portanto, os gradientes de cor são mais sensíveis à idade dos surtos de formação estelar. Enquanto que os gradientes de cor são mais representativos da população estelar, i.e., tipo espectral, temperatura e luminosidade estelares, o gradiente $\mathrm{O} / \mathrm{H}$ está mais relacionado à abundância química do meio interestelar, e à história de formação estelar na galáxia, já que o meio interestelar é enriquecido com Oxigênio através de explosões de supernovas de tipo 2, que são produzidas por estrelas de população I, que são jovens e têm vida relativamente curta.

Ainda em relação aos gradientes de abundância $\mathrm{O} / \mathrm{H}$, utilizando os trabalhos MR94 e ZKH94, elaboramos a Figura 2.14, procurando correlações entre esses gradientes e os gradientes de cor. Corroborando a não-equivalência entre estas duas classes de gradientes, que encontramos no parágrafo anterior, as correlações são inexistentes, apesar de os erros estimados serem pequenos. Portanto, esta ausência de correlação indica que os gradientes fotométricos são mais sensíveis ao fator idade do que à metalicidade. 


\subsection{2 Índices de cor}

Mais uma vez, vamos separar a discussão dos resultados relativos aos índices de cor, analisando primeiramente somente os resultados referentes às galáxias vistas de face, para depois passar aos resultados obtidos quando toda a amostra é considerada.

Temos, em nossa amostra, 124 galáxias vistas de face com o gradiente em (B-V) determinado, o que corresponde a $52 \%$ do total. Em relação ao gradiente (U-B), temos 104 galáxias, ou 51\% do total de galáxias com o gradiente (U-B) determinado. Avaliando somente as galáxias vistas de face, podemos verificar, através da Tabela 2.4, que a cor das galáxias com gradientes nulos é bastante similar à cor dos discos das galáxias com gradientes negativos, tanto em (B-V), quanto em (U-B). Esse comportamento corrobora o cenário de evolução secular, já que indica que é o bojo que se azula na atenuação dos gradientes de cor, e não o disco que se avermelha. Portanto, é material do disco que é coletado para as regiões centrais na atenuação dos gradientes de cor. De fato, outro resultado importante que pode ser extraído da Tabela 2.4 é o de que a cor do disco se mantém constante nas três categorias de gradientes, mas o bojo torna-se cada vez mais azul, quando se parte das galáxias com gradientes negativos para as com gradientes nulos e para as com gradientes positivos. Considerando-se toda a amostra, os resultados não são tão significativos, já que o índice das galáxias com gradientes nulos assume valores mais intermediários entre os valores de bojo e disco das galáxias com o típico gradiente negativo, embora mais próximos dos índices dos discos. Este comportamento está certamente ligado ao fato de as correções por inclinação nas cores de galáxias espirais, como a que aplicamos neste trabalho (seção 2.3.1), serem por demais incertas. Portanto, é muito mais confiável utilizar os resultados referentes às galáxias vistas de face somente.

Na Figura 2.15, mostramos que as cores de bojos e discos se correlacionam, resultado que já foi obtido por Peletier \& Balcells (1996) para os índices (U-R), (B-R), (R-K) e (J-K), porém para uma amostra de galáxias muito menor (somente 30 objetos). Esses autores concluem que, assumindo que as metalicidades em bojos e discos sejam idênticas, então as diferenças entre as idades estelares nestas componentes não pode ser maior do que $30 \%$, o que é compatível com o cenário de evolução secular.

\subsubsection{Barras recorrentes e a importância do cenário de evolução secular}

Norman, Sellwood \& Hasan (1996) sugerem que a formação da barra, sua dissolução e conseqüente construção do bojo possa ser um fenômeno recorrente, ou seja, que ocorra diversas vezes para uma mesma galáxia. Já é um fato bem estabelecido que uma barra se 
desenvolve naturalmente em um disco estelar, através de instabilidades dinâmicas (e.g., Binney \& Tremaine 1987). Também já está claro que o aumento na concentração central de massa, induzido pela barra, é capaz de destruí-la. No entanto, ainda não está claro se uma galáxia que já foi barrada, e teve sua barra dissolvida, pode desenvolver uma nova barra (Friedli 1999). No processo de dissolução da barra, é muito provável que a dispersão de velocidades das estrelas no disco aumente, o que torna mais difícil o desenvolvimento de uma nova barra, já que as barras têm maior facilidade de se originar em discos "frios", i.e., com baixa dispersão de velocidade, conforme o critério de Toomre (e.g., Binney \& Tremaine 1987$)^{4}$.

Em nossa amostra de galáxias, temos galáxias barradas que não tem o gradiente nulo, mas o típico gradiente negativo. Isso pode ser um indício de que a presença de uma barra não é uma condição suficiente para que o gradiente de cor seja atenuado. A quantidade de gás disponível no disco deve ser um outro parâmetro importante nesse sentido, como já foi discutido anteriormente. Por outro lado, a barra nesse caso pode ter sido recém-formada, não tendo tido tempo ainda para homogeneizar as populações estelares ao longo da galáxia. Inversamente, também temos galáxias em nossa amostra que, apesar de não serem barradas, exibem gradientes de cor nulos. Podemos interpretar este caso como sendo o de uma galáxia que teve a sua barra dissolvida recentemente e, por isso, ainda apresenta o gradiente atenuado. Após um certo período de tempo, a evolução da geração de estrelas formada nas regiões centrais da galáxia, que se formou através do gás transportado pela barra, bem como a ausência de novos surtos de formação estelar central, podem tornar o gradiente mais negativo novamente.

Apesar de nossa amostra não ser completa, podemos fazer algumas considerações frutíferas. Considerando que o fenômeno de barras seja realmente recorrente, que todas as galáxias espirais (pelo menos as espirais de tipo tardio) sofram desta instabilidade, e assumindo uma idade média de 10 Giga-anos para essas galáxias, podemos interpretar a fração de galáxias em cada categoria de gradiente como se segue. Vamos imaginar que todas as galáxias se formem com gradientes de cor negativos. Ora, temos $65 \%$ das galáxias com gradientes negativos e $35 \%$ com gradientes nulos ou positivos, tornados assim devido aos processos de evolução secular relacionados à barras. Portanto, o período em que a barra mantém o gradiente atenuado, ou até mesmo positivo, é de cerca de 3 a 4 Giga-anos. Em verdade, como a presença de uma barra pode não ser uma condição suficiente para a atenuação dos gradientes, este valor é apenas um limite inferior. Podemos adotar que o tempo decorrido após a formação da barra para que o gradiente seja atenuado é da ordem da escala de tempo que leva para que ocorra o espessamento da barra, i.e., 1 Giga-ano (ver seção 1.1.3). Se o tempo que leva para que o gradiente volte a tornar-se negativo, após a dissolução da barra, for suficientemente pequeno para que possa ser desprezado,

\footnotetext{
${ }^{4}$ Devemos a G. Gilmore o fato de ter-nos chamado a atenção para este ponto.
} 
podemos estimar o tempo de vida da barra como sendo de cerca de 5 Giga-anos. Portanto, devemos esperar que metade das galáxias espirais sejam barradas, o que está em acordo com as observações, pelo menos no que se refere a galáxias do Universo local.

Se, ao contrário, barras em discos estelares não são recorrentes, podemos interpretar a fração de galáxias em cada categoria de gradiente, tendo em mente dois distintos cenários para a formação de bojos. O cenário monolítico prevê gradientes de cor negativos, já que a população estelar do bojo é mais velha do que a do disco, neste cenário. Portanto, de acordo com essas suposições e os nossos resultados, $65 \%$ das galáxias espirais se formam através do cenário monolítico. No cenário de evolução secular a população estelar do bojo deve ter a mesma idade, ou ser mais jovem, que a do disco e, portanto, galáxias formadas deste modo devem apresentar gradientes de cor nulos ou positivos. Assim, 35\% das galáxias se formariam, nesta conjectura, através do cenário de evolução secular. Em uma conjectura mista, poderíamos supor que todas as galáxias se formem através do cenário monolítico, mas que, em pelo menos $35 \%$ das galáxias, os processos de evolução secular relacionados à barras contribuam para a construção dos seus bojos. 


\section{Capítulo 3}

\section{Fotometria Superficial}

No capítulo anterior, concluímos, entre outras coisas, que $25 \%$ das galáxias avaliadas neste estudo possuem os mesmos índices de cor em bojos e discos, caracterizando uma homegeneização de populações estelares nestas componentes, compatível com a previsão do cenário de evolução secular. Neste capítulo, vamos utilizar uma técnica de decomposição bi-dimensional (2D) para modelar o bojo e o disco, com o objetivo de estimar os parâmetros característicos dos perfis de luminosidade de bojos e discos, em 39 galáxias da amostra.

O interesse na separação das componentes bojo e disco de galáxias é devido ao fato de que a avaliação dos parâmetros fotométricos que descrevem as distribuições de brilho destas componentes, separadamente, nos fornece informações importantes relativas à estrutura das galáxias. Desta forma, a avaliação destes parâmetros contribui também para a avaliação de cenários de formação e evolução de galáxias. A técnica de decomposição 2D, aplicada à imagem de uma galáxia, ajusta um perfil exponencial para o disco, segundo a lei de King, e um perfil que segue a lei de Sérsic, para o bojo. Desta forma, obtemos um modelo para o bojo e para o disco de cada galáxia, que corresponde, aproximadamente, devido às limitações do programa e dos modelos escolhidos, à estrutura real da galáxia.

Através dos perfis de luminosidade dos modelos de cada galáxia, podemos determinar, entre outros parâmetros, as razões entre as luminosidades e os diâmetros de bojo e disco em cada galáxia. A partir das estimativas destes parâmetros, vamos verificar a existência de correlações que possam indicar a ocorrência dos efeitos de evolução secular em galáxias barradas. Em particular, pretendemos verificar se existe uma correlação entre os gradientes de cor e as razões bojo/disco. Se, por exemplo, as galáxias com gradientes 
nulos possuírem bojos mais proeminentes, então esse resultado poderia ser um indício de que a barra realmente transfere gás e estrelas do disco para o bojo, não somente homogeneizando as populações estelares ao longo da galáxia, mas também contribuindo, dessa forma, para a construção do bojo.

Iniciaremos este capítulo descrevendo os critérios para a seleção das 39 galáxias de nossa amostra escolhidas para a decomposição bojo/disco. Como as imagens destas galáxias, que utilizamos para aplicar o programa, foram obtidas através do DSS, na seção 3.2 apresentamos informações relevantes a respeito destas imagens. Em seguida, descrevemos resumidamente o programa que realiza a decomposição bojo/disco, e o procedimento que adotamos na obtenção dos parâmetros desejados, na seção 3.3. A seção 3.4 exibe nossos resultados. Na seção 3.5, apresentamos os resultados da fotometria superficial aplicada em imagens adquiridas por nós, em CCD, no LNA, como um estudo comparativo. A discussão acerca destes resultados, bem como nossas conclusões, são apresentadas na seção 3.6 .

\subsection{Seleção da sub-amostra}

O tempo de processamento do programa para a decomposição bojo/disco em uma galáxia é da ordem de 30 a 120 minutos, dependendo do tamanho da imagem da galáxia, bem como dos valores iniciais dos parâmetros de entrada. No entanto, para maximizar a qualidade do ajuste do modelo à estrutura verdadeira da galáxia, o programa deve ser aplicado em um modo semi-interativo, i.e., o usuário deve aplicar o programa diversas vezes para a mesma galáxia, variando os valores dos parâmetros de entrada, até obter um ajuste com a qualidade desejada. Os detalhes a respeito deste e de outros aspectos relativos ao programa serão apresentados na seção 3.3. No entanto, é importante salientar agora que o tempo de cálculo para a determinação dos modelos de bojo e disco para cada galáxia é demasiado longo.

Além disso, as imagens que utilizamos para modelar as galáxias são imagens do DSS (ver próxima seção). Estas imagens foram obtidas em placas fotográficas com exposições relativamente profundas e, sendo assim, devido à pequena faixa dinâmica destes detectores, algumas imagens encontram-se saturadas na região central das galáxias.

Assim, devido ao longo tempo de processamento do programa e ao problema de saturação nas imagens do DSS, selecionamos uma sub-amostra de galáxias, da nossa amostra total, para a qual realizamos a decomposição bojo/disco. Os critérios satisfeitos pelas galáxias contidas nesta sub-amostra são: 
1. Gradientes de cor bem determinados.

2. Baixa inclinação da normal ao disco da galáxia com relação à linha de visada, excluindo, assim, galáxias vistas de perfil.

3. Ausência de perturbações, tais como faixas de poeira e galáxias companheiras.

4. Área central de saturação pequena em relação ao tamanho aparente do bojo.

Utilizando estes critérios, obtivemos uma sub-amostra inicial de 61 objetos. No entanto, no decorrer do trabalho, encontramos galáxias cuja área central de saturação é maior do que a que havíamos previamente estimado, o que impossibilitou obtermos modelos confiáveis através do programa. Portanto, nossa sub-amostra final de galáxias, para as quais obtivemos os modelos de bojos e discos, é constituída por 39 objetos. Estas galáxias encontram-se na Tabela A.2, no Apêndice A.

Inspecionando as Tabelas A.1 e A.2, pode-se verificar que, em nossa sub-amostra, as frações de galáxias barradas $(\mathrm{SAB}+\mathrm{SB})$ e ordinárias $(\mathrm{SA})$ são similares às mesmas frações na amostra total. Além disso, a distribuição das galáxias na sub-amostra em relação às três categorias de gradientes de cor (negativos, nulos e positivos; ver seção 2.4.2) também é similar à mesma distribuição na amostra total. Portanto, a nossa sub-amostra é representativa da nossa amostra total de galáxias.

\subsection{As imagens do DSS}

Como já foi dito, as imagens que utilizamos para a decomposição bojo/disco das galáxias em nossa sub-amostra são parte do "Digitized Sky Survey". O DSS é um conjunto de placas fotográficas digitalizadas, com imagens obtidas através de câmeras Schmidt, que cobrem todo o céu. O DSS é o resultado de um esforço do "Space Telescope Science Institute" (STScI) de elaborar um catálogo de estrelas-guia (o "Guide Star Catalog" GSC) para as operações de apontamento do telescópio espacial Hubble (ver Lasker et al. $1990)$.

As placas fotográficas que constituem o DSS foram obtidas em três levantamentos. Para o hemisfério Norte $\left(+90^{\circ} \geq \delta \geq+6^{\circ}\right)$, as imagens foram obtidas no observatório Palomar, na Califórnia, Estados Unidos, no telescópio Oschin, que é uma câmera Schmidt com espelho de 1.2 metros de diâmetro, no monte Palomar. A banda fotométrica utilizada é semelhante à banda $\mathrm{V}$ de Johnson-Morgan. Em verdade, foram utilizadas duas bandas bastante similares, cujos comprimentos de onda centrais e larguras (entre parênteses) são, respectivamente, 576 (114) e 565 (140), em nanometros. Exposições típicas foram 
da ordem de 20 minutos. Para o hemisfério Sul $\left(-20^{\circ} \geq \delta \geq-90^{\circ}\right)$, foi utilizada a câmera Schmidt de 1.2 metros de diâmetro do observatório de Siding Spring, Austrália. A banda fotométrica utilizada é similar à banda $\mathrm{J}$ (ou $B_{J}$ ) de Couch-Newell (ver Fukugita, Shimasaku \& Ichikawa 1995), com comprimento de onda característico de 450 nanometros e largura à meia altura de 150 nanometros. Exposições típicas foram da ordem de 60 a 70 minutos. Para a região equatorial do hemisfério celeste, a mesma câmera Schmidt foi utilizada.

Para viabilizar a distribuição do DSS, a equipe do STScI procedeu à compressão de suas imagens. O algoritmo de compressão utilizado é baseado na transformação $H$ (ver White, Postman \& Lattanzi 1992, e referências aí contidas). Neste trabalho, White, Postman e Lattanzi realizaram a fotometria superficial de galáxias na imagem original e em diversas outras imagens com distintos fatores de compressão. A conclusão é a de que, para fatores de compressão até da ordem de 50, os resíduos das magnitudes entre a imagem original e as imagens comprimidas são da mesma ordem de grandeza da incerteza intrínseca na fotometria da imagem original, i.e., cerca de 10\%. A fotometria superficial de galáxias não é afetada pela compressão até fatores da ordem de 50. As imagens do DSS sofreram compressão com fatores da ordem de 10, o que permitiu que fossem armazenadas em um conjunto de 100 CD's ("Compact Discs").

Para obter as imagens DSS das galáxias em nossa sub-amostra, utilizamos o "Skyview Virtual Observatory", que é um serviço prestado pelo Laboratório de Astrofísica de Altas Energias (LHEA) da NASA ("National Aeronautics \& Space Administration"). As imagens podem ser obtidas através do seguinte endereço na "World Wide Web" (WWW): http://skyview.gsfc.nasa.gov/. Também obtivemos uma imagem diretamente dos CD's do DSS, verificando que as imagens obtidas na WWW são idênticas às dos CD's.

As placas fotográficas utilizadas na confecção do DSS são, ao contrário dos CCD's, detectores não-lineares. Quando um feixe de luz incide sobre uma região de uma placa fotográfica, originam-se sais de prata nesta região com uma determinada densidade $\rho$, denominada densidade fotográfica. Entretanto, $\rho$ não é sempre linearmente proporcional ao número de fótons que incidiram nesta região da placa fotográfica durante a exposição desta ao feixe de luz. Para interpretar corretamente as imagens do DSS, precisamos conhecer a intensidade da luz incidente $I$ em cada "pixel" da imagem. A curva característica que relaciona $I$ e $\rho$ nas imagens do DSS pode ser encontrada em Lasker et al. (1990), e é representada pela seguinte equação:

$$
I(\rho)=\Phi_{1} \rho+\Phi_{2} \ln \left(e^{(B \rho)^{C_{1}}}-1\right)+\Phi_{3} e^{(B \rho)^{C_{2}}}+\Phi_{4},
$$

onde $B, C_{1}$ e $C_{2}$ valem, respectivamente, $0.1,0.7$ e 1.0 . Os valores dos coeficientes $\Phi$ 
também são fornecidos por Lasker et al. e dependem de a imagem ter sido obtida em Palomar ou em Siding Spring.

No entanto, os valores em cada "pixel" das imagens originais do DSS não são iguais à densidade fotográfica, mas sim diretamente proporcionais, sendo o fator de conversão igual a 6553.4, conforme pode ser visto nos manuais dos CD's do DSS.

Assim, para interpretar corretamente as imagens do DSS, realizamos o seguinte procedimento. Inicialmente, dividimos o valor de cada "pixel" em todas as imagens pelo fator de conversão 6553.4, tornando o valor em cada "pixel" igual à densidade fotográfica. Em seguida, para linearizar as imagens, aplicamos a equação (3.1) em cada "pixel” de cada imagem. Assim, como produto final, obtivemos imagens linearizadas, com o valor em cada "pixel" igual à intensidade de luz incidente. É importante salientar que as intensidades obtidas através da equação (3.1) são normalizadas pela intensidade do fundo de céu local.

\subsection{Decomposição bojo/disco}

A distribuição de luz em galáxias pode ser estudada através de perfis radiais de brilho superficial, em geral, em unidades de magnitudes por segundo de arco ao quadrado. Estes podem ser decompostos, para galáxias espirais, em 2 componentes: uma que se refere ao bojo, e outra correspondente ao disco. A função que mais se utiliza para descrever a componente disco do perfil de brilho superficial de uma galáxia espiral é uma função exponencial, também conhecida como perfil de King (ver Mihalas \& Binney 1981). Esta função pode ser descrita como:

$$
\Sigma_{d}(r)=\Sigma_{0} e^{-r / h}
$$

em luminosidade (erg $\left.s^{-1}\right)$. Ou como:

$$
\mu_{d}(r)=\mu_{0}+1.086 r / h
$$

em magnitudes. Nas equações acima, $\Sigma_{d}(r)$ e $\mu_{d}(r)$ representam o brilho superficial do disco em função da distância ao centro $r$. $\Sigma_{0}$ e $\mu_{0}$ representam o brilho superficial central do disco, e $h$ é o raio característico do disco.

Para a componente bojo, a função mais utilizada é aquela sugerida por de Vaucouleurs (ver Caon, Capaccioli \& D’Onofrio 1993 e referências aí contidas), descrita como: 


$$
\Sigma_{b}(r)=\Sigma_{e} 10^{-3.33\left[\left(r / r_{e}\right)^{1 / 4}-1\right]}
$$

em luminosidade, ou:

$$
\mu_{b}(r)=\mu_{e}+8.325\left[\left(r / r_{e}\right)^{1 / 4}-1\right]
$$

em magnitudes. Enquanto $\Sigma_{b}(r)$ e $\mu_{b}(r)$ indicam o brilho superficial do bojo em função da distância galactocêntrica $r, r_{e}$ é o raio efetivo do bojo, i.e., aquele que contém metade da luminosidade total da galáxia. $\Sigma_{e}$ e $\mu_{e}$ representam o brilho superficial efetivo, i.e., aquele na distância galactocêntrica $r_{e}$.

Embora a lei de de Vaucouleurs represente bem o perfil de brilho para galáxias elípticas, e também para alguns bojos, vários trabalhos mostraram que alguns bojos são melhor representados por um perfil puramente exponencial (e.g., de Jong 1996a). Nesse caso, torna-se interessante utilizar o perfil generalizado de de Vaucouleurs, proposto por Sérsic (Caon, Capaccioli \& D’Onofrio 1993 e referências aí contidas). O perfil de Sérsic é descrito como:

$$
\Sigma_{b}(r)=\Sigma_{e} 10^{-b_{n}\left[\left(r / r_{e}\right)^{1 / n}-1\right]}
$$

em luminosidade, ou:

$$
\mu_{b}(r)=\mu_{e}+c_{n}\left[\left(r / r_{e}\right)^{1 / n}-1\right]
$$

em magnitudes, onde $b_{n}=0.868 n+0.142$, e $c_{n}=2.5 b_{n}$, com $n$ denominado por índice de Sérsic. No caso em que $n$ é igual a 4 , temos a conhecida lei de de Vaucouleurs, enquanto que $n=1$ nos fornece uma lei exponencial semelhante àquela utilizada para descrever discos.

A inserção de mais um parâmetro livre para representar os perfis radiais de brilho superficial de galáxias espirais certamente produz melhores ajustes. Porém, uma motivação maior para se utilizar o perfil de Sérsic vem do fato de que o índice $n$ parece se correlacionar com alguns parâmetros fundamentais de galáxias, tais como a razão bojo/disco (Andredakis, Peletier \& Balcells 1995).

Como já foi mencionado, utilizamos um programa (de Souza 1997) para realizar a decomposição bojo/disco bi-dimensional nas 39 galáxias de nossa sub-amostra, adotando 
a equação 3.2 para a componente disco, e a equação 3.6 para a componente bojo. As imagens utilizadas por este programa são as imagens linearizadas do DSS, transformadas em uma matriz de dados, na qual cada posição (linha/coluna) representa um "pixel" da imagem, com o valor da intensidade no "pixel" correspondente.

Entretanto, para que o programa possa executar corretamente a minimização dos erros durante a decomposição, é necessário multiplicar a imagem do DSS em intensidade (linearizada e normalizada pelo fundo de céu local) por uma constante, de modo a converter o ruído estatístico na imagem em um ruído de caráter Poissônico, tal como em uma observação direta. Assim, definindo $I_{s}$ como a intensidade do céu $(\approx 1)$, e $\sigma_{s}$ o seu desvio padrão absoluto, precisamos multiplicar a imagem com valores em intensidade $I$ por uma constante $k$, obtendo então valores em contagens: $C=k I$. As contagens do céu seguirão a mesma expressão: $C_{s}=k I_{s}$, e o seu desvio padrão absoluto (i.e., o ruído na imagem), em contagens, é: $\sigma_{c s}{ }^{2}=k^{2} \sigma_{s}{ }^{2}$. Para que $\sigma_{c s}$ obedeça a estatística de Poisson, deve seguir a expressão: $\sigma_{c s}{ }^{2}=C_{s}$. Portanto, temos:

$$
{\sigma_{c s}}^{2}=k^{2} \sigma_{s}^{2}=C_{s}=k I_{s}
$$

Assim, podemos determinar $k$ :

$$
k=\frac{I_{s}}{\sigma_{s}{ }^{2}} .
$$

O valor da intensidade do céu, $I_{s}$, o desvio padrão absoluto do céu, em intensidade, $\sigma_{s}$, bem como a constante $k$, são determinados separadamente para cada galáxia, através da tarefa IMstatistics do pacote IRAF ("Image Reduction \& Analysis Facility"). Esta tarefa foi aplicada em 5 regiões distintas de cada imagem, nas quais se observa, essencialmente, somente o fundo de céu. Os valores medianos de cada parâmetro foram adotados. Antes de executar o programa, ainda é necessário subtrair a contribuição do fundo de céu. Para tanto, simplesmente subtraímos da imagem a constante $C_{s}=k I_{s}$. Além disso, objetos que não fazem parte de nossa análise, tais como, estrelas e galáxias de fundo (bem como defeitos na imagem), são retirados da imagem, através da tarefa IMEDIT do IRAF.

O programa contém vários parâmetros de entrada a serem fornecidos pelo usuário, entre eles:

- o tamanho do "pixel" em segundos de arco (igual a 1.7 para as imagens do DSS);

- os valores iniciais das coordenadas do centro da galáxia; 
- os valores iniciais do brilho superficial central do disco e do brilho superficial efetivo do bojo;

- os valores iniciais do raio característico do disco e do raio efetivo do bojo;

- os valores iniciais do ângulo de posição e da elipticidade de bojo e disco;

- o valor inicial do índice de Sérsic;

- e o valor do "seeing" (adotado como sendo igual a 1 "pixel").

Com estes valores e a matriz de dados correspondente à imagem da galáxia, o programa procura ajustar os perfis de disco e bojo (i.e., as equações 3.2 e 3.6, respectivamente), variando não somente os parâmetros dos perfis, mas também os parâmetros geométricos (elipticidade e ângulo de posição). A variação destes parâmetros é controlada de modo a maximizar a qualidade do ajuste. No ajuste, considera-se que as isofotas dos bojos e discos são elipses perfeitas, e que o disco se extende até o centro da galáxia. Assumimos que não existem erros residuais relativos à subtração do céu, mas apenas um ruído de caráter Poissônico na matriz de dados. Quando a variação na qualidade do ajuste cai abaixo de um certo limite de convergência, o programa é interrompido, gerando os parâmetros a seguir:

- os valores finais do brilho superficial central do disco e do brilho superficial efetivo do bojo;

- os valores finais do raio característico do disco e do raio efetivo do bojo;

- o valor final do índice de Sérsic;

- e as razões entre as luminosidades e os diâmetros de bojo e disco.

Desta forma, o programa é aplicado para cada galáxia cerca de 3 a 5 vezes, tipicamente. Isso porque é necessário variar os valores iniciais dos parâmetros de entrada, até encontrar o ajuste mais satisfatório. Isto decorre do caráter altamente não linear dos perfis de brilho, que, em alguns casos, gera soluções espúrias. Por exemplo, se existem barras ou braços espirais, a orientação do eixo maior da galáxia tende a sofrer variações muito bruscas, particularmente se esta está sendo vista de face.

É comum encontrar na literatura decomposições bojo/disco que utilizam somente uma dimensão ao longo da imagem da galáxia, em geral ao longo do seu eixo-maior. De toda a informação contida na imagem completa da galáxia, extrai-se um valor característico para se construir um perfil que se ajuste em uma única direção. Este método 
tem a vantagem de aumentar a razão sinal/ruído, mas perde toda a informação presente na imagem da galáxia, relativa a componentes não-axissimétricas, como barras, por exemplo. O ajuste bi-dimensional de modelos a imagens de galáxias tem poucos exemplos na literatura (e.g., de Jong 1996a e referências aí contidas). Apesar de o modelo utilizado neste trabalho não incluir uma barra, a técnica utilizando um ajuste bi-dimensional é certamente mais confiável do que um método uni-dimensional, não somente para galáxias barradas, que correspondem a $85 \%$ das galáxias em nossa sub-amostra, mas para galáxias em geral.

Com os parâmetros dos perfis ajustados, o programa constrói imagens artificiais da galáxia modelo, bem como do bojo e do disco separadamente. Em seguida, utilizando a tarefa ELLIPSE do IRAF, construímos os perfis de brilho da galáxia original, da galáxia modelo, do bojo e do disco, além dos perfis de elipticidade, ângulo de posição e do coeficiente de Fourier b4, para a galáxia original e para a galáxia modelo. O comportamento do coeficiente b4 indica o quanto as isofotas da galáxia são distintas de uma elipse perfeita. Um valor positivo para b4 indica isofotas com uma sub-componente "disky", enquanto que um valor negativo indica isofotas "boxy". Se b4 é igual a 0, então a isofota é uma elipse perfeita. Todo esse procedimento nos permite avaliar a qualidade do ajuste determinado pelo programa e ainda outros parâmetros estruturais da galáxia. Além disso, subtraímos da imagem original as imagens sintéticas, obtendo imagens residuais, com o objetivo de avaliar eventuais sub-estruturas.

A Figura 3.1 exibe os resultados da decomposição bojo/disco para a galáxia NGC 488, como um exemplo. Nesta figura, temos, da esquerda para a direita e de cima para baixo:

- imagem original (passada por um filtro mediano e transformada para brilho superficial) com o mapa isofotal sobreposto;

- imagem residual total (imagem original - modelo completo);

- imagem residual do disco (imagem original - modelo do bojo);

- imagem residual do bojo (imagem original - modelo do disco);

- perfis de brilho na banda V (em magnitudes por segundo de arco ao quadrado em função do raio em "pixels"):

- pontos com barras de erro: imagem original;

- linha com traços curtos: modelo do disco;

- linha com traços longos: modelo do bojo; 
- linha cheia: modelo completo;

- pontos com linha cheia: resíduo total em magnitudes por segundo de arco ao quadrado (imagem original - modelo +28 );

- perfis de elipticidade:

- pontos com barras de erro: imagem original;

- linha cheia: modelo completo;

- perfis do ângulo de posição:

- pontos com barras de erro: imagem original;

- linha cheia: modelo completo;

- perfis do coeficiente de Fourier b4:

- pontos com barras de erro: imagem original;

- linha cheia: modelo completo;

Para calibrar nossos dados, de modo a deixar nossos perfis compatíveis com as magnitudes observadas na literatura para as galáxias em nossa sub-amostra, utilizamos a tarefa IMEXAMine do IRAF. Com a tarefa IMEXAmine, calculamos a magnitude da galáxia, na imagem em contagens, em sete valores distintos de abertura, comparando os resultados com a magnitude $\mathrm{V}$ aparente publicada em LdV83,85 para as mesmas aberturas. A constante de calibração $C_{C}$ para cada galáxia é tomada como sendo a mediana das diferenças entre essas magnitudes, somada à constante de transformação para brilho superficial e subtraindo o termo de correção para a extinção Galáctica (ver seção 2.3.1), utilizando os mapas de Schlegel, Finkbeiner \& Davis (1998). Assim,

$$
C_{C}=\operatorname{mag}(L d V 83,85)-\operatorname{mag}(\operatorname{ImeXAmine})+5 \log _{10}(1.7)-3.1 \times E(B-V) .
$$

Muita informação pode ser extraída da Fig. 3.1. Em relação às imagens, vê-se prontamente que o bojo é dominante nessa galáxia. De fato, NGC 488 apresenta a maior razão entre as luminosidades de bojo e disco (igual a 3.1) entre as galáxias de nossa sub-amostra. Também se verifica que os braços espirais são mais aparentes nas imagens residuais, o que é esperado, já que os braços não são ajustados no modelo. Os perfis mostram que o ajuste alcançado é muito bom, e que o bojo segue um perfil puramente exponencial, semelhante ao disco. 

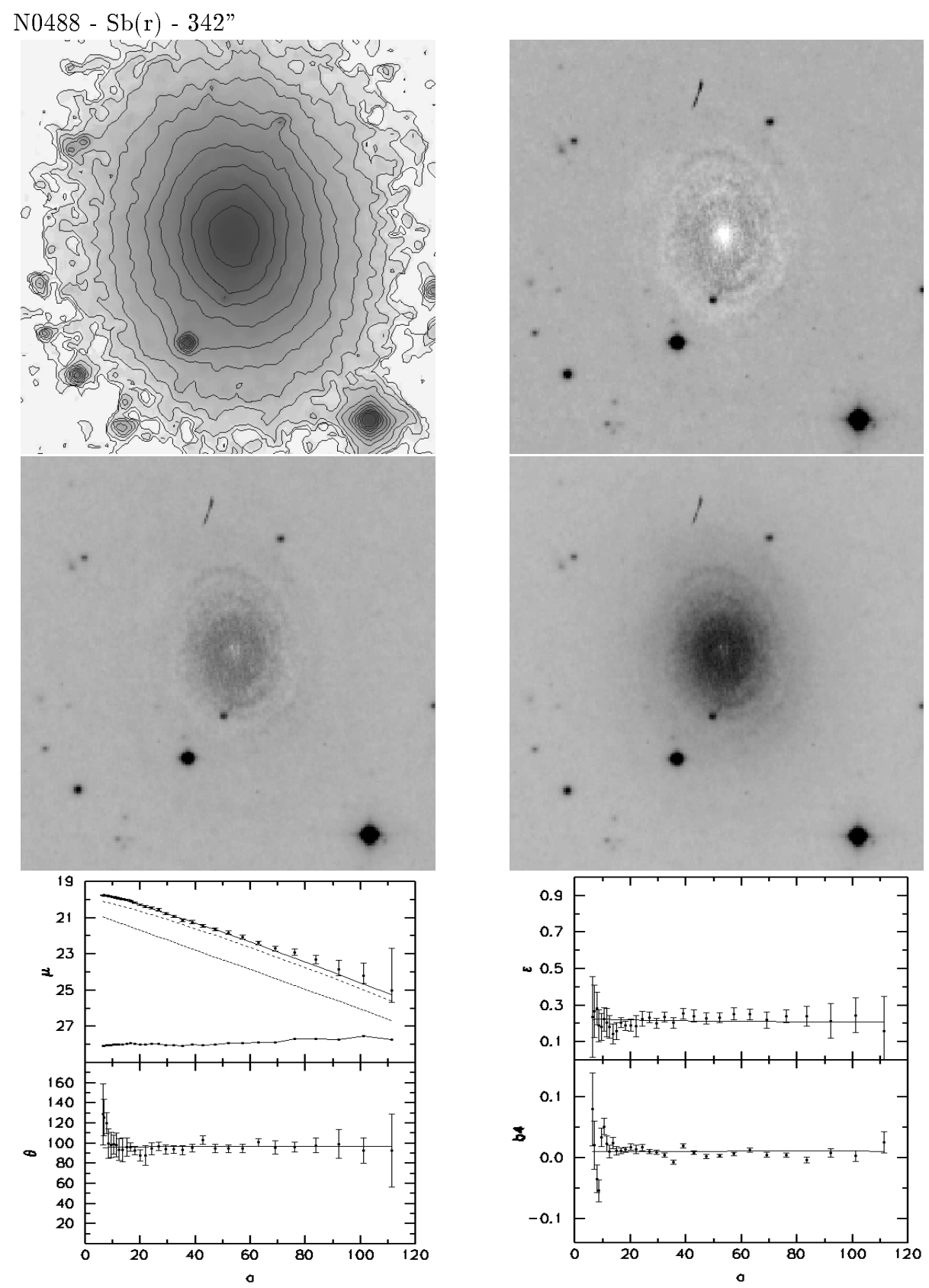

Figura 3.1: Resultados da decomposição bojo/disco para a galáxia Sb(r) NGC 488. No alto está especificada a dimensão das imagens em segundos de arco. Para legendas, ver texto. 


\subsection{Resultados}

A Tabela A.2 exibe os resultados da decomposição bojo/disco para as 39 galáxias de nossa sub-amostra. Como já foi dito, um dos objetivos deste estudo é o de verificar se existe uma correlação entre os gradientes de cor e as razões bojo/disco.

Verificamos que não há qualquer correlação entre as razões bojo/disco e os gradientes de cor. Uma possível explicação para a ausência dessa correlação em nossos dados pode vir do problema relacionado à saturação das imagens do DSS na região central da galáxias. O estudo que realizamos na próxima seção, comparando os resultados da decomposição bojo/disco em imagens do DSS e em imagens CCD, mostra que a saturação central nas imagens DSS afeta substancialmente os perfis de brilho das galáxias e, evidentemente, os perfis de bojos e discos. Veremos que o índice de Sérsic e os parâmetros característicos dos perfis dos discos são muito perturbados por esse problema. No entanto, veremos também que o raio efetivo do bojo é um parâmetro que pode ser determinado com certa confiabilidade através das imagens do DSS, e resulta em uma análise mais acurada.

Com a intenção de verificar o comportamento apontado por de Jong (1996b) e por Courteau, de Jong \& Broeils (1996), de que existe uma correlação entre as escalas de comprimento de bojos e discos em galáxias espirais, comparamos os raios efetivos dos bojos e os raios característicos dos discos que determinamos para as galáxias de nossa sub-amostra (Figura 3.2). Nesta figura, podemos ver que existe uma ligeira correlação, quando se considera toda a sub-amostra, i.e., $\mathrm{T}=3,4$ e 5 . Vemos que a correlação melhora substancialmente ao considerarmos somente as galáxias Sb's ( $\mathrm{T}=3$ ), e que não há correlação para o restante das galáxias ( $\mathrm{T}=4$ e $\mathrm{T}=5$ ). A correlação apresentada nos trabalhos citados acima também apresenta uma elevada dispersão, de modo que a correlação que apresentamos aqui pode ser considerada como uma confirmação desse resultado.

Na Figura 3.3, mostramos os parâmetros característicos dos perfis dos bojos em função dos gradientes de cor das galáxias. Os painéis superiores se referem ao brilho superficial efetivo na banda $\mathrm{V}$ em magnitudes por segundo de arco ao quadrado, e os painéis inferiores dizem respeito ao raio efetivo em segundos de arco. Vemos que existe uma fraca correlação, com elevada dispersão, ou seja, uma leve tendência, de as galáxias com gradientes nulos ou positivos apresentarem bojos com uma concentração central de luz elevada (i.e., um valor reduzido para o brilho superficial efetivo) tanto em (BV) quanto em (U-B). Apesar dos problemas já apontados, relativos à determinação do brilho superficial efetivo do bojo em imagens do DSS, essa leve tendência pode estar indicando que os efeitos de evolução secular, ao atenuar os gradientes de cor, contribuem também para que a distribuição de massa (e, portanto, luminosidade) no bojo seja mais concentrada. Além disso, vemos, nos painéis inferiores da Figura 3.3, que também há 

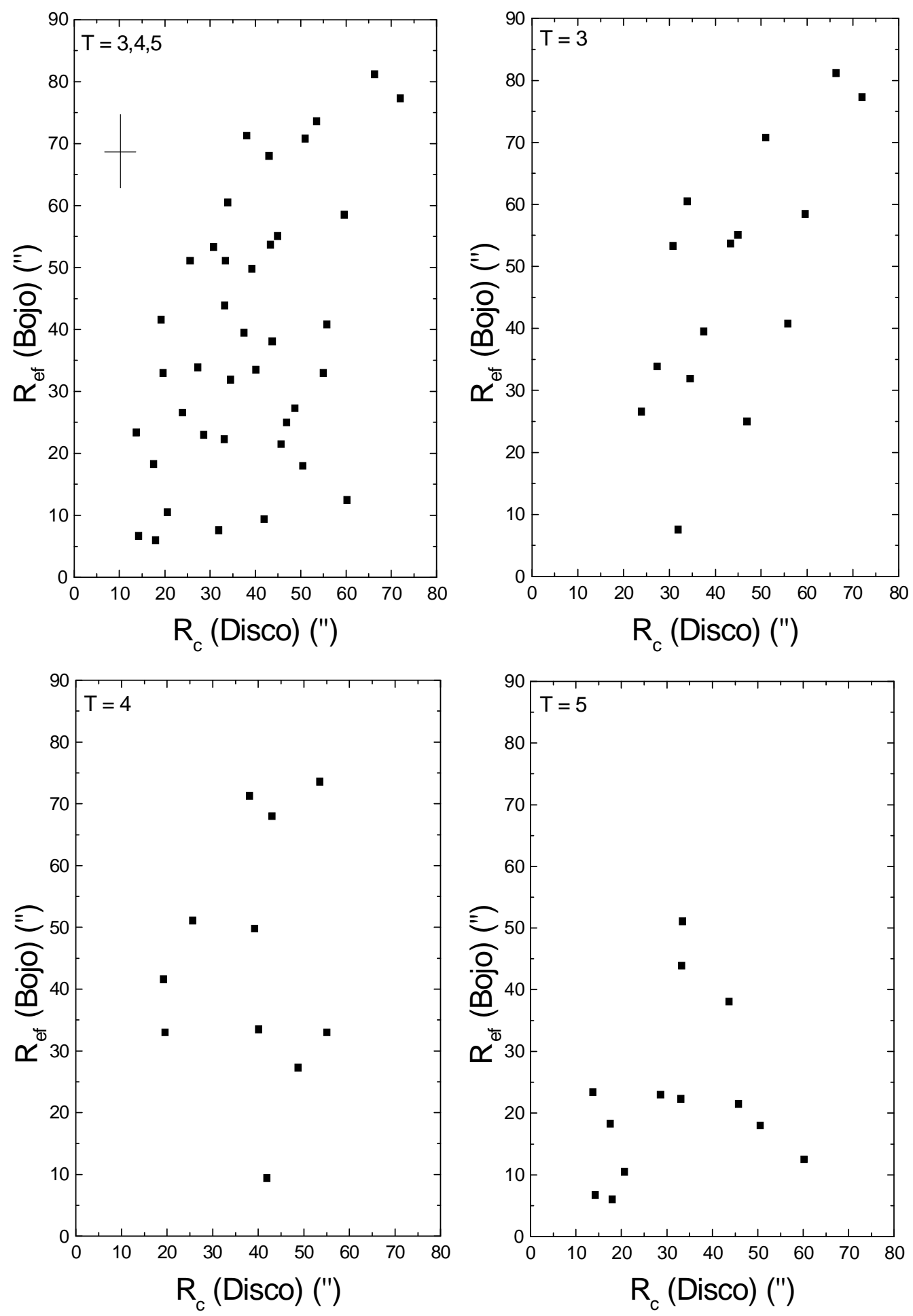

Figura 3.2: A correlação entre os raios efetivos de bojos e os raios característicos de discos. 

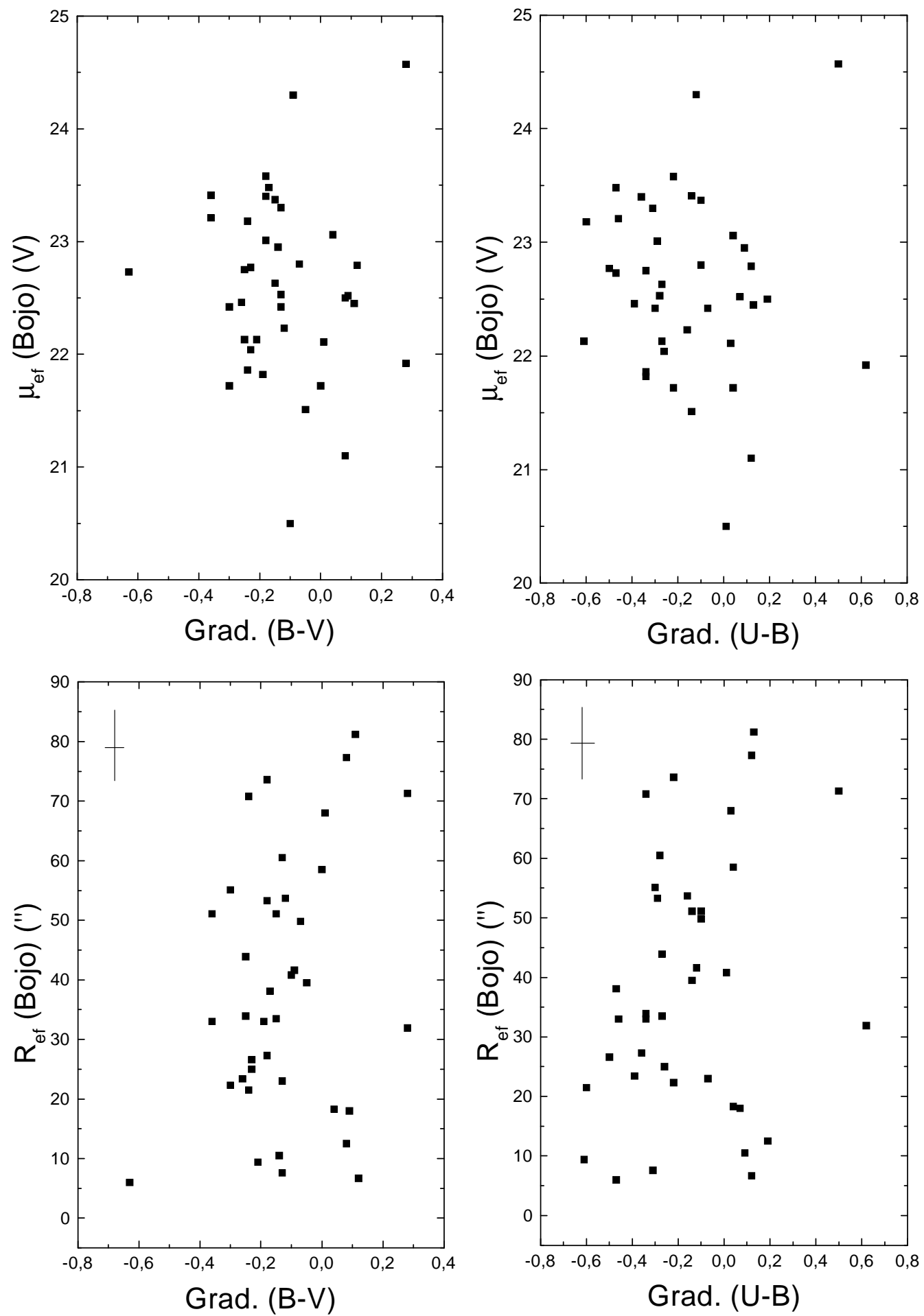

Figura 3.3: Parâmetros característicos dos perfis dos bojos em função dos gradientes de cor. 
uma leve tendência de as galáxias com gradientes nulos ou positivos apresentarem bojos maiores.

Também procuramos outras correlações possíveis entre os parâmetros adquiridos na decomposição bojo/disco e os gradientes de cor, bem como, com os índices de cor de bojos e discos. No entanto, nenhum resultado significativo pareceu-nos digno de nota.

\subsection{Observações no LNA}

Iremos apresentar, nesta seção, resultados obtidos através do imageamento em CCD de 14 galáxias de nossa amostra, realizado no Observatório do Pico dos Dias (OPD Brasópolis), junto ao Laboratório Nacional de Astrofísica (LNA - Itajubá).

Esse estudo nos permitirá fazer comparações com os resultados do Capítulos 2 e da seção anterior. No Capítulo 2, mostramos um estudo de gradientes de cor em galáxias, realizado através de medidas que se utilizaram de técnicas de fotometria fotoelétrica de abertura. Já nas seções anteriores, o estudo apresentado baseia-se em placas fotográficas digitalizadas. Assim, com os dados coletados no LNA, podemos comparar gradientes de cor obtidos através de fotometria fotoelétrica de abertura com aqueles obtidos no imageamento em CCD. Da mesma forma, vamos comparar os resultados da decomposição bojo/disco em imagens do DSS com os resultados da decomposição nas imagens em CCD por nós obtidas.

O restante desta seção assim segue. Na próxima subseção, descreveremos sucintamente a obtenção e o tratamento das imagens coletadas no LNA. A subseção 3.5.2 apresenta o estudo comparativo dos gradientes de cor e dos resultados na decomposição bojo/disco. A discussão e nossas conclusões acerca dos resultados desta seção são apresentadas na subseção 3.5.3.

\subsubsection{Aquisição e tratamento das imagens}

As observações fotométricas foram realizadas em Outubro de 1997, e em Julho e Agosto de 1998, no telescópio com espelho de 60 centímetros de diâmetro localizado no OPD-LNA. A óptica deste telescópio é do tipo Ritchey-Chrétien, e a razão focal no foco Cassegrain é f/13.5. Foi utilizada uma câmera direta do LNA, acoplada a um detector CCD SITe SI003AB, fino e retro-iluminado (o CCD número 101 do LNA). Este CCD possui 1024 por 1024 "pixels" com dimensão de 24 micrometros cada. Como a escala de placa é de 0.57 segundos de arco por "pixel", o campo total observado é de 
aproximadamente 10 por 10 minutos de arco. O ganho neste CCD é de 5 elétrons por ADU, com um ruído de leitura de 5.5 elétrons.

A Tabela 3.1 exibe um resumo das observações. Nesta tabela, mostramos as galáxias observadas em cada noite, bem como os filtros utilizados, o "seeing" (em segundos de arco $)^{1}$ e uma estimativa aproximada da qualidade fotométrica da noite.

Tabela 3.1: Resumo das observações.

\begin{tabular}{||ccccc||}
\hline \hline Noite & Galáxias & Filtros & "Seeing" (") & Qualidade Fotométrica? \\
\hline $27 / 10 / 97$ & $\mathrm{~N} 1637 ; \mathrm{N} 7479$ & $\mathrm{~B} ; \mathrm{V} ; \mathrm{R}$ & 1.0 & $\operatorname{sim}$ \\
$26 / 07 / 98$ & $\mathrm{~N} 151$ & $\mathrm{~B} ; \mathrm{V}$ & 1.8 & $\operatorname{sim}$ \\
$27 / 07 / 98$ & $\mathrm{~N} 7496 ; \mathrm{N} 7531$ & $\mathrm{~B} ; \mathrm{V}$ & 1.8 & não \\
$17 / 08 / 98$ & $\mathrm{~N} 289$ & $\mathrm{~B} ; \mathrm{V}$ & 1.8 & não \\
$18 / 08 / 98$ & $\mathrm{~N} 782$ & $\mathrm{~B} ; \mathrm{V} ; \mathrm{R} ; \mathrm{I}$ & 1.5 & sim \\
& $\mathrm{N} 7314$ & $\mathrm{~B} ; \mathrm{V}$ & & não \\
$19 / 08 / 98$ & $\mathrm{~N} 613$ & $\mathrm{~B} ; \mathrm{V}$ & 1.5 & não \\
$20 / 08 / 98$ & $\mathrm{~N} 488 ; \mathrm{N} 7755$ & $\mathrm{~B} ; \mathrm{V}$ & 1.5 & \\
& $\mathrm{~N} 6769 ; \mathrm{N} 6923$ & $\mathrm{~B} ; \mathrm{V} ; \mathrm{R} ; \mathrm{I}$ & & - \\
\hline $22 / 07 / 98$ & $\mathrm{~N} 6890$ & $\mathrm{~B} ; \mathrm{V} ; \mathrm{R} ; \mathrm{I}$ & - & \\
\hline \hline
\end{tabular}

Nota: a galáxia NGC 6890 foi observada no telescópio com espelho de 1.6 metros do OPD-LNA, com o mesmo detector por nós utilizado.

A fotometria foi realizada em bandas largas, com os filtros B, V, R e I do sistema de Cousins. Foram realizadas 6 exposições na banda B, 5 na banda $\mathrm{V}$ e 3 nas bandas $\mathrm{R}$ e I, tipicamente. A realização de exposições múltiplas tem o objetivo de facilitar a remoção de raios cósmicos, bem como de evitar imagens com artifícios provocados pelo mal acompanhamento do telescópio. O tempo de integração em cada exposição é de 300 segundos. Com o intuito de realizar a fotometria absoluta de cada galáxia, utilizamos as estrelas-padrão publicadas em Graham (1982). Na Tabela 3.2, exibimos as estrelaspadrão observadas em cada noite, bem como os coeficientes de calibração em cada filtro, para cada noite, calculados através da tarefa IMEXAMINE do IRAF.

Os coeficientes de calibração para cada estrela-padrão, $C_{C}$, foram calculados através da seguinte relação:

$$
C_{C}=\operatorname{mag}(\text { Graham })-\operatorname{mag}(\text { instrum. })+k x,
$$

\footnotetext{
${ }^{1} \mathrm{O}$ "seeing" é uma deformação na imagem, provocada pela turbulência atmosférica. Seu valor pode ser estimado como sendo a largura a meia altura no perfil Gaussiano de uma estrela.
} 
Tabela 3.2: Resumo das calibrações fotométricas.

\begin{tabular}{|c|c|c|c|c|c|}
\hline Noite & Estrelas & $C_{C}(\mathrm{~B})$ & $C_{C}(\mathrm{~V})$ & $C_{C}(\mathrm{R})$ & $C_{C}(\mathrm{I})$ \\
\hline $27 / 10 / 97$ & $\begin{array}{l}\text { 18-N-E2 } \\
34-\mathrm{S}-\mathrm{E} 3\end{array}$ & - & - & $20.30 \pm 0.03$ & - \\
\hline $26 / 07 / 98$ & $\begin{array}{c}39-\mathrm{S}-\mathrm{E} 8 \\
47-\mathrm{V}-\mathrm{E} 8 \\
48-\mathrm{W}-\mathrm{E} 8 \\
18-\mathrm{P}-\mathrm{E} 8\end{array}$ & $19.56 \pm 0.06$ & $19.79 \pm 0.03$ & - & - \\
\hline $27 / 07 / 98$ & $\begin{array}{c}20-\mathrm{Q}-\mathrm{E} 1 \\
44-\mathrm{S}-\mathrm{E} 1\end{array}$ & $19.58 \pm 0.03$ & $19.86 \pm 0.04$ & - & - \\
\hline $17 / 08 / 98$ & $\begin{array}{c}39-\mathrm{S}-\mathrm{E} 8 \\
47-\mathrm{V}-\mathrm{E} 8 \\
48-\mathrm{W}-\mathrm{E} 8 \\
18-\mathrm{P}-\mathrm{E} 8\end{array}$ & $19.63 \pm 0.05$ & $19.82 \pm 0.09$ & - & - \\
\hline $18 / 08 / 98$ & $\begin{array}{c}39-\mathrm{S}-\mathrm{E} 8 \\
47-\mathrm{V}-\mathrm{E} 8 \\
48-\mathrm{W}-\mathrm{E} 8 \\
18-\mathrm{P}-\mathrm{E} 8\end{array}$ & $19.75 \pm 0.10$ & $19.96 \pm 0.08$ & $20.06 \pm 0.03$ & $19.59 \pm 0.03$ \\
\hline $19 / 08 / 98$ & $\begin{array}{c}20-\mathrm{Q}-\mathrm{E} 1 \\
35-\mathrm{R}-\mathrm{E} 1 \\
44-\mathrm{S}-\mathrm{E} 1\end{array}$ & $19.41 \pm 0.13$ & $19.67 \pm 0.14$ & - & - \\
\hline $20 / 08 / 98$ & $\begin{array}{c}39-\mathrm{S}-\mathrm{E} 8 \\
47-\mathrm{V}-\mathrm{E} 8 \\
48-\mathrm{W}-\mathrm{E} 8 \\
18-\mathrm{P}-\mathrm{E} 8\end{array}$ & $19.76 \pm 0.03$ & $19.89 \pm 0.05$ & $20.02 \pm 0.03$ & $19.55 \pm 0.03$ \\
\hline $22 / 07 / 98$ & $\begin{array}{c}98-\mathrm{E} 6 \\
27-\mathrm{R}-\mathrm{E} 9\end{array}$ & $22.60 \pm 0.25$ & $22.61 \pm 0.27$ & $22.41 \pm 0.37$ & $22.30 \pm 0.42$ \\
\hline
\end{tabular}

Notas: infelizmente, na noite de 27/10/97 não foi possível realizar a observação de estrelas-padrão. Dessa forma, foi utilizada a constante de calibração da noite anterior. O erro apresentado para cada constante de calibração da noite corresponde ao desvio padrão nas constantes determinadas para cada estrela.

onde mag(Graham) é a magnitude da estrela fornecida por Graham (1982), $k$ é o coeficiente de extinção atmosférica e $x$ é a massa de ar (ver seção 2.1). mag(instrum.) é definido por:

$$
\operatorname{mag}(\text { instrum. })=-2.5 \log _{10} \frac{f}{t}
$$

$\operatorname{com} f$ sendo igual ao fluxo de energia irradiada (em ADU's) pela estrela em uma abertura igual à largura a meia altura de seu perfil Gaussiano, e $t$ sendo o tempo de exposição (ver seção 2.1). Os coeficientes $k$ para os filtros B, V, R e I, são, respectivamente, 0.28 , 0.16, 0.12 e 0.08, correspondendo aos valores de inverno determinados pela equipe técnica do LNA. Para cada noite, foi determinado um coeficiente de calibração médio, através 
daqueles calculados para cada estrela-padrão individualmente. O erro no coeficiente de calibração foi tomado como sendo o desvio padrão nos coeficientes determinados para cada estrela.

Para determinar o coeficiente de calibração para cada galáxia, já transformando os valores em magnitudes para brilho superficial, utilizamos a seguinte relação:

$$
C_{\mu}=2.5 \log _{10}(t)-k x+C_{C}+5 \log _{10}(l)-R \times E(B-V)
$$

onde $l$ é a dimensão do "pixel" em segundos de arco, e $R \times E(B-V)$ é a absorção em magnitudes provocada pela extinção Galáctica (ver seção 2.3.1). $E(B-V)$ foi extraído dos mapas de Schlegel, Finkbeiner \& Davis (1998), e o valor de $R$ nos filtros B, V, R e I, é, respectivamente, 4.1, 3.1, 2.3 e 1.5 (ver Binney \& Merrifield 1998).

Os CCD's são detectores que se caracterizam pela alta eficiência quântica, baixo ruído e alta sensibilidade. No entanto, certos procedimentos devem ser realizados no tratamento das imagens obtidas em CCD's. Esses procedimentos podem ser resumidos como se segue.

Eliminação do "bias". O "bias" é um mecanismo artificial, de origem eletrônica, que aumenta a eficiência da transferência de carga nos CCD's. Como o seu valor varia ligeiramente de "pixel" para "pixel", se obtém uma imagem de "bias" em uma exposição com tempo de integração igual a 1 segundo, e com o obturador fechado. Para melhorar a determinação da imagem de "bias", obtivemos 25 imagens em cada noite. Essas imagens foram combinadas, utilizando o valor médio em cada "pixel", através da tarefa ZEROCOMBINE do IRAF. A imagem final de "bias" deve ser subtraída de cada imagem a ser analisada.

Subtração do "dark current". Este é um sinal causado por elétrons térmicos e, portanto, proporcional ao tempo de integração. No nosso caso, este sinal pode ser desprezado.

Normalização pelo "flatfield". Trata-se de um mapeamento corretivo da variação da sensibilidade ao longo do CCD em exposições com fontes de luz uniformes. Normalmente, utiliza-se, como fonte de luz uniforme, regiões claras do céu ao nascer ou pôr do Sol, ou ainda, exposições tomadas na cúpula, iluminada com luz difusa. Obtivemos 25 imagens de "flatfield" por noite para cada filtro e, utilizando a tarefa FLATCOMBINE do IRAF, essas imagens foram combinadas, utilizando o valor médio em cada "pixel", normalizado pelo valor modal de cada imagem, para obter imagens finais de "flatfield". É necessário 
obter imagens de "flatfield" para cada filtro, pois a variação na sensibilidade do CCD é dependente da distribuição espectral da luz incidente. As imagens a serem analisadas devem ser divididas pela imagem de "flatfield" correspondente.

Cosmética. CCD's podem possuir alguns "pixels" "quentes", i.e., que saturam rapidamente. Estes podem ser eliminados por processos de interpolação linear, ou por mascaramento.

As imagens analisadas foram corrigidas do "bias" e do "flatfield", bem como cortadas das regiões não úteis do CCD, e corrigidas pelo "overscan" ${ }^{2}$, através da tarefa CCDPROC do IRAF.

Para eliminar raios cósmicos e aumentar a razão sinal/ruído das imagens a serem analisadas, utilizamos a tarefa IMCOMBINE do IRAF, combinando as exposições obtidas para cada galáxia, em cada filtro separadamente, utilizando o valor mediano em cada "pixel". Para determinar pequenos deslocamentos entre exposições sucessivas, cada imagem individual foi inspecionada, para determinar a posição de 3 estrelas de referência. Esses pequenos deslocamentos foram calculados pela tarefa IMCENTROID do IRAF, e utilizados pela tarefa IMCOMBINE na confecção da imagem combinada.

O passo seguinte consiste na subtração do fundo de céu. Para determinar a imagem do fundo de céu, inicialmente editamos a imagem combinada de cada galáxia, em cada filtro, retirando a galáxia e estrelas presentes, através da tarefa IMEDIT do IRAF. Em seguida, através da tarefa IMSTATISTICS, determinamos o valor médio da imagem editada, bem como o seu desvio padrão. Todos os valores que estavam fora dos limites valor médio $\pm 3 \times$ o desvio padrão, foram substituídos pelo valor médio, através da tarefa IMREPLACE. Utilizando a tarefa IMSURFIT, ajustamos um polinômio de Legendre de grau 2 (que corresponde a um ajuste linear) à imagem assim obtida, o que nos fornece uma imagem sintética do fundo de céu. Da imagem combinada de cada galáxia subtraímos a imagem sintética do fundo de céu. A imagem com o céu subtraído foi então editada, eliminando-se os objetos que não pertencem à nossa análise, tais como estrelas e regiões Hı presentes na galáxia. Obtivemos, assim, a imagem final de cada galáxia, em cada filtro, pronta para ser estudada.

\footnotetext{
${ }^{2} \mathrm{O}$ "overscan" é uma correção adicional ao "bias". Trata-se de uma região do CCD que não é exposta à luz incidente, mesmo durante uma exposição normal. Desse modo, é análogo ao "bias", mas com um tempo de exposição longo, e determinado no momento da aquisição da imagem a ser analisada.
} 


\subsubsection{O estudo comparativo}

Para determinar os gradientes de cor das galáxias por nós observadas é necessário, inicialmente, calcular o perfil radial de brilho superficial de cada galáxia, em cada filtro utilizado. Para tanto, utilizamos a tarefa ELLIPSE do IRAF. Essa tarefa ajusta isofotas (níveis de mesma intensidade) à imagem da galáxia em estudo, gerando uma tabela com 26 informações, entre essas, a intensidade média, o ângulo de posição, a elipticidade, e o coeficiente de Fourier b4 (ver seção 3.3). Inicialmente, a ELLIPSE foi executada com os centros das isofotas livres, para uma melhor determinação do centro da galáxia. Este foi então fixo para a execução final da tarefa. Adicionando o valor de $C_{\mu}$ à intensidade média de cada isofota, obtivemos os perfis de brilho superficial desejados.

No entanto, os perfis obtidos com o IRAF consistem do brilho superficial em função do raio em "pixels". Esses perfis foram então transformados para as unidades adotadas em LdV83,85 e também no Capítulo 2, i.e., o brilho superficial (em magnitudes por segundo de arco ao quadrado) em função do logaritmo do raio em unidades de 0.1 minutos de arco. Posteriormente, subtraímos os perfis em cada banda, para obtermos perfis dos índices de cor. Obtivemos, portanto, uma tabela semelhante àquela que elaboramos com os dados do LdV83,85, para cada galáxia. Por fim, utilizamos o programa Progress da mesma forma que no Capítulo 2, determinando os gradientes de cor para cada galáxia. Estes são apresentados na Tabela 3.3.

Com os dados apresentados na Tabela 3.3, nota-se que, para 7 das 14 galáxias, os gradientes determinados através das imagens em CCD são os mesmos (dentro dos erros) aos determinados através dos dados de fotometria fotoelétrica de abertura do LdV83,85. Considerando as 3 categorias de gradientes que definimos na seção 2.4.2, os gradientes de 12 das 14 galáxias continuam na mesma categoria na fotometria em CCD. Duas galáxias, NGC 488 e NGC 6769, apresentam grandes discrepâncias. No entanto, na Tabela 3.1 se vê que ambas foram observadas em uma mesma noite, de qualidade não-fotométrica. A Figura 3.4(a) mostra os gradientes (B-V) obtidos através dos dados do LdV83,85 em função daqueles obtidos através do imageamento CCD. A linha cheia representa perfeita equivalência. Nota-se uma boa correlação, o que dá suporte aos resultados da análise dos gradientes, discutidos no Capítulo 2.

Para 6 das 14 galáxias observadas por nós no LNA realizamos a decomposição bojo/disco, utilizando imagens do DSS (ver Capítulo 3). São elas: NGC 151, NGC 289, NGC 488, NGC 613, NGC 7479 e NGC 7755. Utilizamos os mesmos procedimentos aplicados às imagens do DSS na decomposição bojo/disco dessas 6 galáxias, ao utilizar as imagens em CCD. As Figuras 3.4 e 3.5 apresentam as comparações entre os resultados da decomposição bojo/disco em imagens DSS e em imagens CCD. Mais uma vez, a linha 

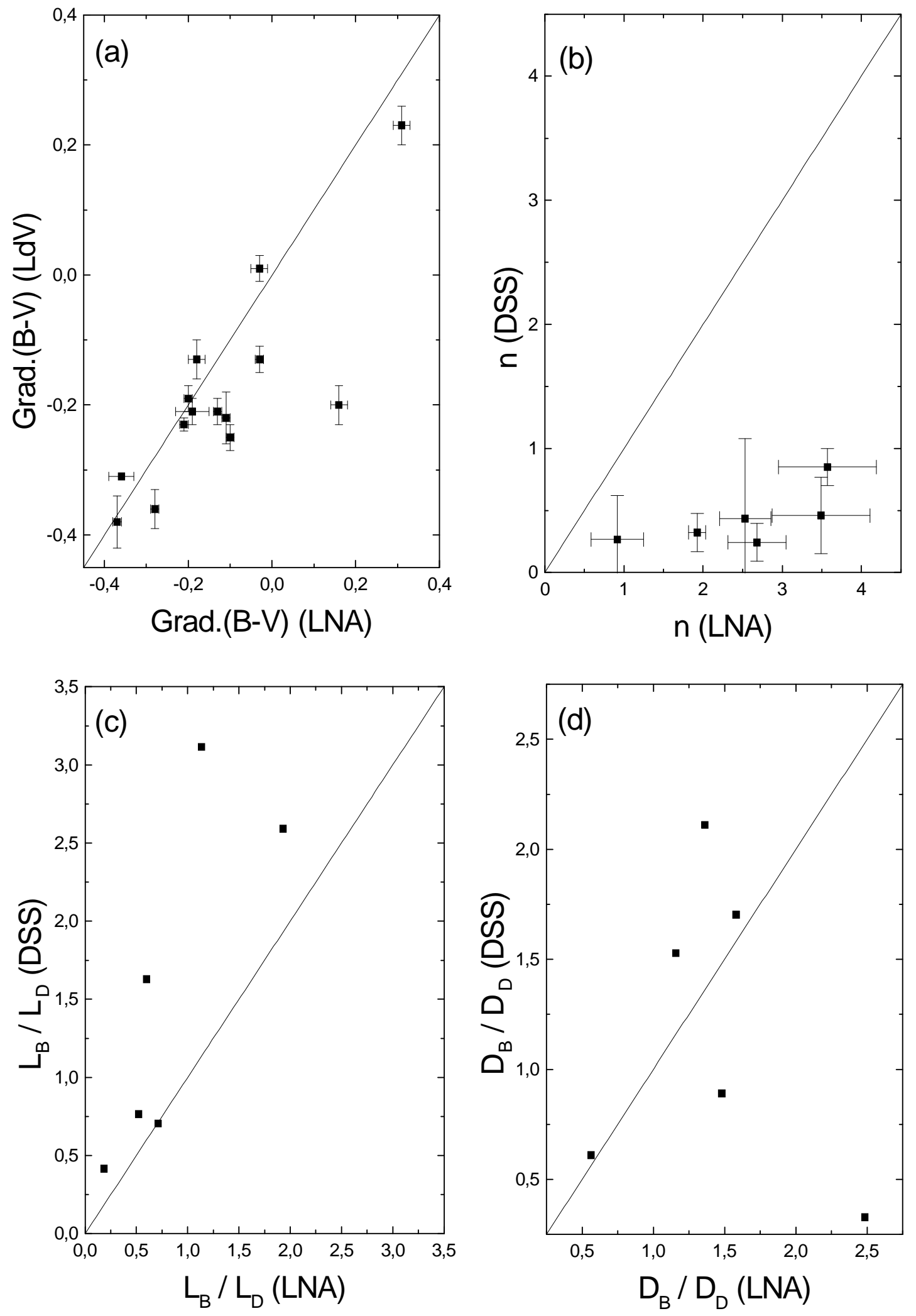

Figura 3.4: (a): comparação entre os gradientes obtidos dos dados do LdV83,85 e aqueles determinados através do imageamento em CCD. (b), (c) e (d): comparação entre os índices de Sérsic e as razões bojo/disco determinados nas imagens DSS e no imageamento CCD. A linha cheia representa perfeita equivalência. 
Tabela 3.3: Gradientes de cor.

\begin{tabular}{||ccccc||}
\hline \hline Galáxia & $G(B-V)(\mathrm{LdV})$ & $G(B-V)$ & $G(B-R)$ & $G(V-I)$ \\
\hline N151 & -0.36 & -0.28 & - & - \\
N289 & -0.19 & -0.20 & - & - \\
N488 & -0.13 & -0.03 & - & - \\
N613 & 0.01 & -0.03 & - & - \\
N782 & -0.31 & -0.36 & -0.47 & -0.10 \\
N1637 & -0.22 & -0.11 & - & - \\
N6769 & -0.20 & 0.16 & -0.17 & -0.18 \\
N6890 & -0.21 & -0.19 & -0.17 & -0.06 \\
N6923 & -0.38 & -0.37 & -0.42 & -0.28 \\
N7314 & -0.21 & -0.13 & - & - \\
N7479 & -0.25 & -0.10 & - & - \\
N7496 & 0.23 & 0.31 & - & - \\
N7531 & -0.23 & -0.21 & - & - \\
N7755 & -0.13 & -0.18 & - & - \\
\hline \hline
\end{tabular}

Notas: a primeira coluna identifica a galáxia; na segunda, apresentamos o gradiente de cor (B-V) obtido no Capítulo 2, e, na terceira, aquele determinado com as imagens adquiridas no LNA. As demais colunas exibem os gradientes em outros índices de cor, também determinados com as imagens adquiridas no LNA. O erro típico é de $0.02-0.03$ magnitudes.

cheia representa perfeita equivalência.

A Figura 3.4(b) apresenta a comparação entre os índices de Sérsic. Verifica-se prontamente que os índices obtidos em imagens DSS são sempre menores que aqueles nas imagens CCD, além de apresentarem uma faixa de valores expressivamente mais estreita. Este comportamento reflete muito provavelmente o fato de que a saturação das placas do DSS afetam o perfil de luminosidade do bojo, tornando-o muito mais achatado do que de fato o é. Na Figura 3.4(c), comparamos as razões entre as luminosidades de bojo e disco, e na Figura 3.4 (d) as razões entre os diâmetros de bojo e disco. Não há barras de erro, pois esses valores são calculados através das imagens-modelo. Apesar de ser uma amostra estatisticamente pequena, nota-se, em ambas as comparações, que a distribuição dos pontos exibe uma clara tendência de que o comportamento das razões bojo/disco é aproximadamente o mesmo, tanto nas imagens DSS, quanto nas imagens CCD. Ou seja, valores elevados para as razões bojo/disco nas imagens DSS também resultam ser mais elevados nas imagens CCD, o mesmo ocorrendo com os valores baixos. No entanto, há um ponto que se faz excessão, correspondente à galáxia NGC 289. Verifica-se, além disso, que as razões entre as luminosidades de bojo e disco obtidas através das imagens do DSS tendem a ser maiores que aquelas obtidas através do imageamento em CCD.

Nas Figuras 3.5(a) e (b), apresentamos as comparações entre os parâmetros ca- 

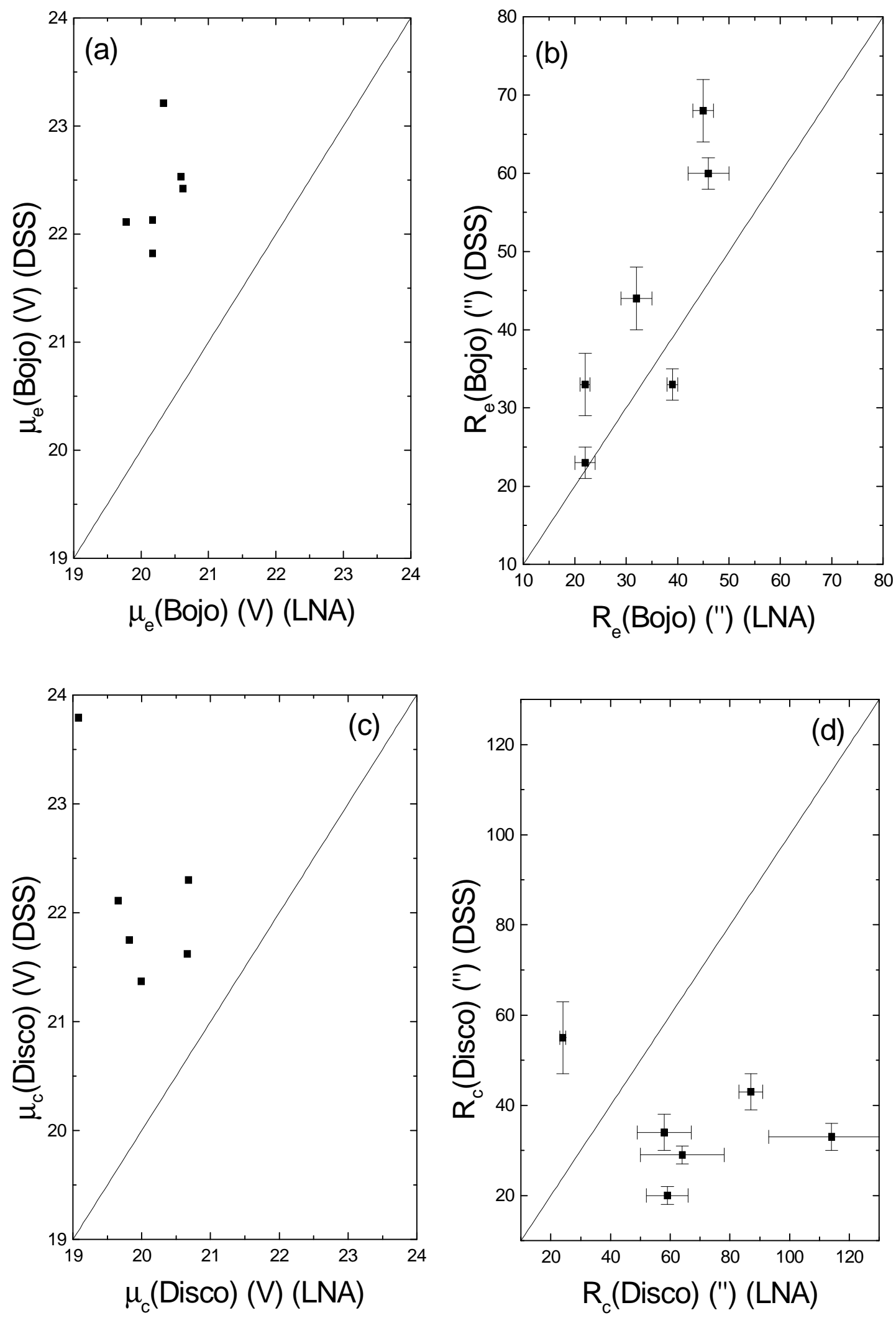

Figura 3.5: Comparações entre os parâmetros característicos dos perfis de bojos e discos obtidos através da decomposição em imagens DSS e no imageamento CCD. A linha cheia representa perfeita equivalência. 
racterísticos dos perfis dos bojos, enquanto que as Figuras 3.5(c) e (d) se referem aos parâmetros característicos dos perfis dos discos. A Figura 3.5(a) mostra que o brilho superficial efetivo do bojo, na banda $\mathrm{V}$, em magnitudes por segundo de arco ao quadrado, determinado nas imagens DSS, é sempre maior que aquele determinado nas imagens CCD. Os pontos estão substancialmente afastados da linha de equivalência. Entretanto, bojos com alta concentração central de luz (i.e., valores baixos para o brilho superficial efetivo) nas imagens DSS, também têm essa propriedade nas imagens CCD. O mesmo ocorre em bojos com pequena concentração central de luz, ou seja, valores elevados para o brilho superficial efetivo. A Figura 3.5(b) exibe a comparação dos raios efetivos (em segundos de arco) dos bojos. Nota-se, mais uma vez, que o comportamento deste parâmetro é o mesmo, tanto nas imagens DSS, quanto nas imagens em CCD. Também pode-se notar que o raio característico dos bojos tende a ser maior nas imagens do DSS. A comparação dos raios efetivos dos bojos mostra que este parâmetro é mais confiável de ser determinado nas imagens do DSS do que o brilho superficial efetivo do bojo, apesar de ser sistematicamente maior que o valor mais acurado determinado a partir da fotometria CCD.

A Figura 3.5(c) mostra que o brilho superficial central dos discos (na banda V, em magnitudes por segundo de arco ao quadrado) determinado em imagens do DSS é também sempre maior que aquele determinado no imageamento CCD. Mais uma vez, os pontos estão substancialmente afastados da linha de equivalência. Com excessão de um único ponto, que corresponde, mais uma vez, à galáxia NGC 289, verifica-se que a amplitude da faixa de valores é bastante semelhante tanto nas imagens do DSS quanto naquelas em CCD, sendo pouco maior do que 1 magnitude por segundo de arco ao quadrado. A Figura $3.5(\mathrm{~d})$ mostra que os raios característicos dos discos (em segundos de arco) nas imagens DSS tendem a ser expressivamente menores do que aqueles obtidos com as imagens CCD. Esta comparação mostra que a dimensão do disco em imagens DSS deve estar afetada pelo processo de subtração do fundo de céu.

\subsubsection{Discussão e conclusões acerca do estudo comparativo}

A princípio, deveríamos esperar que os gradientes de cor em galáxias, determinados através de fotometria fotoelétrica de abertura (como são aqueles obtidos no Capítulo 2, através dos dados do $\mathrm{LdV83,85)}$ tivessem valores menos pronunciados do que aqueles calculados através de fotometria em CCD.

Imaginemos o caso de uma galáxia com o típico gradiente negativo, ou seja, com um índice de cor central maior (mais avermelhado) do que o seu índice de cor periférico, mais azulado. Em se tratando de dados obtidos através de fotometria de abertura, a maior abertura pela qual se realiza a fotometria da galáxia não contém somente a região 
periférica desta (mais azulada), mas também contém a região central, mais avermelhada. De fato, a maior abertura utilizada permite, em geral, que a luz de toda a galáxia atinja o detector. Portanto, em fotometria de abertura, o índice de cor atribuído à região periférica da galáxia em questão não é tão distinto do índice da região central. No caso do imageamento em CCD, o índice de cor medido na região periférica não sofre essa perturbação vinda da luz emitida pela região central da galáxia. Dessa forma, os gradientes de cor calculados no imageamento em CCD são, a princípio, mais acentuados do que aqueles obtidos através de dados em fotometria de abertura. Essa conclusão permanece inalterada para o caso do mais incomum gradiente positivo. No entanto, para galáxias com um índice de cor constante desde a região central até a região periférica, o gradiente de cor obtido será nulo tanto no caso da fotometria de abertura, quanto no imageamento em CCD.

Entretanto, os resultados apresentados na Tabela 3.3 e na Figura 3.4(a) mostram que os gradientes de cor em galáxias, calculados através da fotometria em CCD, são essencialmente equivalentes àqueles determinados por fotometria fotoelétrica de abertura. Portanto, o efeito da perturbação do índice de cor periférico da galáxia, em fotometria de abertura, parece poder ser desprezado. Esse resultado é coerente com aquele apresentado nos dois diagramas inferiores da Figura 2.10, nos quais se compara os gradientes por nós determinados com aqueles obtidos em PH98. Como, nesse último trabalho, também foram utilizados dados obtidos no imageamento em CCD, esses diagramas são, ainda que de maneira mais indireta, também uma comparação entre os gradientes obtidos por fotometria de abertura e aqueles determinados no imageamento em CCD.

Além disso, não se nota, na Figura 3.4(a), qualquer diferença sistemática entre os gradientes obtidos na Capítulo 2 (i.e., por fotometria de abertura) e os gradientes obtidos no presente capítulo (por imageamento em CCD).

Esses resultados indicam que o estudo apresentado aqui permaneceria essencialmente o mesmo, fossem os gradientes de cor determinados através do imageamento em CCD no lugar dos dados extraídos do LdV83,85.

Vejamos agora os resultados referentes à decomposição bojo/disco. A Figura 3.4(b) mostra que o índice de Sérsic para o bojo, calculado pelas imagens do DSS, é sempre menor do que aquele calculado pelas imagens em CCD. Em particular, as imagens do DSS sugerem índices sempre menores do que 1, o que corresponde a um perfil inicialmente relativamente plano, com uma queda posterior. Por outro lado, as imagens em CCD fornecem índices que variam de 1 (perfil puramente exponencial) a 4 (lei de de Vaucouleurs). Esse resultado é esperado, já que sabemos que as imagens do DSS, por serem obtidas em exposições profundas, sofrem de saturação na região central (mais brilhante) 
das galáxias. De fato, os perfis determinados para os bojos na decomposição bojo/disco nas imagens do DSS são bastante distintos nas imagens em CCD. Portanto, as imagens do DSS não nos fornecem valores confiáveis para o índice de Sérsic do bojo. Evidentemente, esse efeito perturba também os outros parâmetros característicos do bojo, bem como os do disco.

A Figura 3.4(c) mostra que existe uma correlação relativamente boa entre a razão bojo/disco (luminosidade) determinada em imagens DSS e aquela determinada em imagens CCD. No entanto, há uma tendência de os bojos nas imagens DSS serem mais luminosos. Esse efeito está relacionado ao problema mencionado no parágrafo acima, referente ao índice de Sérsic, e também pode ser avaliado em conjunto com as Figuras 3.4(d) e 3.5(a) e (b). O fato de os bojos nas imagens DSS possuírem índices de Sérsic menores do que 1, significa que seus perfis não possuem o característico aumento abrupto nas regiões centrais, como no caso de um perfil mais próximo ao de de Vaucouleurs. Assim, os bojos nas imagens DSS têm uma menor concentração central de luz, o que é o que de fato mostra a Figura 3.5(a). Assim sendo, é de se esperar que os raios efetivos dos bojos sejam maiores nas imagens DSS, como se pode verificar na Figura 3.5(b). Por fim, a razão bojo/disco (diâmetro) determinada em imagens do DSS também deve ser afetada, no sentido de os bojos serem maiores nas imagens do DSS. É o que mostra a Figura 3.4(d).

Entretanto, apesar de os parâmetros característicos de bojo e disco serem afetados substancialmente pela saturação central das imagens do DSS, as Figuras 3.4(c) e (d) mostram que existe uma correlação relativamente boa entre as razões bojo/disco determinadas em imagens DSS e aquelas determinadas em CCD. De fato, os bojos mais luminosos, ou maiores, nas imagens do DSS, também o são nas imagens em CCD. O mesmo ocorre com o brilho supeficial efetivo do bojo (Figura 3.5(a)) e o raio efetivo do bojo (Figura 3.5(b)). Portanto, embora os efeitos da saturação central nas imagens do DSS não possam ser deprezados, os resultados da decomposição bojo/disco em imagens do DSS são coerentes com aqueles em que o imageamento CCD é utilizado.

O efeito da sub-estimativa para o índice de Sérsic dos bojos nas imagens do DSS nos parâmetros característicos dos discos pode ser avaliado através das Figuras 3.5(c) e (d). Observa-se que o brilho superficial central dos discos, bem como seus raios característicos, são menores, i.e., os discos são menos luminosos nas imagens DSS, em concordância com as Figuras 3.4(c) e (d) e com o discutido nos parágrafos acima. Por outro lado, o espalhamento dos pontos nos parâmetros característicos dos discos é maior do que nos dos bojos (Figuras 3.5(a) e (b)) e, com o pequeno número de pontos (seis), torna-se difícil afirmar se existe ou não uma correlação entre os parâmetros determinados com as imagens do DSS e aqueles determinados através do imageamento CCD. 
A conclusão geral que extraímos do estudo comparativo realizado nesta seção pode ser resumida no seguinte. Os resultados e conclusões apresentados no estudo dos gradientes de cor (Capítulo 2) permaneceriam essencialmente os mesmos se, ao invés de utilizarmos dados obtidos através de fotometria de abertura, tivéssemos utilizado imagens em CCD para a determinação dos gradientes de cor das 257 galáxias de nossa amostra. Mais ainda, os resultados e conclusões (de caráter qualitativo) obtidos na decomposição bojo/disco das 39 galáxias de nossa sub-amostra (Capítulo 3) não sofreriam mudanças fundamentais, fossem as imagens que utilizamos obtidas com CCD's no lugar de placas fotográficas digitalizadas. Enfim, os resultados e conclusões apresentados nesta Dissertação permanecem essencialmente os mesmos se os dados aqui utilizados forem substituídos por dados obtidos através da mais moderna e acurada técnica de imageamento em CCD.

\subsection{Discussão e conclusões}

Do estudo comparativo que apresentamos na seção anterior, podemos concluir que, apesar da saturação que as imagens do DSS apresentam na região central das galáxias, que influencia de maneira fundamental os parâmetros que obtivemos para os perfis de brilho de bojos e discos, podemos ressaltar certas conclusões com os dados que obtivemos.

Além do estudo comparativo, apresentamos, neste capítulo, 3 principais resultados referentes aos parâmetros obtidos na decomposição bojo/disco. O primeiro deles (Figura 3.2) diz respeito à correlação entre as escalas de comprimento de bojos e discos. Esta correlação foi identificada por de Jong (1996b) e por Courteau, de Jong \& Broeils (1996). Estes trabalhos utilizaram amostras de galáxias uma ordem de grandeza maiores do que a nossa, porém constituídas basicamente por galáxias espirais de tipo tardio. O método de decomposição utilizado nestes trabalhos foi variado. de Jong utilizou um método bidimensional, enquanto Courteau e Broeils utilizaram um método uni-dimensional. Quanto ao índice de Sérsic do bojo, de Jong utilizou um valor fixo ( $\mathrm{n}=1,2$ ou 4) que melhor se ajustava, mais um disco exponencial, enquanto Courteau e Broeils utilizaram $\mathrm{n}=$ 1 ou 4 (fixo) mais um disco exponencial. De qualquer forma, é interessante notar que conseguimos reproduzir a correlação observada, para as galáxias em nossa amostra com $\mathrm{T}=3$. Nos trabalhos de de Jong e de Courteau, de Jong \& Broeils não se faz menção a respeito de a correlação ser diferente entre tipos morfológicos distintos. A dispersão apresentada, tanto no nosso trabalho quanto nos acima citados, é elevada. Uma possível razão para essa elevada dispersão vem dos erros envolvidos nos métodos de decomposição, bem como nas hipóteses assumidas. Baggett, Baggett \& Anderson (1998) mostram que a diferença típica nos ajustes realizados por diferentes autores é da ordem de $100 \%$. A importância dessa correlação reside no fato de que ela mostra que a formação das 
componentes bojo e disco em galáxias espirais não ocorre de forma totalmente distinta e separada, como no cenário monolítico. Portanto, esta correlação tem sido invocada para corroborar o cenário de evolução secular, no qual as formações de bojo e disco estão vinculadas uma à outra.

O segundo resultado está apresentado na Figura 3.3 (painéis superiores). Vimos que existe uma leve tendência de as galáxias com gradientes nulos ou positivos apresentarem bojos com uma maior concentração central de luz, apesar de ser estatisticamente marginal. Esse resultado pode indicar que os efeitos de evolução secular, ao transportar material do disco para o bojo, não somente homogeneizam as populações estelares ao longo da galáxia, o que se reflete em gradientes de cor nulos ou positivos, mas também aumentam a concentração central de massa nos bojos, o que se reflete em uma maior concentração central de luz. Entretanto, esse resultado deve ser considerado com extremo cuidado, já que a dispersão é bastante elevada. Por outro lado, a Figura 2.12 apresenta um resultado análogo, com dados de PH98. Nesta figura, vemos que as galáxias que apresentam gradientes de cor nulos ou positivos também tendem a apresentar uma maior concentração central de luz. Nesse caso, porém, a concentração central de luz se refere ao perfil de brilho da galáxia como um todo, e não somente ao perfil do bojo separadamente.

Por fim, mostramos que as galáxias com gradientes de cor nulos ou positivos têm uma leve tendência a apresentar bojos maiores (Figura 3.3-painéis inferiores). Embora esse resultado também deva ser considerado com extremo cuidado, já que a correlação é bastante fraca, vimos que o raio efetivo do bojo é uma parâmetro que pode ser obtido com certa confiança das imagens do DSS. Esse resultado também é compatível com o cenário de evolução secular, já que nas galáxias em que os processos de evolução secular teriam ocorrido, ou seja, nas galáxias em que os gradientes de cor são atenuados, os bojos devem ser mais proeminentes dentro deste cenário. 


\section{Capítulo 4}

\section{Conclusões e perspectivas}

\subsection{Conclusões}

Realizamos um estudo estatístico da distribuição radial dos índices de cor $(\mathrm{B}-\mathrm{V})$ e (U-B) em uma amostra de 257 galáxias de tipos Sb, Sbc e Sc, ordinárias e barradas, utilizando dados da literatura, obtidos através de técnicas de fotometria fotoelétrica de abertura. Estes dados foram tratados utilizando métodos estatísticos robustos para determinar os gradientes de cor nas galáxias, bem como os índices de cor característicos de bojos e discos, separadamente. Podemos destacar, entre os resultados principais deste estudo:

1. Encontramos na amostra analisada 3 categorias de gradiente, com os respectivos percentuais: $65 \%$ das galáxias possuem gradientes de cor negativos, i.e., mais vermelhos na região central do que na região periférica, um comportamento que pode ser considerado normal. Cerca de $25 \%$ possuem gradientes de cor nulos e $10 \%$ possuem gradientes de cor positivos. Do total de $25 \%$ das galáxias que apresentam gradientes nulos, a família de galáxias barradas $(\mathrm{SAB}+\mathrm{SB})$ contribui com o percentual de aproximadamente $87 \%$ e $81 \%$ na cores $(\mathrm{B}-\mathrm{V})$ e (U-B), respectivamente. Portanto, as galáxias barradas estão super-representadas nesta categoria de objetos, indicando que a barra atua no sentido de homogeneizar a população estelar ao longo de galáxias espirais de tipo tardio.

2. Considerando o índice (B-V), 37\% das galáxias barradas possuem gradientes de cor nulos ou positivos, enquanto que $24 \%$ das galáxias ordinárias apresentam gradientes 
com essas propriedades. Por outro lado, considerando o índice (U-B), $47 \%$ das galáxias barradas possuem gradientes de cor nulos ou positivos, enquanto que apenas $19 \%$ das galáxias ordinárias têm essas categorias de gradientes. Esse resultado é análogo ao de que galáxias barradas parecem ter também tendência a apresentar gradientes da abundância O/H menos acentuados (MR94; ZKH94). Como os índices de cor representam a população estelar que domina a emissão de radiação, este resultado indica que as populações estelares de bojos e discos, em grande parte das galáxias barradas, são similares, ou ainda que a população do bojo é mais jovem do que a população do disco. Este resultado está em desacordo com modelos de formação de galáxias espirais que se baseiam exclusivamente no cenário monolítico de formação. Por outro lado, esse resultado está em acordo com o cenário de evolução secular para a formação e/ou construção de bojos, já que este cenário prevê que barras estelares atuam induzindo formação estelar central, e homogeneizando a população estelar ao longo de galáxias.

3. A cor ao longo das galáxias com gradientes de cor nulos é similar à cor dos discos das galáxias com gradientes de cor negativos, indicando portanto que as modificações ocorrem no bojo e não no disco. Este resultado também está de acordo com as previsões do cenário de evolução secular, e indica que deve haver um fluxo de gás das regiões periféricas para as regiões centrais de galáxias, que provoca surtos de formação estelar central, homogeneizando a população estelar ao longo de galáxias.

4. Confirmando os resultados obtidos por Peletier \& Balcells (1996), que indicam haver uma correlação entre os índices de cor (U-R), (B-R), (R-K) e (J-K) de bojos e discos em uma amostra de 30 galáxias espirais, encontramos, de maneira análoga, uma correlação entre os índices de cor $(\mathrm{B}-\mathrm{V})$ e (U-B) de bojos e discos para as galáxias em nossa amostra, que é substancialmente maior. Essa correlação tem sido utilizada para argumentar que as formações das componentes bojo e disco em galáxias espirais são eventos conexos, e que a diferença na idade das populações estelares de bojo e disco é pequena, favorecendo o cenário de evolução secular.

Os resultados acima citados favorecem o cenário de evolução secular, indicando que, mesmo após formados, os bojos são estruturas que evoluem. Estes resultados podem ser interpretados à luz da hipótese de recorrência de barras, sugerida por Norman, Sellwood \& Hasan (1996), e analisados no sentido de estimar a importância do cenário de evolução secular na formação e/ou construção de bojos e, portanto, na formação de galáxias. Admitindo que a fração de objetos em uma determinada fase de evolução é proporcional ao tempo de permanência nesta fase, mostramos que o tempo de vida de uma barra deve ser da ordem de 5 Giga-anos. Por outro lado, nossos resultados mostram que os processos de evolução secular, relacionados a barras, têm um papel fundamental na evolução de pelo 
menos $35 \%$ das galáxias espirais brilhantes de tipo tardio.

Além disso, realizamos a decomposição dos perfis de brilho de 39 galáxias de nossa amostra, em perfis de brilho separados, para bojos e discos, através de um algoritmo bidimensional (de Souza 1997) aplicado a imagens do DSS, obtendo parâmetros estruturais característicos dos bojos e discos destas galáxias. Estes parâmetros foram explorados em conjunto com os gradientes de cor das galáxias e os índices de cor de bojos e discos, determinados na primeira etapa do trabalho. Os principais resultados obtidos nesta etapa podem ser assim resumidos:

1. Galáxias com gradientes de cor nulos ou positivos têm uma leve tendência a apresentarem bojos maiores e com maior concentração central de luz. Estes resultados podem estar indicando que os processos de evolução secular, ao transportar material do disco para o bojo, não somente homogeneizam as populações estelares destas componentes, como também contribuem para a formação e/ou construção de bojos mais proeminentes e com uma distribuição de massa mais concentrada. Entretanto, estes resultados têm de ser avaliados com extremo cuidado, já que a dispersão apresentada é bastante significativa, e requerem testes mais conclusivos.

2. Confirmando os resultados apresentados por de Jong (1996b) e Courteau, de Jong \& Broeils (1996), que indicam haver uma correlação entre as escalas de comprimento de bojos e discos em galáxias espirais de tipo tardio, encontramos uma correlação entre o raio efetivo dos bojos e o raio característico dos discos das 39 galáxias de nossa sub-amostra. Essa correlação indica que as formações das componentes bojo e disco de galáxias espirais são eventos conexos, favorecendo, mais uma vez, o cenário de evolução secular.

Utilizando imagens em CCD, adquiridas no OPD/LNA-CNPq para 14 galáxias de nossa amostra, realizamos um estudo comparativo, a partir do qual pode-se concluir que:

1. Os gradientes de cor determinados através de dados obtidos com uso de técnicas de fotometria fotoelétrica de abertura se correlacionam bem com os gradientes determinados através de imagens obtidas em CCD. Este resultado indica que aqueles resultados obtidos na análise do Capítulo 2 são robustos.

2. A saturação da qual sofrem as imagens do DSS na região central de galáxias brilhantes afeta de maneira fundamental os perfis de brilho destas galáxias. No entanto, estas imagens podem ser utilizadas para avaliar perfis de brilho em estudos estatísticos, i.e., que envolvem um número relativamente grande de objetos. Em particular, o raio efetivo do bojo é um parâmetro que pode-se obter através destas imagens com um bom grau de confiabilidade. 


\section{$4.2 \quad$ Perspectivas}

Pretendemos dar continuidade ao estudo da importância dos processos de evolução secular na evolução de galáxias, bem como na formação e/ou construção de bojos, e na relação dos processos dinâmicos e cinemáticos relacionados a barras e a atividade nuclear observada em galáxias com AGN's. Um estudo importante neste sentido será aplicar o que foi realizado neste trabalho para uma amostra de galáxias espirais de tipo jovem, i.e., S0's e Sa's. Não há até o momento estudos que indiquem que os processos de evolução secular ocorram nesta classe de galáxias. Por outro lado, outros estudos (e.g., Friedli \& Benz 1995) mostram que as barras em galáxias de tipo jovem têm propriedades distintas daquelas apresentadas por barras em galáxias de tipo tardio.

Em meu projeto de Doutoramento, pretendo realizar um estudo direto das principais famílias de órbitas periódicas em um potencial que modele a distribuição de massa em uma galáxia fortemente barrada, incluindo as órbitas que se afastam do plano do disco da galáxia, isto é, aquelas que dão à barra uma importante estrutura vertical. A estrutura vertical de barras estelares não tem sido estudada com freqüência na literatura. Com o conhecimento adquirido assim da cinemática de estrelas em barras, em órbitas que fujam ao plano do disco, poderemos criar um diagnóstico para identificar a estrutura vertical de barras em galáxias vistas de face. Esse diagnóstico será útil na solução de vários problemas, entre eles na compreensão das diferenças entre barras em galáxias de tipo jovem e aquelas em galáxias de tipo tardio. Ao obter espectros para uma amostra de galáxias fortemente barradas vistas de face, poderemos usar esse diagnóstico para, por exemplo, identificar barras recém-formadas. Realizando o imageamento das galáxias em nossa amostra nas bandas B, V, R, I e K, poderemos estudar a importância das barras na formação e/ou construção de bojos, buscando, portanto, vínculos para os modelos de formação e evolução de galáxias. 


\section{Referências}

Abraham, R.G., Valdes, F., Yee, H.K.C. \& van den Bergh, S.: 1994, ApJ, 432, 75

Abraham, R.G., Tanvir, N.R., Santiago, B.X., Ellis, R.S., Glazebrook, K. \& van den Bergh, S.: 1996, MNRAS, 279, L47

Alladin, S.M. \& Narasimhan, K.S.V.S.: 1982, Physics Reports, 92(6), 339

Andredakis, Y.C., Peletier, R.F. \& Balcells, M.: 1995, MNRAS, 275, 874

Athanassoula, E. \& Bureau, M.: 1999, accepted for publication in ApJ, astro-ph/9904206

Avila-Reese, V. \& Firmani, C.: 1998, in Star Formation in Early-Type Galaxies, ASP Conf. Ser., ed. by P. Carral \& J. Cepa, astro-ph/9808165

Baggett, W.E., Baggett, S.M. \& Anderson, K.S.J.: 1998, ApJ, 116, 1626

Balcells, M. \& Peletier, R.F.: 1994, AJ, 107(1), 135

Baugh, C.M., Cole, S. \& Frenk, C.S.: 1996, MNRAS, 283, 1361

Berentzen, I., Heller, C.H., Shlosman, I. \& Fricke, K.J.: 1998, MNRAS, 300, 49

Binney, J. \& Merrifield, M.: 1998, in Galactic Astronomy, Princeton Series in Astrophysics

Binney, J. \& Tremaine, S.: 1987, in Galactic Dynamics, Princeton Series in Astrophysics

Bouwens, R., Cayón, L. \& Silk, J.: 1998, astro-ph/9812193, accepted for publication in ApJ

Bruzual, G.A., Magris, G.C. \& Calvet, N.: 1988, ApJ, 333, 673

Bureau, M. \& Athanassoula, E.: 1999, accepted for publication in ApJ, astro-ph/9903061

Bureau, M. \& Freeman, K.C.: 1999, accepted for publication in AJ, astro-ph/9904015

Bureau, M., Freeman, K.C. \& Athanassoula, E.: 1999, in When and How do Bulges Form and Evolve?, ed. by C.M. Carollo, H.C. Ferguson \& R.F.G. Wyse, Cambridge: CUP, astro-ph/9901246 
Carollo, C.M., Stiavelli, M., de Zeeuw, P.T. \& Mack, J.: 1997, AJ, 114(6), 2366

Caon, N., Capaccioli, M. \& D'Onofrio, M.: 1993, MNRAS, 265, 1013

Combes, F.: 1999, in Building Galaxies: from the Primordial Universe to the Present, Proceedings of Rencontres de Moriond, 13-20 March 1999, ed. by F. Hammer, T.X. Thuan, V. Cayatte, B. Guiderdoni and J. Tran Thanh Van (Ed. Frontieres), astro$\mathrm{ph} / 9904031$

Combes, F. \& Sanders, R.H.: 1981, AA, 96, 164

Courteau, S., de Jong, R.S. \& Broeils, A.H.: 1996, ApJ, 457, L73

de Jong, R.S.: 1996a, AASS, 118, 557

de Jong, R.S.: 1996b, AA, 313, 45

de Jong, R.S.: 1996c, AA, 313, 377

de Jong, R.S. \& van der Kruit, P.C.: 1994, AASS, 106, 451

de Souza, R.E.: 1997, Tese de Livre Docência, Departamento de Astronomia, Instituto Astronômico e Geofísico, Universidade de São Paulo

de Souza, R.E. \& dos Anjos, S.: 1987, AASS, 70, 465

de Vaucouleurs, G.: 1963, ApJS, 8, 31

de Vaucouleurs, G., de Vaucouleurs, A., Corwin, H.G., Buta, R.J., Paturel, G. \& Fouque, P.: 1991, in Third Reference Catalog of Bright Galaxies, Springer-Verlag, New York (RC3)

Eggen, O.J., Lynden-Bell, D. \& Sandage, A.R.: 1962, ApJ, 136, 748

Elmegreen, D.M.: 1998, in Galaxies and Galactic Structure, Prentice Hall

Elmegreen, D.M. \& Elmegreen, B.G.: 1982a, MNRAS, 201, 1021

Elmegreen, D.M. \& Elmegreen, B.G.: 1982b, MNRAS, 201, 1035

Erwin, P. \& Sparke, L.S.: 1998, in Galaxy Dynamics, proceedings of a conference held at Rutgers University, 8-12 Aug 1998. To appear in ASP Conference Series, edited by D.R. Merritt, M. Valluri, and J.A. Sellwood, astro-ph/9811345

Erwin, P. \& Sparke, L.S.: 1999, astro-ph/9906262, accepted by ApJL

Evans, R.: 1994, MNRAS, 266, 511 
François, P., Vangioni-Flam, E. \& Audouze, J.: 1990, ApJ, 361, 487

Friedli, D.: 1999, in The Evolution of Galaxies on Cosmological Timescales, ed. by J.E. Beckman \& T.J. Mahoney, ASP Conf. Ser., astro-ph/9903143

Friedli, D. \& Benz, W.: 1993, AA, 268, 65

Friedli, D. \& Benz, W.: 1995, AA, 301, 649

Friedli, D. \& Martinet, L.: 1993, AA, 277, 27

Frogel, J.A.: 1985, ApJ, 298, 528

Fukugita, M., Shimasaku, K. \& Ichikawa, T.: 1995, PASP, 107, 945

Giovanelli, R., Haynes, M.P., Salzer, J.J., Wegner, G., da Costa, L.N., \& Freudling, W.: 1994, AJ, $107(6), 2036$

Giovanelli, R., Haynes, M.P., Salzer, J.J., Wegner, G., da Costa, L.N., \& Freudling, W.: 1995, AJ, $110(3), 1059$

Graham, J.A.: 1982, PASP, 94, 244

Ho, L.C., Filippenko, A.V.\& Sargent, W.L.W.: 1997, ApJ, 487, 591

Hubble, E.P.: 1926, ApJ, 64, 321

Hubble, E.P.: 1936, in The Realm of the Nebulae, New Haven: Yale University Press

Humason, M.L.: 1936, ApJ, 83, 10

Ibata, R.A. \& Gilmore, G.F.: 1995, MNRAS, 275, 605

Kauffmann, G. \& White, S.D.M.: 1993, MNRAS, 261, 921

Kitchin, C.R.: 1998, in Astrophysical Techniques, Institute of Physics Publishing, Bristol and Philadelphia

Knapen, J.H.: 1998, in The Central Regions of the Galaxy and Galaxies, IAU Symp.184, p.93

Koopmann, R.A. \& Kenney, J.D.P.: 1998, ApJ, 497, L75

Kormendy, J.: 1982, ApJ, 257, 75

Kormendy, J.: 1993, in Galactic Bulges, IAU Symp.153, p.209

Kormendy, J. \& Bender, R.: 1996, ApJ, 464, L119 
Kormendy, J. \& Illingworth, G.: 1983, ApJ, 265, 632

Kuijken, K. \& Merrifield, M.R.: 1995, ApJ, 443, L13

Lahav, O., Naim, A., Buta, R.J., Corwin, H.G., de Vaucouleurs, G., Dressler, A., Huchra, J.P., van den Bergh, S., Raychaudhury, S., Sodré Jr., L. \& Storrie-Lombardi, M.C.: 1995, Science, 267, 859

Larson, R.B.: 1990, PASP, 102(653), 709

Larson, R.B. \& Tinsley, B.M.: 1978, ApJ, 219, 46

Lasker, B.M., Sturch, C.R., McLean, B.J., Russell, J.L., Jenkner, H. \& Shara, M.M.: 1990, AJ, 99, 2019

Longo, G. \& de Vaucouleurs, A.: 1983, Univ. Texas Monograph in Astronomy No. 3 (LdV83)

Longo, G. \& de Vaucouleurs, A.: 1985, Univ. Texas Monograph in Astronomy No. 3A (LdV85)

Marleau, F.R. \& Simard, L.: 1998, ApJ, 507, 585

Martin, P.: 1995, AJ, 109(6), 2428 (M95)

Martin, P. \& Roy, J.R.: 1994, ApJ, 424, 599 (MR94)

McWilliam, A. \& Rich, R.M.: 1994, ApJS, 91, 749

Merrifield, M.R. \& Kuijken, K.: 1999, AA, 345, L47

Mihalas, D. \& Binney, J.: 1981, in Galactic Astronomy: Structure and Kinematics, W.H. Freeman and Co.

Morgan, W.W.: 1958, PASP, 70, 364

Morgan, W.W. \& Mayall, N.U.: 1957, PASP, 69, 409

Norman, C.A., Sellwood, J.A. \& Hasan, H.: 1996, ApJ, 462, 114

Peletier, R.F.: 1989, PhD Thesis, University of Groningen, The Netherlands

Peletier, R.F. \& Balcells, M.: 1996, AJ, 111, 2238

Peletier, R.F., Valentjin, E.A., Moorwood, A.F.M. \& Freudling, W.: 1994, AASS, 108, 621

Pfenniger, D.: 1993, in Galactic Bulges, IAU Symp.153, p.387 
Prugniel, Ph. \& Héraudeau, Ph.: 1998, AASS, 128, 299 (PH98)

Renzini, A.: 1999, in When and How do Bulges Form and Evolve?, ed. by C.M. Carollo, H.C. Ferguson \& R.F.G. Wyse (Cambridge University Press), astro-ph/9902108

Rich, R.M. \& Terndrup, D.M.: 1997, PASP, 109, 571

Roberts, M.S. \& Haynes, M.P.: 1994, ARAA, 32, 115

Rousseeuw, P.J.: 1984, Journal of The American Statistical Association, 79(388), 871

Rousseeuw, P.J. \& Leroy, A.M.: 1987, in Robust Regression and Outlier Detection, WileyInterscience, New York

Sakamoto, K., Okumura, S.K., Ishizuki, S. \& Scoville, N.Z.: 1999, in When and How do Bulges Form and Evolve?, ed. by C.M. Carollo, H.C. Ferguson \& R.F.G. Wyse, Cambridge University Press, astro-ph/9902005

Sandage, A.: 1961, in The Hubble Atlas of Galaxies, Carnegie Institution of Washington

Sandage, A.: 1975, in Galaxies and the Universe, Stars and Stellar Systems, Vol. 9, Chap. 1, ed. by A. Sandage, M. Sandage \& J. Kristian, The University of Chicago Press

Schlegel, D.J., Finkbeiner, D.P. \& Davis, M.: 1998, Ap.J, 500, 525

Schweizer, F.: 1982, ApJ, 252, 455

Searle, L., Sargent, W.L.W. \& Bagnuolo, W.G.: 1973, ApJ, 179, 427

Sellwood, J.A.: 1993, in Galactic Bulges, IAU Symp.153, p.391

Shlosman, I., Begelman, M.C. \& Frank, J.: 1990, Nature, 345, 679

Shlosman, I., Frank, J. \& Begelman, M.C.: 1989, Nature, 338, 45

Silk, J. \& Bouwens, R.: 1999, in Galaxy Evolution, proceedings of a conference held in Meudon, September, 21 - 25, 1998, astro-ph/9812057

Silva, D.R. \& Elston, R.: 1994, ApJ, 428, 511

Sodré Jr, L. \& Cuevas, H.: 1994, Vistas in Astronomy, 38, 287

Sodré Jr, L. \& Cuevas, H.: 1997, MNRAS, 287, 137

Stetson, P.B., VandenBergh, D.A. \& Bolte, M.: 1996, PASP, 108, 560

Tinsley, B.M.: 1980, Fund. of Cos. Phys., 5, 287

Toomre, A. \& Toomre, J.: 1972, ApJ, 178, 623 
Tully, R.B., Pierce, M.J., Huang, J.S., Saunders, W., Verheijen, M.A.W. \& Witchalls, P.L.: 1998, astro-ph/9802247

van den Bergh, S.: 1960a, ApJ, 131, 215

van den Bergh, S.: 1960b, ApJ, 131, 558

van den Bergh, S.: 1997, AJ, 113, 2054

van den Bergh, S., Abraham, R.G., Ellis, R.S., Tanvir, N.R., Santiago, B.X. \& Glazebrook, K.G.: 1996, AJ, 112, 359

van Houten, C.J.: 1961, BAN, 16, 1

Véron-Cetty, M.P. \& Véron, P.: 1998, ESO Sci. Rep., 18, 1

White, R.L., Postman, M. \& Lattanzi, M.G.: 1992, in Digitised Optical Sky Surveys, ed. by H.T. MacGillivray \& E.B. Thomson, Kluwer, p.167

Wyse, R.F.G.: 1998, MNRAS, 293, 429

Wyse, R.F.G., Gilmore, G. \& Franx, M.: 1997, ARAA, 35, 637

Zaritsky, D., Kennicutt, R.C. \& Huchra, J.P.: 1994, ApJ, 420, 87 (ZKH94)

Zhang, X.: 1996, ApJ, 457, 125

Zhang, X.: 1998, in The Central Regions of the Galaxy and Galaxies, IAU Symp.184, p. 29 


\section{Apêndice A}

\section{Nossa amostra}

Neste apêndice apresentamos a amostra de galáxias selecionada para estudo. Vale lembrar que das 257 galáxias de nossa amostra, obtivemos 239 gradientes de cor (BV) e 202 (U-B). As galáxias cujos gradientes foram descartados, por terem valores muito incertos, são: IC 983, NGC 253, NGC 1169, NGC 1625, NGC 1964, NGC 2276, NGC 2377, NGC 2525, NGC 3344, NGC 3646, NGC 4394, NGC 4402, NGC 5054, NGC 6215, NGC 6300, NGC 6878A, NGC 7307 e UGC 11555. Na Tabela A.1 apresentamos informações a respeito do restante da amostra. A coluna (1) apresenta o nome da galáxia, enquanto que o seu tipo morfológico, segundo o RC3, se encontra na coluna (2). As colunas (3) e (4) apresentam, respectivamente, o gradiente de cor (B-V) e sua incerteza, enquanto que as colunas (5) e (6) apresentam estes valores em relação ao índice (U-B). As colunas (7) e (8) exibem os valores dos índices de cor $(\mathrm{B}-\mathrm{V})$ para bojos e discos, respectivamente. Já os valores dos índices de cor (U-B) para bojos e discos estão exibidos, respectivamente, nas colunas (9) e (10). Para aquelas galáxias que apresentam gradientes nulos, os índices de cor para bojos e discos foram substituídos pelos índices de cor efetivos. Vale indicar agora que os erros médios para os gradientes são 0.02 para $(\mathrm{B}-\mathrm{V})$ e 0.04 para (U-B). Os erros médios para os índices de cor dos bojos são 0.04 para (B-V) e 0.05 para (U-B), enquanto que para os discos os erros são 0.03 para $(\mathrm{B}-\mathrm{V})$ e 0.04 para (U-B).

Na Tabela A.2, apresentamos nossa sub-amostra de 39 galáxias, para as quais a decomposição bojo/disco foi realizada (ver Capítulo 3). Os resultados da decomposição estão assim expostos. A primeira coluna desta tabela identifica a galáxia, enquanto que a coluna (2) exibe a razão entre as luminosidades de bojo e disco. A coluna (3) mostra a razão entre os diâmetros de bojo e disco. Na coluna (4) mostramos o índice de Sérsic do bojo com o respectivo erro absoluto entre parênteses. Nas colunas (5) e (6), apresentamos, 
respectivamente, o brilho superficial central do disco (em magnitudes na banda $\mathrm{V}$ por segundo de arco ao quadrado) e o raio característico do disco (em segundos de arco), com o respectivo erro absoluto entre parênteses. As colunas (7) e (8) exibem, nessa ordem, o brilho superficial efetivo do bojo (em magnitudes na banda $\mathrm{V}$ por segundo de arco ao quadrado) e o raio efetivo do bojo (em segundos de arco), com o respectivo erro absoluto entre parênteses. O erro médio para o raio característico do disco é de 3.5 segundos de arco, enquanto que o erro médio para o raio efetivo do bojo é de 6.3 segundos de arco. 
Tabela A.1: A amostra.

\begin{tabular}{|c|c|c|c|c|c|c|c|c|c|}
\hline $\begin{array}{c}\text { Nome } \\
(1)\end{array}$ & $\begin{array}{c}\text { Tipo } \\
(2)\end{array}$ & $\begin{array}{c}G(B-V) \\
(3)\end{array}$ & $\begin{array}{c}\text { erro } \\
(4) \\
\end{array}$ & $\begin{array}{c}G(U-B) \\
(5)\end{array}$ & $\begin{array}{l}\text { erro } \\
(6)\end{array}$ & $\begin{array}{c}(B-V)_{b} \\
(7)\end{array}$ & $\begin{array}{c}(B-V)_{d} \\
(8)\end{array}$ & $\begin{array}{c}(U-B)_{b} \\
(9)\end{array}$ & $\begin{array}{c}(U-B)_{d} \\
(10)\end{array}$ \\
\hline$\overline{E S O} 271-010$ & SABcd(s) & $-0,02$ & 0,03 & 0,04 & 0,06 & 0,39 & 0,39 & $-0,22$ & $-0,22$ \\
\hline IC0342 & $\mathrm{SABcd}(\mathrm{rs})$ & 0,43 & 0,08 & 0,57 & 0,09 & 0,23 & 0,66 & $-0,51$ & 0,06 \\
\hline IC1954 & $\mathrm{SBb}(\mathrm{s})$ & $-0,06$ & 0,03 & 0,15 & 0,10 & 0,24 & 0,24 & $-0,40$ & $-0,25$ \\
\hline IC1993 & $\mathrm{SABb}(\mathrm{rs})$ & $-0,05$ & 0,03 & $-0,01$ & 0,10 & 0,73 & 0,73 & 0,24 & 0,24 \\
\hline IC2554 & $\mathrm{SBbc}(\mathrm{s})$ & $-0,06$ & 0,03 & 0,08 & 0,04 & 0,19 & 0,19 & $-0,45$ & $-0,45$ \\
\hline IC 4444 & $\mathrm{SABbc}(\mathrm{rs})$ & 0,00 & 0,03 & - & - & 0,40 & 0,40 & - & - \\
\hline IC4839 & $\mathrm{SAbc}(\mathrm{s})$ & $-0,28$ & 0,03 & $-0,44$ & 0,06 & 0,88 & 0,60 & 0,41 & $-0,03$ \\
\hline $\mathrm{IC} 4845$ & $\mathrm{Sb}(\mathrm{rs})$ & 0,13 & 0,00 & $-0,01$ & 0,07 & 0,45 & 0,58 & 0,05 & 0,05 \\
\hline IC4852 & SBbc(s) & $-0,13$ & 0,05 & 0,03 & 0,07 & 0,67 & 0,54 & $-0,07$ & $-0,07$ \\
\hline IC5092 & $\mathrm{SBc}(\mathrm{rs})$ & $-0,01$ & 0,03 & $-0,02$ & 0,09 & 0,69 & 0,69 & 0,09 & 0,09 \\
\hline IC5179 & $\operatorname{Sbc}(\mathrm{rs})$ & $-0,17$ & 0,04 & $-0,11$ & 0,03 & 0,46 & 0,29 & $-0,12$ & $-0,23$ \\
\hline IC5186 & $\mathrm{SABb}(\mathrm{rs})$ & $-0,11$ & 0,01 & $-0,11$ & 0,04 & 0,53 & 0,42 & $-0,06$ & $-0,17$ \\
\hline IC5325 & $\mathrm{SABbc}(\mathrm{rs})$ & $-0,18$ & 0,03 & $-0,05$ & 0,05 & 0,69 & 0,51 & $-0,07$ & $-0,07$ \\
\hline MCG-2-14-4 & SABcd(rs) & $-0,33$ & 0,11 & 0,07 & 0,01 & 0,64 & 0,31 & $-0,11$ & $-0,11$ \\
\hline NGC0001 & $\mathrm{Sb}$ & $-0,14$ & 0,01 & $-0,19$ & 0,05 & 0,76 & 0,62 & 0,19 & 0,00 \\
\hline NGC0024 & $\mathrm{Sc}(\mathrm{s})$ & $-0,20$ & 0,06 & $-0,14$ & 0,06 & 0,29 & 0,09 & $-0,33$ & $-0,47$ \\
\hline NGC0134 & SABbc(s) & $-0,18$ & 0,01 & $-0,35$ & 0,03 & 0,49 & 0,31 & 0,12 & $-0,23$ \\
\hline NGC0150 & $\mathrm{SBb}(\mathrm{rs})$ & $-0,22$ & 0,00 & $-0,21$ & 0,04 & 0,54 & 0,32 & $-0,05$ & $-0,26$ \\
\hline NGC0151 & $\operatorname{SBbc}(\mathrm{r})$ & $-0,36$ & 0,03 & $-0,46$ & 0,06 & 0,73 & 0,37 & 0,33 & $-0,13$ \\
\hline NGC0157 & $\mathrm{SABbc}(\mathrm{rs})$ & $-0,23$ & 0,03 & $-0,27$ & 0,04 & 0,60 & 0,37 & 0,07 & $-0,20$ \\
\hline NGC0210 & $\mathrm{SABb}(\mathrm{s})$ & $-0,17$ & 0,02 & $-0,32$ & 0,00 & 0,78 & 0,61 & 0,30 & $-0,02$ \\
\hline NGC0224 & $\mathrm{Sb}(\mathrm{s})$ & $-0,03$ & 0,00 & $-0,08$ & 0,01 & $-0,10$ & $-0,10$ & $-0,26$ & $-0,26$ \\
\hline NGC0278 & $\mathrm{SABb}(\mathrm{rs})$ & $-0,03$ & 0,04 & - & - & 0,51 & 0,51 & - & - \\
\hline NGC0289 & $\operatorname{SBbc}(\mathrm{rs})$ & $-0,19$ & 0,02 & $-0,34$ & 0,02 & 0,78 & 0,59 & 0,32 & $-0,02$ \\
\hline NGC0309 & $\operatorname{SABc}(\mathrm{r})$ & $-0,63$ & 0,04 & $-0,47$ & 0,10 & 0,91 & 0,28 & 0,26 & $-0,21$ \\
\hline NGC0440 & $\mathrm{Sbc}(\mathrm{s})$ & $-0,16$ & 0,02 & $-0,24$ & 0,06 & 0,51 & 0,35 & $-0,03$ & $-0,27$ \\
\hline NGC0470 & $\mathrm{Sb}(\mathrm{rs})$ & $-0,13$ & 0,03 & 0,01 & 0,06 & 0,63 & 0,50 & $-0,06$ & $-0,06$ \\
\hline NGC0488 & $\mathrm{Sb}(\mathrm{r})$ & $-0,13$ & 0,02 & $-0,28$ & 0,04 & 0,90 & 0,77 & 0,58 & 0,30 \\
\hline NGC0578 & $\mathrm{SABc}(\mathrm{rs})$ & $-0,21$ & 0,03 & $-0,10$ & 0,01 & 0,50 & 0,29 & $-0,15$ & $-0,25$ \\
\hline NGC0613 & $\mathrm{SBbc}(\mathrm{rs})$ & 0,01 & 0,02 & 0,03 & 0,04 & 0,63 & 0,63 & 0,06 & 0,06 \\
\hline NGC0615 & $\mathrm{Sb}(\mathrm{rs})$ & $-0,12$ & 0,01 & $-0,27$ & 0,02 & 0,55 & 0,43 & 0,29 & 0,02 \\
\hline NGC0628 & $\mathrm{Sc}(\mathrm{s})$ & $-0,14$ & 0,01 & $-0,23$ & 0,02 & 0,64 & 0,50 & 0,09 & $-0,14$ \\
\hline NGC0685 & $\mathrm{SABc}(\mathrm{r})$ & $-0,22$ & 0,03 & $-0,15$ & 0,04 & 0,62 & 0,40 & $-0,04$ & $-0,19$ \\
\hline NGC0779 & $\mathrm{SABb}(\mathrm{r})$ & $-0,11$ & 0,02 & $-0,25$ & 0,03 & 0,45 & 0,34 & 0,10 & $-0,16$ \\
\hline NGC0782 & $\mathrm{SBb}(\mathrm{r})$ & $-0,31$ & 0,00 & $-0,53$ & 0,06 & 0,82 & 0,51 & 0,44 & $-0,09$ \\
\hline NGC0864 & $\mathrm{SABc}(\mathrm{rs})$ & $-0,11$ & 0,03 & - & - & 0,55 & 0,44 & - & - \\
\hline NGC0908 & $\mathrm{Sc}(\mathrm{s})$ & $-0,22$ & 0,02 & $-0,50$ & 0,04 & 0,54 & 0,32 & 0,17 & $-0,33$ \\
\hline NGC0958 & $\mathrm{SBc}(\mathrm{rs})$ & $-0,13$ & 0,04 & - & - & 0,48 & 0,35 & - & - \\
\hline NGC1055 & $\mathrm{SBb}$ & $-0,10$ & 0,02 & $-0,26$ & 0,04 & 0,53 & 0,43 & 0,13 & $-0,13$ \\
\hline NGC1068 & $\mathrm{Sb}(\mathrm{rs})$ & $-0,10$ & 0,01 & 0,01 & 0,01 & 0,74 & 0,64 & 0,00 & 0,00 \\
\hline NGC1073 & $\mathrm{SBc}(\mathrm{rs})$ & $-0,17$ & 0,03 & $-0,47$ & 0,04 & 0,62 & 0,45 & 0,22 & $-0,25$ \\
\hline NGC1084 & $\mathrm{Sc}(\mathrm{s})$ & $-0,14$ & 0,04 & $-0,26$ & 0,01 & 0,50 & 0,36 & 0,03 & $-0,23$ \\
\hline NGC1087 & $\mathrm{SABc}(\mathrm{rs})$ & $-0,01$ & 0,04 & 0,11 & 0,04 & 0,31 & 0,31 & $-0,36$ & $-0,25$ \\
\hline NGC1097 & $\mathrm{SBb}(\mathrm{s})$ & 0,08 & 0,03 & 0,12 & 0,02 & 0,64 & 0,64 & 0,03 & 0,15 \\
\hline NGC1187 & $\mathrm{SBc}(\mathrm{r})$ & $-0,15$ & 0,02 & $-0,10$ & 0,04 & 0,60 & 0,45 & $-0,01$ & $-0,11$ \\
\hline NGC1232 & $\mathrm{SABc}(\mathrm{rs})$ & $-0,24$ & 0,01 & $-0,60$ & 0,04 & 0,79 & 0,55 & 0,45 & $-0,15$ \\
\hline NGC1255 & $\mathrm{SABbc}(\mathrm{rs})$ & $-0,36$ & 0,02 & $-0,14$ & 0,04 & 0,62 & 0,26 & $-0,10$ & $-0,24$ \\
\hline NGC1288 & $\mathrm{SABc}(\mathrm{rs})$ & $-0,30$ & 0,02 & - & - & 0,88 & 0,58 & - & - \\
\hline NGC1300 & SBbc(rs) & $-0,18$ & 0,03 & $-0,22$ & 0,03 & 0,71 & 0,53 & 0,21 & $-0,01$ \\
\hline NGC1365 & $\mathrm{SBb}(\mathrm{s})$ & 0,11 & 0,02 & 0,13 & 0,04 & 0,43 & 0,54 & $-0,16$ & $-0,03$ \\
\hline NGC1421 & $\mathrm{SABbc}(\mathrm{rs})$ & $-0,30$ & 0,02 & $-0,22$ & 0,03 & 0,24 & $-0,06$ & $-0,28$ & $-0,50$ \\
\hline NGC1425 & $\mathrm{Sb}(\mathrm{s})$ & $-0,13$ & 0,02 & $-0,25$ & 0,02 & 0,51 & 0,38 & 0,13 & $-0,12$ \\
\hline NGC1483 & $\mathrm{SBbc}(\mathrm{s})$ & $-0,09$ & 0,04 & $-0,04$ & 0,04 & 0,39 & 0,39 & $-0,26$ & $-0,26$ \\
\hline NGC1515 & $\mathrm{SABbc}(\mathrm{s})$ & $-0,09$ & 0,02 & $-0,12$ & 0,01 & 0,33 & 0,33 & $-0,05$ & $-0,17$ \\
\hline NGC1530 & $\mathrm{SBb}(\mathrm{rs})$ & $-0,12$ & 0,04 & $-0,02$ & 0,01 & 0,55 & 0,43 & $-0,11$ & $-0,11$ \\
\hline NGC1536 & $\mathrm{SBc}(\mathrm{s})$ & $-0,03$ & 0,10 & - & - & 0,51 & 0,51 & - & - \\
\hline NGC1566 & SABbc(s) & $-0,06$ & 0,03 & $-0,06$ & 0,05 & 0,57 & 0,57 & $-0,04$ & $-0,04$ \\
\hline NGC1614 & $\mathrm{SBc}(\mathrm{s})$ & 0,02 & 0,03 & 0,16 & 0,04 & 0,44 & 0,44 & $-0,34$ & $-0,18$ \\
\hline NGC1620 & $\mathrm{SABbc}(\mathrm{rs})$ & $-0,24$ & 0,01 & - & - & 0,56 & 0,32 & - & - \\
\hline NGC1637 & $\mathrm{SABc}(\mathrm{rs})$ & $-0,22$ & 0,04 & $-0,26$ & 0,06 & 0,76 & 0,54 & 0,18 & $-0,08$ \\
\hline NGC1672 & $\mathrm{SBb}(\mathrm{s})$ & 0,00 & 0,01 & 0,04 & 0,01 & 0,57 & 0,57 & $-0,05$ & $-0,05$ \\
\hline NGC1688 & $\operatorname{SBd}(\mathrm{rs})$ & 0,15 & 0,04 & 0,42 & 0,12 & 0,30 & 0,45 & $-0,44$ & $-0,02$ \\
\hline NGC1703 & $\mathrm{SBb}(\mathrm{r})$ & $-0,18$ & 0,00 & $-0,64$ & 0,00 & 0,69 & 0,51 & 0,36 & $-0,28$ \\
\hline NGC1784 & $\mathrm{SBc}(\mathrm{r})$ & $-0,30$ & 0,00 & $-0,22$ & 0,05 & 0,81 & 0,51 & 0,24 & 0,02 \\
\hline
\end{tabular}


Tabela A.1: Continuação.

\begin{tabular}{|c|c|c|c|c|c|c|c|c|c|}
\hline $\begin{array}{c}\text { Nome } \\
(1)\end{array}$ & $\begin{array}{c}\text { Tipo } \\
(2)\end{array}$ & $\begin{array}{c}G(B-V) \\
(3)\end{array}$ & $\begin{array}{c}\text { erro } \\
(4)\end{array}$ & $\begin{array}{c}G(U-B) \\
(5)\end{array}$ & $\begin{array}{c}\text { erro } \\
(6) \\
\end{array}$ & $\begin{array}{c}(B-V)_{b} \\
(7)\end{array}$ & $\begin{array}{c}(B-V)_{d} \\
(8)\end{array}$ & $\begin{array}{c}(U-B)_{b} \\
(9)\end{array}$ & $\begin{array}{c}(U-B)_{d} \\
(10)\end{array}$ \\
\hline NGC1792 & Sbc(rs) & $-0,19$ & 0,03 & $-0,22$ & 0,04 & 0,51 & 0,32 & $-0,06$ & $-0,28$ \\
\hline NGC1796 & $\mathrm{SBc}(\mathrm{rs})$ & $-0,08$ & 0,01 & $-0,09$ & 0,04 & 0,31 & 0,31 & $-0,26$ & $-0,26$ \\
\hline NGC1832 & SBbc(r) & $-0,43$ & 0,02 & $-0,42$ & 0,06 & 0,77 & 0,34 & 0,19 & $-0,23$ \\
\hline NGC1888 & $\mathrm{SBc}(\mathrm{s})$ & $-0,14$ & 0,05 & $-0,26$ & 0,05 & 0,43 & 0,29 & 0,11 & $-0,15$ \\
\hline NGC1961 & $\mathrm{SABc}(\mathrm{rs})$ & $-0,33$ & 0,09 & - & - & 0,73 & 0,40 & - & - \\
\hline NGC2082 & $\mathrm{SBb}(\mathrm{r})$ & $-0,18$ & 0,03 & $-0,13$ & 0,06 & 0,67 & 0,49 & $-0,08$ & $-0,21$ \\
\hline NGC2090 & $\mathrm{Sc}(\mathrm{rs})$ & $-0,10$ & 0,02 & $-0,20$ & 0,03 & 0,61 & 0,51 & 0,17 & $-0,03$ \\
\hline NGC2206 & SABbc(rs) & $-0,25$ & 0,05 & - & - & 0,66 & 0,41 & - & - \\
\hline $\mathrm{NGC} 2207$ & SABbc(rs) & $-0,32$ & 0,03 & - & - & 0,64 & 0,32 & - & - \\
\hline NGC 2223 & $\mathrm{SABb}(\mathrm{r})$ & $-0,25$ & 0,02 & $-0,57$ & 0,08 & 0,88 & 0,63 & 0,54 & $-0,03$ \\
\hline NGC2268 & SABbc(r) & $-0,08$ & 0,02 & - & - & 0,53 & 0,53 & - & - \\
\hline NGC2336 & $\operatorname{SABbc}(r)$ & $-0,21$ & 0,03 & $-0,61$ & 0,05 & 0,60 & 0,39 & 0,37 & $-0,24$ \\
\hline NGC2339 & $\mathrm{SABbc}(\mathrm{rs})$ & $-0,12$ & 0,02 & - & - & 0,75 & 0,63 & - & - \\
\hline NGC2347 & $\mathrm{Sb}(\mathrm{r})$ & $-0,19$ & 0,03 & - & - & 0,76 & 0,57 & - & - \\
\hline NGC2389 & $\mathrm{SABc}(\mathrm{rs})$ & $-0,21$ & 0,08 & - & - & 0,55 & 0,34 & - & - \\
\hline $\mathrm{NGC} 2417$ & $\operatorname{Sbc}(\mathrm{rs})$ & $-0,12$ & 0,03 & $-0,09$ & 0,08 & 0,62 & 0,50 & 0,00 & 0,00 \\
\hline NGC 2442 & SABbc(s) & $-0,30$ & 0,02 & $-0,30$ & 0,01 & 0,86 & 0,56 & 0,34 & 0,04 \\
\hline NGC2487 & $\mathrm{SBb}$ & $-0,38$ & 0,03 & $-0,42$ & 0,08 & 0,93 & 0,55 & 0,41 & $-0,01$ \\
\hline $\mathrm{NGC} 2512$ & $\mathrm{SBb}$ & $-0,08$ & 0,01 & 0,02 & 0,05 & 0,54 & 0,54 & $-0,05$ & $-0,05$ \\
\hline NGC2565 & SBbc & 0,02 & 0,01 & $-0,08$ & 0,12 & 0,52 & 0,52 & 0,07 & 0,07 \\
\hline NGC2595 & $\mathrm{SABc}(\mathrm{rs})$ & $-0,06$ & 0,02 & $-0,01$ & 0,02 & 0,60 & 0,60 & 0,07 & 0,07 \\
\hline NGC2608 & $\mathrm{SBb}(\mathrm{s})$ & $-0,09$ & 0,06 & $-0,08$ & 0,07 & 0,53 & 0,53 & $-0,06$ & $-0,06$ \\
\hline NGC 2613 & $\mathrm{Sb}(\mathrm{s})$ & $-0,16$ & 0,01 & $-0,42$ & 0,04 & 0,47 & 0,31 & 0,28 & $-0,14$ \\
\hline NGC2683 & $\mathrm{Sb}(\mathrm{rs})$ & $-0,08$ & 0,01 & $-0,23$ & 0,02 & 0,34 & 0,34 & 0,07 & $-0,16$ \\
\hline $\mathrm{NGC} 2712$ & $\mathrm{SBb}(\mathrm{r})$ & $-0,19$ & 0,03 & - & - & 0,63 & 0,44 & - & - \\
\hline $\mathrm{NGC} 2715$ & $\mathrm{SABc}(\mathrm{rs})$ & $-0,11$ & 0,06 & - & - & 0,27 & 0,16 & - & - \\
\hline $\mathrm{NGC} 2776$ & $\mathrm{SABc}(\mathrm{rs})$ & 0,04 & 0,05 & 0,04 & 0,05 & 0,52 & 0,52 & $-0,11$ & $-0,11$ \\
\hline $\mathrm{NGC} 2815$ & $\mathrm{SBb}(\mathrm{r})$ & $-0,24$ & 0,02 & $-0,34$ & 0,07 & 0,60 & 0,36 & 0,37 & 0,03 \\
\hline $\mathrm{NGC} 2841$ & $\mathrm{Sb}(\mathrm{r})$ & $-0,12$ & 0,01 & $-0,24$ & 0,03 & 0,68 & 0,56 & 0,36 & 0,12 \\
\hline NGC2874 & SBbc(r) & $-0,26$ & 0,04 & $-0,40$ & 0,04 & 0,62 & 0,36 & 0,23 & $-0,17$ \\
\hline NGC2889 & $\mathrm{SABc}(\mathrm{rs})$ & $-0,26$ & 0,02 & $-0,39$ & 0,10 & 0,87 & 0,61 & 0,37 & $-0,02$ \\
\hline NGC2903 & SABbc(rs) & 0,03 & 0,02 & 0,16 & 0,03 & 0,40 & 0,40 & $-0,24$ & $-0,08$ \\
\hline NGC 2935 & $\mathrm{SABb}(\mathrm{s})$ & $-0,12$ & 0,05 & $-0,07$ & 0,10 & 0,76 & 0,64 & 0,13 & 0,13 \\
\hline NGC2955 & $\mathrm{Sb}(\mathrm{r})$ & 0,19 & 0,07 & - & - & 0,21 & 0,40 & - & - \\
\hline NGC2964 & $\operatorname{SABbc}(r)$ & $-0,08$ & 0,04 & $-0,06$ & 0,01 & 0,49 & 0,49 & $-0,18$ & $-0,18$ \\
\hline NGC2989 & SABbc(s) & $-0,17$ & 0,03 & $-0,12$ & 0,00 & 0,42 & 0,25 & $-0,16$ & $-0,28$ \\
\hline NGC2997 & $\mathrm{SABc}(\mathrm{rs})$ & 0,08 & 0,02 & 0,19 & 0,03 & 0,68 & 0,68 & 0,01 & 0,20 \\
\hline NGC3001 & SABbc(rs) & $-0,09$ & 0,06 & $-0,12$ & 0,06 & 0,58 & 0,58 & 0,02 & $-0,10$ \\
\hline NGC3054 & $\mathrm{SABb}(\mathrm{r})$ & $-0,14$ & 0,02 & $-0,23$ & 0,03 & 0,74 & 0,60 & 0,26 & 0,03 \\
\hline NGC3079 & $\mathrm{SBc}(\mathrm{s})$ & $-0,25$ & 0,01 & $-0,50$ & 0,07 & 0,31 & 0,06 & 0,02 & $-0,48$ \\
\hline NGC3095 & $\mathrm{SABc}(\mathrm{rs})$ & $-0,39$ & 0,03 & $-0,44$ & 0,05 & 0,67 & 0,38 & 0,19 & $-0,25$ \\
\hline NGC3124 & $\mathrm{SABbc}(\mathrm{rs})$ & $-0,19$ & 0,03 & - & - & 0,80 & 0,61 & - & - \\
\hline NGC3145 & $\operatorname{SBbc}(\mathrm{rs})$ & $-0,25$ & 0,01 & $-0,12$ & 0,12 & 0,72 & 0,47 & 0,18 & 0,06 \\
\hline NGC3177 & $\mathrm{Sb}(\mathrm{rs})$ & 0,04 & 0,02 & $-0,21$ & 0,05 & 0,54 & 0,54 & 0,51 & 0,30 \\
\hline NGC3223 & $\mathrm{Sb}(\mathrm{s})$ & $-0,25$ & 0,00 & $-0,34$ & 0,04 & 0,76 & 0,50 & 0,36 & 0,02 \\
\hline NGC3281 & $\operatorname{Sab}(s)$ & $-0,10$ & 0,01 & $-0,19$ & 0,06 & 0,74 & 0,64 & 0,31 & 0,12 \\
\hline NGC3289 & $\mathrm{SB} 0+(\mathrm{rs})$ & $-0,04$ & 0,03 & $-0,03$ & 0,02 & 0,31 & 0,31 & $-0,01$ & $-0,01$ \\
\hline NGC3310 & SABbc(r) & 0,00 & 0,01 & 0,05 & 0,04 & 0,19 & 0,19 & $-0,54$ & $-0,54$ \\
\hline NGC3318 & $\mathrm{SABb}(\mathrm{rs})$ & $-0,34$ & 0,02 & $-0,50$ & 0,04 & 0,58 & 0,24 & 0,13 & $-0,37$ \\
\hline NGC3333 & $\mathrm{SABbc}$ & $-0,19$ & 0,04 & 0,13 & 0,15 & 0,20 & 0,01 & $-0,55$ & $-0,42$ \\
\hline NGC3347 & $\mathrm{SBb}(\mathrm{rs})$ & 0,03 & 0,01 & $-0,07$ & 0,02 & 0,61 & 0,61 & 0,16 & 0,16 \\
\hline NGC3351 & $\mathrm{SBb}(\mathrm{r})$ & 0,03 & 0,02 & 0,19 & 0,05 & 0,66 & 0,66 & $-0,03$ & 0,16 \\
\hline NGC3353 & $\mathrm{Sb}$ & 0,13 & 0,06 & 0,13 & 0,05 & 0,17 & 0,30 & $-0,57$ & $-0,44$ \\
\hline NGC3390 & $\mathrm{Sb}$ & $-0,13$ & 0,02 & $-0,16$ & 0,08 & 0,32 & 0,19 & $-0,06$ & $-0,22$ \\
\hline NGC3521 & $\mathrm{SABbc}(\mathrm{rs})$ & $-0,07$ & 0,03 & - & - & 0,52 & 0,52 & - & - \\
\hline NGC3627 & $\mathrm{SABb}(\mathrm{s})$ & $-0,20$ & 0,02 & $-0,21$ & 0,02 & 0,62 & 0,42 & 0,18 & $-0,03$ \\
\hline NGC3628 & $\mathrm{Sb}$ & $-0,11$ & 0,04 & - & - & 0,28 & 0,17 & - & - \\
\hline NGC3689 & $\mathrm{SABc}(\mathrm{rs})$ & 0,13 & 0,10 & - & - & 0,37 & 0,50 & - & - \\
\hline NGC3810 & $\mathrm{Sc}(\mathrm{rs})$ & $-0,21$ & 0,06 & $-0,27$ & 0,07 & 0,64 & 0,43 & 0,08 & $-0,19$ \\
\hline NGC4051 & $\mathrm{SABbc}(\mathrm{rs})$ & 0,28 & 0,04 & 0,50 & 0,05 & 0,37 & 0,65 & $-0,44$ & 0,06 \\
\hline NGC4088 & $\mathrm{SABbc}(\mathrm{rs})$ & $-0,36$ & 0,01 & - & - & 0,55 & 0,19 & - & - \\
\hline NGC4096 & $\mathrm{SABc}(\mathrm{rs})$ & $-0,20$ & 0,05 & $-0,22$ & 0,03 & 0,32 & 0,12 & $-0,15$ & $-0,37$ \\
\hline NGC4156 & $\mathrm{SBb}(\mathrm{rs})$ & $-0,01$ & 0,08 & 0,32 & 0,17 & 0,72 & 0,72 & $-0,31$ & 0,01 \\
\hline NGC4216 & $\mathrm{SABb}(\mathrm{s})$ & $-0,20$ & 0,02 & $-0,29$ & 0,03 & 0,59 & 0,39 & 0,35 & 0,06 \\
\hline
\end{tabular}


Tabela A.1: Continuação.

\begin{tabular}{|c|c|c|c|c|c|c|c|c|c|}
\hline $\begin{array}{c}\text { Nome } \\
(1)\end{array}$ & $\begin{array}{c}\text { Tipo } \\
(2)\end{array}$ & $\begin{array}{c}G(B-V) \\
(3)\end{array}$ & $\begin{array}{c}\text { erro } \\
(4)\end{array}$ & $\begin{array}{c}G(U-B) \\
(5)\end{array}$ & $\begin{array}{c}\text { erro } \\
(6) \\
\end{array}$ & $\begin{array}{c}(B-V)_{b} \\
(7)\end{array}$ & $\begin{array}{c}(B-V)_{d} \\
(8)\end{array}$ & $\begin{array}{c}(U-B)_{b} \\
(9)\end{array}$ & $\begin{array}{c}(U-B)_{d} \\
(10)\end{array}$ \\
\hline NGC4254 & $\mathrm{Sc}(\mathrm{s})$ & $\begin{array}{c}-0,15 \\
\end{array}$ & 0,01 & $-0,14$ & 0,00 & 0,64 & 0,49 & 0,06 & $-0,08$ \\
\hline NGC4258 & SABbc(s) & $-0,06$ & 0,03 & 0,03 & 0,06 & 0,39 & 0,39 & $-0,04$ & $-0,04$ \\
\hline NGC4273 & $\mathrm{SBc}(\mathrm{s})$ & $-0,03$ & 0,09 & - & - & 0,33 & 0,33 & - & - \\
\hline NGC4303 & $\mathrm{SABbc}(\mathrm{rs})$ & $-0,13$ & 0,03 & 0,04 & 0,07 & 0,65 & 0,52 & $-0,01$ & $-0,01$ \\
\hline NGC4321 & $\operatorname{SABbc}(\mathrm{s})$ & 0,04 & 0,01 & 0,06 & 0,06 & 0,61 & 0,61 & $-0,04$ & $-0,04$ \\
\hline NGC4388 & $\mathrm{Sb}(\mathrm{s})$ & $-0,03$ & 0,01 & 0,09 & 0,01 & 0,17 & 0,17 & $-0,34$ & $-0,34$ \\
\hline NGC4414 & $\mathrm{Sc}(\mathrm{rs})$ & $-0,17$ & 0,01 & $-0,37$ & 0,15 & 0,75 & 0,58 & 0,38 & 0,01 \\
\hline NGC4501 & $\mathrm{Sb}(\mathrm{rs})$ & $-0,24$ & 0,01 & $-0,34$ & 0,03 & 0,76 & 0,52 & 0,36 & 0,02 \\
\hline NGC4527 & SABbc(s) & $-0,24$ & 0,03 & $-0,14$ & 0,05 & 0,68 & 0,44 & 0,08 & $-0,06$ \\
\hline NGC4535 & $\mathrm{SABc}(\mathrm{s})$ & 0,09 & 0,02 & 0,07 & 0,09 & 0,53 & 0,53 & $-0,06$ & $-0,06$ \\
\hline NGC4536 & $\mathrm{SABbc}(\mathrm{rs})$ & $-0,29$ & 0,02 & $-0,17$ & 0,06 & 0,54 & 0,25 & $-0,08$ & $-0,25$ \\
\hline NGC4548 & $\mathrm{SBb}(\mathrm{rs})$ & $-0,16$ & 0,03 & $-0,28$ & 0,01 & 0,87 & 0,71 & 0,49 & 0,21 \\
\hline NGC4565 & $\mathrm{Sb}$ & $-0,19$ & 0,02 & $-0,20$ & 0,07 & 0,32 & 0,13 & 0,06 & $-0,14$ \\
\hline NGC4579 & $\mathrm{SABb}(\mathrm{rs})$ & $-0,12$ & 0,01 & $-0,16$ & 0,02 & 0,84 & 0,72 & 0,41 & 0,25 \\
\hline NGC4593 & $\mathrm{SBb}(\mathrm{rs})$ & 0,28 & 0,11 & 0,62 & 0,03 & 0,65 & 0,93 & $-0,40$ & 0,22 \\
\hline $\mathrm{NGC4647}$ & $\mathrm{SABc}(\mathrm{rs})$ & $-0,32$ & 0,12 & - & - & 0,83 & 0,51 & - & - \\
\hline NGC4651 & $\mathrm{Sc}(\mathrm{rs})$ & $-0,26$ & 0,00 & $-0,52$ & 0,00 & 0,73 & 0,47 & 0,34 & $-0,18$ \\
\hline NGC4666 & $\mathrm{SABC}$ & $-0,15$ & 0,00 & - & - & 0,42 & 0,27 & - & - \\
\hline NGC4699 & $\mathrm{SABb}(\mathrm{rs})$ & $-0,05$ & 0,01 & $-0,14$ & 0,02 & 0,75 & 0,75 & 0,41 & 0,27 \\
\hline NGC4900 & $\mathrm{SBc}(\mathrm{rs})$ & 0,12 & 0,01 & 0,12 & 0,09 & 0,42 & 0,54 & $-0,27$ & $-0,15$ \\
\hline NGC4902 & $\mathrm{SBb}(\mathrm{r})$ & $-0,39$ & 0,09 & - & - & 0,94 & 0,56 & - & - \\
\hline NGC4911 & SABbc(r) & $-0,17$ & 0,06 & $-0,34$ & 0,01 & 0,86 & 0,69 & 0,41 & 0,07 \\
\hline NGC4939 & $\operatorname{Sbc}(\mathrm{s})$ & $-0,29$ & 0,02 & $-0,36$ & 0,06 & 0,70 & 0,41 & 0,24 & $-0,12$ \\
\hline NGC5005 & $\mathrm{SABbc}(\mathrm{rs})$ & $-0,16$ & 0,03 & $-0,18$ & 0,02 & 0,69 & 0,53 & 0,29 & 0,11 \\
\hline NGC5033 & $\mathrm{Sc}(\mathrm{s})$ & $-0,30$ & 0,03 & $-0,11$ & 0,06 & 0,65 & 0,35 & 0,15 & 0,04 \\
\hline NGC5055 & $\operatorname{Sbc}(\mathrm{rs})$ & $-0,16$ & 0,01 & $-0,37$ & 0,06 & 0,68 & 0,52 & 0,19 & $-0,18$ \\
\hline NGC5188 & $\mathrm{SABb}(\mathrm{s})$ & $-0,21$ & 0,10 & $-0,34$ & 0,06 & 0,62 & 0,41 & 0,19 & $-0,15$ \\
\hline NGC5194 & $\operatorname{Sbc}(\mathrm{s})$ & $-0,14$ & 0,01 & $-0,24$ & 0,02 & 0,58 & 0,44 & 0,04 & $-0,20$ \\
\hline NGC5236 & $\mathrm{SABc}(\mathrm{s})$ & 0,32 & 0,01 & 0,25 & 0,04 & 0,47 & 0,79 & $-0,20$ & 0,05 \\
\hline NGC5248 & $\mathrm{SABbc}(\mathrm{rs})$ & $-0,07$ & 0,02 & $-0,10$ & 0,03 & 0,58 & 0,58 & 0,06 & $-0,04$ \\
\hline NGC5364 & $\mathrm{Sbc}(\mathrm{rs})$ & $-0,18$ & 0,02 & $-0,36$ & 0,03 & 0,67 & 0,49 & 0,24 & $-0,12$ \\
\hline NGC5371 & $\mathrm{SABbc}(\mathrm{rs})$ & $-0,35$ & 0,03 & $-0,55$ & 0,04 & 0,91 & 0,56 & 0,51 & $-0,04$ \\
\hline NGC5426 & $\mathrm{Sc}(\mathrm{s})$ & $-0,22$ & 0,04 & $-0,33$ & 0,10 & 0,53 & 0,31 & 0,00 & $-0,33$ \\
\hline NGC5427 & $\operatorname{Sc}(\mathrm{s})$ & $-0,09$ & 0,00 & - & - & 0,52 & 0,52 & - & - \\
\hline NGC5483 & $\mathrm{Sc}(\mathrm{s})$ & $-0,14$ & 0,03 & - & - & 0,63 & 0,49 & - & - \\
\hline NGC5530 & $\mathrm{Sbc}(\mathrm{rs})$ & $-0,29$ & 0,04 & $-0,50$ & 0,02 & 0,74 & 0,45 & 0,50 & 0,00 \\
\hline NGC5592 & $\operatorname{SBbc}(\mathrm{s})$ & $-0,08$ & 0,01 & $-0,05$ & 0,05 & 0,52 & 0,52 & $-0,04$ & $-0,04$ \\
\hline NGC5633 & $\mathrm{Sb}(\mathrm{rs})$ & $-0,32$ & 0,15 & - & - & 0,70 & 0,38 & - & - \\
\hline NGC5643 & $\mathrm{SABc}(\mathrm{rs})$ & 0,07 & 0,14 & 0,21 & 0,08 & 0,58 & 0,58 & $-0,10$ & 0,11 \\
\hline NGC5653 & $\mathrm{Sb}(\mathrm{rs})$ & 0,31 & 0,10 & $-0,09$ & 0,07 & 0,24 & 0,55 & $-0,12$ & $-0,12$ \\
\hline NGC5676 & $\operatorname{Sbc}(\mathrm{rs})$ & $-0,22$ & 0,02 & $-0,40$ & 0,02 & 0,59 & 0,37 & 0,20 & $-0,20$ \\
\hline NGC5746 & $\mathrm{SABb}(\mathrm{rs})$ & $-0,17$ & 0,04 & $-0,45$ & 0,10 & 0,46 & 0,29 & 0,29 & $-0,16$ \\
\hline NGC5792 & $\mathrm{SBb}(\mathrm{rs})$ & $-0,21$ & 0,02 & $-0,20$ & 0,00 & 0,47 & 0,26 & 0,01 & $-0,19$ \\
\hline NGC5850 & $\mathrm{SBb}(\mathrm{r})$ & $-0,23$ & 0,04 & $-0,26$ & 0,05 & 0,90 & 0,67 & 0,45 & 0,19 \\
\hline NGC5859 & SBbc(s) & $-0,05$ & 0,06 & - & - & 0,40 & 0,40 & - & - \\
\hline NGC5861 & $\mathrm{SABc}(\mathrm{rs})$ & $-0,26$ & 0,06 & - & - & 0,68 & 0,42 & - & - \\
\hline NGC5879 & $\mathrm{Sbc}(\mathrm{rs})$ & $-0,14$ & 0,02 & - & - & 0,36 & 0,22 & - & - \\
\hline NGC5899 & $\mathrm{SABc}(\mathrm{rs})$ & $-0,18$ & 0,06 & - & - & 0,59 & 0,41 & - & - \\
\hline NGC5907 & $\mathrm{Sc}(\mathrm{s})$ & $-0,23$ & 0,01 & $-0,30$ & 0,04 & 0,17 & $-0,06$ & $-0,21$ & $-0,51$ \\
\hline NGC5921 & $\operatorname{SBbc}(\mathrm{r})$ & $-0,15$ & 0,02 & $-0,27$ & 0,02 & 0,73 & 0,58 & 0,23 & $-0,04$ \\
\hline NGC5962 & $\mathrm{Sc}(\mathrm{r})$ & $-0,19$ & 0,04 & $-0,16$ & 0,06 & 0,66 & 0,47 & 0,11 & $-0,05$ \\
\hline NGC5970 & $\mathrm{SBc}(\mathrm{r})$ & $-0,17$ & 0,00 & - & - & 0,71 & 0,54 & - & - \\
\hline NGC5985 & $\mathrm{SABb}(\mathrm{r})$ & $-0,13$ & 0,02 & $-0,31$ & 0,03 & 0,67 & 0,54 & 0,27 & $-0,04$ \\
\hline NGC5987 & $\mathrm{Sb}$ & $-0,10$ & 0,04 & - & - & 0,63 & 0,53 & - & - \\
\hline NGC6052 & $\mathrm{Sc}$ & 0,08 & 0,03 & $-0,16$ & 0,03 & 0,18 & 0,18 & 0,20 & $-0,54$ \\
\hline NGC6181 & $\mathrm{SABc}(\mathrm{rs})$ & $-0,18$ & 0,02 & $-0,17$ & 0,03 & 0,49 & 0,31 & $-0,12$ & $-0,29$ \\
\hline NGC6207 & $\mathrm{Sc}(\mathrm{s})$ & 0,06 & 0,02 & $-0,04$ & 0,02 & 0,20 & 0,20 & $-0,39$ & $-0,39$ \\
\hline NGC6217 & $\mathrm{SBbc}(\mathrm{rs})$ & 0,12 & 0,04 & 0,17 & 0,03 & 0,40 & 0,52 & $-0,31$ & $-0,14$ \\
\hline NGC6221 & $\mathrm{SBc}(\mathrm{s})$ & $-0,18$ & 0,02 & 0,03 & 0,03 & 0,62 & 0,44 & $-0,06$ & $-0,06$ \\
\hline NGC6239 & $\mathrm{SBb}(\mathrm{s})$ & $-0,05$ & 0,02 & 0,06 & 0,03 & 0,18 & 0,18 & $-0,39$ & $-0,39$ \\
\hline NGC6384 & $\operatorname{SABbc}(\mathrm{r})$ & $-0,26$ & 0,03 & $-0,26$ & 0,04 & 0,70 & 0,44 & 0,28 & 0,02 \\
\hline NGC6412 & $\mathrm{Sc}(\mathrm{s})$ & $-0,12$ & 0,03 & - & - & 0,57 & 0,45 & - & - \\
\hline NGC6574 & $\mathrm{SABbc}(\mathrm{rs})$ & $-0,12$ & 0,03 & $-0,12$ & 0,06 & 0,67 & 0,55 & 0,10 & $-0,02$ \\
\hline NGC6643 & $\mathrm{Sc}(\mathrm{rs})$ & $-0,14$ & 0,01 & $-0,17$ & 0,05 & 0,49 & 0,35 & $-0,10$ & $-0,27$ \\
\hline
\end{tabular}


Tabela A.1: Continuação.

\begin{tabular}{|c|c|c|c|c|c|c|c|c|c|}
\hline $\begin{array}{c}\text { Nome } \\
(1) \\
\end{array}$ & $\begin{array}{c}\text { Tipo } \\
(2) \\
\end{array}$ & $\begin{array}{c}G(B-V) \\
(3) \\
\end{array}$ & $\begin{array}{c}\text { erro } \\
(4) \\
\end{array}$ & $\begin{array}{c}G(U-B) \\
(5) \\
\end{array}$ & $\begin{array}{c}\text { erro } \\
(6) \\
\end{array}$ & $\begin{array}{c}(B-V)_{b} \\
(7)\end{array}$ & $\begin{array}{c}(B-V) d \\
(8)\end{array}$ & $\begin{array}{c}(U-B)_{b} \\
(9)\end{array}$ & $\begin{array}{c}(U-B)_{d} \\
(10)\end{array}$ \\
\hline NGC6699 & SABbc(rs) & $-0,22$ & 0,02 & $-0,24$ & 0,04 & 0,76 & 0,54 & 0,14 & $-0,10$ \\
\hline NGC6744 & $\mathrm{SABbc}(\mathrm{r})$ & $-0,10$ & 0,03 & 0,20 & 0,09 & 0,71 & 0,61 & 0,40 & 0,60 \\
\hline NGC6753 & $\mathrm{Sb}(\mathrm{r})$ & $-0,13$ & 0,02 & $-0,17$ & 0,03 & 0,86 & 0,73 & 0,24 & 0,07 \\
\hline NGC6764 & $\operatorname{SBbc}(\mathrm{s})$ & 0,13 & 0,06 & 0,26 & 0,06 & 0,32 & 0,45 & $-0,35$ & $-0,09$ \\
\hline NGC6769 & $\mathrm{SABb}(\mathrm{r})$ & $-0,20$ & 0,03 & $-0,49$ & 0,13 & 0,76 & 0,56 & 0,42 & $-0,07$ \\
\hline NGC6780 & $\mathrm{SABc}(\mathrm{rs})$ & $-0,28$ & 0,10 & $-0,04$ & 0,07 & 0,76 & 0,48 & 0,01 & 0,01 \\
\hline NGC6814 & $\mathrm{SABbc}(\mathrm{rs})$ & $-0,11$ & 0,05 & 0,28 & 0,13 & 0,82 & 0,71 & $-0,06$ & 0,22 \\
\hline NGC6872 & $\mathrm{SBb}(\mathrm{s})$ & $-0,11$ & 0,02 & $-0,24$ & 0,03 & 0,52 & 0,39 & 0,31 & 0,07 \\
\hline NGC6887 & $\mathrm{Sbc}$ & $-0,20$ & 0,07 & $-0,37$ & 0,09 & 0,52 & 0,32 & 0,16 & $-0,21$ \\
\hline NGC6890 & $\mathrm{Sb}(\mathrm{rs})$ & $-0,21$ & 0,02 & $-0,24$ & 0,04 & 0,82 & 0,61 & 0,24 & 0,00 \\
\hline NGC6923 & $\mathrm{SBb}(\mathrm{rs})$ & $-0,38$ & 0,04 & $-0,33$ & 0,04 & 0,76 & 0,38 & 0,23 & $-0,10$ \\
\hline NGC6925 & $\mathrm{Sbc}(\mathrm{s})$ & $-0,35$ & 0,02 & $-0,52$ & 0,12 & 0,55 & 0,20 & 0,23 & $-0,29$ \\
\hline NGC6951 & $\mathrm{SABbc}(\mathrm{rs})$ & 0,00 & 0,05 & 0,07 & 0,07 & 0,62 & 0,62 & 0,10 & 0,10 \\
\hline NGC6984 & $\mathrm{SBc}(\mathrm{r})$ & $-0,35$ & 0,03 & $-0,36$ & 0,01 & 0,62 & 0,27 & 0,06 & $-0,30$ \\
\hline NGC7038 & $\operatorname{SABc}(\mathrm{s})$ & $-0,13$ & 0,03 & $-0,27$ & 0,03 & 0,63 & 0,50 & 0,25 & $-0,02$ \\
\hline NGC7083 & $\operatorname{Sbc}(\mathrm{s})$ & $-0,20$ & 0,02 & $-0,27$ & 0,02 & 0,63 & 0,43 & 0,13 & $-0,14$ \\
\hline NGC7090 & $\mathrm{SBc}$ & $-0,01$ & 0,06 & $-0,05$ & 0,01 & $-0,11$ & $-0,11$ & $-0,59$ & $-0,59$ \\
\hline NGC7125 & $\mathrm{SABc}(\mathrm{rs})$ & $-0,14$ & 0,01 & 0,09 & 0,09 & 0,36 & 0,22 & $-0,20$ & $-0,20$ \\
\hline NGC7126 & $\mathrm{Sc}(\mathrm{rs})$ & $-0,17$ & 0,02 & $-0,30$ & 0,05 & 0,49 & 0,32 & 0,01 & $-0,29$ \\
\hline NGC7137 & $\mathrm{SABc}(\mathrm{rs})$ & 0,02 & 0,01 & 0,07 & 0,02 & 0,51 & 0,51 & $-0,12$ & $-0,12$ \\
\hline NGC 7171 & $\mathrm{SBb}(\mathrm{rs})$ & $-0,20$ & 0,01 & $-0,35$ & 0,05 & 0,67 & 0,47 & 0,15 & $-0,20$ \\
\hline NGC 7177 & $\operatorname{SABb}(r)$ & $-0,16$ & 0,02 & $-0,17$ & 0,02 & 0,76 & 0,60 & 0,33 & 0,16 \\
\hline NGC7184 & $\mathrm{SBc}(\mathrm{r})$ & $-0,28$ & 0,01 & $-0,33$ & 0,09 & 0,50 & 0,22 & 0,11 & $-0,22$ \\
\hline NGC7205 & $\operatorname{Sbc}(\mathrm{s})$ & $-0,29$ & 0,01 & $-0,44$ & 0,02 & 0,60 & 0,31 & 0,11 & $-0,33$ \\
\hline NGC7314 & $\mathrm{SABbc}(\mathrm{rs})$ & $-0,21$ & 0,02 & $-0,32$ & 0,05 & 0,54 & 0,33 & 0,01 & $-0,31$ \\
\hline NGC7329 & $\mathrm{SBb}(\mathrm{r})$ & $-0,20$ & 0,04 & $-0,35$ & 0,01 & 0,78 & 0,58 & 0,38 & 0,03 \\
\hline NGC7331 & $\mathrm{Sb}(\mathrm{s})$ & $-0,13$ & 0,01 & $-0,33$ & 0,04 & 0,57 & 0,44 & 0,25 & $-0,08$ \\
\hline NGC7339 & $\mathrm{SABbc}(\mathrm{s})$ & 0,08 & 0,11 & 0,17 & 0,03 & 0,32 & 0,32 & $-0,37$ & $-0,20$ \\
\hline NGC7412 & $\mathrm{SBb}(\mathrm{s})$ & $-0,23$ & 0,01 & $-0,50$ & 0,03 & 0,64 & 0,41 & 0,29 & $-0,21$ \\
\hline NGC7448 & $\operatorname{Sbc}(\mathrm{rs})$ & $-0,14$ & 0,02 & $-0,22$ & 0,00 & 0,30 & 0,16 & $-0,17$ & $-0,39$ \\
\hline NGC7479 & $\operatorname{SBc}(\mathrm{s})$ & $-0,25$ & 0,02 & $-0,27$ & 0,02 & 0,78 & 0,53 & 0,30 & 0,03 \\
\hline NGC7496 & $\mathrm{SBb}(\mathrm{s})$ & 0,23 & 0,03 & 0,33 & 0,06 & 0,35 & 0,58 & $-0,42$ & $-0,09$ \\
\hline NGC7531 & $\operatorname{SABbc}(\mathrm{r})$ & $-0,23$ & 0,01 & $-0,38$ & 0,02 & 0,60 & 0,37 & 0,19 & $-0,19$ \\
\hline NGC7537 & Sbc & $-0,22$ & 0,03 & $-0,08$ & 0,04 & 0,30 & 0,08 & $-0,42$ & $-0,42$ \\
\hline NGC7541 & $\mathrm{SBbc}(\mathrm{rs})$ & $-0,21$ & 0,04 & $-0,22$ & 0,05 & 0,45 & 0,24 & $-0,10$ & $-0,32$ \\
\hline NGC7590 & $\mathrm{Sbc}(\mathrm{rs})$ & $-0,36$ & 0,03 & $-0,37$ & 0,10 & 0,55 & 0,19 & 0,05 & $-0,32$ \\
\hline NGC7606 & $\mathrm{Sb}(\mathrm{s})$ & $-0,18$ & 0,04 & $-0,29$ & 0,08 & 0,57 & 0,39 & 0,11 & $-0,18$ \\
\hline NGC7640 & $\operatorname{SBc}(s)$ & $-0,20$ & 0,02 & $-0,01$ & 0,02 & 0,02 & $-0,18$ & $-0,59$ & $-0,59$ \\
\hline NGC7673 & $\mathrm{Sc}$ & 0,12 & 0,04 & 0,23 & 0,14 & 0,19 & 0,31 & $-0,58$ & $-0,35$ \\
\hline NGC7716 & $\operatorname{SABb}(r)$ & $-0,22$ & 0,03 & - & - & 0,81 & 0,59 & - & - \\
\hline NGC7723 & $\mathrm{SBb}(\mathrm{r})$ & $-0,09$ & 0,04 & 0,00 & 0,05 & 0,58 & 0,58 & 0,00 & 0,00 \\
\hline NGC7742 & $\mathrm{Sb}(\mathrm{r})$ & $-0,15$ & 0,05 & $-0,37$ & 0,20 & 0,79 & 0,63 & 0,32 & $-0,05$ \\
\hline NGC7755 & $\mathrm{SBc}(\mathrm{rs})$ & $-0,13$ & 0,03 & $-0,07$ & 0,04 & 0,74 & 0,61 & 0,05 & 0,05 \\
\hline NGC7757 & $\mathrm{Sc}(\mathrm{rs})$ & $-0,24$ & 0,07 & $-0,29$ & 0,12 & 0,51 & 0,27 & $-0,07$ & $-0,36$ \\
\hline NGC7782 & $\mathrm{Sb}(\mathrm{s})$ & $-0,25$ & 0,06 & $-0,59$ & 0,19 & 0,82 & 0,56 & 0,51 & $-0,08$ \\
\hline UGC03973 & $\mathrm{SBb}$ & 0,13 & 0,10 & 0,30 & 0,07 & 0,30 & 0,43 & $-1,02$ & $-0,72$ \\
\hline UGC04013 & $\mathrm{Sb}$ & 0,13 & 0,05 & 0,44 & 0,12 & 0,13 & 0,26 & $-1,08$ & $-0,64$ \\
\hline
\end{tabular}


Tabela A.2: A sub-amostra.

\begin{tabular}{|c|c|c|c|c|c|c|c|}
\hline $\begin{array}{c}\text { Nome } \\
(1)\end{array}$ & $\begin{array}{c}\mathrm{B} / \mathrm{D} \text { (Lum.) } \\
(2)\end{array}$ & $\begin{array}{c}\text { B/D (Diâm.) } \\
\text { (3) }\end{array}$ & $\begin{array}{c}\text { n (erro) } \\
(4)\end{array}$ & $\begin{array}{c}\mu_{c}(\mathrm{D}) \\
(5)\end{array}$ & $\begin{array}{c}R_{C}(\mathrm{D}) \text { (erro) } \\
(6)\end{array}$ & $\begin{array}{c}\mu_{e}(\mathrm{~B}) \\
(7)\end{array}$ & $\begin{array}{c}R_{e}(\mathrm{~B}) \text { (erro) } \\
\text { (8) }\end{array}$ \\
\hline NGC0151 & 0.705 & 2.111 & 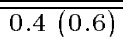 & 21.37 & $19.6(2.0)$ & 23.21 & $33.0(3.8)$ \\
\hline NGC0289 & 2.592 & 0.328 & $0.3(0.2)$ & 23.79 & $55.0(8.2)$ & 21.82 & $33.0(1.9)$ \\
\hline NGC0309 & 0.034 & 2.882 & $0.5(1.0)$ & 21.62 & $18.0(1.3)$ & 22.73 & $6.0(4.9)$ \\
\hline NGC0488 & 3.115 & 1.703 & $0.8(0.1)$ & 21.75 & $33.9(3.8)$ & 22.53 & $60.5(2.2)$ \\
\hline NGC0613 & 1.629 & 0.890 & $0.2(0.2)$ & 22.11 & $43.0(3.9)$ & 22.11 & $68.0(3.8)$ \\
\hline NGC1068 & 1.394 & 0.362 & $0.2(0.1)$ & 21.45 & $55.8(3.8)$ & 20.50 & $40.8(1.8)$ \\
\hline NGC1073 & 0.225 & 1.664 & $1.7(1.7)$ & 22.74 & $43.7(3.9)$ & 23.48 & $38.1(9.1)$ \\
\hline NGC1097 & 1.695 & 0.848 & $0.4(0.2)$ & 21.80 & $72.0(8.7)$ & 21.10 & $77.3(5.3)$ \\
\hline NGC1187 & 0.538 & 0.811 & $0.4(0.4)$ & 21.84 & $33.4(2.3)$ & 23.37 & $51.1(5.7)$ \\
\hline NGC1232 & 0.040 & 1.920 & $0.4(1.9)$ & 21.45 & $45.7(2.7)$ & 23.18 & $21.5(15.3)$ \\
\hline NGC1255 & 1.562 & 2.361 & $0.3(0.2)$ & 22.28 & $25.6(3.2)$ & 23.41 & $51.1(3.4)$ \\
\hline NGC1300 & 0.835 & 1.196 & $1.4(0.9)$ & 22.91 & $53.5(6.8)$ & 23.58 & $73.6(12.11)$ \\
\hline NGC1365 & 1.542 & 0.920 & $0.4(0.4)$ & 22.15 & $66.3(10.3)$ & 22.45 & $81.2(7.6)$ \\
\hline NGC1672 & 1.318 & 0.855 & $0.5(0.3)$ & 22.39 & $59.6(8.2)$ & 21.72 & $58.5(5.2)$ \\
\hline NGC1784 & 0.612 & 2.908 & $0.5(0.3)$ & 22.25 & $33.1(2.5)$ & 21.72 & $22.3(2.5)$ \\
\hline NGC2336 & 0.059 & 1.682 & $0.3(1.0)$ & 21.60 & $41.9(2.2)$ & 22.13 & $9.4(3.5)$ \\
\hline $\mathrm{NGC} 2442$ & 0.461 & 0.700 & $0.3(0.7)$ & 21.66 & $44.9(5.6)$ & 22.42 & $55.1(7.4)$ \\
\hline $\mathrm{NGC} 2776$ & 0.248 & 0.355 & $0.4(0.6)$ & 21.22 & $17.5(1.0)$ & 23.06 & $18.3(3.4)$ \\
\hline NGC 2889 & 1.631 & 0.730 & $0.3(0.1)$ & 21.67 & $13.7(1.1)$ & 22.46 & $23.4(1.3)$ \\
\hline NGC2997 & 0.011 & 1.788 & $0.3(1.0)$ & 21.10 & $60.2(5.1)$ & 22.50 & $12.5(24.6)$ \\
\hline NGC3001 & 0.277 & 2.345 & $1.4(1.8)$ & 20.78 & $19.2(1.6)$ & 24.30 & $41.6(9.6)$ \\
\hline NGC3223 & 0.822 & 0.772 & $0.6(0.3)$ & 21.15 & $27.3(1.8)$ & 22.75 & $33.9(2.4)$ \\
\hline NGC4051 & 0.182 & 1.998 & $1.8(1.5)$ & 21.39 & $38.1(2.9)$ & 24.57 & $71.3(29.0)$ \\
\hline NGC4501 & 1.462 & 2.635 & $0.4(0.2)$ & 20.81 & $51.0(4.2)$ & 21.86 & $70.8(3.8)$ \\
\hline NGC4535 & 0.044 & 3.875 & $0.6(0.9)$ & 21.61 & $50.5(3.6)$ & 22.52 & $18.0(9.4)$ \\
\hline NGC4579 & 0.669 & 1.203 & $0.8(0.3)$ & 20.94 & $43.3(2.2)$ & 22.23 & $53.7(4.3)$ \\
\hline NGC4593 & 0.888 & 0.778 & $0.7(0.4)$ & 22.10 & $34.5(3.1)$ & 21.92 & $31.9(3.2)$ \\
\hline NGC4699 & 0.528 & 0.452 & $0.4(0.2)$ & 20.47 & $37.5(1.9)$ & 21.51 & $39.5(3.3)$ \\
\hline NGC4900 & 0.015 & 5.170 & $0.2(1.0)$ & 20.56 & $14.2(0.9)$ & 22.79 & $6.7(6.8)$ \\
\hline NGC5248 & 0.485 & 2.532 & $0.3(0.5)$ & 21.22 & $39.2(3.1)$ & 22.80 & $49.8(5.5)$ \\
\hline NGC5364 & 0.224 & 0.395 & $1.0(0.9)$ & 22.07 & $48.7(3.9)$ & 23.40 & $27.3(7.2)$ \\
\hline NGC5850 & 0.824 & 0.579 & $0.9(0.4)$ & 23.03 & $46.9(4.7)$ & 22.04 & $25.0(2.9)$ \\
\hline NGC5921 & 0.411 & 0.435 & $0.5(0.6)$ & 22.07 & $40.1(4.0)$ & 22.63 & $33.5(5.0)$ \\
\hline NGC5985 & 0.008 & 3.838 & $0.2(1.0)$ & 21.19 & $31.9(1.6)$ & 23.30 & $7.6(11.8)$ \\
\hline NGC7125 & 0.176 & 1.802 & $1.1(1.9)$ & 22.43 & $20.6(1.9)$ & 22.95 & $10.5(3.7)$ \\
\hline NGC7412 & 0.875 & 1.688 & $0.2(0.3)$ & 21.99 & $23.9(2.2)$ & 22.77 & $26.6(2.2)$ \\
\hline NGC7479 & 0.415 & 0.610 & $0.3(0.4)$ & 21.62 & $33.2(2.6)$ & 22.13 & $43.9(4.4)$ \\
\hline NGC7606 & 0.803 & 2.999 & $0.3(0.2)$ & 21.05 & $30.8(2.1)$ & 23.01 & $53.3(3.4)$ \\
\hline NGC7755 & 0.764 & 1.528 & $0.5(0.3)$ & 22.30 & $28.6(2.3)$ & 22.42 & $23.0(2.0)$ \\
\hline
\end{tabular}




\section{Apêndice B}

\section{Exemplos de gradientes de cor}

Neste apêndice, apresentamos mais exemplos dos gradientes de cor $(\mathrm{B}-\mathrm{V})$ e $(\mathrm{U}-\mathrm{B})$ para 20 galáxias de nossa amostra. Pode-se notar, mais uma vez, a existência das três categorias de gradientes definidas por nós na seção 2.4.2. Também pode-se verificar a importância da utilização de métodos estatísticos robustos na determinação dos gradientes. As figuras são similares à Figura 2.4, exceto que não apresentamos aqui os ajustes dos gradientes. 

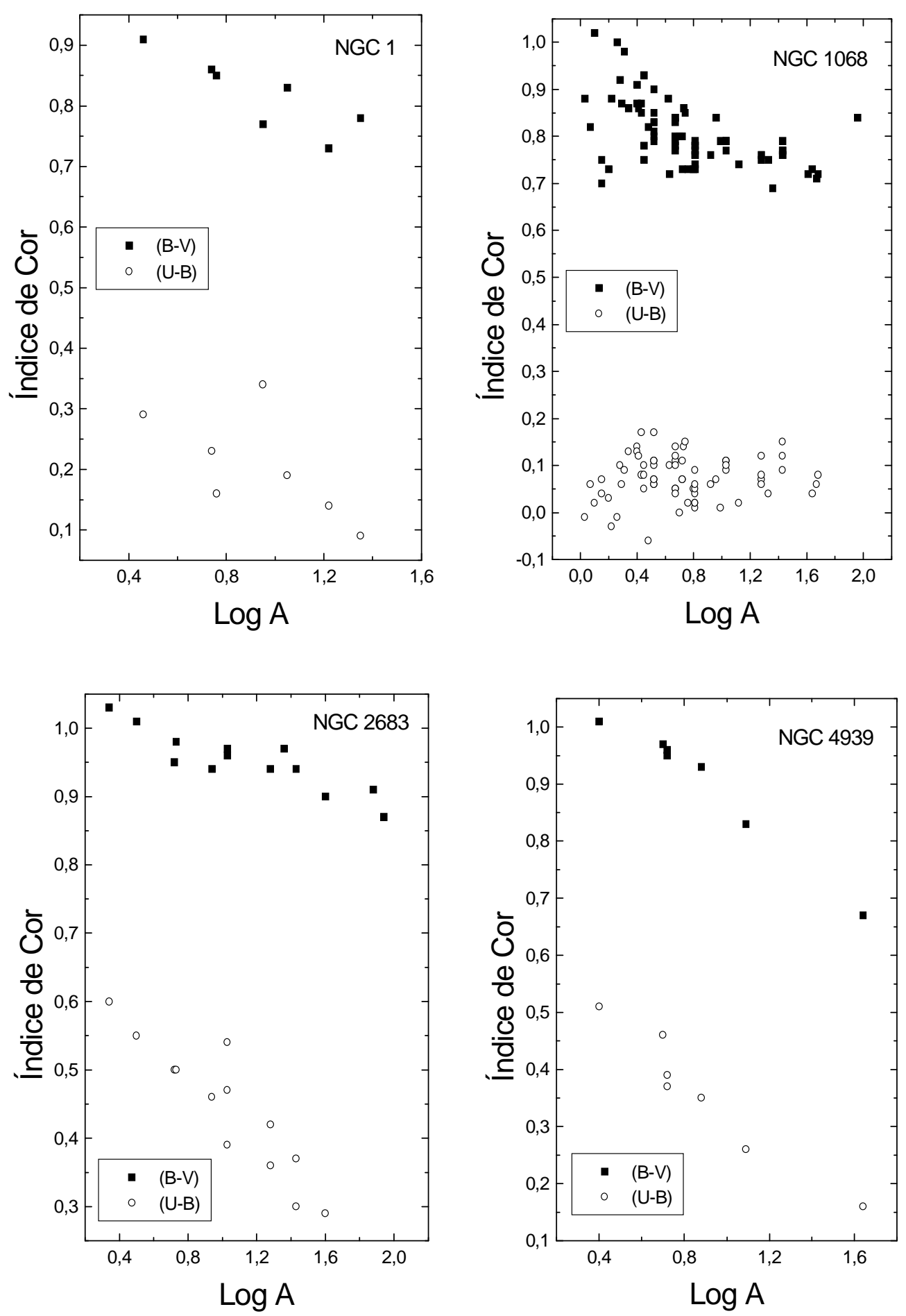

Figura B.1: Mais exemplos de gradientes de cor para vinte galáxias em nossa amostra. Pode-se notar, mais uma vez, a existência das três categorias de gradientes (confira os valores na Tabela A.1). Os índices de cor em magnitudes estão expressos em função do logaritmo da abertura do diafragma em unidades de 0.1 minutos de arco. Os quadrados indicam o índice (B-V), enquanto que os círculos indicam o (U-B). 

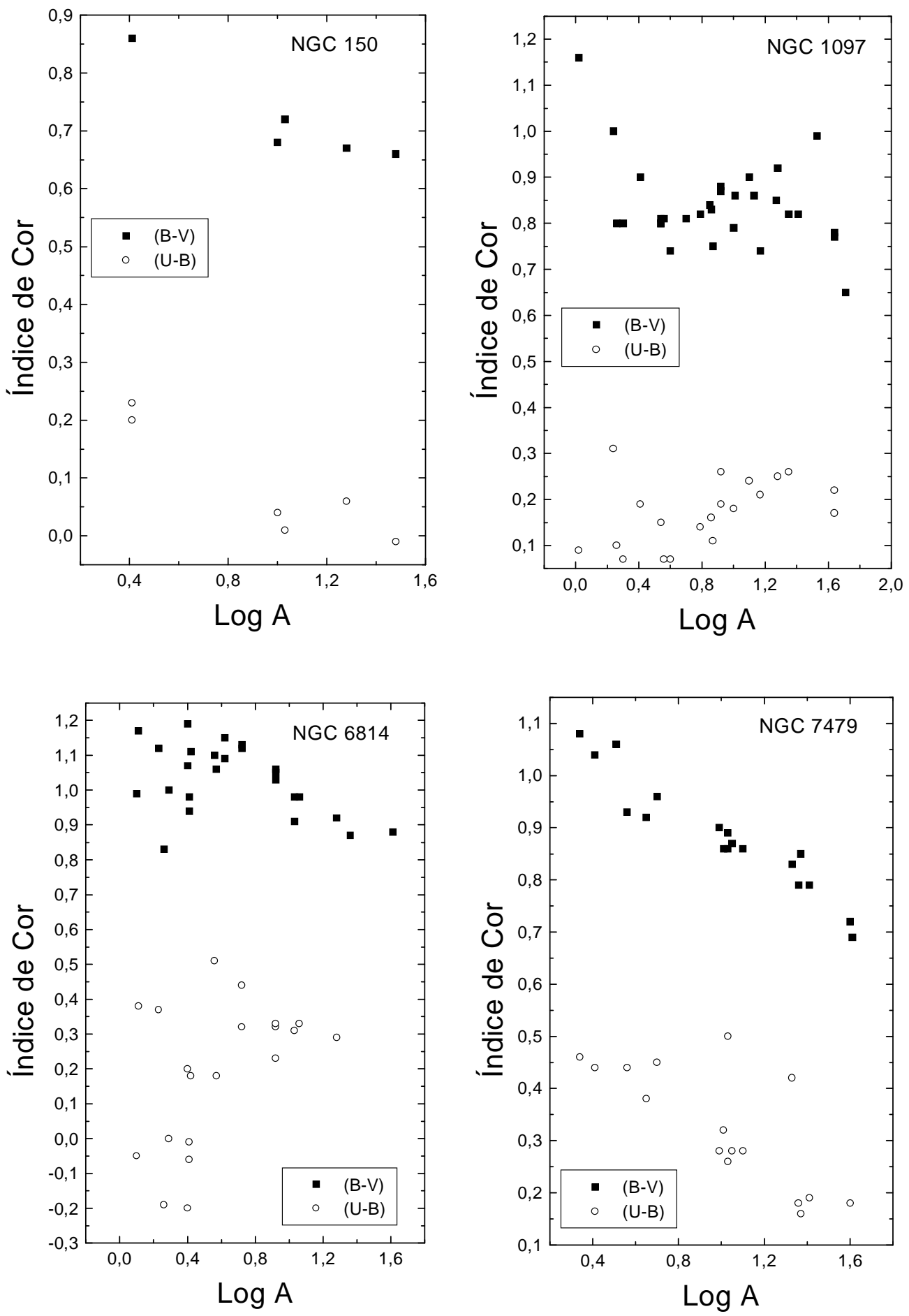

Figura B.1: Continuação. 

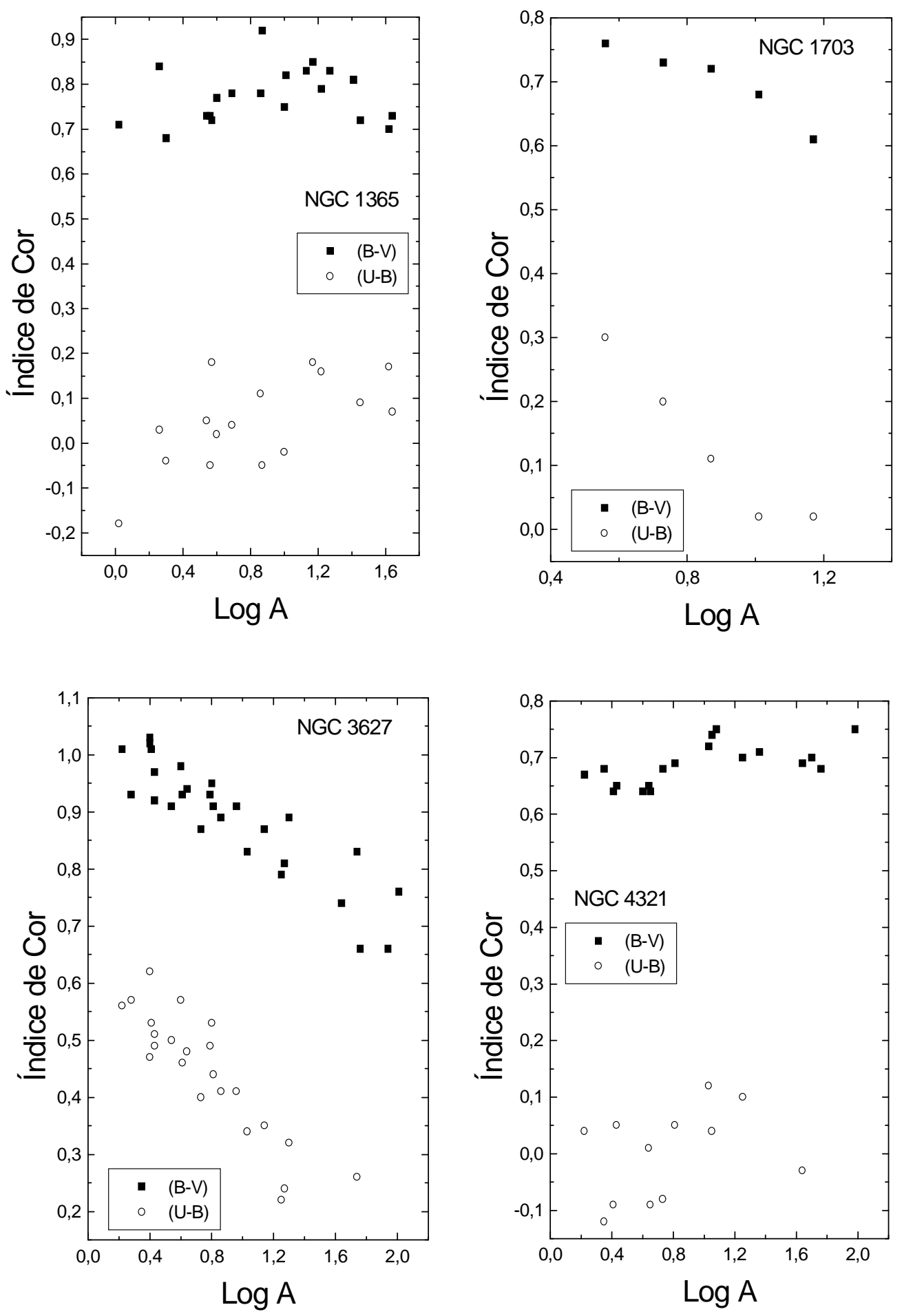

Figura B.1: Continuação. 

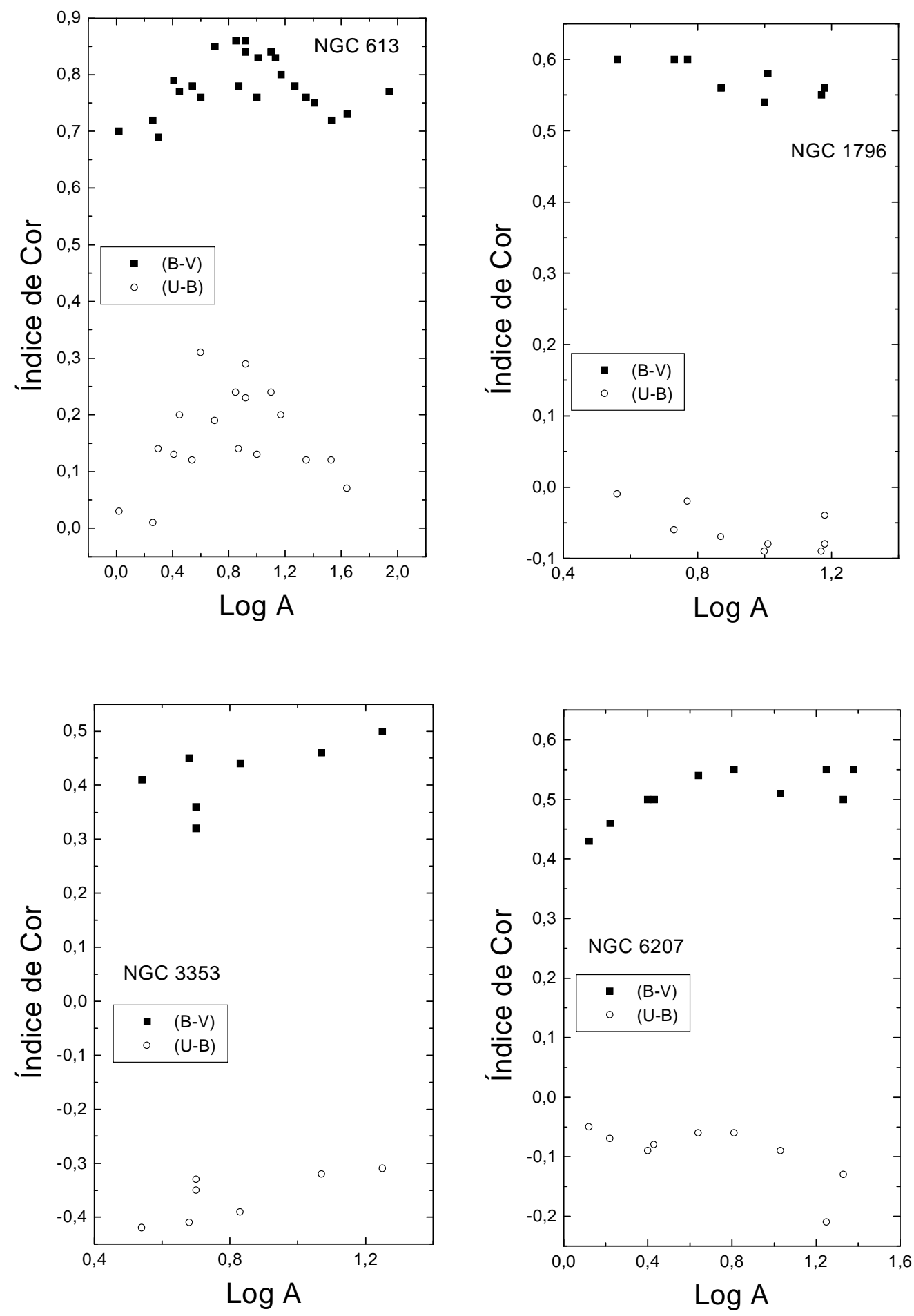

Figura B.1: Continuação. 

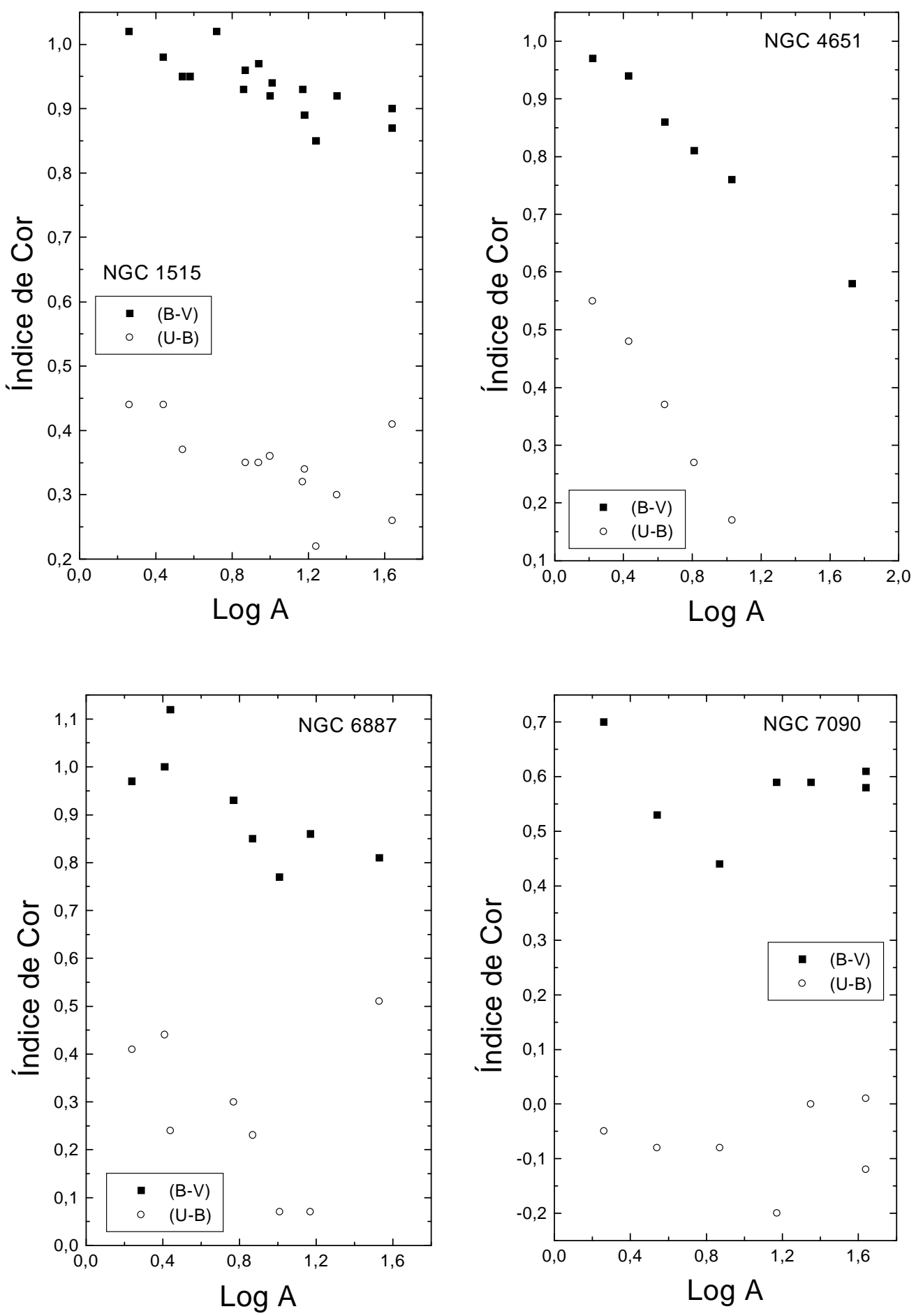

Figura B.1: Continuação. 


\section{Apêndice $\mathrm{C}$}

\section{Exemplos de resultados da decomposição bojo/disco}

Este apêndice exibe mais exemplos dos resultados obtidos através do algoritmo de decomposição bojo/disco. As figuras são análogas à Figura 3.1. A Figura C.1 apresenta mais sete exemplos da decomposição com imagens do DSS, que se referem às seguintes galáxias: NGC 151, NGC 1073, NGC 1784, NGC 2997, NGC 3223, NGC 7125 e NGC 7479. Na Figura C.2 mostramos resultados referentes à aplicação do algoritmo de decomposição em imagens que obtivemos em CCD no OPD/LNA, que se referem às galáxias NGC 151, NGC 488 e NGC 7479. Assim, o leitor pode comparar os resultados da decomposição para estes três últimos objetos em imagens DSS e naquelas imagens obtidas em CCD. Pode-se avaliar a influência das barras na qualidade do ajuste, bem como verificar o efeito da saturação central nas imagens do DSS sobre os perfis de brilho. 

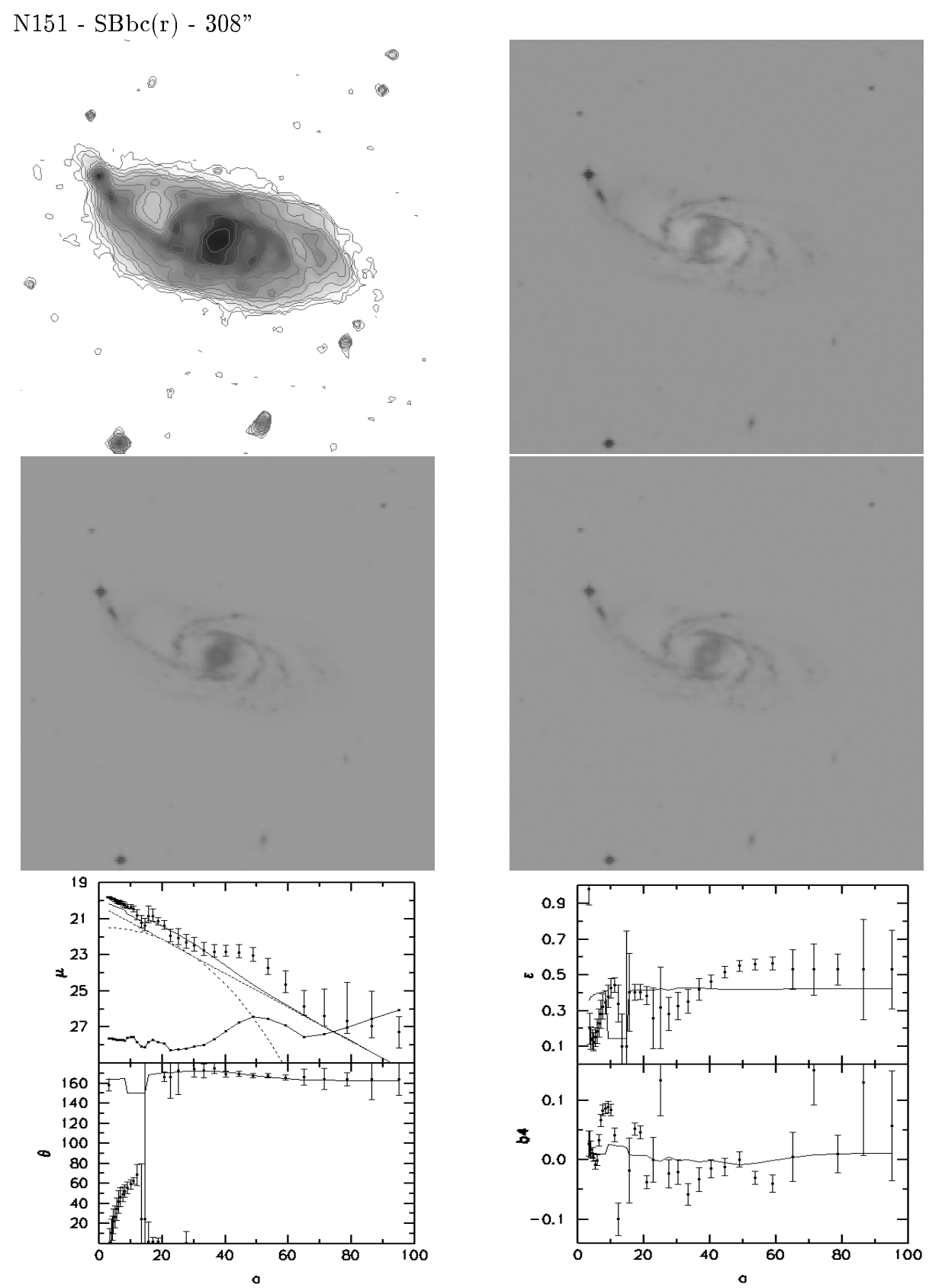

Figura C.1: Mais exemplos dos resultados obtidos através da aplicação do algoritmo de decomposição bojo/disco em imagens do DSS. As figuras são análogas à Figura 3.1. 

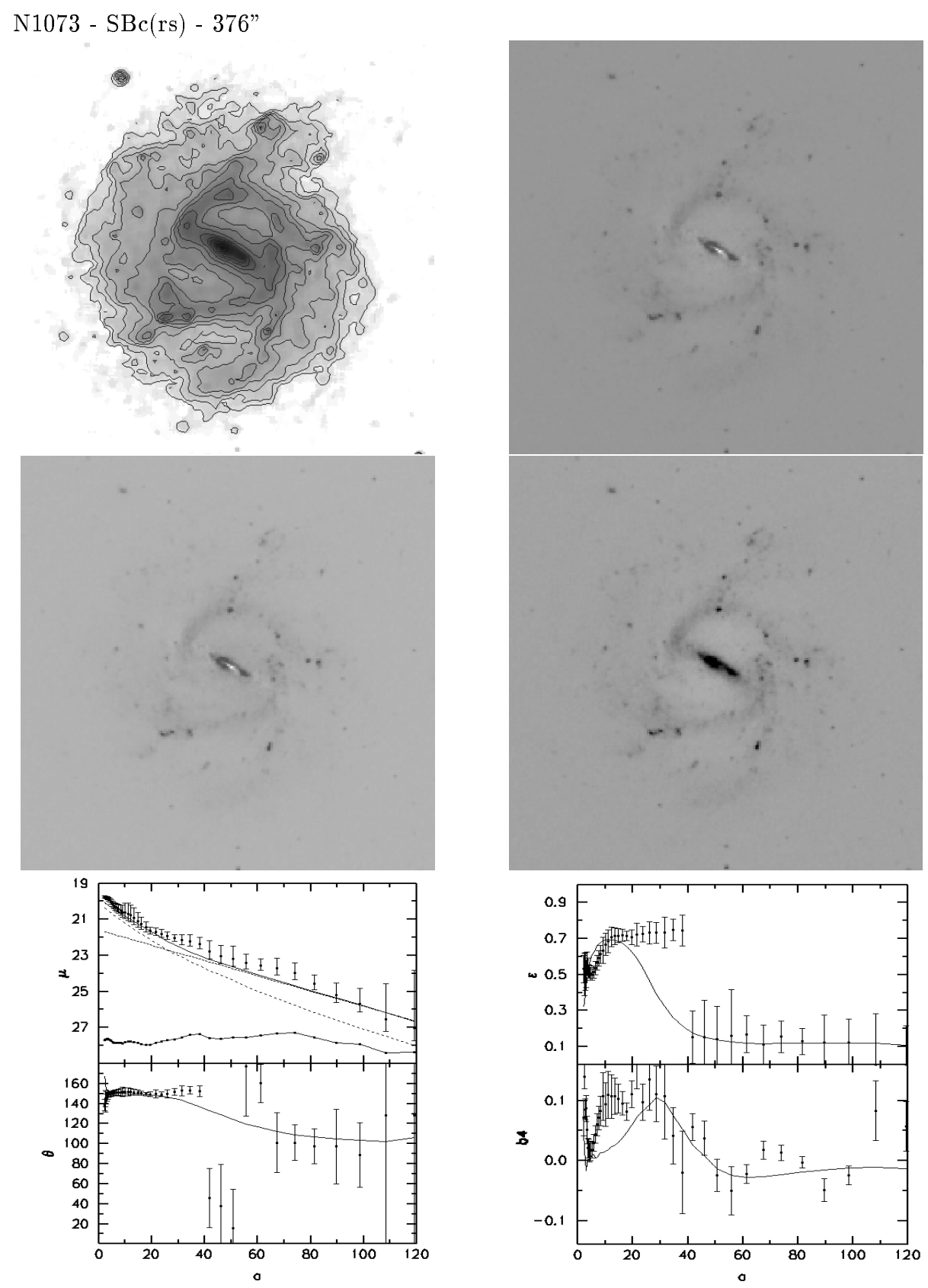

Figura C.1: Continuação. 

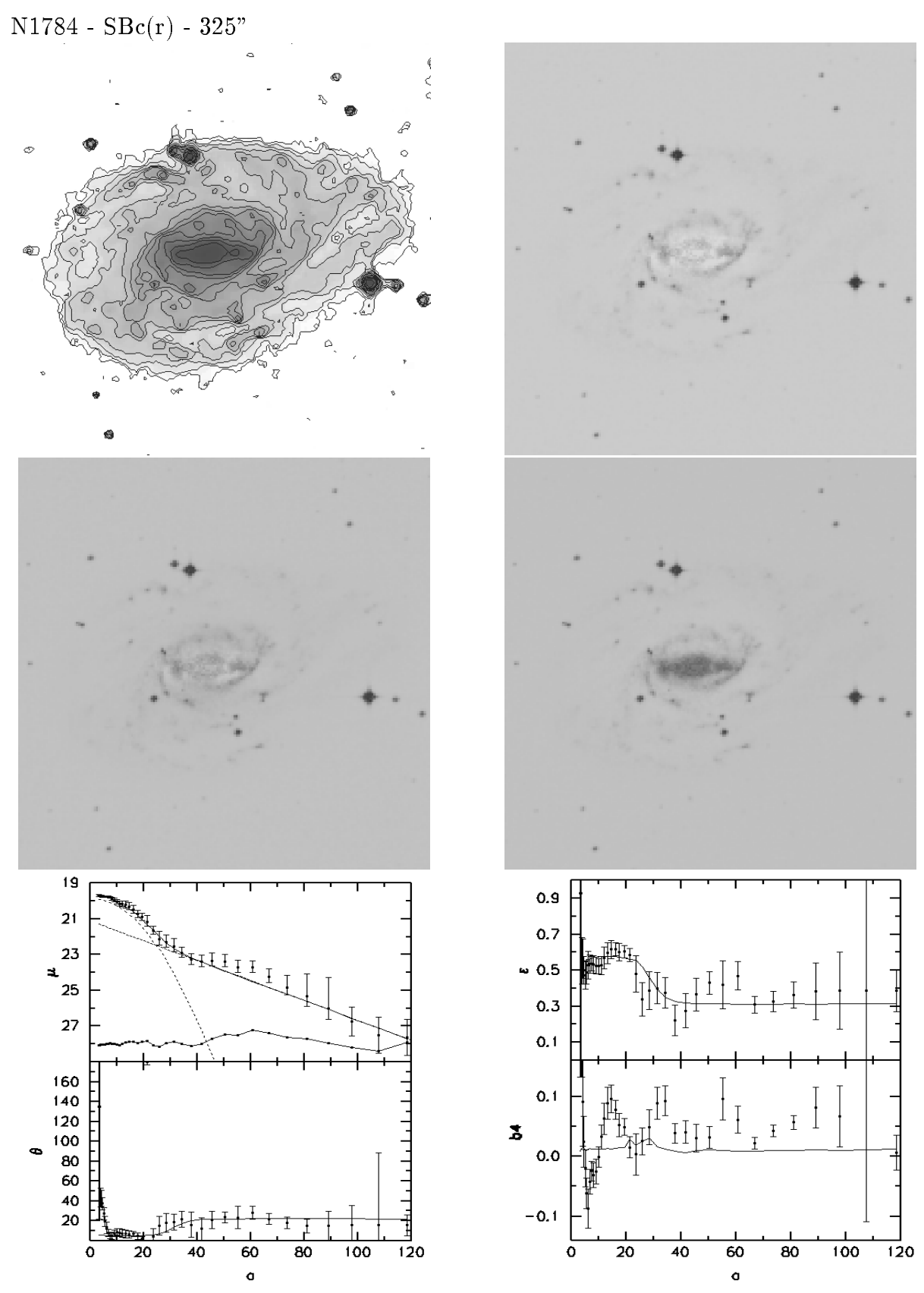

Figura C.1: Continuação. 


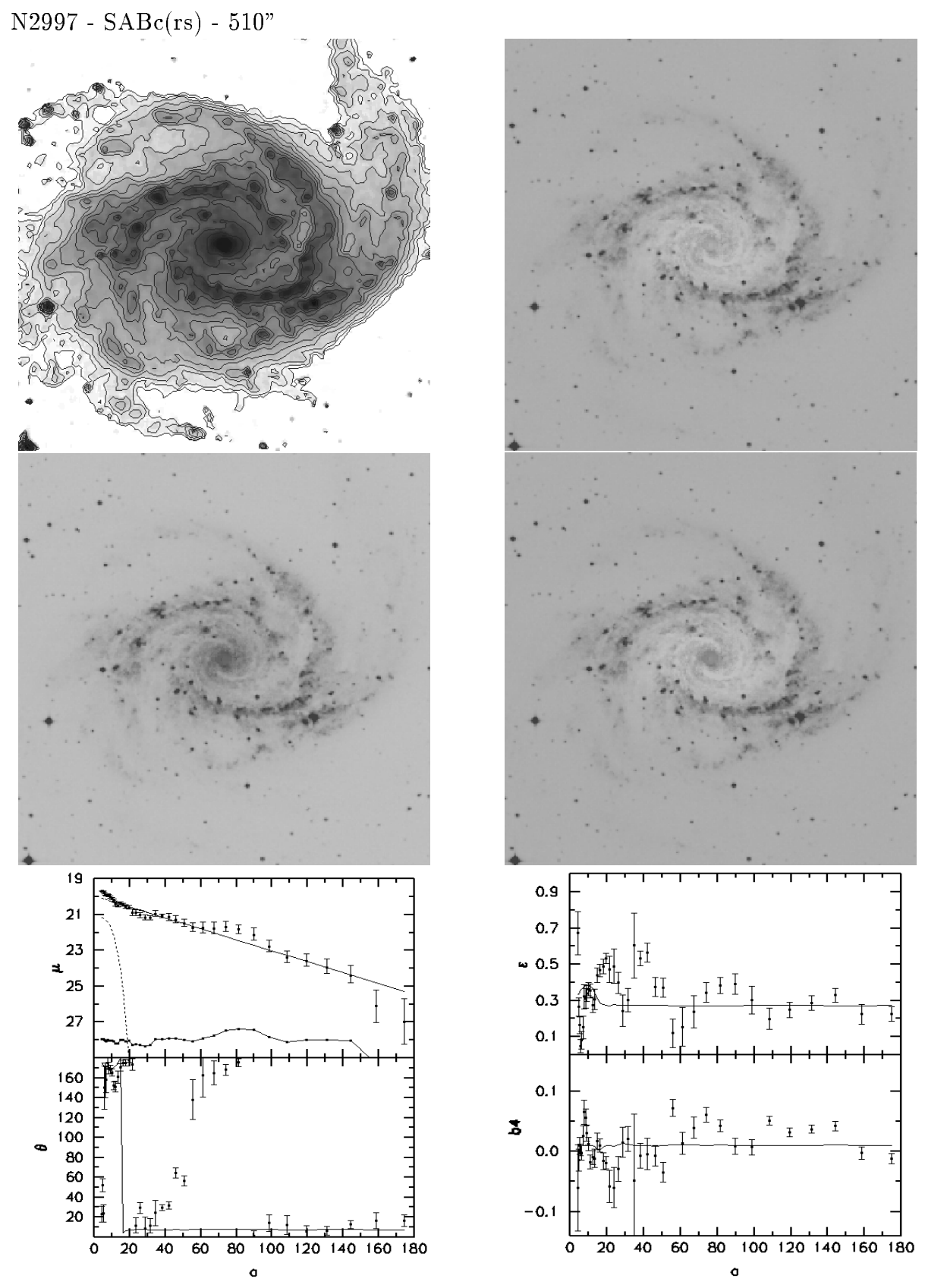

Figura C.1: Continuação. 

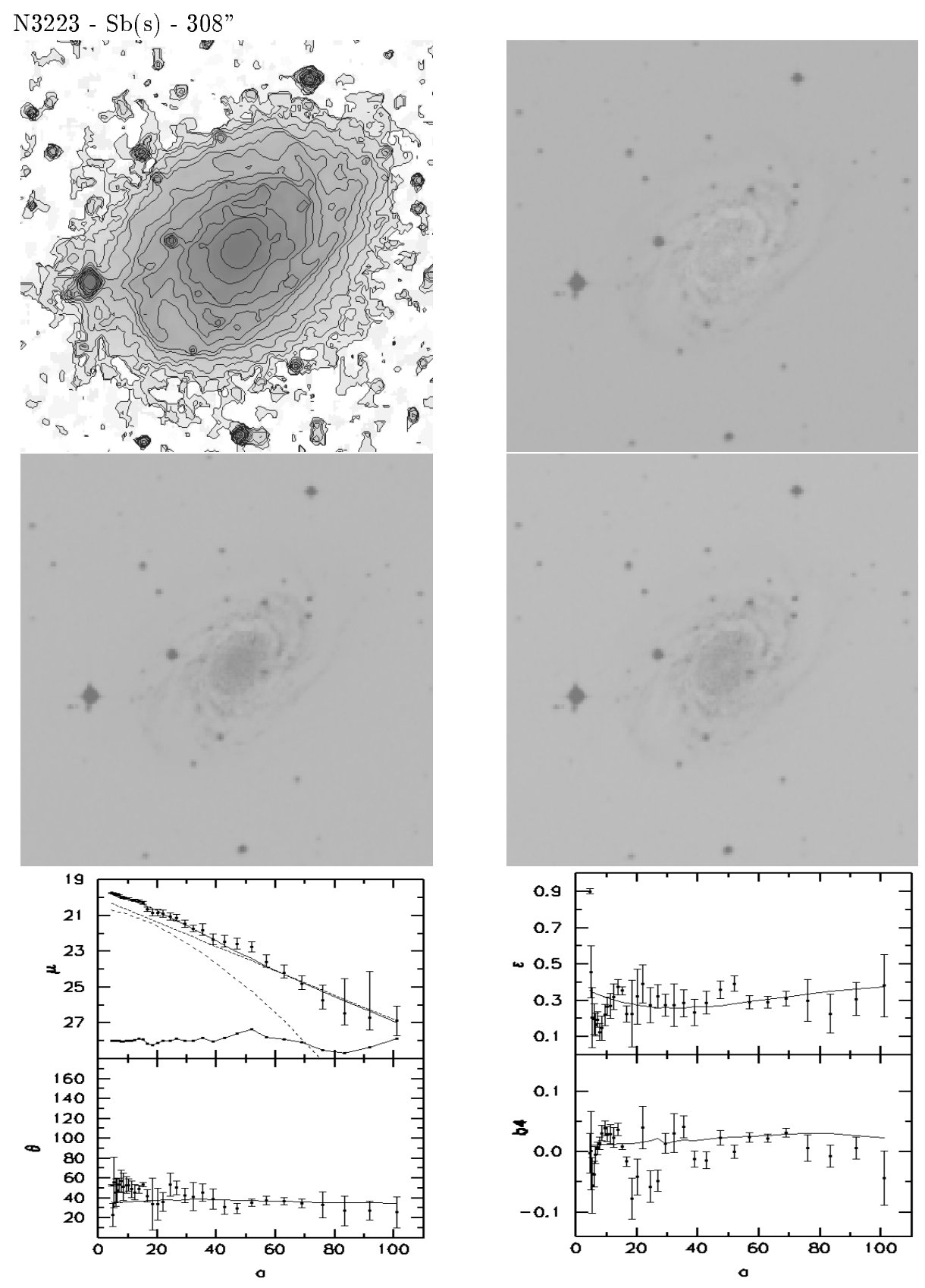

Figura C.1: Continuação. 

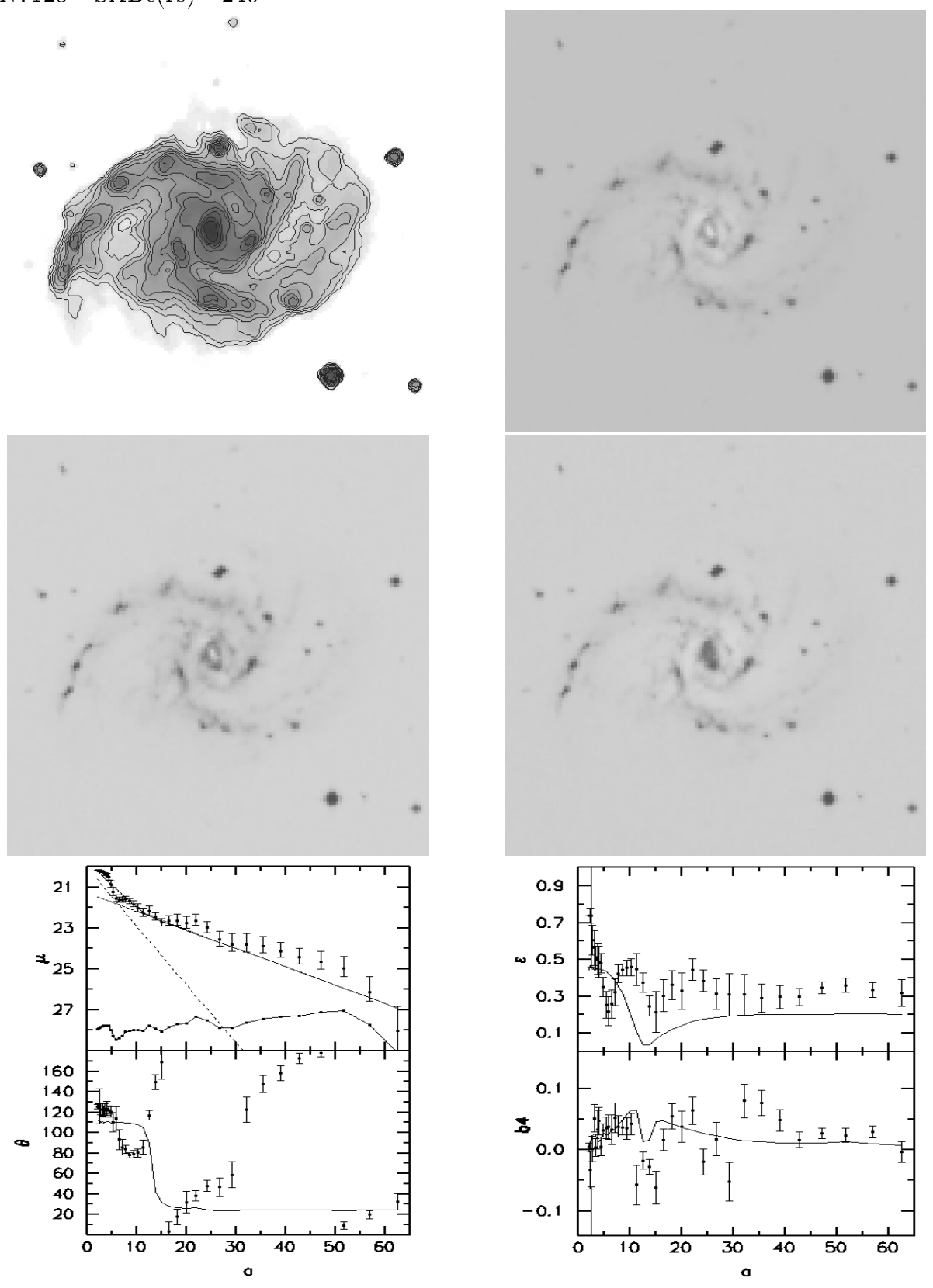

Figura C.1: Continuação. 


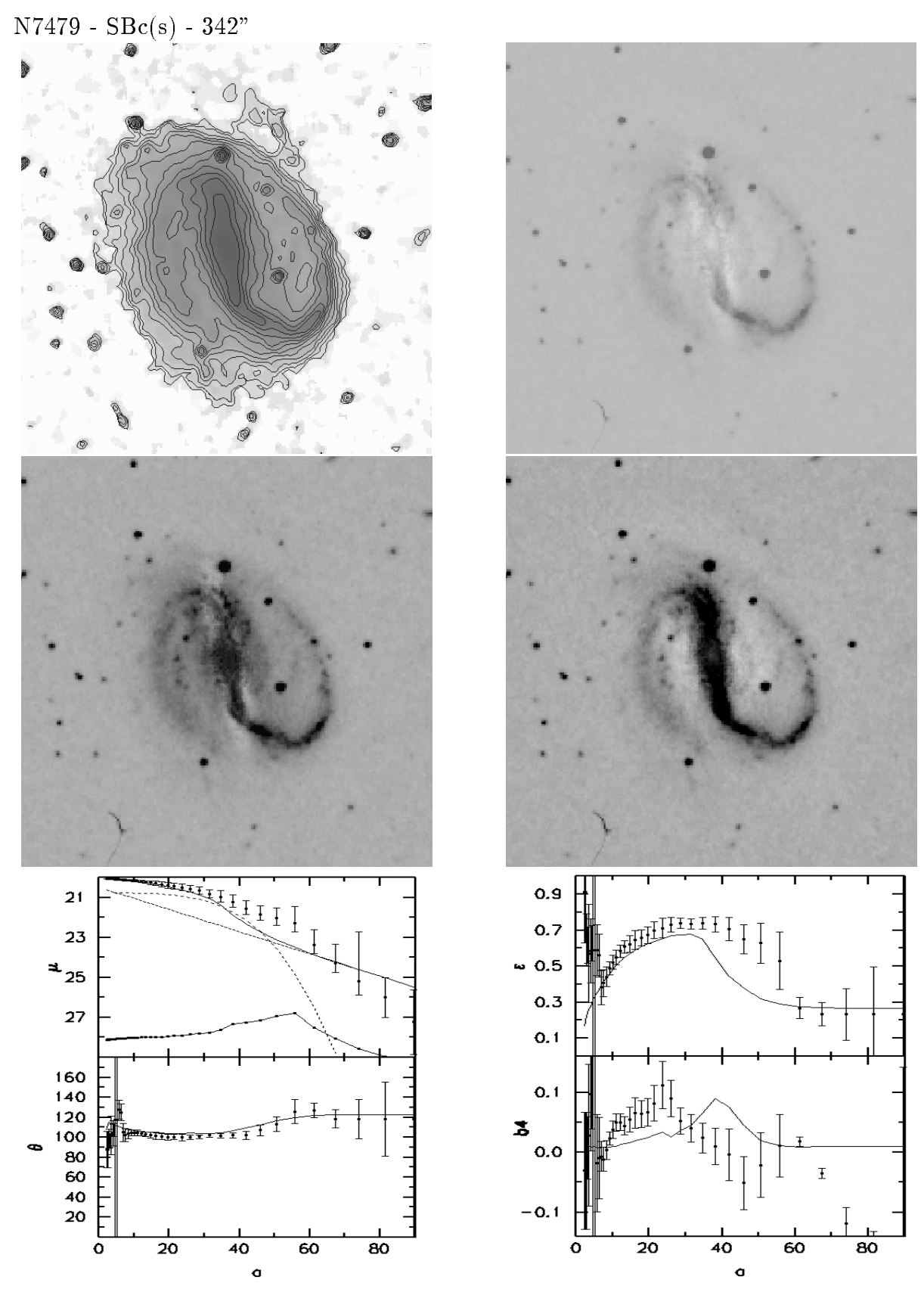

Figura C.1: Continuação. 

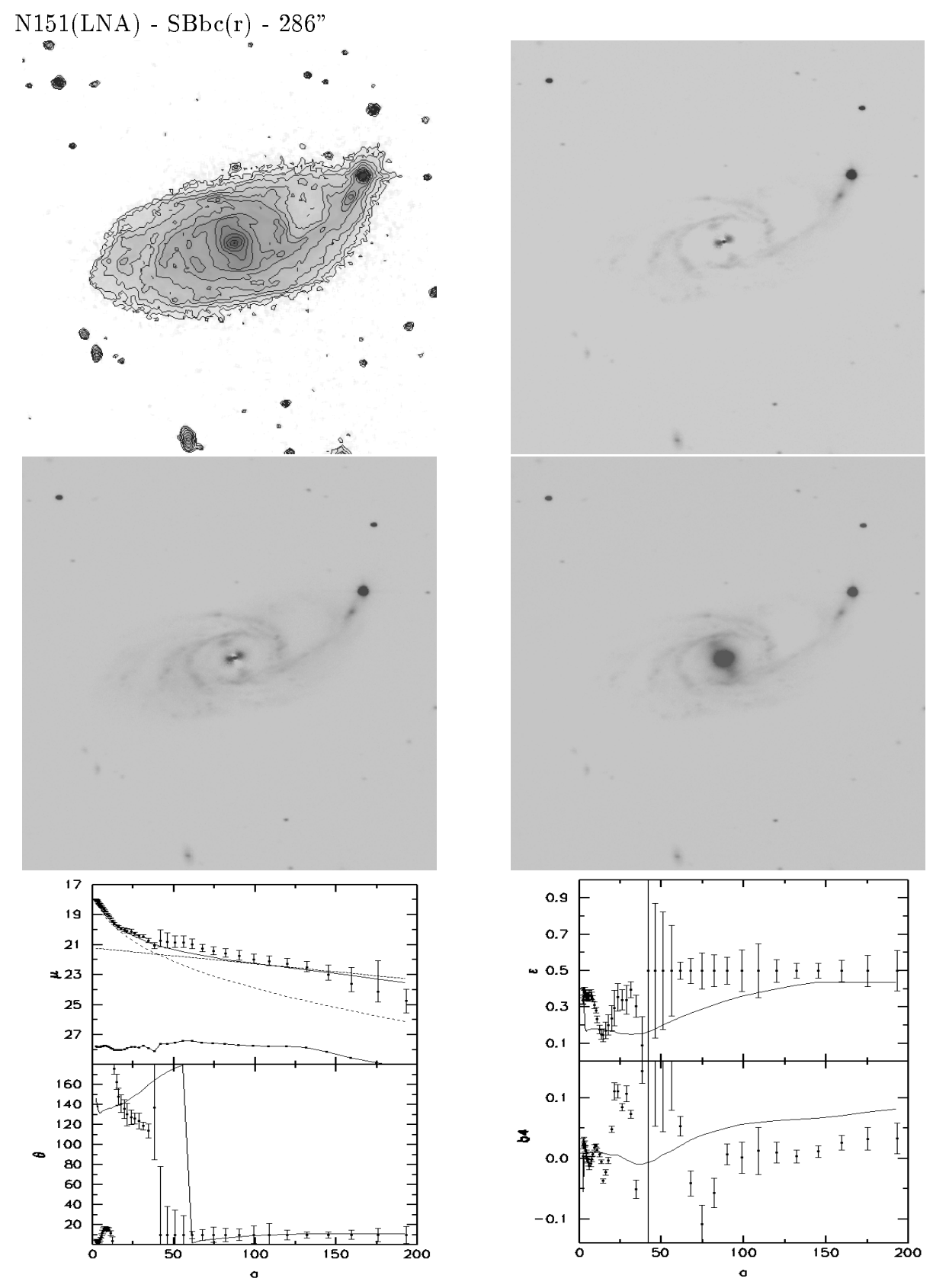

Figura C.2: Exemplos de resultados obtidos através da aplicação do algoritmo de decomposição em imagens obtidas em CCD. Os resultados referentes às imagens DSS para essas mesmas galáxias foram exibidos na Figura C.1 e na Figura 3.1. As figuras são análogas à Figura 3.1. 

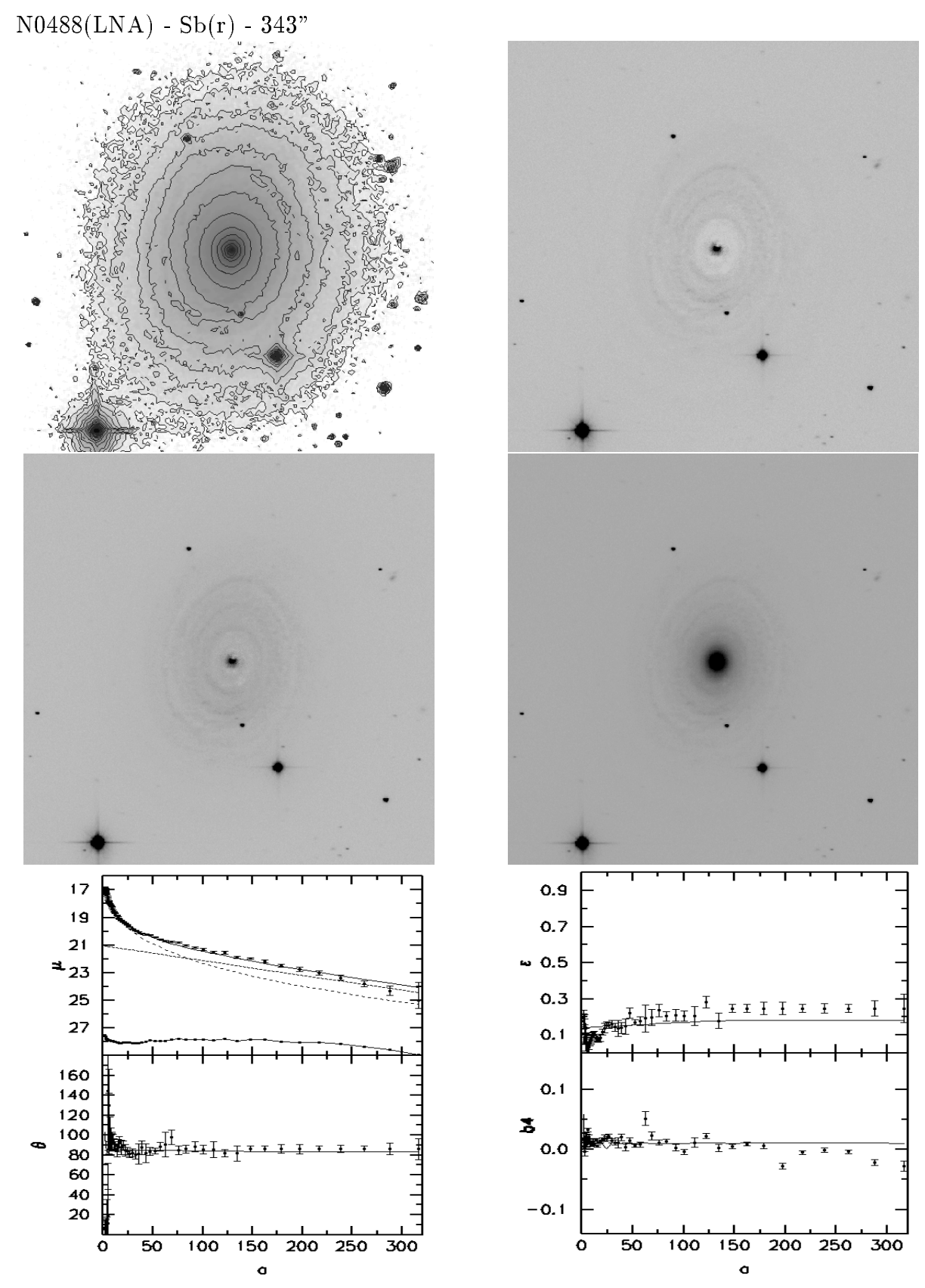

Figura C.2: Continuação. 


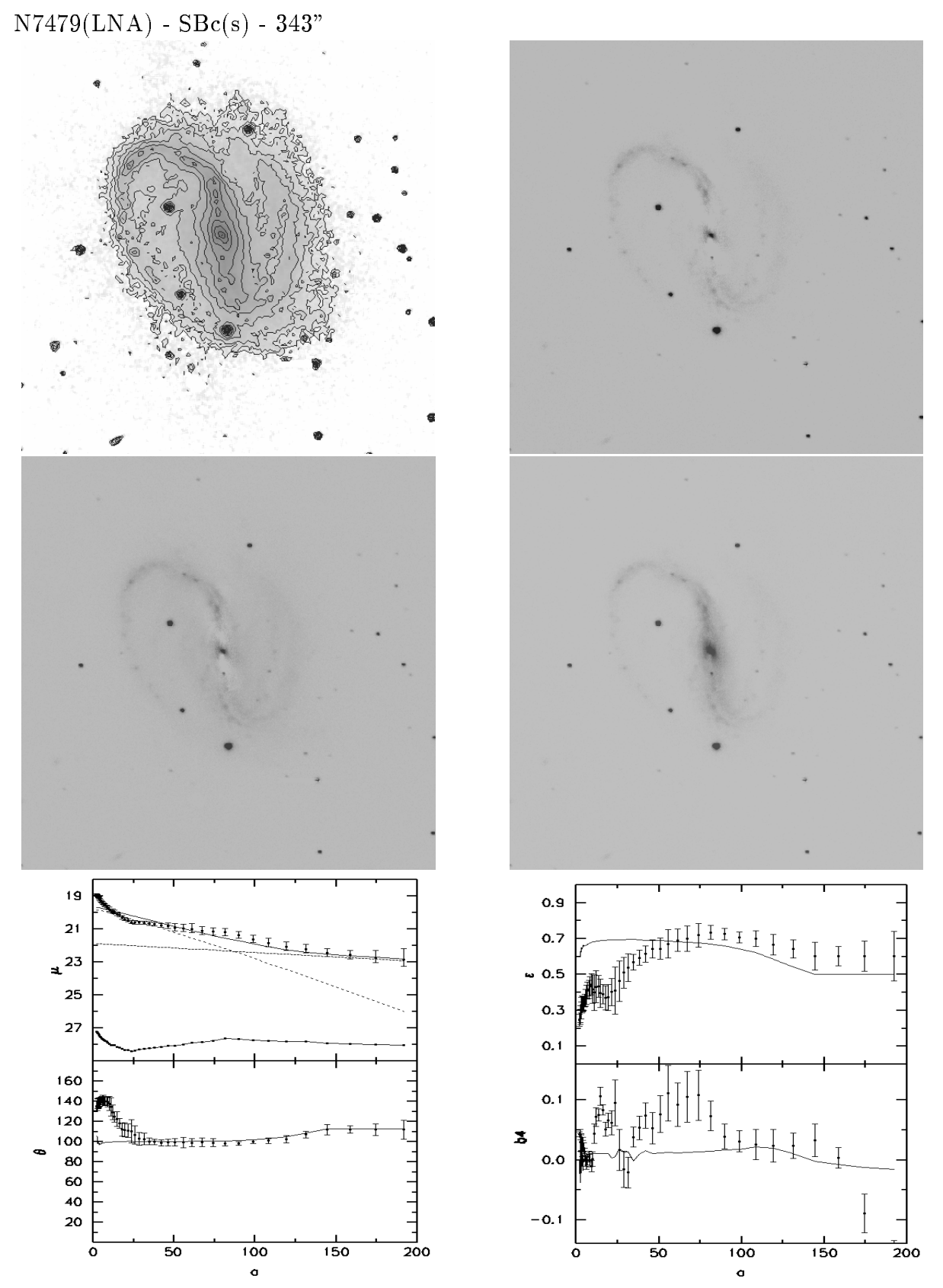

Figura C.2: Continuação. 